\title{
Teacher Education Policy and Practice
}

International Perspectives and Inspirations

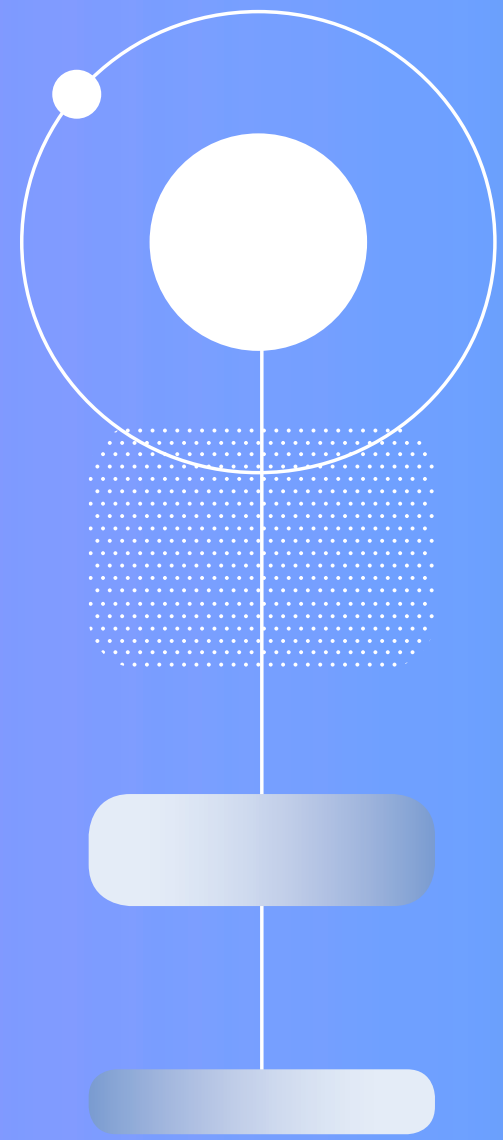



Teacher Education Policy and Practice

International Perspectives and Inspirations 


\section{Teacher Education Policy and Practice}

International Perspectives and Inspirations

Edited by

Michelle Attard Tonna and Joanna Madalińska-Michalak 
KEY CONCEPTS SERIES, VOL. 1

Teacher Education Policy and Practice - International Perspectives and Inspiration

Edited by: Michelle Atard-Tonna and Joanna Madalińska-Michalak

Reviewed by: Dr Francesca Caena, University of Venice, Italy; Professor Eve Eisenschmidt, Tallinn University, Estonia; Professor Joanna Madalińska-Michalak, University of Warsaw, Poland; Professor Vlasta Vizek Vidovic †, Institute of Social Research, Zagreb, Croatia; Professor Marco Snoek, Amsterdam University of Applied Sciences, Netherlands

Design: Diana Makulska / Podpunkt

DTP: $\quad$ Papercut

Printed by: $\quad$ MEDIA Drukarnia Studio Reklamy Rafał Przybylak

Publisher: $\quad$ Foundation for the Development of the Education System Polish National Agency for the Erasmus+ Programme

Al. Jerozolimskie 142a, 02-305 Warsaw

www.frse.org.pl | kontakt@frse.org.pl

(C) Foundation for the Development of the Education System, Warsaw 2018 ISBN: 978-9949-29-023-9

This publication has been published with the financial support of the Foundation for the Development of the Education System

The information and views set out in this report are those of the author and do not necessarily reflect the official opinion of the European Union. Neither the European Union institutions and bodies nor any person acting on their behalf may be held responsible for the use which may be made of the information contained therein.

Free copy

\section{frSe}

Citation:

Teacher Education Policy and Practice - International Perspectives and Inspiration, edited by M. Attard-Tonna and J. Madalińska-Michalak, Foundation for the Development of the Education System, Key Concepts Series vol. 1, Warsaw 2018 


\section{Table of Contents}

9

Acknowledgements

11

Introductory chapter

Teacher education - perspectives and inspirations

Michelle Attard Tonna and Joanna Madalińska-Michalak

Teacher Education - Theory, Policy and Practice

24

Research, theory and practice in initial teacher

education: new contexts, new challenges

Maria Assunção Flores

44

Teacher education and the end of theory

Kenneth Wain

64

Teachers' continuing professional development:

trends in European countries

Pawet Poszytek and Liliana Budkowska

80

Competency frameworks for teachers:

a contribution from the European education policy

Jesús Manso and Lucía Sánchez-Tarazaga 
Reform of teacher education and teacher educator competences A survey study of Danish teacher educators' competences and needs for capacity building

Jens Rasmussen

\section{Initial and Continuing Teacher Education}

- Towards Professionalism and Quality

122

Access to learning within Further and Higher educational levels Liliana Marić

148

Reform of Initial Teacher Education in Wales: taking an analytical approach to the issues using activity theory Jan Barnes and Jane Waters

168

What skills do contemporary teachers need? The need to improve emotional intelligence and self-regulation in the opinion of teachers preparing for the job Katarzyna Szorc and Agnieszka Itendo-Milewska

194

Teacher team's maturity as the basis for a learning school Bożena Tohwińska

216

Teachers' digital competence from a global perspective Marthese Spiteri and Shu-Nu Chang Rundgren

236

The learning outcomes approach: reflections from two Maltese trainers

Doreen Said Pace and Anita Seguna 
Teacher CPD needs: perspectives from teachers in Malta and the Republic of Ireland

Michelle Attard Tonna, Timothy Murphy and Cathal de Paor

288

Personal and Social Development practice within a European neoliberal Maltese education System

Amanda Bezzina

314

A professional learning community model for a Maltese Catholic Church Primary School: A case study

Christopher Bezzina and Mark A. Farrugia

344

Teachers in communities of practice: perspectives and experiences from three doctoral research students

James Calleja, Doreen Mizzi and Ivan Riolo

372

Implementing inquiry science in the early years:

teachers' achievements and challenges

Suzanne Gatt and Claire Buttigieg

392

Moving to multi-cultural classrooms: lessons from the Celtic Tiger Anita Gracie

414

The PACK checklist: A proposed pedagogical tool for multicultural foreign language learning settings

George Cremona 



\section{Acknowledgements}

This book was completed with the participation and assistance of many people. We wish to acknowledge and thank the many individuals and organisations who donated their time, energy and expertise to help in the preparation of this book. Firstly, we would like to acknowledge The Teacher Education Policy in Europe (TEPE) Scientific Network, which deserves recognition for acting as the main inspiration and impetus for this book. The 2016 annual TEPE conference, which was hosted by the Faculty of Education, University of Malta, acted as a platform for these writers to present their research, and TEPE Board Members provided all the necessary academic support to review the abstracts, advise on the themes selected and suggest valuable feedback throughout.

Secondly, we would like to acknowledge the essential and invaluable support of academic colleagues from TEPE Board who contributed to the peer review process. The members of TEPE Board at that time who contributed to the whole process of peer review are listed below: Dr Francesca Caena, University of Venice, Italy; Professor Eve Eisenschmidt, Tallinn University, Estonia; Professor Joanna MadalińskaMichalak, University of Warsaw, Poland; Professor Vlasta Vizek Vidovic †, Institute of Social Research, Zagreb, Croatia; Professor Marco Snoek, Amsterdam University of Applied Sciences, Netherlands.

Also we would like to acknowledge the equally worthy contribution to the process of peer review from reviewers from University of Malta. In particular, we would like to express our gratitude to Professor Christopher Bezzina, Dr Michael Buhagiar, Dr James Calleja and Dr Mario Pace.

We would like to give our sincere appreciation to the each author of this book for sharing with the readers their knowledge and expertise in the field of teacher education, and for cooperating with us as book editors throughout the whole process of preparing this book.

Finally, we would like to extend our special thanks to the Publisher of this book - the Foundation for the Development of Education System. 



\section{Introductory chapter}




\title{
Teacher education \\ - perspectives and inspirations
}

\author{
Michelle Attard Tonna \\ University of Malta \\ Joanna Madalińska-Michalak \\ University of Warsaw
}

This book grew out of the Teacher Education Policy in Europe Network annual conference which in $\mathbf{2 0 1 6}$ was organised in Malta and held by the Faculty of Education, University of Malta. The Teacher Education Policy in Europe (TEPE) Scientific Network is an academic network that builds on the previous European collaborative projects in the field of teacher education policy - TNTEE and EUDORA. Today, TEPE Network central goals relate to:

$\rightarrow$ advancing research in and on Teacher Education;

$\rightarrow$ increasing mobility and extending the European Dimension in Teacher Education;

$\rightarrow$ enhancing quality through the renewal of evaluation cultures in Teacher Education.

TEPE Network annual conferences showed that in 10 years, the TEPE Network initiative has established firm roots and we can notice that the number of TEPE supporters and contributors has grown year by year. The conferences bring together educational researchers, policymakers, teachers and practitioners from Europe and beyond. The TEPE conferences show that the manifold dimensions of teacher education are increasingly attracting the attention of researchers, teacher educators, policymakers and prospective and in-service teachers. A significant feature of contemporary theory, research and practice in the field of teacher education is consensus on the values of 
exploring the diversity of international experience for understanding the dynamic process of development of the education systems in different parts of the world, with a particular focus on the role of the teacher and teacher education.

The theme of the $10^{\text {th }}$ TEPE Network conference "Teacher Education from a Global Perspective" encouraged academics, teachers, teachers' educators and education officials to present their research and engage in discerning discussions about their work, their concerns and their visions for teacher education. The conference has been hosted in Malta to put an emphasis on Europe and the MENA (Middle East and North Africa) region. The strategic position of Malta in the middle of the Mediterranean Sea and enriched with a history of 7,000 years gives the island a unique mélange of cultures. In the educational sphere, it has historically participated actively in the work and activities of the European Union as well as those of international and regional organisations and institutions.

Attendees at the TEPE 2016 conference discussed such themes as:

$\rightarrow$ Initial teacher education in Europe and in a global world;

$\rightarrow$ Teachers in schools as learning organisations in Europe and from a global perspective;

$\rightarrow$ Teachers and teacher education for multicultural settings;

$\rightarrow$ Theory, policy and practice in teacher education in Europe and from a global perspective;

$\rightarrow$ Reflections on teacher education at Masters level.

The theme of the $10^{\text {th }}$ TEPE Network conference opened the debate regarding the need of quality teacher education institutions and lifelong opportunities for all teachers to learn and to grow. It also established the notion that all teachers should receive adequate education and training throughout all phases of their preparation to teaching and professional development of their career, and the need for teachers to seek and make use of learning opportunities within their schools and communities. This conference gave opportunities to share research findings and expertise in and on teacher education throughout the world, giving rise to different perspectives about how to offer teachers the chance to learn and become a teacher.

The motivation for the theme of this book: "Teacher Education Policy and Practice - International Perspectives and Inspirations" has been 
to create a platform for contributing to international debate on innovative thinking, practice and research in teacher education. Our position as editors of this book is that teachers' learning in a professional context, requires a broad and robust research base in order to clearly understand what they go through in the various phases of their learning journey in different national and international contexts and we this hope that this book contributes to other valid research in the area.

This book, through its different chapters, tries to connect with a wide literature. The experience reported is complex and we have made a decision to develop only two parts to organise the chapters, and to avoid the tendency of simplifying and being reductionist in our interpretations. Rather than having an emergent and unifying theme, this book allows the authors to have their individual say, and the stylistic range of the book reflects this. The reader may note a number of themes which feature constantly across the chapters, yet these themes are being investigated in particular contexts rendering the chapters unique and presenting the reader with a window to a number of different educational scenarios. The core themes explored in this book address a new educational world of teaching, training, policies and reform. The authors critique and challenge these themes because we are currently facing the greatest challenge to the teaching profession. Never before teachers, teaching and teacher education have had such importance. The quality of the teacher supersedes all the factors inside the school which affect children's learning and achievement, including standards, assessment, resources, and the quality of the school's leadership. Teachers matter and we notice a sense of urgency in politics, academia, and also among the public about the need to get more high-quality teachers. This urgency is putting teachers and teaching at the forefront of change (Hargreaves \& Fullan, 2012).

One of the important themes that this book elaborates upon is that relating to policies in teacher education. The professional development of teachers, and, more specifically, the understanding of how teachers learn and transform their knowledge into practice, is a complex process. Moreover, it occurs in particular educational policy environments, some of which are more appropriate and conducive to learning than others. It is hence important to study, experiment, discuss and reflect on teacher professional learning vis-à-vis the interacting links and influences of the history and tradition of groups of teachers, the expectations of 
education systems and teachers' conditions and opportunities to learn that are open to them.

As Darling-Hammond et al. (2017) identify, the policies which predominantly shape the teaching force and the work of teachers are those relating to recruitment; teacher preparation; induction and mentoring; professional learning; teacher appraisal; and career and leadership development. These policies are mutually supportive and affect each other in a direct manner. Policy systems that support high quality teaching practices are extremely important in this era characterised by knowledge expansion and change (ibid.). What are teachers expected to teach students entering school today? They may well work in jobs that do not yet exist so they need to be able to find and evaluate knowledge to new ideas, answers and solutions. Moreover, societies are becoming increasingly more diverse and people with different perspectives and cultures bring new ideas and possibilities. The kind of teaching which is required in this context is challenging and dynamic. Teachers need to enable very diverse students to learn higher-order skills, so they themselves need a range of new skills; be able to understand the content more deeply and flexibly; understand how children learn and develop in cultural contexts; develop effective teaching strategies that foster reasoning and incorporate the appropriate technologies in their practice. Policy must thus be directed toward the development of a teacher workforce that is able to make the best decisions about teaching based on the expertise they have nurtured from their training and the wisdom they have accumulated from their experiences. Apart from having a strong teaching workforce, policies must also focus on how to develop teaching contexts that enable good practice. In the policy design process, the learning environment and the teaching context must be acknowledged as vital components of effective teaching as the qualities of individual teachers.

Another theme which constantly features in this book is that related to teacher competences and the kind of learning teachers are to be subjected to. The need of a generation of teachers who can help their students become independent, provide them with motivation and interest for lifelong learning and urge them to become autonomous learners is uncontested. The knowledge, skills and attitudes of each of Europe's 6 million teachers are of great importance and the responsibility of governments, higher education institutions and 
teacher educators is very big. The demands made on teachers and schools to modernise education requires them to develop their own competences and initial teacher education and CPD needs to be of the highest quality. The emphasis which is often put on teacher competencies presents a restricted view of teaching as a profession. As editors, we prefer to adhere to a integrative perspective of what makes a good teacher, characterised by a state of harmony between various levels. A more holistic approach toward teacher development is one in which competence is not equated with competencies and where views based on different paradigms, like the humanistic and behaviourist perspectives, are also respected. Teachers' judgements and actions are of great social significance. Thus, teachers need skills of enquiry and evaluation, skills of analysis, synthesis and action. They need to be engaged in professional discourse and contribute significantly to the development of educational policy and practice. Teaching is not an easy occupation. The challenges for all stakeholders are considerable and the challenges for teacher educators and for teachers themselves are greater than ever.

Continuing Professional Development (CPD) is one of the distinguishing characteristics of a professional practitioner, which is particularly important in the context of continuing rapid change schools are characterised with. The conditions under which teachers work often influence the learning opportunities they engage in. There are numerous diverse routes for teacher professional learning, from conventional external courses to managed learning in the workplace. The increasing prescriptive nature of teachers' work promotes passive and generic short-term models of teacher learning, like isolated workshops, often in response to various curricular, assessment related issues or policies. Such practices typically involve teachers engaging in reactive practices, listening to presentations designed to inform them of new initiatives. Active CPD practices like study groups with colleagues, in-school peer observations and professional learning communities are usually found in more democratic conceptions of teacher professionalism and are considered by many as superior in quality than the managerial-driven ones. Teachers need to be supported in developing more collaborative and research informed approaches to their CPD. CPD provision needs to have a clear link to classroom teaching and learning and schools 
need to be supported in developing strategies to help different groups of teachers.

An important component of CPD is the teacher educator who facilitates teacher learning. In the context of teacher education, conceptualising and enacting practices of teaching and learning comprise the specialist knowledge of teacher educators described by many as a pedagogy of teacher education. A teacher educator develops a teacher's identity and thus needs to create the conditions, and enact practices, for this to come about. The role of a teacher educator is to help student-teachers and practising teachers to conceptualise professional knowledge of practice as something which helps them grow as pedagogues. It is important for teacher educators to appreciate the pedagogical reasons that underpin their students' practices; to allow teachers to see the knowledge of teaching as meaningful, helpful and informative in their journey; to help them form identities based on a vision of teaching that goes well beyond teaching (Loughran, 2014). Fulfilling this vision is easier said than done.

One of the key words in teacher education literature is 'effectiveness'. How are schools, higher education institutions and CPD providers to determine that their teacher training programme is effective? Effectiveness can be defined as the impact on knowledge, skills, values, attitudes, behaviours and changes in practice in the workplace - knowing that learning has been achieved and that the teacher is 'fit to practise'. It is hence problematic in evaluating the effectiveness of these programmes, unless strategies for effectiveness are tailored to the practice and workplace context of an individual teacher. Nonetheless, a good national plan that recognises the continuing needs of teachers as learners in a changing society is crucial for a well-educated, flexible, highly competent teaching force. The need to optimise teachers' contribution in students' learning has been endorsed at European level as an educational policy priority. Research on what works and on policies which are likely to meet future challenges successfully are essential.

Each chapter in this book tells a story, often based on research, and it was important for us as editors not to lose sight of that. These stories (or chapters) can be read in any order and we recommend no particular order in which they are to be read. We articulate briefly each of the chapters in this book by using a chronological order simply to maintain the order in which they are presented. Chapter 1 by Maria 
Assunção Flores, one of the TEPE 2016 keynote speakers, speaks of the divide between theory and practice in initial teacher education and the need to develop supportive partnerships between universities and schools to combine teaching, research, theory and practice in a more consistent manner. Chapter 2 is also another conference keynote, by Kenneth Wain and which closely links to the argument of the previous chapter regarding for the need of theory and practice in teacher education. Wain questions the conventional notions of schooling and the technicist approach that often characterises teacher education. In Chapter 3 Poszytek and Budkowska debate teacher professionalism in Europe, particularly as a result teachers are being trained and supported in schools. Manso and Sánchez-Tarazaga in Chapter 4 discuss the importance of teachers acquiring new competences to respond to demands brought about by changes through globalisation, the digital era, migratory movements and the heterogeneity of classrooms, amongst others. The competences of teacher educators are explored by Rasmussen in Chapter 5 , in which research through a national survey on teacher educator competences in Denmark is presented.

Maric, the author of Chapter 6, presents research which problematises the quality of inclusive education within further and higher educational institutions in Malta while Barnes and Waters in Chapter 7 explain the current challenges in Wales brought about by the requirements for new kinds of provision for initial teacher education across the country. In Chapter 8, Szorc and Iłendo-Milewska present research which recognises the relation between the level of emotional intelligence and the level of self-regulation among teachers. The daily relations which develop between the school's management team and teachers is researched by Tołwińska in Chapter 9 , and Spiteri and Chang Rundgren in Chapter 10 introduces the concept of digital competence as a teacher's prerequisite for today's education in a globalised world. Said Pace and Seguna outline the work of learning outcomes and the effect of this framework in the Maltese education system in Chapter 11. They discuss the implications that this framework has on teachers' and learners' roles and explore the concept of 'constructive alignment' as an effective means of responding to a change in mindset. The learning needs of teachers in Ireland and Malta are presented in a comparative study by Attard Tonna, Murphy and de Paor in Chapter 12 and an evaluation of the initial training of PSD teachers in Malta, by Bezzina, 
can be found in the subsequent chapter. Chapter 14's authors, Bezzina and Farrugia, explore the culture of a newly established primary school in Malta and through action research examine the professional learning community model found in this school. Three different doctoral studies located in Malta are brought together in Chapter 15. Calleja, Mizzi and Riolo speak about the notion of communities of practice and present findings which describe the lived experiences of the teacher participants and researchers informing this study. In Chapter 16, Gatt and Buttigieg discuss the challenges that teachers in primary schools experience in changing their pedagogy in science to one of inquiry based learning and the use of stories to enable children deal with scientific concepts in their curriculum. Gracie in Chapter 17 delves into the challenges which teachers in Northern Ireland are facing due to multi-ethnic and often multi-lingual classrooms while Cremona, in the final chapter, presents the findings of a study among Maltese students of German as a foreign language and the adoption of a checklist for teachers through which curricular change can be facilitated. 


\section{References}

$\rightarrow$ Darling-Hammond, L., Burns, D., Campbell, C., Goodwin, A. L., Hammerness, K., Low, E.-L., Mclntyre, A., Sato, M. and Zeichner, K. (2017). Empowered educators: How high-performing systems shape teaching quality around the world. San Francisco, CA: Jossey-Bass

$\rightarrow$ Hargreaves, A. \& Fullan, M. (2012). Professional capital: Transforming teaching in every school. New York, NY: Teachers College Press.

$\rightarrow$ Loughran, J. J. (2014). Pedagogies of developing teacher identity. In C. J. Craig \& L. Orland-Barak (Eds.), International teacher education: Promising pedagogies (Part A) (pp. 257-272). UK: Emerald Group Publishing Limited. Published online: 01 Dec 2014; 257-272. 


\section{Biographical notes:}

Michelle Attard Tonna is an academic member of staff at the Faculty of Education, University of Malta, coordinating school-based mentoring on a national level. This role oversees the mentoring of student-teachers during their field placement. Her primary research interests include the professional development of teachers and comparative studies of the way teachers learn. She has contributed to various European-wide studies in the area of teacher learning and also participated in various conferences and European networks in which she has presented her research. She has completed a PhD with the University of Aberdeen, UK, focusing her research on professional teacher learning in Malta.

Joanna Madalińska-Michalak is Professor of Social Sciences (field Educational Research) at the University of Warsaw and head of the Chair of Didactics and Teacher Education, Faculty of Education at University of Warsaw, Poland. Her research interests include teacher education, teachers' and school principals' development, teacher professionalism and ethics, educational leadership, and research ethics. She has published widely on these topics both nationally and internationally. She is President of Polish Educational Research Association (PERA), a member of Board of Scientifc Associations at the Polish Academy of Science, and a Chair of Teacher Education Policy in Europe Scientific Network (TEPE). She serves as a member of the Board of Directors of International Council of Education for Teaching (ICET), a representative of Polish Educational Research Association in World Education Research Association (WERA), a member of Council Board of European Educational Research Association (EERA). She is a Vice-President of World Education Research Association. 


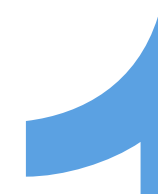


Teacher Education

- Theory, Policy and Practice 


\title{
Research, theory and practice in initial teacher education: \\ new contexts, new challenges ${ }^{1}$
}

\author{
Maria Assunção Flores \\ University of Minho
}

\section{Abstract}

In this chapter, I look at the post-Bologna framework by highlighting new contexts and new challenges with regard to the tensions in teacher education curriculum and structure or organisation. Next I will focus on the research dimension in ITE which remains a controversial issue in existing literature. Inquiry-based teacher education has been advocated in more recent literature, but it is far from representing a common approach and it faces various challenges. This chapter also includes a brief overview of the teacher education model at the University of Minho mainly in regard to its approach to practicum in the context of post-Bologna.

\section{Keywords:}

\section{teacher}

education

research

practice

student teachers

1. This chapter draws on a keynote address at the TEPE (Teacher Education Policy in Europe) 2016 conference, held at the University of Malta, Malta. It is also based on Flores $(2015,2016)$. 


\section{Introduction}

Theory and practice in initial teacher education (ITE) have been widely discussed in existing literature over the years. The separation between these two essential dimensions in the process of becoming a teacher and the need to overcome a technical rationality perspective have been identified as persisting challenges in teacher education in many contexts (Korthagen, 2010; Van Nuland, 2011; Flores, 2016). More recently, the importance of research in teacher education has also been advocated even though different perspectives of research may co-exist (see, for instance, Flores, 2017a; Sancho-Gil, Sánchez-Valero \& Domingo-Coscollola, 2017; Valeeva \& Gafurov, 2017; Marcondes, Leite \& Ramos, 2017).

My argument is that a redefinition of university and school roles in teacher education is needed within the context of strong, coherent and supportive partnerships. This perspective is crucial if we are to move beyond the binary of theory and practice in teacher education in which research may be seen as the linking element. In other words, combining 'teaching and research, theory and practice' in a more consistent way may represent a move towards teacher education as a space of transformation, one which goes beyond a mere process of adaptation or of application of theory to practice (Flores, 2016). Of course the ways in which teaching and research, theory and practice in teacher education are organised is dependent upon the philosophy and structure of a given teacher education model. It may include a more radical perspective, starting with practice at the very beginning of the teacher education programme or by incorporating a gradual contact with the teaching contexts through, for instance, short-term internships, or through research projects led by universities and schools. It may also include a philosophy of teacher education which lies in the articulation between university and school, teaching and research throughout a given programme.

In this chapter, I look at the post-Bologna framework by highlighting new contexts and new challenges with regard to the tensions in teacher education curriculum and structure or organisation. Next I will focus on the research dimension in ITE which remains a controversial issue in existing literature. Inquiry-based teacher education has been advocated in more recent literature, but it is far from representing a common approach and it faces various challenges (Flores et al., 2016). This 
chapter also includes a brief overview of the teacher education model at the University of Minho mainly in regard to its approach to practicum in the context of post-Bologna.

\section{The importance of quality teacher education}

Teacher quality is dependent upon quality teacher education. Existing literature, however, points to different understandings of teacher quality and teacher education quality in diverse contexts (DarlingHammond \& Lieberman, 2012a; Hilton, Flores \& Niklasson, 2013; Laurie, Nonoyama-Tarumi, McKeown \& Hopkins, 2016). What do we mean by teacher quality and quality teacher education? As a dynamic concept, quality needs to be understood in context as it relates to different expectations of various stakeholders (Flores, in press).

In some contexts, concerns with performativity, funding and external compliance have had implications for academics and for teacher educators: "competition rather than cooperation came to be seen as a key driver of quality with accountability measured by performativity and compliance with raising achievement as key" (Alcorn, 2014, p. 447). Similarly, in England, Maguire (2014) highlights the need to ensure teacher quality "by reforming teaching at source by regulating and controlling initial teacher education" (p. 779). She discusses the "technology of erasure" which relates to "the erasure of the work of progressive and reforming teacher educationalists who have in different times attempted to produce new ways of using school-based experiences to produce new forms of teacher (and trainee teacher) knowledge" (p.780). As Mayer (2014, p. 471) argues, it is essential to overcome a "naïve view of teacher quality" which has been associated with "a linear relationship between policy and educational outcomes without accounting for school culture, resources and communities."

Teacher education is seen paradoxically as essential and as irrelevant (Sancho-Gil, 2014). In other words, teacher education has been understood as a crucial element to foster the quality of teaching and learning but at the same time there have been policies that undervalue the role of teacher education and teacher educators and in some contexts the role of universities and schools as sites for professional learning. However, there is consensus about two key features: i) teacher education can make a difference in quality teachers and quality teaching in schools; ii) teacher education needs to be seen as a continuum within 
a lifelong perspective (Flores, 2011, 2014; Imig, Wiseman \& Neel, 2014). Drawing upon empirical research, Flores (in press) discusses the need to unpack teacher quality. She discusses issues such as motivation, innovation of practice, commitment and resilience as core elements around the concept of teachers as leaders of learning which stands at the core of being a teacher. Conway, Murphy, Rath, and Hall (2009), in a cross-national study of teacher education in nine countries, identified a number of principles underpinning quality teacher education, particularly the quality of knowledge integration, opportunities for observation, thoughtful feedback and critical reflection on classroom and school situations, and professional values and identity. If there is consensus on the importance of quality ITE for improving teaching and learning, there is less agreement on how to define and assess quality. Cultural differences, traditions and historical and social factors must be taken into account in order to understand how teacher education has evolved over the years in different contexts.

In a recent paper, Darling Hammond (2017) analyses high quality systems leading to the preparation and development of high quality teachers, namely in Finland, Singapore, Canada and Australia. She argues that, despite their differences, these systems include "multiple, coherent and complementary components associated with recruiting, developing, and retaining talented individuals to support the overall goal of ensuring that each school is populated by effective teachers" (Darling-Hammond, 2017, p. 294). Among other issues are the recruitment of highly able candidates into high-quality programmes and the connection between theory and practice through thoughtful coursework and the integration of high-quality clinical work in settings where good practice is supported (Darling-Hammond, 2017). Thus, quality teacher education depends on the ways in which teacher competences and standards are defined (and who defines them and how) as well as on the wider social and cultural context and the policy environment in which it is embedded.

\section{Curriculum of initial teacher education: integrating theory and practice, teaching and research}

Although teacher education has been seen as a key element in efforts to improve teaching and student learning and achievement, diversity in its content and form, including different modes of government 
intervention, emerges in Europe and beyond (Flores, 2011; Flores, Vieira, \& Ferreira, 2014; Imig, Wiseman, \& Neel, 2014; Goodwin, 2012; Hammerness, van Tartwijk \& Snoek, 2012; Mayer, Pecheone \& Merino, 2012; Darling-Hammond, 2012; Darling-Hammond \& Lieberman, 2012b; Ellis \& McNicholl, 2015). It is therefore possible to identify contradictory trends, for instance, a move towards higher qualifications for teachers at a Master degree level (e.g., Finland, Portugal, France, Malta), which, in many cases, has been associated with greater emphasis on the research component, and at the same time the development of a more pragmatic, short and school-based orientation (e.g., some ITE programmes in the UK, USA and Australia).

This diversity in teacher education programmes is related to a number of factors among which are different ways of looking into the university and schools' role in the process of learning to teach and different conceptions of school, curriculum, and teacher professionalism. In addition, the policy, economic and cultural contexts are influential. As Craig (2016) recently argued, the structure of education is not only shaped by history, culture and economics, but increasingly dictated by politics. The key components of teacher education curriculum depend on the structure and philosophy of education that underpin them. In other words, teacher education has been seen paradoxically as the panacea to improve education, and teaching and learning in schools and classrooms, and at the same time it has been subjected to criticisms which call into question its effectiveness in preparing high quality teachers for the 21st century (Flores, 2016). So, the question is: what kinds of teachers are to be trained?

Teachers may be seen as doers of the curriculum within a more technical and top-down orientation. Conversely, they may also be understood as key players in the enactment of the curriculum and agents of change in the contexts in which they work. Thus, in order to fully understand teacher education it is essential examine the political, social, cultural and economic contexts in which it is embedded along with the conceptual and epistemological assumptions underpinning its curriculum models and organisational systems (Flores, 2016, 2017b).

By and large, teacher education programmes include studies in education, subject matter along with pedagogical content knowledge, and practice. Yet, Kansanen (2014, p. 281), focusing on the Finnish context, alerts that "how to build a dynamic and successful curriculum 
founded on these elements is apparently the key to getting good teachers into the education system of the country." In Europe and elsewhere globalisation has been a major driver of change along with governmental pressure to enhance the quality of teachers and teaching, in many cases associated with the results of international assessments.

It is therefore possible to identify both convergences and divergences in ITE curriculum internationally, for instance related to a great diversity in terms of structure, focus and pedagogy worldwide (with varying modes of governmental involvement). A report on teacher education curricula in the European Union points to considerable variation in terms of the skills and competences required for the teaching profession in the official documents in different countries (Piesanen \& Valijarvi, 2010). The same report indicates that subject competences, pedagogical competences, and the integration of theory and practice are mentioned in all the EU countries' relevant documents, whereas quality assurance, mobility, leadership, and continuing and lifelong learning are often left out. The same report also suggests that whereas in most EU countries, national documents, laws and regulations stipulate general guidelines and frameworks for the organisation of teacher education, higher education institutions are granted a degree of autonomy to develop their own curricula. Both consecutive and concurrent structures carried implications for the ways in which curriculum components were integrated, but all included some kind of field experience in a school setting. In recent research, Zuzovsky and Donitsa-Schmidt (2017) compared the effectiveness of these two models of ITE programmes in Israel. They claim that graduates of the consecutive model outperformed graduates of the concurrent model in most of the measures used in the study. The authors put forward two possible explanations: the profile of the students in each model and the layered manner in which the curricular components are organised in the two models.

The fragmentation and/or integration of ITE curriculum components and the articulation between schools and universities as sites for professional learning have been widely discussed in the literature (e.g., Cardoso, 2012; Flores, Santos, Fernandes, \& Pereira, 2014; Elstad, 2010; Duda \& Clifford-Amos, 2011; Clarke, Lodge, \& Shevlin, 2012; Goodwin, 2012; Aydin et al., 2015). Research has found discrepancies between what student teachers learn in their programmes and their experience 
in clinical practice (Wang, Odell, Klecka, Spalding, \& Lin, 2012) pointing to a binary opposition between schools and universities (Wilson \& I'Anson, 2006) in the education of teachers-to-be.

A brief glimpse of the international literature pertaining to ITE curriculum reveals that subject knowledge, subject didactic knowledge, general education studies and practicum are generally present in ITE programmes, but there is great variation in regard to its location in the programme and to their interaction to enhance student teachers' professional learning. In most cases, it is up to student teachers to make the necessary links between the different components of the ITE curriculum.

Related to this is the prevalence of the academic logic in detriment to the professional one (Canário, 2001; Formosinho, 2009) along with the nature of the academic culture. Departmental organisation within the university and the valorisation of research can be detrimental to teaching in terms of Faculty career progression. Individualistic working patterns rather than cooperation is often associated with issues of promotion. In this context, it is difficult to foster curriculum articulation and coherence in ITE. The fragmentation between ITE components has also been associated with the historical curricular separation between foundations and methods courses within ITE and in particular the disconnect between theoretical and practical knowledge (Grossman, Hammerness \& McDonald, 2009), and to the tensions between the professional and academic logic of teacher education and the curricular organisation of the time and space of each component in ITE curriculum (Formosinho, 2009). A study in Spain highlighted a number of shortcomings in ITE - namely the lack of quality, inadequate practices, difficulties in promoting learning, and a lack of preparedness for entering the teaching profession (Sancho-Gil, 2014). These challenges are to be linked to the ways in which, in different ITE programmes, the role and responsibility of universities and schools is understood, namely in regard to the teaching practice component, ranging from schools playing a host role (work placement model) to shared responsibility between both institutions, through to schools providing the entire training (school-based training) (Flores, 2016). 


\section{The research dimension in teacher education:}

\section{configurations and variations internationally}

A look at international literature on curriculum of initial teacher education points to various ways of integrating research into teacher education programmes as well as ways of articulating it with teaching. For instance, the introduction of research into the curriculum in France has been seen as a strong feature (Lapostolle \& Chevaillier, 2011) and the research (action-research) component in the practicum has been seen as a positive aspect of the Master Degree in Teaching in Portugal (Flores, Vieira, \& Ferreira, 2014).

In Europe and elsewhere the research component in ITE curriculum varies: in some cases it is non-existent; in other cases it is not explicit in the curriculum but it is up to the training institutions to foster the development of student teachers' research competences, for instance during practicum; and, in other cases, an explicit curriculum unit on research methods is included in the ITE curriculum as well as an inquiry approach to the practicum (Flores, 2016). Great variation across programmes internationally exists ranging "from one compulsory methods course to a critical reading of research papers and use of databases for policymaking recommendations" (Niemi \& Nevgi, 2014, p.132) to the development of a pedagogical intervention project with a research component (action research) during the practicum in a school (Flores, Vieira, \& Ferreira, 2014). The most paradigmatic example of a research-based orientation to ITE is the Finnish case. It entails "well-balanced knowledge and skills in both theory and practice" (Sahlberg, 2012, p. 9) according to a "systematic continuum from the foundations of educational thinking to educational research methodologies and then on to more advanced fields of educational sciences" (p. 11). However, as Niemi and Nevgi (2014, p. 132) argued, "preparing for research-based work in the teaching profession can also be undermined because of the pressure to provide new teachers with skills that are measured through students' learning outcomes in highstakes testing."

As such, the research component in ITE may take different forms in different countries. In Brazil, for instance, a national programme has been launched to foster the establishment of partnerships between schools and universities, to enhance the research dimension and to integrate theory and practice in ITE. The Pibid, as it is named in 
Portuguese (Programa Institucional de Bolsa de Iniciação à Docência - Institutional programme for grants to initiate teaching) draws upon the following principles: i) emphasising teacher education on teachers' work at school and on real experiences; ii) combining theoretical and methodological teacher knowledge of higher education institutions and the practical and experiential knowledge of teachers in schools; iii) paying attention to the multiple dimensions of the daily work of school and to research leading aimed at solving practical situations and innovations in education; and, iv) promoting dialogue and collaborative work fostering the social nature of the teaching profession (Brazil, 2012). In 2014, a total of 49,321 grants were in place, of which 40,092 were granted to student teachers, 3,052 to coordinators and 6,177 to supervisors (Hardoim, Pessôa, \& Chaves, 2014). It seems reasonable to suggest that a diverse array of research conceptions have been realised through such a process (e.g. some no doubt more school-related, others more university-centred and led by academics in collaboration with student teachers). In fact, recent empirical work pertaining to Pibid has demonstrated the contribution it has made to the grant holders' (bolsistas) identity development and to a form of preliminary induction into teaching (Hardoim, Pessôa, \& Chaves, 2014), through to raising awareness of current complex conditions of being a teacher and to the valorisation of the teaching profession (Santos \& Silva, 2014), as well as to fostering collaboration between schools and universities and to the consolidation of teacher professional knowledge (Cruz, Oliveira, \& Campelo, 2014). In a recent paper, Marcondes, Leite and Ramos (2017) argue that the Pibid has shown positive outcomes in regard to the development of partnerships between universities and schools. Such a programme, they state, has provided the opportunity for many student teachers to experience teaching in real schools from the very beginning of their teacher education but they warn about challenges that need to be addressed in the future. These include poor working conditions, lack of self-esteem, and issues of equity and social justice.

In Portugal, following the Bologna process, a new policy on ITE was issued in 2007 (Decree-Law 43/2007), aimed at contributing to valuing teacher socioprofessional status and to improving the quality of teachers in order to address the challenges of education of Portuguese society. In order to become a teacher, a three-year degree (licenciatura) is needed, plus a master's degree in teaching. This means the existence 
of higher qualifications to become a teacher (from pre-school to secondary school) and the need to include a research dimension in ITE. However, this new configuration (consecutive model) implies the separation between training in the first cycle (three-year programme called licenciatura) and second cycle (master's degree level now required to enter the teaching profession). This fragmentation is seen to represent a drawback from previous models of teacher education such as the integrated model. In this process, over four to five years, student teachers would study educational sciences and subject matter simultaneously from the very beginning of the course (see, Flores, Vieira \& Ferreira, 2014; Flores, 2016). In the integrated model (prior to the implementation of the Bologna process) the subject area (e.g. English, Biology, Maths, etc.) and the pedagogical component were distributed simultaneously throughout the course. The new model, however, emphasises the subject knowledge and didactics and the professional practice occurring mainly at universities (which implies less time spent in schools). Added to this is the prevalence of the academic-oriented culture (which emphasises knowledge fragmentation and individualism) to the detriment of the professional culture (which attends to the specific nature of learning to teach) (Canário, 2001; Formosinho, 2009). This has implications for the ways in which professional practice is understood and put into practice where it is possible to identify the lack of articulation between discourse and practice.

This new configuration of professional education implies a reduced time and space for practicum (which occurs only at the master's level), with implications for the pedagogical activities that student teachers are able to do. As Moreira and Vieira (2012: 97) stated, 'the impact of this structural change is not yet clear; will second-cycle student teachers take teaching more seriously because they had more time to decide to become teachers, or will they take it less seriously because their training is shorter. And will they be able to integrate subject and pedagogical knowledge now that these curricular components are clearly separated?' The answer to these questions remains to be seen but there have been efforts to make the best of difficult circumstances, especially in the context of practicum in Year 2 of the Master's degree in Teaching.

Although legal regulations do not state that the practicum must have a research component, the fact that students earn a master's diploma 
was tacitly understood by institutions as a motive to introduce it (Flores et al, 2016). Actually, "training in educational research methodologies" was identified as a compulsory component of ITE curricula in the first legal framework issued in 2007, with no credits allocated to it, and with the purpose of "enabling prospective teachers to adopt a research stance in their professional performance in specific contexts, on the basis of an understanding and critical analysis of relevant educational research" (Decree-Law No. 43/2007). The current legal framework issued in 2014 no longer stipulates research as a curriculum component.

\section{Teacher education at the University}

\section{of Minho: key features of the model}

In Portugal, the most recent legal changes point to an increase in the importance of subject knowledge and specific didactics along with longer programmes for initial teacher education at the master's degree level (Decree-Law No. 79/2014, 14 May). This new legislative scenario stipulates the key components of ITE curriculum as subject matter, general education, specific didactics, ethical, social and cultural dimensions (although with specific credits attached to them) and professional practice.

Despite the strict legal framework under which higher education institutions must organise their ITE programmes, it is possible to make the best of challenging circumstances at the institutional level namely as far as the research component during practicum is concerned (Flores, Vieira, Silva and Almeida, 2016). The University of Minho, in Portugal, developed a coherent and research-oriented practicum, despite the legal and institutional constraints. The goals of practicum include: i) to promote a critical understanding and intervention in pedagogical contexts; ii) to deepen the development of subject matter and pedagogical competencies; iii) to develop a research culture and collaboration in professional training; and, iv) to develop the integration of cultural, social and ethical aspects in professional training.

In order to frame practicum in a more consistent way, three main dimensions associated with the professional profile of preservice teachers were also identified: the conceptual dimension (which relates to the theoretical framework of professional practice, including subject knowledge, didactics, general educational knowledge, research and context); the strategic dimension (associated with the methodological 
framework of professional practice, including processes and techniques of analysis and development of subject knowledge and of teaching and learning, regulation and research of teaching, and understanding and transformation of intervention contexts); and, the axiological dimension (which deals with the values of professional practice, including ethical and political values that underpin educational action with its ethical and political implications). Practicum is seen as a key component of the ITE programme occurring in Year 2 of the Master's degree in teaching. It includes elements observation of professional contexts; integrating research into practicum through the development of a pedagogical project (in some cases following an action-research orientation) at school and a portfolio; and the writing up of a final report presented in a public viva voce examination. The underlying assumption is to foster a reflective component oriented towards student teacher professional development under a democratic view of education in order to link theory and practice, and teaching and research. However, a number of challenges in integrating research into practice remain. Flores, Vieira, Silva and Almeida (2016), identify the following: time constraints (research, and particularly action research projects imply time and doing research in a condensed 2-year degree is rather challenging); the risk of making the practicum more academic and less professionoriented; the need for supervisors and cooperating teachers to reshape traditional roles and expand professional competences in order to become partners of pedagogical inquiry and renewal; the existence of performative and managerial cultures that may undermine the development of pedagogical inquired-based projects; the lack of a scholarship of teacher education.

Meta-analyses of 28 reports on the role of research in practicum in the context of the Master's degree in teaching at the University of Minho pointed to the relevance of research in developing pedagogical practice focused on the quality of teaching and learning (Vieira et al., 2013). However, it also identified the co-existence of different modes of articulating research and teaching which are associated with diverse views of teacher education and the role of research in practice and in the (re)construction of professional competences. The authors identified the development of diverse approaches to education, the mobilisation of different kinds of knowledge, the articulation of pedagogical and research purposes in practicum, and the diversity of data collection 
methods and assessment modes. In general, Vieira et al.'s (2013) study indicates that reflective practice emerged from the practicum reports in which research is used to understand and transform education and to enable the (re)construction of the thinking and practice of teachers-to-be. As for the constraints, amongst others, the study revealed that more needs to be done in terms of making the ethical and conceptual framework underpinning the pedagogical projects more explicit, the mobilisation of knowledge about research in justifying the methodological options and data analysis, integration of theory and practice and reflection about the limitations and recommendations for training, supervision and research on teaching.

\section{Concluding remarks}

Taking into account the Portuguese context, the concern of making the best of challenging circumstances emerges by integrating research into practicum (Flores, Vieira, Silva and Almeida, 2016). As Flores et al. (2016) also highlight, the emergence of an inquiry-based culture is "both innovative and controversial" as it implies "dealing with tensions related to visions of teacher education" and with "(in)coherences between curriculum rhetoric and implementation." If we are to move beyond the binary of theory and practice in teacher education, research may be seen as the linking element within the context of strong, coherent and supportive partnerships between universities and schools.

Existing literature points to the existence, in many contexts, of an alignment between a restricted view of school curriculum linked to an outcome-led orientation, along with, in some cases, a back to basics movement, and a more didactic and narrow view of ITE curriculum, leaving behind the ethical, cultural and political dimension of teaching. Reflecting on the English context, Maguire (2014) suggests that the curriculum: "more and more [focused] on successful in-school experience, technical skills such as teaching literacy through centrally prescribed methods, behaviour management, familiarity with testing regimes, etc. Other matters, for example, those of commitment, values and judgements are frequently side-lined, made optional or simply omitted" (p. 779).

However, other perspectives do co-exist within a view of teachers as professionals and as curriculum makers within a research-based orientation to ITE. The need to manage different and sometimes 
contradictory logics associated with national regulations, institutional constraints and contextual possibilities is a critical aspect of ITE. Thus, it is possible to identify a number of issues that need to be taken into account in discussing theory, practice and research in teacher education:

$\rightarrow$ The importance of developing a scholarship of teacher education whereby ITE programmes are analysed and improved. This requires the participation of teacher educators, mentors and student teachers by negotiating meanings and confronting views and practices of teaching, learning and developing as teachers.

$\rightarrow$ The need for teacher educators to look at their own professional development and to investigate their practices in teacher education. Teacher educators are teachers but they are also researchers on and in teacher education and this implies investigating their own practices.

$\rightarrow$ The need to develop more explicit pedagogies of teacher identity development during initial teacher education. Despite the emergence of studies on this topic, research in order to understand the ways in which teacher identity develops during initial teacher education is in its infancy.

For teacher education to be a space of transformation, it must focus not only on what teachers should know and be able to do but also on what it means to be a teacher (Flores, 2016). Teaching is about values, beliefs, actions and commitments. ITE curriculum needs to provide preservice teachers with opportunities to think and reflect upon their role as teachers in transforming education and on the implications of their actions as teachers. As Tryggvason (2009) argued, ITE curriculum should provide students with opportunities to learn how to take responsibility for ethical choices. And this has implications for the role, identity and actions of teacher educators. 


\section{References}

$\rightarrow$ Alcorn, N. (2014). Teacher education in New Zealand 1974-2014. Journal of Education for Teaching 40(5), 447-460.

$\rightarrow$ Aydin, S., Demirdogen, B., Akin, F. N., Uzuntiryaki-Kondakci, E. \& Tarkin, A. (2015). The nature and development of interaction among components of pedagogical content knowledge in practicum. Teaching and Teacher Education, 46, 37-50.

$\rightarrow$ Canário, R. (2001). A prática profissional na formação de professores. Revista Portuguesa de Formação de Professores, 1, 25-38.

$\rightarrow$ Cardoso, E. (2012). Problemas e desafios na formação inicial de professores em Angola: Um estudo nos ISCED da Região Académica II, PhD Dissertation, University of Minho, Portugal

$\rightarrow$ Clarke, M., Lodge, A. \& Shevlin, M. (2012). Evaluating initial teacher education programmes: Perspectives from the Republic of Ireland. Teaching and Teacher Education, 28, 141-153.

$\rightarrow$ Conway, P., Murphy, R., Rath, A. \& Hall, K. (2009). Learning to teach and its implications for the continuum of teacher education: A nine-country cross-national study. Report commissioned by the Teaching Council, University College, Cork, Ireland.

$\rightarrow$ Craig, C. (2016). The structure of teacher education. In. J. Loughran \& M. L. Hamilton (Eds.) International handbook of teacher education (pp. 69-135). Dordrecht: Springer Press.

$\rightarrow$ Cruz, G. B., Oliveira, F. L. \& Campelo, T. da. S. (2014). Programa de Iniciação à Docência: Contribuições para a Formação de Professores. In M. A. Flores, C. Coutinho, \& J. A. Lencastre (Orgs.), Proceedings of the International Conference Formação e trabalho docente na sociedade da aprendizagem, organised within the context of International Study Association on Teachers and Teaching (ISATT) and Research Centre on Child Studies (pp. 383-393). Braga: CIEC, UMinho. ISBN 978-972-8952-30-3. 
$\rightarrow$ Darling-Hammond, L. (2012). Teacher preparation and development in the United States: A changing policy landscape. In L. Darling-Hammond \& A. Lieberman (Eds.), Teacher education around the world: Changing policies and practices (pp. 130150). London: Routledge.

$\rightarrow$ Darling-Hammond, L. (2017). Teacher education around the world: What can we learn from international practice? European Journal of Teacher Education, 40(3), 291-309.

$\rightarrow$ Darling-Hammond, L. \& Lieberman, A. (2012a). Teacher education around the world: What can we learn from international practice. In L. Darling-Hammond \& A. Lieberman (Eds.), Teacher education around the world: Changing policies and practices (pp. 151-169). London: Routledge.

$\rightarrow$ Darling-Hammond, L. \& Lieberman, A. (Eds.) (2012b). Teacher education around the world: Changing policies and practices. London: Routledge.

$\rightarrow$ Decree-Law 43/2007, 22 February. Lisbon: Diário da República.

$\rightarrow$ Decree-Law 79/2014, 14 May. Lisbon: Diário da República.

$\rightarrow$ Duda, A. \& Clifford-Amos, T. (2011). Study on teacher education for primary and secondary education in six countries of the Eastern Partnership: Armenia, Azerbaijan, Belarus, Georgia, Moldova and Ukraine. Final report. European Commission, Directorate-General for Education and Culture.

$\rightarrow$ Ellis, V. \& McNicholl, J. (2015). Transforming teacher education: Reconfiguring the academic work. London: Bloomsbury Academic Publishing Plc.

$\rightarrow$ Elstad, E. (2010). University-based teacher education in the field of tension between the academic world and practical experience in school: A Norwegian perspective. European Journal of Teacher Education, 33(4), 361-74.

$\rightarrow$ Flores, M. A. (2011). Curriculum of initial teacher education in Portugal: New contexts, old problems. Journal of Education for Teaching, 37(4), 461-70.

$\rightarrow$ Flores, M. A. (2014). Teacher learning in the workplace in pre-service teacher education in Portugal: Potential and limits from a Pre-service teacher perspective. In O. McNamara, J. Murray, \& M. Jones (Eds.), Workplace learning in teacher education. International practice and policy (pp. 243-260). Dordrecht: Springer.

$\rightarrow$ Flores, M. A. (2015). Formação de professores: questões críticas e desafios a considerar, in CNE - Conselho Nacional de Educação (Ed.) Estado da Educação 2014, Lisboa: Conselho Nacional de educação, pp. 262-277, ISBN:978-9728360-91-7

$\rightarrow$ Flores, M. A. (2016). Teacher education curriculum. In J. Loughran \& M. L. Hamilton (Eds.) International handbook of teacher education (pp. 187230). Dordrecht: Springer Press. 
$\rightarrow$ Flores, M. A. (2017a). Editorial. Practice, theory and research in initial teacher education: International perspectives. European Journal of Teacher Education, 40(3), 287-290.

$\rightarrow$ Flores, M. A. (2017b). Contributos para (re)pensar a formação de professores, in CNE (Ed.) Lei de Bases do Sistema Educativo. Balanço e Prospetiva, Volume II (pp. 773-810), Lisboa: Conselho Nacional de Educação., ISBN: 978-989-8841-16-2

$\rightarrow$ Flores, M. A. (in press). Unpacking teacher quality: Key issues for early career teachers. In A. Sullivan, B. R. Johnson \& M. Simons (Eds.), Attracting and keeping the best teachers: Problems and possibilities. Dordrecht: Springer.

$\rightarrow$ Flores, M. A., Santos, P., Fernandes, S., \& Pereira, D. (2014). Pre-service teachers' views of their training: Key issues to sustain quality teacher education. Journal of Teacher Education for Sustainability, 16(2), 39- 53.

$\rightarrow$ Flores, M. A., Vieira, F. \& Ferreira, F. I. (2014). Formação inicial de professores em Portugal: problemas, desafios e o lugar da prática nos mestrados em ensino pós-Bolonha. In M. C. Borges \& O. F. Aquino (Orgs.), A formação inicial de professores: olhares e perspectivas nacionais e internacionais (pp. 61-96). Uberlândia: EDUFU.

$\rightarrow$ Flores, M. A., Vieira, F., Silva, J. L. \& Almeida, J. (2016). Integrating research into the practicum: Inquiring into inquiry-based professional development in postBologna Initial Teacher Education in Portugal. In M. A. Flores \& T. Al-Barwani (Eds.) Redefining teacher education for the post-2015 era: Global challenges and best practice (pp. 109-124). New York: Nova Science Publisher

$\rightarrow$ Formosinho, J. (2009). A academização da formação de professores. In J. Formosinho (Coord.), Formação de professores. Aprendizagem profissional e acção docente (pp. 73-92). Porto: Porto Editora.

$\rightarrow$ Goodwin, A. L. (2012). Quality teachers, Singapore style. In L. Darling-Hammond \& A. Lieberman (Eds.), Teacher education around the world: Changing policies and practices (pp. 22-43). London: Routledge.

$\rightarrow$ Grossman, P., Hammenrness, K. \& McDonald, M. (2009). Redefining teaching, re-imagining teacher education. Teachers and Teaching: Theory and Practice, 15(2), 273-298.

$\rightarrow$ Hammerness, K., Tartwijk, J. \& Snoek, M. (2012). Teacher preparation in the Netherlands: Shared visions and common features. In L. Darling-Hammond \& A. Lieberman (Eds.), Teacher education around the world: Changing policies and practices (pp. 44-65). London: Routledge.

$\rightarrow$ Hardoim, R. L. A., Pessôa, T. L. da S. \& Chaves, I. M. B. (2014). Narrativas de iniciação à docência na relação universidade-escola. In M. A. Flores, C. Coutinho \& J. A. Lencastre (Orgs.), Procedings of the International Conference Formação 
e trabalho docente na sociedade da aprendizagem, organised within the context of International Study Association on Teachers and Teaching (ISATT) and Research Centre on Child Studies (pp. 145-153). Braga: CIEC, UMinho. ISBN 978-972-8952-30-3.

$\rightarrow$ Hilton, G., Flores, M. A. \& Niklasson, L. (2013). Teacher quality, professionalism and professional development: Findings from a European project. Teacher Development, 17(4), 431-447.

$\rightarrow$ Imig, D., Wiseman, D. \& Neel, M. (2014). A formação de professores nos EUA: mudanças dinâmicas, resultados incertos. In M. A. Flores (ed.), Formação e desenvolvimento profissional de professores: Contributos internacionais (pp. 61-80). Coimbra: Almedina.

$\rightarrow$ Kansanen, P. (2014). Teaching as a Master's level profession in Finland: Theoretical reflections and practical solutions. In O. McNamara, J. Murray, \& M. Jones (Eds.), Workplace learning in teacher education: International practice and policy (pp. 279-292). Dordrecht: Springer.

$\rightarrow$ Korthagen, F. A. J. (2010). How teacher education can make a difference. Journal of Education for Teaching, 36(4), 407-423.

$\rightarrow$ Lapostolle, G. \& Chevaillier, T. (2011). Teacher training in France in the early 2000s. Journal of Education for Teaching, 37(4), 451-459.

$\rightarrow$ Laurie, R., Nonoyama-Tarumi, Y., McKeown, R. \& Hopkins, C. (2016). Contributions of education for sustainable development (ESD) to quality education: A synthesis of research. Journal of Education for Sustainable Development 10(2), 226-242.

$\rightarrow$ Maguire, M. (2014). Reforming teacher education in England: 'An economy of discourses of truth'. Journal of Education Policy, 29(6), 774-784.

$\rightarrow$ Marcondes, M. I. Leite, V. F. \& Ramos, R. K. (2017). Theory, practice and research in initial teacher education in Brazil: Challenges and alternatives. European Journal of Teacher Education, 40(3), 326-341.

$\rightarrow$ Mayer, D. (2014). Forty years of teacher education in Australia: 1974-2014. Journal of Education for Teaching, 40(5), 461-473.

$\rightarrow$ Mayer, D., Pecheone, R. \& Merino, N. (2012). Rethinking teacher education in Australia: The teacher quality reforms. In L. Darling-Hammond \& A. Lieberman (Eds.), Teacher education around the world: Changing policies and practices (pp. 110-129). London: Routledge.

$\rightarrow$ Moreira, M. A. \& Vieira, F. (2012). Preservice teacher education in Portugal: The transformative power of local reform. In J. M. Paraskeva \& J. Torres (Eds.), Globalism and power: Iberian education and curriculum policies (pp. 94-105). New York: Peter Lang. 
$\rightarrow$ Niemi, H. \& Nevgi, A. (2014). Research studies and active learning promoting professional competences in Finnish teacher education. Teaching and Teacher Education, 43, 131-142.

$\rightarrow$ Piesanen, E. \& Valijarvi, J. (2010). Lot 2: Teacher education curricula in the EU, Final Report, Finish Institute for Educational Research, a study commissioned by the European Commission's Directorate-General for Education and Culture http://ktl.jyu.fi/img/portal/17545/TEC_FINAL_REPORT_12th_Apr2010_WEB. pdf?cs $=1271922032$

$\rightarrow$ Sahlberg, P. (2012). The most wanted: Teachers and teacher education in Finland. In L. Darling-Hammond \& A. Lieberman (Eds.), Teacher education around the world: Changing policies and practices (pp. 1-21). London: Routledge.

$\rightarrow$ Sancho, J. (2014). Fundamental e irrelevante: Las paradojas de la formación inicial del profesorado. In M. A. Flores \& C. Coutinho (Eds.), Formação e trabalho docente: Tendências e desafios atuais (pp. 17-34). Santo Tirso: De Facto Editores.

$\rightarrow$ Sancho-Gil, J. M., Sánchez-Valero, J.-A. \& Domingo-Coscollola, M. (2017). Research-based insights on initial teacher education in Spain. European Journal of Teacher Education, 40(3), 310-325.

$\rightarrow$ Tryggvason, M. T. (2009). Why is Finnish teacher education successful? Some goals Finnish teacher educators have for their training. European Journal of Teacher Education, 32(4), 369-382.

$\rightarrow$ Valeeva, R. A. \& Gafurov, I. R. (2017). Initial teacher education in Russia: Connecting theory, practice and research. European Journal of Teacher Education, 40(3), 342-360.

$\rightarrow$ Van Nuland, S. (2011). Teacher education in Canada. Journal of Education for Teaching, 37(4), 409-421.

$\rightarrow$ Vieira, F., Silva, J. L., Vilaça, T., Parente, C., Vieira, F., Almeida, M. J., Pereira, I., Solé, G., Varela, P., Gomes, A. \& Silva, A. (2013). O papel da investigação na prática pedagógica dos mestrados em ensino. In B. Silva et al. (Orgs.), Atas do XII Congresso Internacional Galego-Português de Psicopedagogia (pp. 26412655). Braga: Universidade do Minho.

$\rightarrow$ Wang, J., Odell, S. J., Klecka, C. L., Spalding, E. \& Lin, E. (2012). Understanding teacher education reform. Journal of Teacher Education, 61(5), 395-402.

$\rightarrow$ Wilson, G. \& l'Anson, J. (2006). Reframing the practicum: Constructing performative space in initial teacher education. Teaching and Teacher Education, 22, 353-361.

$\rightarrow$ Zuzovsky, R. \& Donitsa-Schmidt, S. (2017). Comparing the effectiveness of two models of initial teacher education programmes in Israel: Concurrent vs. consecutive. European Journal of Teacher Education, 40(3), 413-431. 


\section{Biographical note:}

Maria Assunção Flores is an Associate Professor with qualification at the University of Minho, Portugal. She received her PhD at the University of Nottingham, UK. She was visiting scholar at the University of Cambridge, UK in 2008/2009 and at the University of Glasgow in 2016/2017. Her research interests include teacher professionalism and identity, teacher education and professional development, teacher appraisal, and higher education. She has published extensively on these topics both nationally and internationally. She was the Chair of the Board of Directors of the International Council on Education for Teaching (ICET) between 2011-2015 and she is currently the Chair of the International Study Association on Teachers and Teaching (ISATT). She is also executive director of the journal Teachers and Teaching: Theory and Practice and co-editor of the European Journal of Teacher Education. 


\title{
Teacher education and the end of theory
}

\author{
Kenneth Wain \\ University of Malta
}

\section{Abstract}

The progression from teacher training to teacher education was inspired and justified in many countries in the middle of the twentieth century by the incorporation into the training of teachers of a newly proclaimed area of expertise called educational theory, which included the evolving disciplines comprising the philosophy, sociology, psychology and history of education, to replace the 'Principles of Education' offered by the training colleges. The fact that the introduction of these academic disciplines, of 'theory', was what justified preparing teachers in universities where they would be educated into a profession rather than in training colleges where they were just trained into a vocation is often missed or forgotten today. While the new awareness of the importance of theory to practice did not signify diminishing the importance of training, the move sparked a debate about the relative importance of theory and practice and about the proper relationship between them in teacher education that has endured with time with a theory-to-practice model ascendant in the beginning only to suffer a reversal of fortune in later years, in the 1980s, when it was supplanted by a practice-to-theory model, and an even further reversal in more recent times to the extent that in many teacher education jurisdictions today 'theory' has been rendered redundant and often totally abandoned. A move which has, in reality, signified a return to 
teacher training conducted nearly entirely by and in schools. It has also signified the replacement of the professionally educated teacher with a technicist concept of the teacher as what teacher 'education' is about; one that conceives of practice as technique performed through a baggage of skills or competences. This paper looks critically at these developments, particularly at the de facto abandonment of 'education' encouraged also by the policy language of lifelong learning within which the current debate about teacher-education has evolved.

\section{_- Keywords: \\ teacher training \\ teacher education \\ theory, practice \\ lifelong learning}




\section{Introduction}

I imagine that I must be the only one here in this auditorium to have been trained as against being educated as a teacher. I did my two-year teacher training course at an all-male residential college run by Christian Brothers in Malta in the early 1960s. In those days of segregation our female counterparts were trained in a similar institution run by an order of nuns. Of course, the fact that they came packaged as training colleges does not mean that they had no ambitions to 'educate' their students, indeed, it was for this purpose that they were residential. Their purpose was to form us as good Catholic educators, and this required teaching us Divinity, avoiding dangerous literature (Freud and Rousseau, for instance), and living in a Catholic social environment. The training colleges were taken over from the religious orders by a post-Independence Labour government in the early 1970s. In the late 1970s, the three-year training course, as it now was, was replaced with a four-year bachelor of education degree and a one-year PGCE course offered by a newly created Faculty of Education at the University of Malta. The training colleges had trained primary school teachers only, secondary schools teachers were recruited directly with their university degree and without any training, and were distinguished from primary school teachers by being addressed as masters instead of teachers. The implication was that, unlike in primary school, all one requires to teach in a secondary school is mastery of the content, one's subject.

\section{Education and / or training}

As one would expect from an ex-colony Britain has been the point of reference for much of our policy-making in education in Malta even after independence, including the switch to teacher education. Using the word 'education' instead of 'training' was justified by its relocation from college to campus which was in turn justified by the incorporation into the teacher education course of something new and controversial at the time called educational theory. Before, the training colleges had offered students 'Principles of Education' instead; a concoction uncharitably described by a leading educational philosopher of the time as a mishmash, a loose assortment of odds and ends; some history of education, something about the 'great educators', Plato, Locke, Rousseau etc., some child psychology, and so on. Educational theory, on the other hand, included the evolving disciplinary forms of inquiry comprising 
the philosophy, sociology, psychology and history of education and was intended to raise the standard of initial teacher education and to serve practicing teachers, administrators and policy-makers in the interest of better, more professional, educational practices in schools. The fact that the introduction of these academic disciplines was what justified moving initial teacher education from college to campus, and consequently permitted teachers to claim professional status, is often missed or forgotten today. Two centuries and a half ago in Emile Rousseau asked the rhetorical question: "How can a child be well educated by one who has not been well educated himself?" (p.17) This move towards teacher education acknowledged its pertinence, and led naturally to non-rhetorical questions concerning the qualities of an educated teacher, the knowledge she needed besides how to teach, and how to educate an educated teacher. For while a trained teacher needed technical knowledge, the how of teaching, the educated teacher needed more; her technical knowledge needed to be informed with theory, with the education disciplines. Or so the argument went. Nothing was implied in it that teachers did not need to be trained. Training is indispensable for any good practice and teaching is most certainly a practice, a matter of knowing how to do something, therefore of having skills which once instructed can be progressively improved and refined by practice towards more competent performance, which is their object. The language of teacher training suggests that it is best done by accomplished practitioners who have perfected their craft, and/ or recognised instructors or coaches similarly well-versed in the craft of teaching, rather than by academics well-versed in theory.

Educating, the argument continued, names something more complex and difficult to define than teaching. The difference can be illustrated with a simple example. If the object is to teach someone to drive a car competently and safely on the road then one puts the learner in the hands of a driving instructor not a car engineer or a mechanic, because knowing how to drive a car safely and competently is not about knowing how a car works, which is a kind of theoretical knowledge which is also technical. Practice will usually transform the novice driver from being a merely competent performer to being accomplished to different degrees. We need teachers, the argument went, who are more than instructors, who are educators; more like engineers and mechanics who know the car they drive than drivers who only know how to drive 
it, though they need to know that too. They need, as Rousseau first taught us, to know the child or learner, who is a someone, a person and not a unit of production, to push the car analogy a little bit further. Rousseau's point is that knowing the child is at least as critical for the teacher as knowing what and how to teach her; indeed that one cannot properly do the one without the other if what one intends is to educate her. Also, the drive itself cannot be a simple matter of getting the car from point $A$ to point $B$ if we want to call point $B$, the point of arrival, being educated. In short, educators need to know the nature and point of their enterprise, what educating is about, what they should be doing in its name, how the skills of teaching are turned to the purpose of educating, otherwise their practice is unintelligent or blind. And for this they need theories to guide the skills, to guide their practice. Skills you can teach to dogs, cats, dolphins, parrots, and so on, but animals are not educated (at least in our modern understanding of the word), persons are. Which observation brings a moral dimension to teaching which has nothing to do with having the skills to teach, important as these are. It is to do with having values which are learned differently (as Socrates remarked they cannot properly speaking be taught).

Knowing the child, the argument continued, needs the assistance of psychology. And because children are not disembodied minds but socially embedded beings it needs the assistance of sociology and history also. Understanding the nature of the enterprise of 'education' as a distinct human, social, enterprise with its own language, its own vocabulary and conceptual structure constituted with terms like teaching, learning, schooling, educating, instructing, testing, training, curriculum, assessment, examinations, intelligence, and so on, a language one needs to be literate in and theoretically conversant with it, is also necessary. Otherwise one risks misconstruing one's enterprise; one could, for instance, unintentionally indoctrinate and/or brain-wash one pupils, transmit inert, or dead, facts and data to them for regurgitation, and so on, while thinking that what one is doing is educating them, and for this they need the assistance of philosophy. And since educating is a moral and political enterprise defined by relationships (thus raising issues of rights, responsibilities, justice, power, authority, and so on) before it is anything else, it needs philosophy to bring home, to sensitize teachers in a properly reflective, critical, manner to these dimensions of their teaching. 


\section{Theory and practice in teacher education}

The argument for theory having been made more or less in this way, the next question was predictably about the proper relationship of theory to practice which, though an eminently philosophical one obviously concerned all educational theorists at work in teacher education alike and not just philosophers, psychologists and sociologists, but also methodologists who are as much theorists as are psychologists and sociologists, methodology being the theory of how to teach not the practice of teaching. Indeed, it is fallacious to think of methodology as anything more than practice inspired theory. But that makes it no more and no less practical to teaching than are the education disciplines which are similarly practice inspired, and therefore no more and no less relevant to it. 'Relevance' is, of course, a hard word to define, its meaning being contestable no one definition will pin it down in any objective or uncontested way, though I've heard lots of people holding forth with conviction about what is relevant to teacher education and what is not as if the contrary were the case. What lies at the heart of what I would call the 'fallacy of relevance' is the error of distinguishing methodology as practical from educational theory on the grounds that it is theoretical, and therefore abstract and intellectual not practical. The distinction doesn't work because practice, any sort of practice, of knowing how to do something, even the most mundane like crossing the road, or turning on the fan, or opening a can of beans, is inevitably theory-informed. It involves not just knowing how but knowing that some things are the case, while theory itself is a form of practice, of intellectual practice. In theorising one also does something, and there are better and worse ways of doing that something, of doing theory, just as there are in practising skills. Not just, as Aristotle taught us there are intellectual virtues we need to possess besides practical ones - but more about Aristotle later! And methodology is not, of course, any less an intellectual practice than educational theory is either; the whole business of dichotomising the two is epistemologically flawed and harmful. As such it is not any more or less related to what happens in schools and classrooms or to the practice of teaching or educating than are the disciplines. The two are on the same level and in the same situation in the matter of relevance to practice. Indeed, the methodology of teaching belongs quite as much to educational theory as does psychology, history, and sociology, all of which have their own 
methodologies, and has no more or less claim to being practical than they do.

Granted that theory is never absent from our lives, from what we do, the question for teacher educators is never one of theory or no theory but of what kind of theory the education of an educated teacher needs that is different from that required of a teacher who is merely trained. And the answer to it, namely the illumination of that practice by psychological, sociological, historical, philosophical, and methodological theory, was unequivocal in teacher education at the time, in the 1960s and 1970s. I must clarify two things here before I conclude this narrative of the past, of origins, at least temporarily. First, that I use the word 'merely' with no intended disrespect towards those of my generation, and those who came before and after, who underwent teacher training, but simply to mean 'only'. Nor am I suggesting that teacher training, even in the earliest times when it took the form of apprenticeship with an experienced practicing teacher, was devoid of theory, since this would be contradicting what I have just been saying. It is the source and kind of theory and the way it is used to inform practice that is different not its presence or absence. But more about this later. Here, I leave the narrative to come to the present day which, in many countries is witnessing a trend to shift the location and control of initial teacher education away from campus not back to the colleges but entirely to schools themselves. Should this trend continue, it creates two theoretical possibilities for the fortunes of educational theory. One would locate it, together with teacher education initial and in-service, entirely in the schools responding pragmatically to their perceived needs, producing their own knowledge entirely. The other, while similarly locating teacher education in schools and encouraging them to produce their own knowledge, would object to the self-referential parochialism this model implies and argue that the school's knowledge is best produced jointly with the theorists and researchers on campus. The first, self-referential, model is objectionable on different sociopolitical, epistemological, and professional grounds that I will not go into here. The second is more interesting, and, though it wants to shift the control of teacher education initial and continuing from campus to school perceives the need for ongoing dialogue and cooperation with the theorists on campus and in educational research institutions. 
I'm mentioning these possibilities because my impression is, though not aided by any comparative work, that countries in Europe and elsewhere have since the middle to late 1980s gone down a disturbing route in their directions. This is Ivan Snook, for instance: "As a result of the current ideology in New Zealand (and, of course, elsewhere), there have been strong moves to de-professionalize teaching and to increase competition in teacher training. As a result, pre-service courses have become shorter, cheaper and (arguably) less demanding. More significantly, the contextual studies needed for a full profession have tended to be reduced. The history, philosophy and sociology of education have been downgraded and often excluded altogether." The disturbing consequence of all this, he says, is that "teacher education is producing technicians who will be uncritical of their important role in society and subservient to the business interests which are trying to control schools." (p.143) I'll return to them in a moment after signaling a significant and relevant change to the policy discourse on teacher education globally in recent times and absent in the past brought about by the universal recognition today that educational policy in general must be rooted in the demands of lifelong learning. The rationale of lifelong learning assumes a fast-changing world driven by an aggressive technology which renders all knowledge permanently temporary and impermanent, including that of schools and teachers. I cannot myself fault its logic but I can, and have frequently, voiced my concern that the policy discourse of lifelong learning identifies it primarily as a tool for a competitive economy, for the creation of knowledge-based societies, and, more generally with a means-ends culture of performativity. On the other hand, the reality which the necessity of lifelong learning brings to the fore where teacher education is concerned is that it cannot be limited as in the past to initial training with occasional inservice training added on here and there where the need arises. On the contrary it must, while it starts from initial training, continue through the teacher's professional life either as recurrent or continuous learning. The first requires lifelong programmed in-service training provision. The second, more interesting and challenging requires a culture of continuous learning to be built into the very operation of schools reconceived as learning organisations. 


\section{Teacher education located in schools}

My problem with this concept of the school, which was already around in the early 1990 s, is that the notion of the learning organization has its original home in the world of business not that of education. Some could see this as an advantage rather than otherwise since our schools already speak the language of business, jargon and all. Today our schools are run by management teams, they produce mission statements, development plans, attainment targets, they are subjected to quality control and audits, and so on; all terms imported from the world of business. The managerialist language coincides with the policy discourse of lifelong learning of the 1990s, in EU policy documents for instance which were dominated by the interests of business and which, and this is a truly significant point, signaled the eradication of education. Thus in a White Paper published in 1995 titled Teaching and Learning: Towards the Learning Society the European commission declared the end of years of 'heated debate' on 'educational principles' since, it affirmed, there was now consensus on them and we can concentrate of matters of strategy, means-ends matters, only. The disturbing thing is that when one examines the educational principles it mentions they turn out to be not 'educational' at all but operational, strategic directives that put the interests of business and of a competitive European economy at the forefront of the commission's policy agenda, with employability at the top as the central concern for schools ahead of other more social concerns like social cohesion and democratic citizenship. And when it speaks of more recognizable educational aims like those of 'emancipation' and equality of opportunity, it describes the first flatly as self-reliance, further defined as 'occupational capacity', and the second as providing "everyone access to a broad range of knowledge and to build up their abilities for employment and economic life." (p.44 LLBS11) While the stated aim of 'occupational capacity' or employability is to produce workers who can adapt flexibly to the training demands made by continuous technological change and are capable of self-directed learning. The aims of social cohesion and democratic citizenship, are acknowledged in the document, but only on the margins and left, more or less, to take care of themselves or to be defined by the ethos of a consumeristic culture.

Let me repeat my support for the basic premise of lifelong learning which implies that, whatever else may be the case, the traditional 
stand-alone view of initial teacher education should be abandoned and replaced by an initial teacher education conceived as the preliminary stage of a career-long learning project. I would also support the suggestion that this initial stage should be about educating selfdirected learners, with one important proviso that though this should mean being largely self-reliant for one own learning needs, selfdirection should not mean self-containment. On the contrary it needs to be understood and supported by a school culture that encourages by creating suitable spaces for its initiatives. Besides ones project of professional growth is not achieved alone but with others within the school community of fellow-teachers and others, within and with which one works. And this is where the idea of schools conceived of as learning organisation, as places where, to quote a prominent writer on the subject of the mid-1990s "the process of learning is permanent not intermittent, holistic not segmented, problem-centred, context related, and includes all members of the enterprise," is tempting. (Bradshaw in LS in a Postmodern World p.73)

This model could render operational elaboration to the more interesting second notion of a school-based initial and continuous teacher education I described briefly earlier with a different ethos and agenda from that of a business organization. One that thinks of itself as a learning community rather than a learning business, modeled on John Dewey's description of a democratic schooling community which is socially cohesive and inclusive, and led by educational leaders rather than managers. Dewey conceives of such a community as a 'form of life' marked by its commitment to open, free and interactive communication through which its members grow personally and socially. This account of education as 'growth' rather than as aims-directed also belongs to Dewey who described it as opening onto further growth, and not closed by inertia or dogma, and which is therefore a flexible, experimental, dynamic, process both for the individual and the community. It is not surprising that this understanding of education as open-ended growth fits in well with the conception of learning as a lifelong process driven by change and Dewey is, in fact, often recognised as a progenitor of the idea of lifelong learning turned not, first and foremost, to the interest of the economy but of a free and open society. Within Deweyan democratic communities the heated debate of 'educational principles' never stops; indeed stopping would be tragic for them, fatal. Principles 
that are protected from debate through laziness or impatience with it or because they are taken as given and beyond it quickly become static and dogmatic, the stuff not of democratic but of totalitarian politics. Any consensus arrived at through democratic debate can be regarded only as a temporary resting-place, a solution to an immediate problem, not as a permanent point of arrival.

I admit, of course, that this Deweyan vision of the school as a democratic learning organization is utopian, but this troubles me only to an extent. It does not trouble me as a philosopher because articulating utopian vocabularies with the hope of rendering them attractive for others, practitioners and policy-makers, should be, among other things, what doing philosophy is about. But it does trouble me as a teacher-educator operating in a world which is not utopian, at least in my view, and which operates with a dominant performativist vocabulary which is practically as far from it as you can get. Performativity is insidious; by representing the criteria of effectiveness and efficiency of output as its key values it presents itself as entirely technical and non-ideological, independent of normative interests when it is anything but that. As master narrative of our postmodern world it wins global support for this reason, for apparently being nonideological. Performativity suggests, like the EU white paper of 1995 I quoted some minutes ago with which it is consistent, that the ends of education should be taken as given and that we can focus entirely on the means, on the 'how', on the technical, operational aspects of lifelong learning. That we should stop asking the tedious question 'why?', or 'for what purpose?', which are political questions. The world of 'education' produced by a performativist culture is summarized by Alis Oancea and Janet Orchard as one where "Standards and measures of performance, systems through which performance may be monitored and reported, as well as quality assurance structures and mechanisms intended to regulate this process of accountability, have flourished in recent times within neo-managerialist approaches to public policy and administration developed in Western countries.' (Alis Oancea and Janet Orchard, JOPE, Vol. 46, No. 4, 2012, pp. 574-588, p.575) It is a culture which produces the technicist image of the teacher as one possessing a basket of skills or competences measured by their efficiency and effective results, referred to by Snook. And the fact that it sets aside the debate about that contestable issue of education, namely about the 
kinds of persons we want our future generations to be and the kind of society we want to live in (apart from one populated by entrepreneurs or adaptable, employable, human resources and avaricious consumers of marketable goods) renders it attractive for policy-makers obsessed with business and the economy. Insensitive to the fact that the fact that these matters about education have been hotly debated in the past shows a sensitivity to their importance in the past, to what is at stake, which they lack, to our considerable cost.

Let me put some context on this. The hotly debated issue about education that dogged the Western world from the early days of modern mass schooling in the nineteenth century was over the respective merits of truth and freedom; over whether the task of schooling should be viewed primarily as one of socializing new generations into the society's truth, or whether it should be about cultivating free individuals able to think critically and outside that truth. The conservative right prioritised truth over freedom, the liberal left freedom over truth. The politics of modern schooling is marked by the debate to work a compromise between these equally valid demands made on them, and modern schooling has evolved within the tension of that debate which, we are now told, we can consider dead, superseded because, in our post-ideological world the politics that rendered it relevant are dead, we can safely, to repeat the argument, set our sights and focus our energies on the operational, strategic, issues, namely on what works for the economy. Hence we need bother our teachers no more with it (if we ever have), we need only to teach them to teach and to learn how to learn, and the job, which is a purely technical one, is done. Nor need we teacher-educators bother it either since it has stopped being our business though we should continue to call what we are doing without it 'education' to preserve its status as a profession. Nor, it follows, need we bother further with the question of how educational theory and practice are properly related, sine the need for educational theory dies with education. Nor should we worry about the outcome of all this, well-described by Snook; that teaching is de-professionalised because the contextual studies that render it such, a profession, of history, philosophy, psychology, and sociology of education, the studies of educational theory, are reduced, downgraded in value if not excluded altogether from pre-service training courses which can, as a result, be shorter and less demanding, and cheaper too (a crucial consideration) 
their business being to produce not teachers as agents of social change as is required in a free society, but uncritical technicians subservient to the interests of business and the economy.

\section{Teacher competences}

Of course performativity does not really drive theory away at all because, even given the argument that all we need is gifted teacher technicians competent to teach, in this case to perform efficiently, the question inevitably follows; ' $w$ hat are the competences required by a competent teacher technician?'. And the answer, whatever it is, will be a theory of some sort. Indeed, there are several competing theories about what these competences are that have been with us now for quite some time, and the debate about them is as inconclusive as the debate about education ever was. And this is because, notwithstanding the delusions of those positivists still inhabiting the world of teacher education, there is no set of teacher competences that can be defined in any objective way or acknowledged universally, not even within the profession. In our faculty we premised our recent colloquium about the curriculum of our new MTL course with the undertaking to replace the old theoryto-practice model of teacher education which was tacitly operative in our old BEd. (Hons) and PGCE courses from the start, with a practiceto-theory model. I think this is right, especially if it protects us from temptation such as we may have harboured in the past, to begin our deliberations on the new curriculum by itemizing the qualities of 'a teacher,' which would invariably, in today's climate produce a package of teaching skills and competences, however defined. For starting with a theory of this kind logically contradicts and is inconsistent with a practice-to-theory model besides being clearly inconsistent with the rationale of lifelong learning which rejects the assumption that any such package could be anything but provisional. More than that, it would regress us to teacher training and to a model of it which is even more theory-impoverished than it was in the day of the training colleges, poor as it was undoubtedly then. I'm not trying to show any concern here with the implicit decision to demote theory, to devalue it with respect to practice, which is implied in replacing the theoryto-practice model with the practice-to-theory, but that the decision will materialize with time into the narrow technicist model of teacher training I have been criticising. I think we are well rid of the theory-to- 
practice model which is the opposite end of the spectrum from the technicist. Where practice is thought of as applied theory and which required students in initial teacher education to read the books and the academic articles produced by educational theory and apply it critically and selectively to their practice for its guidance.

In effect this model was losing favour already with the theorists themselves in the early 1980s mainly because it didn't work for the people for whom it was supposed to work, namely the teachers in education and in-service, and the policy-makers who complained that the theory was difficult, exotic, and distant from the real concerns of teachers in the classroom, and therefore irrelevant to their interests, but also because the coherence of the notion of applied theory itself was put in question. It was challenged already with a practice-to-theory model which acknowledged teaching as primarily practice-based rather than the other way around, and which sought to redefine the teacher in practice as her own theorist and arbiter of what knowledge is relevant for the unique needs of her own practice. In short, by recasting her as a reflective practitioner. And what better understanding of practical knowledge than the classical Aristotelian which describes it as phronesis or practical wisdom, as being capable of judicious deliberation and empowered to act on it. In short, as being capable of praxis. Wilfred Carr has pointed out that phronesis is related to the Greek idea of a bios praktikos, 'a way of life' (like Dewey's understanding of democracy), of a distinctive kind referred to by Socrates as examined or reflective, and which is essentially ethical and political (which for the Greeks meant essentially the same thing, since both referred to life in the polis) in substance. In other words a life lived with others in a community, and thereby a cooperative life, one of relationships. In Aristotle phronesis is distinguished from two other kinds of knowledge: epistemic, which is about unchanging truths and is contemplative, the realm of metaphysics, and technical or skill-based which falls in the realm of the craft, the vocational. The language of competences is of the last, vocational, kind. Unsurprisingly, it has its home in the world of vocational training of the mid-to-late 1980s when it started what Terry Hyland describes as a "'quiet revolution' (Burke, 1989, p. 1) in vocational education and training courses" in Britain, following closely onto the introduction of National Vocational Qualifications (NVQs), and which was immediately attractive for a hard-nosed cost-cutting 
Conservative government suspicious of educational theory in general, and concerned in those troubled times, as one writer has put it, "that a preoccupation with critique - Marxist, feminist, 'progressive' and other - was cultivating radical attitudes among student teachers that were inhospitable to the inherited traditions and work practices of schools." The Education Reform Act it passed in 1988 responded politically to this threat by introducing successive waves of change in teacher education in Britain which included "the requirement to align the design of teacher education programmes to a range of specified competences (sometimes more than 90 competences)." Of course, this background questions the political innocence of competence-based teacher education programmes! The Reform Act also brought "A shift in the main location of many teacher education programmes from campus to school through new 'partnership' requirements," which refers to what I said earlier on the subject (Padraig, 137-138). The two-actions together started teacher education on a slippery slope towards the outcome described by Snook two decades or so later.

It needs clarification here that I am not here arguing against teaching teaching skills or competences in teacher education. Indeed, I have been emphasising the point that teaching as a practice is a matter of knowing how, and therefore, inevitably, a matter of having skills and competences of certain kinds (like asking questions, instructing, assessing, presenting, demonstrating, and so on) that are measurable on a performative scale. Nor am I am arguing that these skills and competences should not be itemized by teacher educators and taught to beginning teachers in initial training, as part of their education. What I am arguing against is what Hyland in another article describes as the "one-dimensional, technicist approach reflected in the obsession with skills and competences (Hyland and Merrill 2003)" that proceeded from the "'new vocationalist' thrust of the late 1980s and 1990s," for the same reason as his, that it is "'morally impoverished." (p.64) For that is precisely what it is; morally and, I would say, politically impoverished also. It is impoverished also by its exceedingly poor understanding of practical knowledge (which various critics have commented does poor justice to vocational education itself), especially when it is compared with the Aristotelian understanding as praxis, and therefore as rooted in the world not in a craft, which I have just described. Finally, it is epistemologically impoverished also because it is reductive of the 
extraordinarily rich knowledges and intelligences human beings are capable of to one kind, the technical, disregarding the rest. In so doing it disregards the dimensions of the imagination and of the emotions since these are not skills, not a matter primarily of knowing how though there have been several spurious attempts to so define them, even if they need skills, knowing how, for their activation or practice.

\section{Concluding remarks}

The worrying thing is that this technicist reductionism Hyland refers to and that has, as Nigel Blake et.al. have observed, and as I observed myself earlier in fact when I described the hegemonic power of its performativist culture, taken over the entire 'educational' landscape in the West, constitutes the very devaluing and distortion of the human in our learning culture. Its insidious political agenda is well-described by Robin Usher et.al. who analysing it in Foucaltian terms, namely as a discourse of power, describe it "as an element in a contemporary discursive practice which works to regulate and shape through selfregulation, in other words, a discourse that is part of a strategy of governance that both mobilises capacities and produces consent without oppression" (p. 83). This obsession with 'quality control', with policing, with assessment has, indeed, always been the dark side of technicist reductionism, or instrumental rationality, as it has also been called, functioning in schools to bring teachers under an invisible regime of disciplinary self-management. As against its political ethic I would, in conclusion, exercising my visionary licence as a philosopher, propose a contrary ethic of creative autonomous action, of praxis, imbued with a deep care and concern for self and others in the school community, students, colleagues, and parents, conceived as democratic which I described earlier. Initiating student teachers into this kind of ethic against the technicist is how I propose we understand teacher education, and how I understand the job of teacher educators. Such an initiation would be into a rich examined, reflective, professional teaching life of the kind captured by the concept of phronesis. It would also propose what Heidegger called a poetic being in the world; the ability to engage with one's world creatively and to re-invent oneself and one practice in the process. I close with a quote from a document of the General Teaching Council of Northern Ireland (2005) significantly named Teaching the Reflective Profession and I will leave it there. The 
title itself reminds us what teaching should be, namely a reflective practice. "Teaching," it says, "can never be reduced to a set of discrete skills to be mastered in some mechanical process of assimilation. To adopt such a reductionist approach would be to deny the intellectual basis of our work and the richness of the ongoing dialogue and learning that enhances our professional practice" (Padraig, 146). In other words, it would signify killing teaching as a profession. 


\section{References}

$\rightarrow$ Bradshaw, D. C.A., (Ed.) (1995). Bringing learning to life: The learning revolution, the economy, and the individual. London: The Falmer Press.

$\rightarrow$ Carr, W., (2005). Philosophy and education. In W. Carr (Ed.), The RoutledgeFalmer reader in philosophy of education (34-49). Oxford: Routledge.

$\rightarrow$ European Commission, (1995). Teaching and learning: Towards the learning society. Brussels: European Union.

$\rightarrow$ Hogan, P. (2010). The new significance of learning: Imagination's heartwork. Oxford: Routledge.

$\rightarrow$ Oancea, A., Orchard, J., (2012). The future of teacher education. Journal of Philosophy of Education, 46(4), 574-588.

$\rightarrow$ Rousseau, J., (1991). Emile or On Education. London: Penguin Classics.

$\rightarrow$ Snook, I., (2012). Lifelong education: Some Deweyan themes. In D.N., Aspin, J. Chapman, K. Evans, \& R. Bagnall (Eds.) Second international handbook of lifelong learning Part 1 (139-149). Dordrecht: Springer.

$\rightarrow$ Terry, H. (2007). Lifelong learning and vocational education and training: Values, social capital and caring in work-based learning provision. In D. N. Aspin (Ed.), Philosophical perspectives on lifelong learning (pp. 27-69). Dordrecht: Springer. 


\section{Biographical note}

Kenneth Wain is professor at the University of Malta where he served as Head of the Department of Education Studies and Dean of the Faculty of Education and where he currently teaches philosophy of education and moral and political philosophy. He received his $\mathrm{PhD}$ from the University of London and over the years he has published numerous articles in these areas of philosophy as well as several chapters in books. Professor Wain was involved in preparing several reports and studies related to the most significant educational reforms and policies in Malta in the 1990 s and early 2000 s, chairing committees and policy groups and advising the Ministry of Education. 



\title{
Teachers' continuing professional development: \\ trends in european countries
}

\author{
Paweł Poszytek \\ Foundation for the Development of the Education System, Poland \\ Liliana Budkowska \\ Foundation for the Development of the Education System, Poland
}

\section{Abstract}

In this chapter we will speak about the issue of teachers' professionalism and the role of the institutional support in fostering teachers' professionalism by the largest national organisation in Poland. The organisation is called - the Foundation for the Development of the Education System (FRSE) and it is a leader in European-funded project management, also in direct cooperation with European Union. The starting point of our discussion is the current teacher education policy in Europe and its focus on developing teachers' professional competences throughout their careers and the suggestions concerning effective ways of stimulating teachers' lifelong professional learning and assessing their competences with consistent tools. Regarding this policy direction, the most significant activities and achievements of the Foundation for the Development of the Education System in the field of developing teachers' professionalism is presented in the main part of the presentation. The special attention is paid to the type of teachers training abroad like job shadowing, observation periods, professional development courses or specific events, the European Commission programme for teachers that supports teacher training (Erasmus+), and the platforms for teachers, schools, experts, and others to find information on news, trends, policies, initiatives, and activities 
in the field of school education, as well as contribute by discussing and engaging important issues with peers, will be presented. In the final part of the presentation, some important recommendations for fostering teachers' professional in Europe and beyond it are presented.

\section{Keywords:}

teachers' professional competences

initial teacher training

continuing professional development

teacher leadership 


\section{Introduction}

In this chapter the issue of teachers' continuing professional development and its trends in European countries are discussed.

The starting point for this chapter is the current teacher education policy in Europe and its focus on developing teachers' professional competences throughout their careers and the suggestions concerning effective ways of stimulating teachers' lifelong professional learning and assessing their competences with consistent tools. Regarding this policy direction, the most significant activities and achievements of the Foundation for the Development of the Education System ${ }^{1}$ in the field of developing teachers' professionalism is presented in the main part of this chapter. Special attention is paid to the type of teachers training abroad doing job shadowing, observation periods, professional development courses or specific events, the European Commission programme for teachers that supports teacher training (Erasmus+). Furthermore, the platforms for teachers, schools, experts, and others to find information on news, trends, policies, initiatives, and activities in the field of school education, as well as contribute by discussing and engaging important issues with peers, will be presented. In the final part of the article, some important recommendations for fostering teachers' professional learning in Europe and beyond it are also presented.

Many education systems have to contend with challenges linked to a smooth transition from the stage of initial teacher training to the stage of their professional development. The challenges mainly relate to the question as to which competences should be developed in preservice teachers when they are trained and which ones, for various reasons, have to be included in continuing professional development. To get a clearer picture, it is worth emphasising that we are talking mainly about key competences, but not only. Although a review of continuing professional development (CPD) systems operating in Europe is a complex task, due to the diversity of solutions applied by

1. The Foundation for the Development of the Education System (FRSE) is the largest national organisation in Poland. It is a leader in European funded projects management. It directly cooperates with the European Union. The authors of this chapter have several years of experience working in the system of professional development of teachers and management of international educational projects addressed also to this group of beneficiaries. The authors also actively serve as experts for the Polish Ministry of National Education in the process of gaining further professional degrees by teachers. 
different countries, it is a challenge worth facing, as it will allow us to determine the level at which these competences are developed as part of formal and non-formal education. Therefore, using past experience resulting from a number of attempts to describe various aspects of European education systems, we have to refer to a certain grid or a parameter matrix describing and defining something, which we generally call the system of continuing professional development, in whatever shape it may function in practice. Basing on materials published by Eurydice, the European Commission's official source of data, we are able to develop such a parameter matrix linked to the degree of CPD system centralisation/decentralisation, statutory duty to undergo CPD, timing of the implementation of CPD-related tasks, types of institutions offering CPD, development of CPD plans and the accreditation of CPD providers.

\section{The system of CPD for teachers - centralised or decentralised}

An analysis of teacher support models in Europe shows that a growing number of countries are developing so-called decentralised continuing professional development systems (European Commission, 2013).

However, the notion of a centralised or decentralised system is neither clear nor easy to define. We can assume that on the one end of the spectrum, we have a strongly centralised system where CPD is organised by nationwide institutions accountable to the national education authority only, whereas on the other end, there is a system where the main role in the organisation of CPD is played by schools, e.g. in Slovenia and Lithuania, as a result of the 1998 reform, school principals are responsible for improving teachers according to national educational goals. In order to better understand what relevant processes entail and to go beyond the dichotomy between the centralised and decentralised systems, which does not quite reflect the intricacies and nuances of the matter under analysis, we have to divide the existing or theoretically possible systems into more categories, while being aware that some of them may overlap. Such an approach will allow us to analyse the situation more thoroughly:

$\rightarrow$ Centralised system - Slovakia, Romania, Croatia. In Croatia, the main role is played by a central institution, namely the Education 
Institute with its four branch offices. The Education Institute is responsible both for supervision and guidance for teachers.

$\rightarrow$ Decentralised system (regional, local and school levels) - Belgium, Denmark, the Netherlands, Sweden, Iceland, Estonia, Hungary, Italy, Lithuania and Slovenia. For example, as a result of reforms implemented in Slovenia and Lithuania, heads of school are responsible for CPD for teachers in line with the national objectives of education.

$\rightarrow$ External/market-based system - a system that is theoretically possible, but not operating in a pure form in any country, where schools use external services of various independent CPD providers.

$\rightarrow$ Internal system - CPD at school level, for which Norway can partly be an example where each school appoints one teacher responsible for the organisation of training.

$\rightarrow$ Networking-based system - part of the Malta's system is an example, in which schools are encouraged to develop networks and provide mutual CPD support.

$\rightarrow$ Mixed system - Poland, Finland, Great Britain. In Finland, for example, the ministry develops a training programme and lists priority topics, which are to be implemented by various institutions at the local level. In Poland, this mixed nature is due to the assignment of responsibility for CPD at all levels: central, regional and local one.

In many countries, the situation is changing dynamically, various reviews are based on data collected in different periods, which significantly contribute to an unclear view of the situation. However, this degree of accuracy is not necessary for our purpose. Above all, we need to determine which elements or parameters should be taken into account when reflecting on CPD systems. As it is difficult to present a single, general and coherent typology, we will analyse the parameters, which determine compulsory and optional CPD support provided for teachers.

\section{Compulsory or optional CPD for teachers}

Analysis of the documents published by European Commission (2013), as indicated in the report entitled "Status of CPD for teachers in general 
lower secondary education" (ISCED 2), according to central regulations, 2013/14, shows that in Europe CPD for teachers is a professional responsibility in a number of countries, such as Estonia, Cyprus, Latvia, Luxembourg, Hungary, Malta, Austria, Portugal, Montenegro and Serbia. As part of this responsibility, the minimum number of hours of training is stipulated, e.g. from 8 hours in Luxembourg to 68 hours in Serbia. In five countries, the minimum amount is expressed as numbers of days. For example, teachers in Belgium and Finland are expected to take part in CPD for at least three days a year, while in Cyprus this minimum requirement amounts to four days, and five days in Lithuania and Slovenia. In Great Britain (Scotland), teachers have a contractual requirement to complete a maximum of 35 hours of CPD annually, and as part of their working year they must also attend five days of continuing professional development activity planned by their employers. The second group are countries in which CPD is regarded as a professional duty, and involvement in it is further encouraged by making it an element of promotion requirements. For example, in Spain, Croatia, Lithuania, Portugal, Romania, Slovenia, and Slovakia, CPD is regarded as a significant asset for career advancement. The third option involves CPD as an optional measure. Although in Iceland CPD is optional, teachers are recommended to engage in 170-190 hours of CPD annually, whereas in France, participation in CPD is regarded as a right and the legislation specifies that teachers are entitled to at least 20 hours of continuing professional development per year. Poland is the only country where $\mathrm{CPD}$ is a precondition for professional advancement, which - just as career development - takes account of the degree of CPD plan implementation (Regulation of the Polish Minister of National Education of 1 March 2013 on obtaining professional promotion degrees by teachers).

Implementation of CPD - during or after working hours

In most European countries, CPD is organised outside working hours. However, Eurydice sources do not specify whether "working hours activities" are to be understood as all working hours or as the teaching load. A number of countries allow participation in CPD during regular working hours and the differences refer to whether or not teacher replacement is provided and whether or not hours spent on CPD are included in working hours. So, in Belgium (German-speaking Community), Germany, the Netherlands, Austria, Liechtenstein, 
Estonia, Latvia, Lithuania and Hungary compulsory CPD is organised within working hours and involves teacher replacement, whereas the Flemish Community of Belgium, Finland, Sweden, Great Britain and Malta provide CPD within working hours, but without providing teacher replacement. The French Community of Belgium, Denmark, France, Italy, Norway, Bulgaria and Slovenia organise optional CPD within working hours and with teacher replacement. Various forms of CPD are provided outside working hours in Romania (compulsory CPD) and in Ireland, Greece, Spain, Portugal, Iceland, Cyprus, the Czech Republic, Poland and Slovenia (optional CPD, at teachers' discretion).

\section{Institutions providing CPD for teachers}

In most European countries, higher education institutions (HEls) and teacher in-service training centres are the main providers of CPD. For example, in Sweden, future teachers and then in-service teachers are trained by the same HEl, which guarantees the continuity of the process. In Austria, teacher training institutions closely cooperate with those providing CPD, which has been a requirement imposed by a recent reform. Similarly, in some federal states in Germany, teacher training centres operating within HEls coordinate cooperation between these HEls and CPD centres. In Belgium, Italy, Austria, Finland, Great Britain and Slovenia, CPD for teachers is organised at local or school levels. A private market offering CPD is emerging in Central and Eastern Europe. To regulate this activity, Great Britain and Portugal are considering the introduction of a system registering and accrediting CPD providers. Greece and Cyprus have CPD centres specially established for teachers (European Commission, 2007, pp. 51-52, and European Commission, 2003, pp. 111-112). The Foundation for the Development of the Education System (FRSE), which is a foundation of the State Treasury changing the face of Polish Education for over 20 years, is one of the institutions providing CPD for teachers in Poland. FRSE offers opportunities to acquire basic and specialist knowledge both in a formal and academic way and also in non-formal and practical settings. FRSE is the only Polish institution possessing an immense experience in managing a dozen or so of EU education programmes. In 2007-2013, it coordinated the "Youth in Action" and "Lifelong Learning Programme" (Erasmus, Leonardo da Vinci, Comenius and Grundtvig) in Poland. The credibility of the Foundation has directly translated into 
entrusting it with the function of the Erasmus + National Agency in the years 2014-2020. The Foundation also implements EU information and educational initiatives, such as the European Language Label, eTwinning, Eurodesk Poland, Europass, Eurydice and EPALE. Last, but not least, it supports cooperation with Eastern countries through the PolishLithuanian Youth Exchange Fund, Polish-Ukrainian Youth Exchange Council and the SALTO Eastern Europe and Caucasus Resource Centre. For some years, FRSE has been the operator of the EEA Scholarship and Training Fund and of the Sciex-NMSch Scholarship Fund. Most programmes and initiatives offered involve mobility abroad, including staff mobility carried out to improve skills and professional competences. School staff are given an opportunity to explore modern and innovative teaching methods as well as educational institution management, which allows them to achieve the main objective - work quality improvement in their institution in specified areas necessitating changes, and the strengthening of international cooperation. Education institutions present their development plan in an application (European Development Plan), which outlines areas necessitating improvement, compliance of project activities with the needs and specificity of the institution, as well as long-term benefits to be brought by the project. Project objectives are determined together by teachers and the school headmaster in line with the needs of the school and its employees, owing to which not only the person carrying out a mobility, but also the whole institution derives benefits from the project's implementation. Project participants obtain grants to participate in certain forms of support such as teaching assignments - activities enabling teachers to conduct classes in partner schools; staff training - participation in organised activities or training abroad, job shadowing, and participation in conferences or seminars.

As part of FRSE's extensive offer, teachers can apply for funding of their projects involving international cooperation between education institutions, education authorities and other organisation active in the field of school education. Such activities should focus on the introduction of long-term changes, innovations and good practices wherever necessary to ensure high quality education. In particular, they should aim at the enhancement of young people's achievements (especially that of students at risk of dropping out of school or with low levels of basic skills), but also at raising the quality of early education 
and care, as well as the development and strengthening teachers' professional competences. The eTwinning programme defining the school community as one composed of schools and pre-schools from all over Europe (and not only) and cooperating also in the area of CPD for teachers by using electronic media is another offer addressed to teachers. Teachers and students use the internet for the purposes of international cooperation - they cooperate, exchange information and learning resources. eTwinning extends the scope of pedagogical opportunities offered to students and teachers, and encourages learning and opening to Europe. The programme has already attracted over 400,000 teachers from 160,000 schools who each year work together in over 50,000 projects.

\section{Accreditation of CPD providers}

In most European countries, CPD for teachers undergoes accreditation or evaluation. In Sweden and Norway, where CPD provision is mainly based in $\mathrm{HEls}$, regulations governing the evaluation of those $\mathrm{HEls}$ also include CPD evaluation. In Germany, Spain, Hungary, The Netherlands, Poland, Portugal, Slovenia, Bulgaria and Romania, regulations governing accreditation and evaluation are applicable to all kinds of institutions. Depending on the institution, Italy and Ireland apply both procedures (accreditation or evaluation) or just one of them. Italy does not accredit HEls and institutions providing CPD for teachers. Ireland accredits practically all providers save HEls. Belgium, Denmark, Finland, Sweden and Iceland accredit or evaluate only some providers. For example, Finland accredits only CPD courses offered by HEls. Cyprus, Lithuania, Malta, Great Britain and France have no regulations concerning accreditation and evaluation, but most of these countries apply evaluation practices not regulated by law. Invitations to tender for CPD provision are issued in France.

To sum up the above information, we should reiterate that diversified CPD systems operate across Europe. In most countries, CPD for teachers is compulsory, which means an obligation put on teachers, sealed through a collective agreement as part of their working conditions.

Even in countries where there is no such obligation, CPD is a career advancement requirement. However, there is a considerable diversity of CPD providers, HEls and in-service teacher training centres being predominant. In most cases, there are CPD accreditation or evaluation 
systems in place. However, training offers do not always meet teachers' needs. Teachers report that they need more training in teaching methods than in the contents of their subject (OECD, 2014).

Awareness of teachers' needs and their regular identification is conducive to the systematisation of training offers. In Europe, three main players might be involved in the identification of CPD needs: the top-level authority for education (usually the national ministry of education), local authorities or schools themselves. In Greece, for example, the top-level education authority on its own determines the types of training teachers need, and those allowed to provide it. In France, Croatia, Italy, Austria, Norway, Macedonia and Turkey, needs and plans relating to training are determined both by the top-level education authority and local authorities or schools themselves. In France, the Ministry of Education develops National Training Programme, which provides a general framework for the development of training plans by administrative units called academies. In Italy, CPD needs and plans are determined by schools themselves and the top-level authority is involved when training is linked to reforms or modernisation.

In a number of education systems, for example in Belgium (Germanspeaking Community), the Czech Republic, Denmark, Germany. Lithuania, the Netherlands, Poland, Slovakia, Finland and Sweden, CPD needs and plans are established solely at local level and by schools. Teachers are frequently consulted. In Norway, a national CPD plan is developed in cooperation between the Association of Local and Regional Authorities, three teacher unions, the Association of School Leaders, the National Council for Teachers' Education, and the Ministry of Education and Science. At a local level, the authorities are responsible for identifying the needs of teachers and developing a competence development plan for them together with local employee associations. Luxembourg and Great Britain (Scotland) are the only education systems in which training plans are primarily the responsibility of individual teachers, although such needs are discussed and agreed with their supervisors.

In almost all countries, schools have a vital role to play in determining CPD needs (except in Greece). This happens through merging the needs of individual teachers into a more general school development plan or by combining those needs with more general interests of the school itself or its education authority. It is compulsory to have CPD plans in place at 
school level in over two-thirds of education systems. In countries where formal CPD programmes are compulsory, their practical development may be the responsibility of school leaders (e.g. Bulgaria, the Czech Republic, Cyprus, Hungary, Austria, Poland, Slovakia and Slovenia) or education councils (Belgium, Portugal, Romania).

All education systems provide some kind of support to cover expenditure on CPD. The mechanisms for doing so vary. Most countries adopt two of the following procedures: public authorities offer free courses (run centrally or by accredited providers), schools are subsidised by the authorities for organising CPD (directly or after submitting individual applications) and teachers apply for funding to cover or reclaim the costs of CPD to themselves. In most countries, CPD is financially supported. Teachers may be granted paid study leave and schools may obtain support in the form of temporary replacement.

As can be seen, regardless of the form, place or type of teacher support, it is necessary to verify from the perspective of CPD the extent to which strictly professional competences are linked to other competences acquired by teachers in the process of everyday education. For example, for the purposes of this discussion the following competences are important: the ability to reflect on and evaluate one's own skills, ability to develop, implement and adapt syllabi, the ability to cooperate with others and develop joint projects in education, as well as to manage them, etc. Such competences are difficult to develop in future teachers during formal education. The development of such competences often requires more time, more experience as well as the confrontation of knowledge formally acquired during education and real-life teaching work in classrooms. Obviously, the development of those competences will occur naturally in the course of work, but it has to be supported by teachers' participation in continuing professional development. A matrix containing all competences - save subject-related competences - which we should develop in future teachers should be the starting point for that kind of a system. One such matrix was created in the course of the project entitled "European Profile for Language Teacher Education - A Frame of Reference" (Kelly \& Grenfel, 2004). This profile contains a description of competences desired in a teacher. Analysis of this document shows that not every future teacher can develop all of those competences in the course of formal education. Therefore, the development of those competences 
has to be continued during CPD. Due to the curriculum implemented by a $\mathrm{HEI}$ and to the type of a school where future teachers will be placed, as well as to the context of specific challenges presented by their school, each teacher will start from a different level because their individual competences will be developed to a different extent and their needs relating to CPD will differ. Therefore, the development of each individual teacher will have to be different. This means that CPD offers should be tailored to each individual teacher's needs and based on the initial competence profile of a teacher leaving the education system and entering the profession. An example of such a profile is shown below:

\section{Competence:}

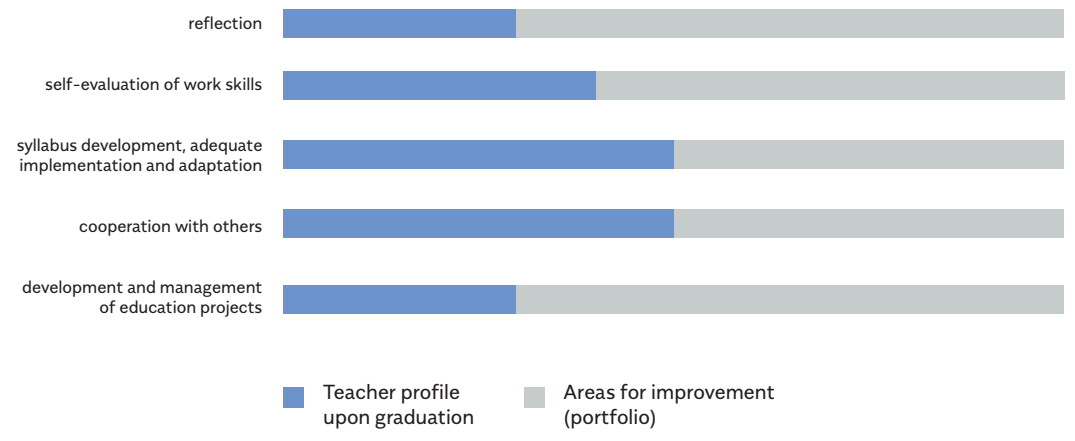

In light of the above, the possibility of introducing a teacher competence portfolio is worth considering and the process described above must be seen as part of lifelong learning. In consequence, each teacher should be able to programme a CPD process for himself/herself, whereas somebody else, for example school leaders or methodology advisors or consultants should monitor the process. Therefore, acquiring or developing new competences must occur as part of CPD and a portfolio containing a set of desired competences and self-evaluation tools for teachers could be helpful in the process of CPD organisation and planning. Moreover, this kind of system could easily be combined with the existing teacher professional advancement system. Owing to that, the professional advancement itself could become more rational and effective than it currently is. In this system, direct responsibility 
for CPD would be assumed by teachers themselves and partly by the head of school where they work, or a person appointed for this purpose, such as a methodology advisor or consultant. The remaining elements of the system, that is the national, regional, local authorities, school leaders, universities, CPD centres, etc. would perform tasks supporting the system by providing a CPD offer of reliable quality and monitoring the process, especially whether or not a teacher's competence development plan includes national, regional, local or school priorities and whether or not self-evaluation is reliable. This would be a mixed model of continuing professional development, where a lot of entities have different tasks to perform, but it is the teacher that would be central to the process, which would mean strong decentralisation on the one hand, right to the very bottom, and therefore, not ending with schools but with teachers, and with full supervision of the process from higher levels on the other. The idea of introducing a teacher competence portfolio was presented by the author of this analysis in 2007 in Brussels at a meeting of an expert group of the ELIN network (European Language Inspectors' Network) with European Commission representatives, and was well received. Unfortunately, so far this ambitious idea has not been implemented.

It is worth mentioning here arguments which are pro and against the competency based approach. There is a lot of valid criticism which should be mentioned, particularly related to the fact that this approach encourages a system of accountability measures, and more scrutiny, on teachers. Moreover, teaching cannot simply be reduced to competences. It is also worth stressing that the above solution offers a fundamental advantage - it is consistent with the idea of Qualification Framework. Qualifications or competences described for first- or second-cycle study programmes can be compared against the desired teacher competence profile, thus serving as a basis for the development of individual CPD plans. 


\section{References}

$\rightarrow$ European Commission (2003). Key topics in education in Europe. Volume 3 - Working conditions and pay. Brussels: Eurydice.

$\rightarrow$ European Commission (2006). Kluczowe problemy edukacji w Europie. Tom 3 - Atrakcyjność zawodu nauczyciela-wyzwanie XXI wieku. Warsaw: FRSE.

$\rightarrow$ European Commission (2007). Zapewnianie jakości w kształceniu i doskonaleniu zawodowym nauczycieli w Europie. [Quality Assurance in Teacher Education in Europe]. Warszawa: FRSE.

$\rightarrow$ European Commission (2009a). Key data on education in Europe 2009. Brussels: EACEA.

$\rightarrow$ European Commission (2009b). Zakres autonomii i odpowiedzialności nauczycieli w Europie. [Levels of Autonomy and Responsibilities of Teachers in Europe]. Warsaw: FRSE.

$\rightarrow$ European Commission (2013). Study on policy measures to improve the attractiveness of the teaching profession in Europe, Vol. II. Final report.

$\rightarrow$ European Commission/EACEA/Eurydice (2015). The teaching profession in Europe: Practices, perceptions, and policies. Eurydice Report. Luxembourg: Publications Office of the European Union.

$\rightarrow$ Guskey, T. R. \& Sparks, D. (1991). What to consider when evaluating staff development. Educational Researcher, 5(15), 5-12.

$\rightarrow$ Kelly, M., Grenfell, M., Gallagher-Brett, A., Jones, D., Richard, L. \& Hilmarsson-Dunn, A. (2002). The training of teachers of a foreign language: Developments in Europe. Brussels: European Commission.

$\rightarrow$ Kelly M. \& Grenfell, M. (2004). European profile for language teacher education. A frame of reference (EPLTE), Brussels: European Commission. http://www.lang.soton.ac.uk/profile/ report/MainReport.pdf

$\rightarrow$ OECD (2014). TALIS 2013 Results. An international perspective on teaching and learning. Paris: OECD Publishing. 


\section{Biographical notes:}

Paweł Poszytek, PhD, Director General of the Polish National Agency of Erasmus+ Programme. He is a member of several working groups by the European Commission and the Ministry of National Education of the Republic of Poland, coordinator of the Country profile Project implemented by the Council of Europe, reviewer of the national core curriculum in foreign language teaching in 2008 and co-author of 2016/2017 curriculum update. He is former member of the executive board of the European Association of Language Teaching and Assessment, former coordinator of Lingua, European Language Label and eTwinning programmes in Poland and member of the board of the Polish National Agency of Lifelong Learning Programme. Mr. Paweł Poszytek presented the Higher Education-Business Engagement Index on several international conferences, i.e. during UIIN conference in Adelaide in February 2017.

Liliana Budkowska is director of External and Inter-sectoral Programmes Department Foundation for the Development of the Education System (FRSE). She is a member of several working groups by the European Commission and the Ministry of National Education of the Republic of Poland, now coordinator of the "Profile of the Teachers Competences." She is a former coordinator of the European Commission Programme - Comenius in Poland, dedicated to school education (2007-2013). Mrs Budkowska has got many experiences in presentations at the conferences, seminars on the national and international level in the field of education, especially in the field of developing teachers' professionalism. 



\title{
Competency frameworks for teachers: a contribution from the European education policy
}

\author{
Jesús Manso \\ Autonomous University of Madrid \\ Lucía Sánchez-Tarazaga \\ Jaume I University
}

\section{Abstract}

In this chapter we provide a review about the European educational policy regarding teacher competency frameworks. The European Union acknowledges the importance of conceiving the teacher profile based on a framework with the required professional competencies to face the challenges of the new context and strengthen the teaching profession. What we tackle here are the fundamentals of those competency-based patterns from the most recent regulation's review in Europe in the field of education, regarding three key aspects: concept, design and implementation. Firstly, we have to pay attention to the concept. There is a continuing controversy over how to define "competency" as it is a polysemic term. Secondly, we deal with some ways to implement these frameworks across particular European policies. One of the key ideas present in the literature is the difficulty for agreement, because it requires a preliminary discussion about education goals, assumptions about learning, the expectations of society and its demands to teachers, available resources, priorities and political will, and the status of the teaching profession, among others. Thirdly, we highlight the main benefits for their implementation, such as creating a shared discourse about the teaching profession, providing a selfassessment tool or consistency to teacher policies. We also provide 
two examples of teacher competency frameworks which have been proposed by important contributors. In conclusion, this framework, as is stated in the European education policy, could interconnect initial training, selection, induction and continued development of teachers. That is, it would allow the creation of a lifelong learning structure for the teaching profession and ensure they further develop them throughout their careers.

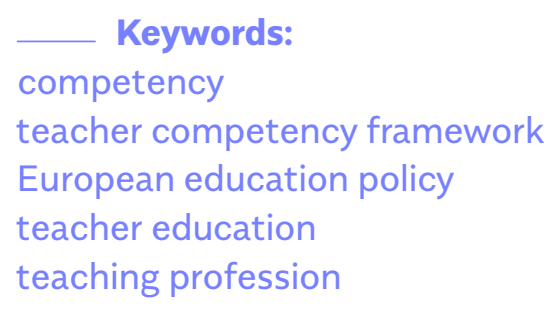




\section{Introduction}

There is no European country that in the last two decades has not carried out any reform of different scopes, in order to reach greater levels of quality in their respective educational systems (Eurydice, 2013). This search for improvement has been placing more emphasis on different elements throughout these years: during the 90s, those improvement goals were focused on the curriculum transformation and a bigger regional autonomy regarding education management; at the end of that same decade, it changed to performance assessment systems, and more recently, to the competence development of students and teacher training (Barber \& Mourshed, 2007; Marchesi, Tedesco \& Coll, 2009).

Therefore, many studies on teaching issues can be found allowing teachers to become the centre of the educational debate in Europe. In fact, as Álvarez conveys (2015), those very international institutions warned of the need for caring about teacher quality in order to improve educational systems, prioritising an already hot topic in the academic and scientific literature (Willms, 2000). In many cases, their initial motivation is justified as teaching performance and achievement have generally been the key levers to reach the desired quality, and more specifically, the fundamental variable of students' academic learning process and success (Hanushek, 2004; Konstantopoulos, 2006; Rivkin, Hanushek \& Kain, 2005; Rockoff, 2004).

In any case, the main strength of these studies and research consists of highlighting something already known in the pedagogical discourse, but frequently ignored in practice: teachers count (Darling-Hammond et al., 2005). The fact of placing teachers as the determining element of quality in any educational system has resulted in the revision of its key defining characteristics; that is, their profile, considered as the set of competences needed to carry out their professional activity according to value-based criteria and quality parameters. Referring to a teaching profile is, therefore, to conceive cognitive, skills and attitudinal elements defining teachers as professionals, or, in other words, a reference framework that gathers all their professional competences.

Firstly, in this chapter we will introduce the reasons explaining the expansion of teaching competences that help to contextualise the following sections. We provide an overview of how teacher competences in Europe evolved and the determining factors explaining why teacher 
competence has become so relevant today. Secondly, we tackle the basic guidelines from the European legislation related to the design of a teacher profile. It is based on developments in conceptualising, designing and applying teacher competency frameworks. Thirdly, we set out two examples of these frameworks to further illustrate the raised issues in this chapter. Finally, we share some reflections and conclusions about the importance of teacher competences in providing a teacher profile for quality education.

\section{The expansion of teaching competences in Europe: some explanatory factors}

The first references available about the expansion of teaching competences were recorded in the 90s in Anglo-Saxon countries like the United Kingdom, Australia, the United States, Ireland or New Zealand (Vandermensbrugghe, 2004). In that context, teachers did not receive this approach as expected as it was considered as a way to control their work that did not exist before. Little by little, political pressures focusing on the search of a better teaching quality encouraged the setting of standard systems which included a series of assessment criteria for teaching performance. Some of their predecessors were the American University teacher training programmes, known as Performance of Competency-Based Teacher Education Programs ("P/CBTE"). These programmes, which emerged during the 70 s at Universities in the United States, are based on the description (at least from the theoretical point of view) of competences stemming from the analysis of teaching-related tasks (job analysis) and the skills required. Their incursion in teaching was significant as long as teacher training was "professionalised".

Nowadays, the renewed interest in the study of teacher competences within the European educational context can be explained by several factors, from which two are highlighted: 1) the new education and social demands, which determine teachers' tasks; and 2) the expansion of the competence learning approach in education.

The society we live in has little to do with that of some decades ago. Constant and rapid change processes (social, cultural and pedagogical) occurring in most European education systems have modified work conditions of teachers, specifically increasing the number of functions to be carried out and their complexity (Prats, 2016). 
Globalisation, immersion in the digital era and the improvement of ICTs, the extension of learning spaces and lifelong learning, migratory movements, the schooling of all children in primary education, the extension of mandatory education, the heterogeneity of classrooms and the educational integration of diversity, altogether with the loss of authority and the discredit of the teaching role, are some of the continuing challenges in this 21st century (Bernal \& Teixidó, 2012). Moreover, reforms in European education systems have affected the management of education centres, as they have given an increased autonomy to local stakeholders and involved teachers in non-teaching tasks, suggesting also a training necessity for these type of roles, long neglected.

These new demands are also gathered in several recent reports by international organisations (Eurydice 2013; OECD, 2011, 2012) and documentation produced by the European educational policy (for example, Education Council, 2001; Commission of the European Communities, 2007).

Thus, and taking as a reference the reports of the Eurydice network from the beginning of the present century, there is an explicit mention of the importance of teachers acquiring new skills as a result of these huge changes. In this sense, it points out the existence of a unanimous agreement on the need to boost the acquisition of those skills, necessary for carrying out the teaching tasks, so that teachers can achieve the aim of a quality education at educational centres. Furthermore, it considers that teachers' roles should not be restricted to the mere transfer of the contents of a subject, and sets some questions related to teacher competences like:

$\rightarrow$ What is expected of the teaching profession (or should be expected of it) today and to an even greater extent in the future?

$\rightarrow$ What are teachers themselves taught during their initial training?

$\rightarrow$ What quality and skills criteria have to be satisfied for teachers to be regarded as qualified for the occupation?

$\rightarrow$ What arrangements are made to help young entrants to become fully-fledged members of their profession?

$\rightarrow$ From what facilities may in-service teachers benefit so as to acquire the new skills expected of them?

$\rightarrow$ What training requirements are teachers expected to fulfil in the course of their careers?

(Eurydice 2002, p. 10-11) 
Another example we want to highlight is that suggested by the Education Council, emphasising the importance of improvement and the adaptation of both knowledge and capacities of teachers to the new social context. Improving education and training for teachers and trainers, upgrading the initial education and in-service training of teachers and trainers so that their knowledge and skills respond both to the changes and expectations in society, and to the varied groups they teach and train is a major challenge to the education and training systems over the next 10 years (Education Council, 2001, p. 8).

In both cases, it is agreed that teachers have to assume new functions and competences (or at least an extension of them) due to the background complexity and the changing educational demands in the present century.

Besides the new demands presented, it is also convenient to consider the effect of the expansion of competence learning in the education field on the definition of competency profiles of teachers. These are projects usually emerging from a supranational context and mainly aimed at competence development more from a curriculum approach than that of teachers themselves, although affecting their professional profile. As Caena (2014, p. 326) describes, the focus on teacher competences can be viewed as a consequence of the European shift towards key competences in school education curricula.

Some of the initiatives related to competency learning which have had an impact on the European educational policy in general are the Tuning project, the PISA study and the DeSeCo project, among others ${ }^{1}$.

The Tuning project directed the design of university degrees to competences in order to achieve convergence in higher education (González \& Wagenaar, 2003). The main reasons given to motivate the adherence to this approach were: 1) transparency of professional and academic profiles of degrees; 2 ) an education more focused on students and their results; 3 ) a greater demand of lifelong learning processes and flexibility in learning organisation; 4) the search of higher rates of employability and citizenship; 5) a greater degree of comparability 
among the different European qualifications and the encouragement of student mobility.

For its part, the PISA study has set a periodic evaluation of 15 yearold students' learning through a series of indicators in order to create an international comparison among the different educational systems. As a result of this international evaluation, the DeSeCo project was also launched in order to identify those competences necessary in citizens and to set a possible framework for their assessment.

This approach was developed by a team of experts in the European Union (within the Education and Training 2010 work programme), creators of a European reference framework on the key competences for Life-Long Learning. This framework describes for the first time in a European level the essential competences citizens need for their personal fulfilment and issued eight key competences which were crucial for their incorporation in our country's mandatory education curriculum (European Parliament \& European Council, 2006).

\section{Competency frameworks for teachers: Concept, design and motivations for their application from a European perspective}

The picture of social and educational changes analysed and the new curriculum approach aimed at competence learning requires unavoidable challenges for educational systems and, by all means, for teachers (Berns, 2013). The focus of the educational paradigm has moved from the teaching task to students' learning, so that the traditional view of the teacher profile as an academic expert and mediator mastering knowledge does not seem to be enough to give an answer to current demands (Martín et al., 2014). The traditional tasks of teachers have been modified, diversified and expanded and, in the light of this scenario, it is urgent to revise teachers' profiles, redefine both their work and training, and adapt their teaching method (Martínez, 2016).

However, reflecting the essential qualities of a good teacher in a competency list is not an easy task and some questions may arise: How is one to decide the importance of some competences above others? Is it possible to agree on the key characteristics of these competences? Is it possible to find already defined competency frameworks in the international context? 
Some of these questions, indeed, have been gathered by the European Union. In fact, the characteristics a teacher must have, and the development of competency frameworks, have been described by European institutions as a key priority in the reform of every educational system to be undertaken, due to their connection with most of the policies in the education field (Caena, 2014).

One of the most important contributions to this matter was given by the expert team working in the programme ET-2010 through the setting of the Common European Principles for Teacher Competences and Qualifications (European Commission, 2005). The European principles describe a vision of teaching in Europe with the following characteristics: (a) a profession which requires a high qualification; (b) considered within the lifelong learning context; (c) with a professional development based on mobility; and (d) based on the collaboration between teachers and institutions. Besides these common principles, the EU proposes three environments where teachers from the Member States should be able to operate in: (a) working with others; (b) working with knowledge, technology and information; and (c) working with and within society.

More recently, within the strategic communication framework known as Rethinking education, promoted by the European Commission at the end of 2012, Member States are urged to include a revision and consolidation of the professional profiles of all teacher types (teachers from every level, heads of school and teacher educators) in their educational policies. Key actions are reviewing the effectiveness as well as the academic and pedagogical quality of Initial Teacher Education, introducing coherent and adequately resourced systems for recruitment, selection, induction and professional development of teaching staff based on clearly defined competences needed at each stage of a teaching career, and increasing teacher digital competence (European Commission 2012a, p. 15).

Moreover, the above mentioned document is accompanied by other five working papers collecting data on initiatives of the European educational systems and good practices, among which is highlighted the report entitled: Supporting the teaching professions for better learning outcomes (European Commission, 2012b), related to the support to the teaching profession, which also devotes a specific section to competency frameworks for teachers. As complements there 
are two other documents dealing with the subject of study in detail: Policy approaches to defining and describing teacher competences (European Commission, 2011) and Supporting teacher competence development for better learning outcomes (European Commission, 2013a).

After an in-depth analysis of these three European reports and the support of other secondary resources, we are now presenting the main ideas which, in our understanding, represent the European legislation guidelines related to the design of a teacher competency profile.

\section{Concept}

First, we will briefly deal with the conceptualisation of competency frameworks and the teaching competences stemming from the analysis of the above mentioned documents.

Caena (2014), education consultant at the European Commission and involved in the study of competency frameworks for teachers, considers this professional framework as a structure of descriptors which collects not only the acquired formal knowledge (through accreditation) but also the one extended later on throughout their professional career.

On the other hand, the European Commission assumes that the concept of teaching competency covers (or, at least, it should) the following characterisation: (a) it allows teachers to meet complex demands mobilising resources in a specific context; (b) it empowers teachers to act properly according to the situation, developing tasks in an effective (with the expected results) and efficient way (optimising both resources and efforts); (c) it can be demonstrated up to a certain level throughout their professional career, and (d) it is conceived as an integration of tacit and explicit knowledge, cognitive and procedural skills and provisions (motivations, beliefs, emotions...).

This last characteristic implies an understanding of competences as a dynamic integration of cognitive and metacognitive skills, leading to the concept of the profession in four areas (European Commission, 2013a):

$\rightarrow$ learning to think as teachers: it implies a critical revision of their own beliefs and the development of a pedagogical thought;

$\rightarrow$ learning to know as teachers: it refers to different aspects of knowledge, including the one generated by their own practices; 
$\rightarrow$ learning to feel as teachers: it is directly related to the professional identity, including emotional and intellectual aspects like attitudes, expectations, leadership and values;

$\rightarrow$ learning to act as teachers: it implies the integration of thoughts, knowledge and attitudes in practice and in different contexts.

\section{Design: implementation characteristics}

One of the key ideas present in the literature consulted is the difficulty for agreement on a competency framework for teachers. It is also not static, neutral or universal, so a preliminary discussion and agreement on broader subjects like the education goals, assumptions about learning, the expectations of society and its demands to teachers, resources available, priorities and political will, the teaching profession status, or the existing traditions and culture, among others (FIER, 2010), is necessary.

Therefore, an observation to be noticed is that this framework may change depending on the education systems from different countries. So much so that one of the analysed reports shows the existing heterogeneity in the design of competency frameworks in Europe. Through a survey study (European Commission, 2013a) it is concluded that the differences among countries are due to the following variables:

$\rightarrow$ the detail level (or lack of it) in the description of teaching competences;

$\rightarrow$ whether competences are just described for initial training or as a project to be developed throughout the whole teaching career;

$\rightarrow$ the political tools in which they are used: legislation, regulations, guidelines, university curriculum, or teachers' accreditation, among others;

$\rightarrow$ the actors in charge of implementing the education policy (government organisations, training institutions or professional organisms);

$\rightarrow$ the aims and uses given to them by political education strategies.

In any case, those reports provide some guidelines for the design and later implementation of frameworks which deserve to be highlighted and which we are presenting now (European Commission, 2011; European Commission, 2012b; European Commission, 2013a). 
First, and in its early design phase, the competency framework for teachers should cover the following variables: taking into account the culture of the country, resulting from an agreement on key subjects (for instance: the purpose of education, the meaning of proper teaching, etc.), including all the dimensions of the teaching work, being coherent with the expected students' learning results (but not just limited to that), and combining stability, duration and flexibility attributes.

Some of the key questions used as guidelines in this phase can be: What its purpose is going to be (students, teachers, management teams, trainers, employers...)? What philosophy underlies its outline (educational, learning, professional...)? How is it going to be structured? Will the competency descriptors be applied to every stage of the teaching career or will specific ones be designed for each stage? Will they be applied to every education level (pre-school, primary, secondary...)? Are they aimed at the present or at future desirable characteristics?

Secondly, every country has to find its own way and schedule to design the first draft on competences for teachers. In fact, two stages of development for competency frameworks have been identified, in which Member States can be grouped, and there is a specific action proposed for each of them. On the one hand, for those countries at the beginning of the implementation, the framework must focus on its first design with the help of taxonomies, some of which are included in that very same report (European Commission, 2012b). On the other hand, those countries for which a description of competences already exists should focus on debugging them and setting them for each stage of the teaching career (initial training, induction...) and each educational level (pre-school, primary, secondary...).

Regarding the contents and style of the professional framework, competence descriptors should be written in terms of learning results and aimed at action, teacher motivation towards professional growth, reflecting the culture and context they are going to be used in, and providing adequate, specific and clear information (so that every agent involved can understand them). Besides, competences should be constantly updated to meet new pedagogical, sociological and technical demands.

Finally, and once designed, its implementation phase is equally important. In this sense, consistency with the development, use and purpose of the competence scheme design is essential. Therefore, 
a commitment with a long-term process on the part of the educational administration is necessary. Secondly, roles of every party involved must be defined and, at the same time, discussion spaces must be created throughout the implementation process. It must be clear it is a process carefully planned and agreed by every party involved, especially by teachers. The participation of this group in its design is necessary, so that is not perceived as an imposition or a control mechanism. Some of the questions that can act as guidelines in the process are: To what extent are teachers involved in the process? Are their perspectives included in the proposal? Which other groups could be consulted (educational institutions, teacher trainers, families, students...)? How could they be involved? Moreover, implementation should be carried out according to a realist schedule, allowing enough time for its correct execution.

A lesson learned that can be observed through the European texts consulted is that the existence of competency frameworks for teachers does not ensure teaching quality by themselves; the most important thing is their purpose and the way they are applied. On the other hand, they also stress that the development of these common frameworks does not necessarily mean a significant financial investment for Member States.

\section{Motivations for their application}

Despite the complexity at the hour of betting for a competency framework for teachers, its application can help strengthen their profession within the educational system according to the following terms:

$\rightarrow$ creating a shared discourse about the teaching profession, allowing the involvement of all the key agents (administration, employers and teachers themselves);

$\rightarrow$ supporting teachers creating a clear and transparent image of their role in society while enhancing their professionalism, and favouring a greater prestige of their work;

$\rightarrow$ becoming the starting point to encourage teachers (present and future) as a self-assessment tool, reflection about their practice, and their possibilities of professional development;

$\rightarrow$ guiding the design of teacher related policies, which is something essential from our point of view. 
In fact, in one of the reports mentioned above (European Commission, 2012a), it is specified that every Member State must undertake the definition of those competences and qualities required in teachers through a competency framework as a priority action, as a starting point at current selection processes and training procedures and for professional development.

Regarding teacher selection, it is affirmed that it is not clear that current selection procedures in many Member States attract the best candidates. Therefore, one of the first measures should be the creation of an effective recruitment system based on a clear competence profile including key, measurable indicators.

As far as initial training is concerned, the competency framework for teachers is considered vital to ensure that every initial training programme provides students the use of key competences and the capacity and motivation to keep on renovating them throughout their careers.

On the other hand, no doubt a competency scheme could be included in induction programmes and teacher assessment processes. In fact, one of the measures considered is the monitoring of teachers' progress so that feedback about their performance is provided regularly by an assessment system according to those standards in the competency framework.

\section{Two proposals at a glance}

In this section we propose two examples of teacher competency frameworks made by institutions involved within the context of the European Union that have most contributed to this topic.

First, we present the initiative developed by the Finnish Institute for Educational Research (FIER, 2010), which was developed as an outcome of the research sponsored by the European Commission itself and in which 27 member countries participated.

They established eight groups of competences (called clusters, according to the terminology that the FIER uses) with some examples of items that help to describe them (see Table 1): 
Table 1. Teacher competency framework proposed by FIER (2010)

\begin{tabular}{|c|c|}
\hline Competences & Description \\
\hline Subject competence & $\begin{array}{l}\text { Managing, structuring and restructuring subject knowledge, } \\
\text { integrating subject knowledge and pedagogic skills, } \\
\text { applying constructive strategies in subject knowledge } \\
\text { processing }\end{array}$ \\
\hline Pedagogic competencies & $\begin{array}{l}\text { Employing a range of teaching and learning strategies, } \\
\text { supporting students' autonomous learning, using diverse } \\
\text { teaching methods, stimulating students' socio-emotional } \\
\text { and moral development, encouraging multicultural respect } \\
\text { and understanding, teaching heterogeneous classes, } \\
\text { guiding and supporting learners }\end{array}$ \\
\hline Integrating theory and practice & $\begin{array}{l}\text { Integrating study and practicum, using research-based } \\
\text { learning, using guided teaching practice, learning the } \\
\text { acquisition of information and development of knowledge, } \\
\text { supporting research orientation, carrying out research }\end{array}$ \\
\hline Co-operation and collaboration & $\begin{array}{l}\text {...between students, colleagues, parents and schools, } \\
\text { working effectively with the local community, with work- } \\
\text { based training providers and stakeholders, supporting } \\
\text { communication skills, using collaborative learning methods, } \\
\text { promoting safe, respectful school environment }\end{array}$ \\
\hline Quality assurance & $\begin{array}{l}\text { Understanding and applying the principles of assessment, } \\
\text { contributing to systems of quality assurance, using the } \\
\text { results of assessment to evaluate and improve teaching } \\
\text { and to improve standards of attainment }\end{array}$ \\
\hline Mobility & $\begin{array}{l}\text { Supporting students' and teachers' European and } \\
\text { international contacts, encouraging student exchange, } \\
\text { learning and using European languages, learning and } \\
\text { understanding different (European) cultures }\end{array}$ \\
\hline Leadership & $\begin{array}{l}\text { Supporting leadership competencies so as to develop the } \\
\text { institution and the learning environment, collaboration } \\
\text { between institutions and communities, regional } \\
\text { collaboration, staff development, strategic, pedagogic } \\
\text { and economic leadership, encouraging teachers to career } \\
\text { development) }\end{array}$ \\
\hline Continuing and Lifelong Learning & $\begin{array}{l}\text { Supporting and preparing students for lifelong learning, } \\
\text { understanding the importance of self-development to } \\
\text { continue their professional development throughout their } \\
\text { careers }\end{array}$ \\
\hline
\end{tabular}

The second proposal is carried out by the European Commission (2012b) from the strategy "Rethinking education", which has already been mentioned. The European Commission defined an exhaustive list (up to 28) of core competences, as they are called in the original text, 
broken down into three main areas: a) knowledge and understanding, b) skills, c) dispositions: beliefs, attitudes, values and commitment (see Table 2). In addition, of the main competences required for effective teaching in the $21^{\text {st }}$ century, it is pointed out that teachers require a series of specific competences according to the subject they teach or the stage in which their students are, although it is not specified which ones.

Table 2. Teacher competency framework proposed by the European Commission (2012b)

\begin{tabular}{|c|c|}
\hline COMPETENCES & DESCRIPTION \\
\hline Knowledge and understanding & $\begin{array}{l}\rightarrow \text { Subject matter knowledge } \\
\rightarrow \text { Pedagogical Content Knowledge (PCK) } \\
\rightarrow \text { Pedagogical knowledge } \\
\rightarrow \text { Curricular knowledge } \\
\rightarrow \text { Educational sciences foundations } \\
\rightarrow \text { Contextual, institutional, organizational aspects } \\
\text { of educational policies } \\
\rightarrow \text { Issues of inclusion and diversity } \\
\rightarrow \text { Effective use of technologies in learning } \\
\rightarrow \text { Developmental psychology } \\
\rightarrow \text { Group of processes and dynamics, learning theories, } \\
\text { motivational issues } \\
\rightarrow \text { Evaluation and assessment processes and methods }\end{array}$ \\
\hline Skills & $\begin{array}{l}\rightarrow \text { Planning, managing and coordinating teaching } \\
\rightarrow \text { Using teaching materials and technologies } \\
\rightarrow \text { Managing students and groups } \\
\rightarrow \text { Monitoring, adapting and assessing teaching/learning } \\
\text { objectives and processes } \\
\rightarrow \text { Collecting, analysing, interpreting evidence and data for } \\
\text { professional decisions and teaching/learning improvement } \\
\rightarrow \text { Using, developing and creating research knowledge to } \\
\text { inform practices } \\
\rightarrow \text { Collaborating with colleagues, parents and social services } \\
\rightarrow \text { Negotiation skills } \\
\rightarrow \text { Reflective, metacognitive, interpersonal skills for learning } \\
\text { individually and in professional communities } \\
\rightarrow \text { Adapting to educational contexts characterised by multi-level } \\
\text { dynamics with cross-influences }\end{array}$ \\
\hline $\begin{array}{l}\text { Dispositions: beliefs, attitudes, } \\
\text { values, commitment }\end{array}$ & $\begin{array}{l}\rightarrow \text { Epistemological awareness } \\
\rightarrow \text { Dispositions to change, flexibility, ongoing learning } \\
\text { and professional improvement, including study and research } \\
\rightarrow \text { Commitment to promoting the learning of all students } \\
\rightarrow \text { Dispositions to promote students' democratic attitudes } \\
\text { and practices, as European citizens } \\
\rightarrow \text { Critical attitudes to one's own teaching } \\
\rightarrow \text { Dispositions to team-working, collaboration and networking } \\
\rightarrow \text { Sense of self-efficacy }\end{array}$ \\
\hline
\end{tabular}




\section{A competency framework for teachers to strengthen the profession}

Now that we have introduced some general guidelines about competency frameworks for teachers in the context of the European educational policy, we consider it pertinent to dedicate some words in this chapter to reflection as a prelude to future complementary studies to enrich the subject, both from a descriptive and an evaluative perspective.

First, when designing teacher competency frameworks, every country or organisation can identify specific competences, organised according to their own taxonomy and a unique naming. As Perrenoud reminds us (2006), the identification of competency frameworks is not neutral in any case, as they imply a range of theoretical and ideological options designed by each organisation to represent the profession (their particular point of view on education and teachers). Therefore, the lack of agreement we can find in proposals done at Member level seems reasonable, as each of them is unique, and it can be stated that there is no single European teacher profile (FIER, 2010).

Nevertheless, these frameworks should share one common characteristic at least: the necessity to understand the teacher profile beyond that of an expert in knowledge. The following insists on this fact: (...) we can no longer afford to build education systems on the outdated notion that the teacher merely 'transmits' existing knowledge into the heads of passive learners (European Commission, 2012, p. 19). Thus, it is important to denote a greater emphasis on other type of characteristics beyond the cognitive for a good teaching performance: cooperation with the education community (teachers, families and other agents), participation in the educational centre or management of diversity, among others.

Secondly, it is worth focusing on the fact that it would sound pretentious to deduce the existence of mere teaching competences, as it is true that some statements from frameworks could be applied to other work environments (for instance, teamwork, ICTs training...). Anyway, and according to Perrenoud (2006), it is equally valuable to count on their proposals as they are carrying out a competence transfer process to the teaching background.

Furthermore, and even though content here has been focused on the professional profile of teachers, it is no less important to cover competences pertaining to teacher trainers (university teachers, 
internship monitors, induction phase mentors, among others), usually ignored in both research national and international educational policies, but, however, with a decisive impact on education quality (European Commission, 2012b). In fact, the European Union has started to acknowledge their relevance and right now there are research papers about them in the different European educational systems and an approach on what a competency profile could be (European Commission, 2013b).

Thirdly, the complexity of competences is such that it is very unlikely for a teacher to achieve all of them or, at least, to be able to develop them to the same extent. Therefore, the European Commission suggests taking competences into account within an educational system or teacher team, emphasising the importance of conceiving teaching as cooperation among professionals (European Commission, 2013a).

Moreover, it can be deduced that we cannot expect that all competences needed are achieved during the initial training period, as is highlighted by the European educational policy (European Council, 2009). It follows the idea that their development during the induction stage and the ongoing exercise of the profession is unavoidable, the mentoring process being a key factor (OECD, 2005).

Finally, despite the evidence of the growing importance of teachers and the advance in the study of competency frameworks for teachers in the European policy, the documental analysis carried out invites us to consider the need to move from discourse to practice; what Caena calls "a shift from policy-as discourse to policy-as-practice" (2014, p. 311). In this sense, it is urgent to establish the necessary mechanisms to design a competency profile for teachers which help the development of competences along the professional career, as it is considered in the European Union educational policy.

No doubt this is a very demanding effort, as the articulation of a competency framework for teachers through an agreement implies the reconstruction of the teacher profile and, accordingly, a turn in teaching policies in European educational systems, which should undertake far-reaching measures (Manso \& Valle, 2013).

But, on the other hand, this opportunity should not be missed, as this framework would allow the creation of a lifelong learning structure (OECD, 2005). A structure which could interconnect initial training, 
selection, induction and continued development of those who teach, especially taking into account that these policies, as they are currently set, do not generate the necessary trust to develop a reserve of quality teachers (Martínez, 2016), or as the European Commission indicates (2012b, p. 28): “(...) the description of the competences required by teaching staff is, in itself, only useful if it is embedded in a wider systemic strategy to select the right candidates, develop their core competences in initial teacher education, and ensure they further develop them throughout their careers."

In other words, the aim for this new scheme is to become, in the first instance, a vehicle to open a dialogue among the different stages of the teaching career going a step further in the way to quality and the strengthening of the profession. 


\section{References}

$\rightarrow$ Álvarez, G. (2015). La cualificación de maestro en Europa: aportaciones a partir del análisis de las influencias supranacionales y los modelos europeos. Tendencias pedagógicas, 25, 9-34.

$\rightarrow$ Barber, M. \& Mourshed, M. (2007). How the world's best-performing schools systems come out on top. London: McKinsey \& Company.

$\rightarrow$ Bernal, J.L. \& Teixidó, J. (2012). Las competencias docentes en la formación del profesorado. Madrid: Síntesis.

$\rightarrow$ Berns, M. (2013). Contexts of competence: Social and cultural considerations in communicative language teaching. New York: Springer Science \& Business Media.

$\rightarrow$ Caena, F. (2014). Teacher competence frameworks in Europe: policy-asdiscourse and policy-as-competence. European Journal of Education, 49, (3), 311-331.

$\rightarrow$ Clark, C. M. (1995). Thoughtful teaching. London: Cassell.

$\rightarrow$ Commission of the European Communities (2007). Communication from the Commission to the Council and the European Parliament: Improving the quality of teacher education. Brussels, 3.8.2007 $\operatorname{COM(2007)} 392$ final. Available at: http://eur-lex.europa.eu/legal-content/EN/TXT/PDF/?uri=CELEX:52007DC0 392\&from=EN

$\rightarrow$ Darling-Hammond, L., Holtzman, D., Gatlin, S.J. \& Vasquez, J. (2005). Does teacher preparation matter? Evidence about Teacher Certification, Teach for America, and Teacher Effectiveness. Education Policy Analysis Archives, 13(42), 16-17.

$\rightarrow$ Education Council (2001). Report from the Education Council to the European Council "The concrete future objectives of education and training systems" [5680/91 EDU 18]. 477.

$\rightarrow$ European Commission (2005). Common European principles for teacher competencies and qualifications. Brussels: Directorate-General for Education and Culture. 
$\rightarrow$ European Commission (2011). Policy approaches to defining and describing teacher competences (Report of a Peer Learning Activity in Naas, 2-6 October 2011), Education and Training 2020 Programme.

$\rightarrow$ European Commission (2012a). Communication from the Commission to the European Parliament, the Council, the European Economic and Social Committee and the Committee of the Regions: Rethinking Education: Investing in skills for better socio-economic outcomes. Strasbourg, 20.11.2012 $\operatorname{COM(2012)} 669$ final. Available at: http://eur-lex.europa.eu/legal content/EN/ TXT/PDF/?uri=CELEX:52012DC0669\&from=EN

$\rightarrow$ European Commission (2012b). Supporting the teaching professions for better learning outcomes. Accompanying the document Communication from the Commission "Rethinking Education: Investing in skills for better socioeconomic outcomes". Strasbourg, 20.11.2012 SWD(2012) 374 final. Available at: http://eur-lex.europa.eu/legal-content/EN/TXT/PDF/?uri=CELEX:52012S c0374\&from $=p \mid$

$\rightarrow$ European Commission (2013a). Supporting teacher competence development for better learning outcomes. Available at: http://ec.europa.eu/education/policy/ school/doc/teachercomp_en.pdf

$\rightarrow$ European Commission (2013b). Supporting teacher educators for better learning outcomes. Available at: http://ec.europa.eu/education/policy/school/ doc/support-teacher-educators_en.pdf

$\rightarrow$ European Council (2009). Council conclusions of 12 May 2009 on a strategic framework for European cooperation in education and training ('ET 2020') (2009/C 119/02). Official Journal of the European Union, serie C, $n^{\circ} 119$, 28/05/2009.

$\rightarrow$ European Parliament \& European Council (2006). Recommendation of the European Parliament and of the Council of 18 December 2006 on key competences for lifelong learning (2006/962/EC). Official Journal of the European Union, L 394/10, 30/12/2006.

$\rightarrow$ Eurydice (2002). Key topics in education in Europe. The teaching profession in Europe: Profile, trends and concerns Report II: Supply and demand: general lower secondary education. Luxembourg: Publications Office of the European Union.

$\rightarrow$ Eurydice (2013). Key data on teachers and school leaders in Europe. Luxembourg: Publications Office of the European Union.

$\rightarrow$ FIER (2010). Education and Training 2010: Three studies to support School Policy Development. Lot 2: Teacher Education Curricula in the EU. Final Report. Jyväskylä: University of Jyväskylä. Available at: https://ktl.jyu.fi/julkaisut/ julkaisuluettelo/julkaisut/2010/ec2 
$\rightarrow$ González, J. \& Wagenaar, R. (Eds.) (2003). Tuning educational structures in Europe. Informe Final - Fase I Bilbao, Universidad de Deusto. Available at http://www. ub.edu/cubac/sites/default/files/tuning_educational_structures_espanyol_0.pdf

$\rightarrow$ Hanushek, E. (2004). Some simple analytics of school quality. Working Paper No. 10229. Cambridge, MA: National Bureau of Economic Research.

$\rightarrow$ Konstantopoulos, S. (2006). Trends of school effects on student achievement: Evidence from NLS: 72, HSB: 82, and NELS: 92. Teacher College Record, 108/12, 2550-2581.

$\rightarrow$ Manso, J. \& Valle, J.M. (2013). La formación inicial del profesorado de secundaria en la Unión Europea.Revista Española de Educación Comparada, 22, 165-184.

$\rightarrow$ Marchesi, Á., Tedesco, J. C. \& Coll, C. (Coord.) (2009). Calidad, equidad y reformas en la Enseñanza. Madrid: Fundación Santillana.

$\rightarrow$ Martín, E, Pozo, J. I., Mateos, M., Martín, A., \& Pérez-Echeverría, M. (2014). Infant, primary and secondary teachers' conceptions of learning and teaching and their relation to educational variables. Revista Latinoamericana de Psicología, 46(3), 211-221.

$\rightarrow$ Martínez, M. (2016). La formación inicial de los maestros: una responsabilidad compartida. Bordón, 68(2), 9-16.

$\rightarrow$ OECD (2005). Teachers matter. Attracting, developing and retaining effective teachers. Paris: OECD.

$\rightarrow$ OECD (2011). Building a high-quality teaching profession: Lessons from around the world. Paris: OECD.

$\rightarrow$ OECD (2012). Preparing teachers and developing school leaders for the 21st Century: Lessons from around the world. Paris: OECD.

$\rightarrow$ Perrenoud, P. (2006). Dix nouvelles compétences pour enseigner. Nogent-leRotrou: ESF-Editeur.

$\rightarrow$ Prats, E. (2016). La formación inicial docente entre profesionalismo y vías alternativas: mirada internacional. Bordón, 68(2), 19-33.

$\rightarrow$ Rivkin, S. E., Hanushek, E.A. \& Kain, J.F. (2005). Teachers, schools, and academic achievement. Econometrica, 73/2, 417-458.

$\rightarrow$ Rockoff, J.E. (2004). The impact of individual teachers on students' achievement: Evidence from panel data. American Economic Review, 94/2, 247-252.

$\rightarrow$ Vandermensbrugghe, J. (2004). The unbearable vagueness of critical thinking in the context of the Anglo-saxonisation of education. International Education Journal, 5(3), 417-422.

$\rightarrow$ Willms, J. D. (2000). Monitoring school performance for standards-based reform. Evaluation and Research in Education, 14, 237-253. 


\section{Biographical notes:}

Jesús Manso has a PhD in Education and is Vice-Dean of the Faculty of Teacher Training and Education of the Autonomous University of Madrid (Spain). His doctoral thesis is entitled "Initial secondary teacher education in Spanish educational system" (2012). He has a Second National Award in Psycho-pedagogy studies for Excellence in Academic Achievement University. Areas coordinator of the Research Group on Supranational Education Policies and is external consultant in the Organización de Estados Iberoamericanos (OEI) in area of teacher training (from 2013) and in Save the Children - Spain (from 2016). He contributed to research stays abroad at Uppsala University (Sweden), in the Research Unit for Studies in Educational Policy, and at University ORT of Montevideo (Uruguay), in the Group of Teacher Development Program for Promotion of Educational Reform in Latin America (GTDPREAL).

Lucía Sánchez-Tarazaga has a PhD in Education. Her thesis focuses on teaching competencies and initial teacher training in Secondary Education. She is working as a teacher at Universitat Jaume I in the Department of Education and also teaches in a high school. Her teaching background refers both to initial and in-service teacher training. Her main experience at teaching is related to the Bachelor's Degree in Early Childhood Education and Master's in Secondary Education. She collaborates with the University Teacher Training Service Department and has organised different workshops for teachers. She also participates as a researcher in several projects related to educational innovation and initial teacher training. Her main areas of research refer to teacher training as well as teacher competency development. 


\section{Reform of teacher education and teacher educators' competences. A survey study of Danish teacher educators' competences and needs for capacity building}

Jens Rasmussen

Aarhus University

\section{Abstract}

Danish teacher education was reformed in 2012 for the third time in only fifteen years. However, teacher educator competences were not mapped at all during these years. It means that nobody (the political system, the educational system or others) knows whether teacher educators are equipped for the needs of the reforms and whether they themselves find their competences adequate. In this article, the results of a national survey study on teacher educator competences are presented. The study provides information about the teacher educators' competences and just as important the teacher educators' personal experience of their needs for capacity building in order to being able to implement the reform as it is intended. The study includes all teacher educators employed at the seven university colleges in Denmark providing teacher education.

\section{Keywords: \\ teacher education \\ teacher educators \\ teacher education reform \\ capacity building}




\section{Introduction}

It is generally accepted that reforms of the education system must be accompanied by training of teachers and trainers. Thus, the reform of the Danish basic school (Folkeskole) in 2014 is followed by extensive training of school teachers. The same has not been true for teacher educators after the reform of the Danish teacher education in 2013.

The failure of education might relate to an expectation that the training of teacher educators is not necessary, since virtually all teacher educators today are university educated and possess a Master's degree. However, no information about teacher educators' competences in relation to the expectations placed on them because of the teacher education reform and the public school reform is available.

In order to map teacher educators' competences and their self-perceived need for skill enhancement it was at the end of 2014 decided to conduct a survey study of the teacher educators' competences and competence needs. The survey was conducted by the Department of Education (DPU), Aarhus University, in co-operation with University Colleges Denmark and supported by the Danish Agency for Higher Education.

\section{Teacher education reform}

The third reform of teacher education in Denmark in just 15 years was conducted in 2012 and implemented in 2013. Reforms are usually carried out with the aim of developing an education or the aim of correcting deficiencies of the actual provided education. The previous reforms of teacher education in Denmark in 1997 and 2006 were largely directed at correcting deficiencies, while the reform in 2013 can be described as a thoroughly revision of the previous reform. The 2013-reform has been described as a paradigm shift in Danish teacher education (Rasch-Christensen \& Rasmussen, 2014, p. 15). The reform introduces competence goals, organises training courses in modules, as is common in university programmes, and it has as its intention to train teachers for the basic school legislation now in force. The 2013-reform also aims - stronger than previous teacher education reforms - at professional competences and at making the students experts in teaching.

The 2012-reform of teacher education not only put strong demands on the teacher educators at the University Colleges, it also with its shift from management by content to management by learning goals introduces new demands, which largely challenges traditional ways of 
thinking about teacher education. In addition, the reform also pays stronger attention to linking school practice with teaching at the university colleges, a strengthened research-based education, and increased focus on IT.

\section{Reforms' success}

Teacher educators play a crucial role in the quality of teacher education, the development of teacher training, and the implementation of the reform of teacher education. Despite this recognition of teacher educators' important role, they are not shown much attention in research. It is simply said that teacher educators belong to "a hidden profession" (European Commission, 2013, p. 6). The European Commission increasingly is becoming aware of, on the one side, a clear recognition of the great importance of teacher education and on the other side that the profession of teacher educators has been politically ignored. "Teacher educators are crucial players for maintaining - and improving - the high quality of the teaching workforce. They can have a significant impact upon the quality of teaching and learning in our schools. Yet they are often neglected in policy-making, meaning that some Member States do not always benefit fully from knowledge and experience of this key profession." (European Commission, 2013, p. 4).

Only lately, are teacher educators being shown political interest. A clear European tendency to prioritise the competences of teacher educators is perceptible (European Commission, 2010). The EU Education Ministers have identified teacher educators as a profession, which should be given high priority. Among other things, it is said that many Member States probably have strategies for supporting teachers and principals, but often no specific strategies for recruitment, selection, qualification and professional development of teacher educators (European Commission, 2014). At the same time - not least inspired by the successful school development in Ontario - an increased awareness of building capacity in terms of professional development into reform processes is of significant importance to make them successful (Fullan, 2006) here quoted from (Levin, 2010, p. 7)). Attention is also called to the importance of teacher educators as seeing themselves as a profession with its own professional identity as trainers of future teachers.

The 2013-reform of teacher education and the 2014-reform of the public school (Folkeskole) place new demands and expectations to the 
competences of teacher educators. It is widely known and recognised that the opportunities for a successful implementation of a school reform stands or falls with the teachers and that the same applies for the implementation of a teacher education reform. A teacher education reform is dependent on teacher educators and especially the competences, the reform requires.

Teacher educators are expected to master and practise the same teaching methods that student teachers are expected to be taught and to be able to model teaching and teaching methods that the teacher students are expected to acquire. Teacher educators are increasingly expected to be the professional and that as a natural element in their professional work are able to "practise what they preach" (Lunenberg \& Korthagen, 2005; Smith, 2005).

A Norwegian study of the perception of study quality in the Norwegian teacher education program from 2008 , which in many ways has inspired the Danish teacher education reform, point to teacher educators dual challenge. They not only have to teach their students, they also have to teach their students to be good teachers for their students. The study showed that it is important not just for practice teachers but also for teacher educators at the university colleges to be good role models for the student teachers (Finne, Mordal, \& Stene, 2014, p. 74).

It takes two things to a good reform: The reform in itself and the implementation of the reform. The reform must - of course - be an adequate response to widespread acknowledged problems in teacher education, but equally important is it that the teacher educators are shown attention in the sense of capacity building necessary for the implementation of the reform. It may be difficult to convince the teacher educators that the new initiatives are valuable if they cannot be sure of getting support for implementing them (Timperley, 2008, p. 18).

\section{Mapping teacher educator competences}

Given the above, it seemed essential to map the Danish teacher educators' competences to see if the implementation of the reform, including training and support for teacher educators, can be better supported in order to increase the likelihood of the reform's success.

Although the 2012-reform of teacher training is the third reform in just 15 years, an assessment of teacher educators' competences was never conducted. This means that no one-neither the political system 
nor the educational system - know whether teacher educators actually are equipped to lift the requirements of the reforms and whether the teacher educators find themselves equipped for the new tasks.

In the following sections I present the findings of a survey study conducted at the end of 2014 one and a half year after the reform was implemented in August 2013 (Rasmussen, Pedersen, \& Stafseth, 2015) The survey study was mainly concerned with mapping teacher educators' competences to train student teachers in competences that are geared towards professional practice in schools. In addition to the collection of such information, the study also focused on the teacher educators' self-reported need for training.

\section{Method}

The study included all teacher educators at the seven university colleges in Denmark. The questionnaire, which was sent electronically to all teacher educators in Denmark, was developed and pilot tested. Each teacher educator at the 16 local teacher training institutions at the seven university colleges were via e-mail sent a link to the electronic questionnaire. A reminder procedure was repeated three times and in addition e-mails were sent to the heads of all teacher training institutions to urge them to encourage the teacher educators to participate in the study.

A total of 771 e-mails were sent to approved e-mail addresses. Of these, 282 teacher educators completed the questionnaire and 99 answered parts of it. All completed and started responses are included. The response rate goes from 49.4 to 36.5 due to some respondents only completing part of the questionnaire.

A number of conditions could explain why the questionnaire is not answered. Perhaps the scheme is too comprehensive and therefore too time-consuming (set to 20-25 minutes) to answer in a busy day. It may also explain why some respondents dropped out underway. Another reason might be that some teacher educators are dissatisfied with the reform, and therefore do not want to answer the questionnaire, because they think that their answers can be used to strengthen the implementation of a reform they do not like. Messages like the following might be seen as an indication of this:

"I have decided not to complete and return the questionnaire. The reason is that the questions' nature and theme to me seems to be school political tendentious. Or put another way: The questions - and 
the demanded answers - are not equivalent with what I feel are relevant issues in teacher education." (Teacher educator). "I have answered the questionnaire but not forwarded it. Based on a democratic understanding of education and a search for - via teaching - development of the opportunity of conversation, I do not trust that the study will improve the possibilities for this" (Teacher educator).

The opposite, that some fail to complete the questionnaire because they are satisfied with the reform and with their competences to carry out teaching after the reform, can also be a reason. Statistical tests (dropout analysis) for the factors of gender, age and seniority in teacher training show that there is no significant difference between the proportion who answered the questionnaires (respondents), and the total population of teacher educators in Denmark ( $p$-value $\geq 0.05$ ). It is therefore assumed that the study is representative.

The survey of teacher educators' assessment of their need for competence-development is complemented by a study on whether the needs fall differently depending on the number of years teacher educators have been in teacher training (seniority). A chi-test to see whether there are significant correlations between the age ranges and the group of teacher educators as a whole, was conducted ( $p$-value $\geq 0.05$ ).

For most questions in the questionnaire, closed response categories are used. The answer scales employed range from 1 (very large extent) to 6 (Not at all) with four intermediate response categories. The intermediate values 2-5 is not connected with labels, but the interpretation we have used are 2: To a large extent, 3 and 4: To some extent, and 5: To a small extent. By using an equal number of response categories respondents are "forced" to indicate their answers in either the positive or the negative side. By the account of the answers the categories 1 and 2, and 5 and 6 are combined, while 3 and 4 is seen as a divide between a predominantly positive or largely negative assessment. In tables and graphs, all six response categories are presented.

The results of the survey are presented below in three parts: First, a characteristic of teacher educators, then the teacher educators' practice is explained and finally the teacher educators' own assessment of their need for competence development is treated.

\section{Teacher educator characteristics}

The collected data shows that in the researched group $57 \%$ of the respondents are women, while $43 \%$ are men, which does not differ 
significantly from the total group of teacher educators ( $p$-value $=$ $0.3839)$. The respondents have an average age of 49.5 years. There are very few respondents under 30 years (1\%), $14 \%$ are in their thirties, $34 \%$ in their forties, $33 \%$ in their fifties, and $18 \%$ are older than 60 years. It also corresponds the total group of teacher educators ( $p$-value $=0.5145$ ).

Regarding the issue of education, $8 \%$ of the respondents hold a PhD-degree, which corresponds to the latest figures (7\%) from 2011 (EVA 2011). $87 \%$ of the respondents hold a Master's degree, which, as the EVA-study shows, corresponds to that 9 out of 10 teacher educators hold a Master's degree.

As far as position and seniority are concerned, the respondents can be divided into the following job categories: $1 \%$ of them are docents, $73 \%$ are associate professors, $15 \%$ assistant professors, $3 \%$ temporary teachers, and $5 \%$ are PhD-students.

The respondents have been in teacher education between 0 and 43 years. $23 \%$ between $0-4$ years, $17 \%$ between $5-9$ years, $25 \%$ between $10-14$ years, $21 \%$ between $15-19$ years, $11 \%$ between $20-24$ years, while $3 \%$ have been in teacher education for more than 24 years. This means that $60 \%$ have been in teacher education for more than 10 years. This distribution does not differ significantly from that of the total group of teacher educators ( $p$-value $=0.5326$ ).

The respondents have teaching experience from a wide range of areas within the education system. 59\% have been teachers in the basic school, $25 \%$ have been teachers in boarding and private schools, $10 \%$ have taught special education, $35 \%$ have been teachers in upper secondary education, $18 \%$ in pre-school teacher education, $21 \%$ in other medium length educations, and $31 \%$ in university teaching. Many have teaching experience from several colleges.

The vast majority of respondents $(78 \%)$ have within the past five years participated in one or more research and/or development projects.

\section{Teacher educators practice}

\section{Management by objectives}

With the teacher education reform and the reform of the Folkeskole, management by objectives was introduced in the form of competence goals. The new curricula can be described as having focus on the 
centrality of the learner and not as earlier on a prescriptive specification of knowledge content.

The teacher educators indicate that, to quite a high degree, they practise management by objectives. The single elements of that kind of teaching are practised with some variation. Three quarters or more of the respondents say they plan lessons based on the objectives of the modules, that they make the students familiar with these objectives, that they organise educational activities which enables the students to practice and train their competences, and that their teaching is informed by new research.

Approximately one-third of the respondents indicate that they use formative assessments of student learning for their further planning of teaching. Only about half of the respondents use systematic feedback, differentiated teaching, and results from research and development work.

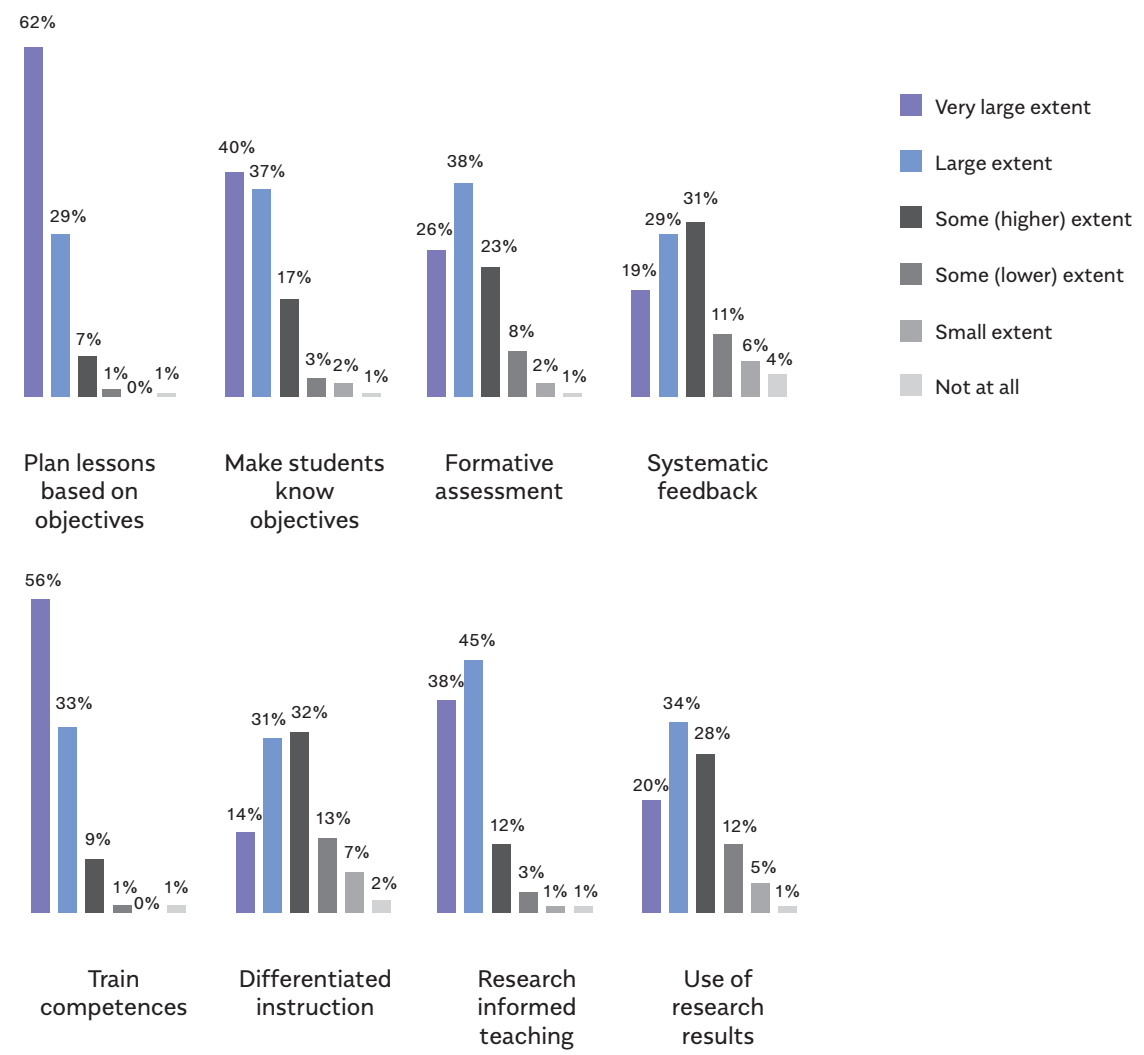

Figure 1: Intentions in the reform of teacher education 


\section{Learning goal guided teaching}

A very large part of the teacher educators (75-80\%) responded that they teach management by objectives and use the national Common Objectives for the public school as a didactic tool. The teacher educators also indicate that they teach the key elements of learning goal guided teaching: Breaking down goals, use of skills and knowledge goals, signs for learning, identification of students' academic level, formative assessment and feedback. Only a few teacher educators say they hardly or not at all feel competent to perform teaching guided by learning goals $(5-7 \%)$.
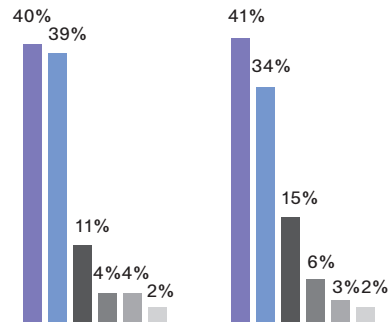

Management by objectives

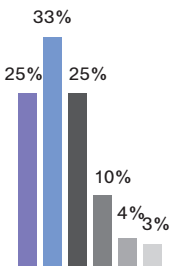

Signs for learning

\section{Common} objectives as didactic tool

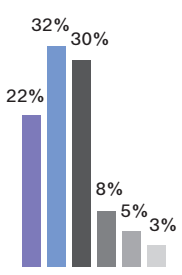

Identification
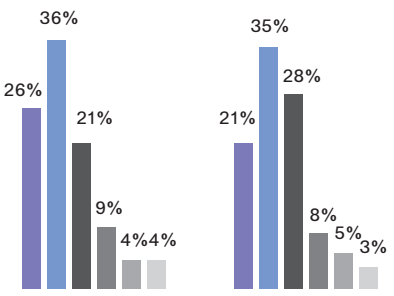
Breaking down objectives

$39 \%$ of academic level

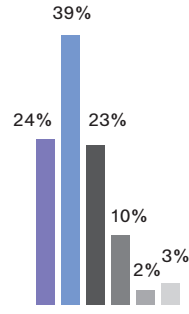

Formative assessment
Very large extent

Large extent

Some (higher) extent

Some (lower) extent

Small extent

Not at all

Skills and knowledge objectives

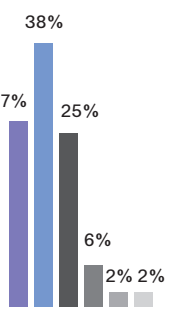

Forms

of feedback

Figure 2: Intentions in the reform of the Folkeskole

\section{Professional skills}

The teacher educators teach the most of the key elements of the teacher education programme such as differentiated instruction, variation in teaching to meet students' different learning styles, 
classroom management, management of good learning environments, and teaching that meets a linguistically diverse classroom. To a lesser extent, this is true for teaching special organised inclusive education, home-school co-operation and education of students with Danish as a second language.

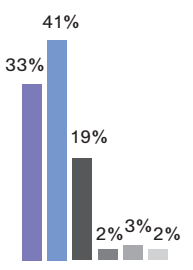

Differentiated instruction

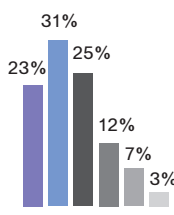

Teaching for linguistically diverse classrooms
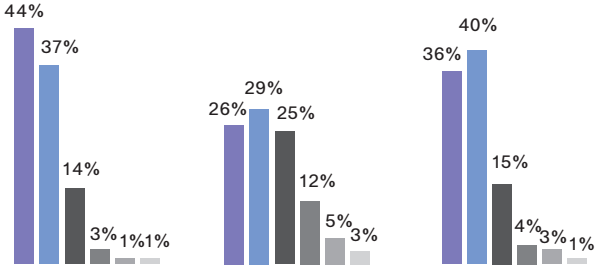

Classroom management

$$
\begin{aligned}
& \text { Varied } \\
& \text { teaching }
\end{aligned}
$$

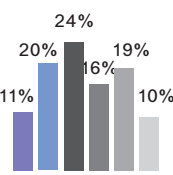
Home-school
co-operation

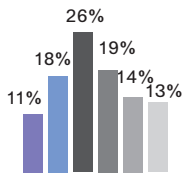

Teaching students with

Danish as a second language
Manage good learning environments
Very large extent

Large extent

Some (higher) extent

Some (lower) extent

Small extent

Not at all

Figure 3: Teaching professional competences

\section{Coupling teaching to the school practice}

Between one third and half of the teacher educators used to a very large, large, and some extent teaching methods that according to research, have high impact on the teacher students' construction of teaching skills such as micro-teaching, video/web cam-based feedback, teaching labs and study groups (Hattie, 2009, p. 112-13; Helmke, 2010, p. 328-334). Action research or similar approaches are used to a very large, large and some extent by between three quarters and almost all teacher educators. 


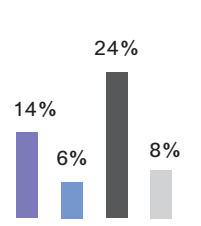

Very large extent

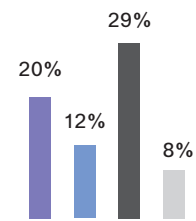

Large extent

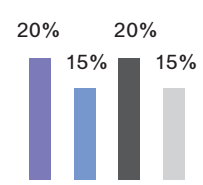

Some extent
Micro-teaching

Video/web-cam based feedback

Action research

Teaching labs

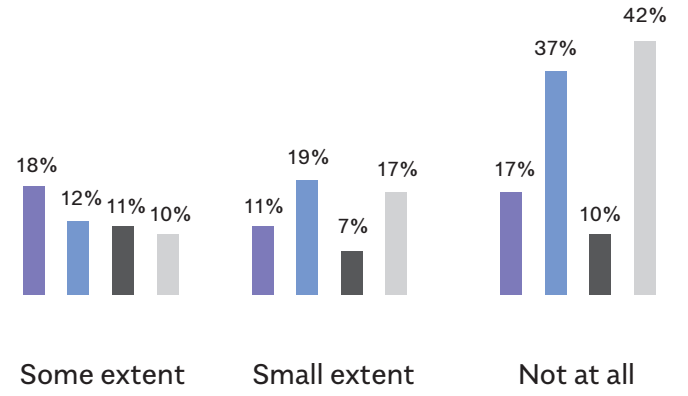

Figure 4: Coupling teaching to school practice

\section{Need for competence development}

\section{Teaching the key elements of public school reform}

The reforms of teacher education and the Folkeskole are followed by major changes in the demands to the teacher educators' knowledge, skills and competences. They are expected to transform their daily practices so that they match the many new elements of the reforms.

The number of competences that the respondents report they need to improve is several. The need seems large in relation to all major elements of the reform such as the transition from teaching guided by content goals to teaching guided by learning goals, formative assessment, feedback methods, differentiated teaching, classroom management, teaching of bilingual students, teaching and inclusion of students with special educational needs, school-home co-operation, innovation and entrepreneurship. However, the teacher educators express especially large needs regarding feedback methods, teaching of bilingual students, teaching and inclusion of students with special education needs as well as innovation and entrepreneurship. 
The needs seem especially large when it comes to inclusion of students with special educational needs, particularly for teacher educators, who have been in teacher education in a short (less than 5 years) or shorter (5-9 years) time.

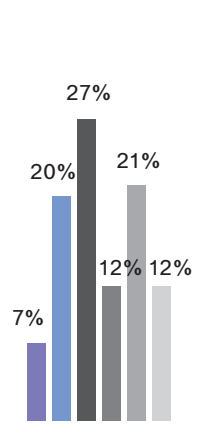

From content to goal oriented education
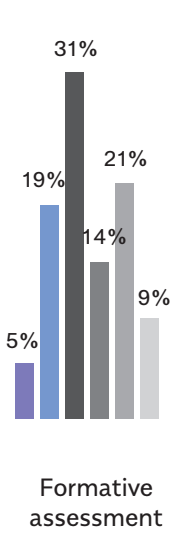
assessment

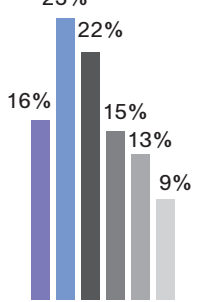

$$
25 \%
$$

Clasroom management

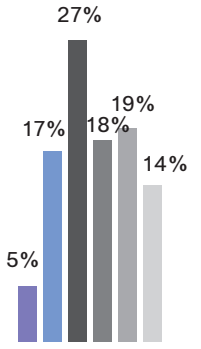

Bilingual students
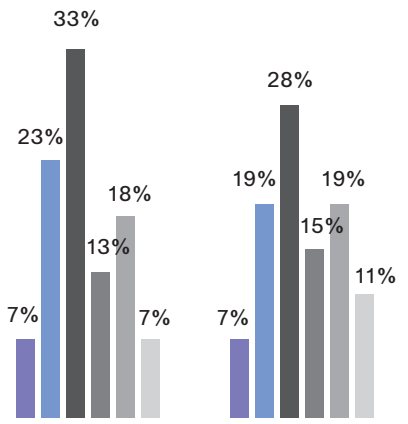

Very large extent

Large extent

Some (higher) extent

Some (lower) extent

Small extent

Not at all

Differentiated management
Feedback methods

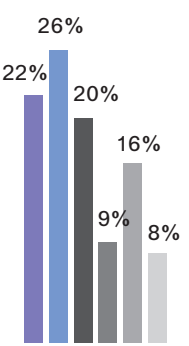

Inclusion of students with special needs

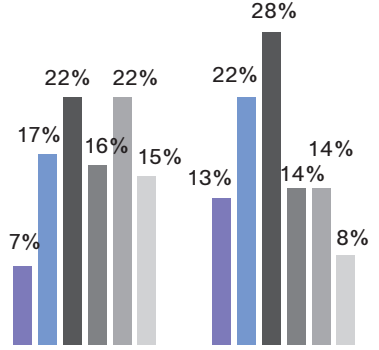

School-home Innovation and co-operation entrepreneurship

Figure 5: Competence needs about professional competences in the school

\section{Coupling practice, subject didactics and cooperation}

About half of the respondents express to a very large, large and some extent a need for being updated in regard to learning materials used in the public schools, subject didactics and internal co-operation with other professional groups. The teacher educators express a larger need for competence development regarding co-operation with practice 
teachers, co-operation with university scholars, and to a less degree to couple theory and concepts with teacher students teaching practice, and in bringing practice knowledge into their teaching.

The need for competence development regarding didactic qualification is larger for teacher educators, who have been less than 14 years in teacher education and less for teacher educators, who have been more than 15 years in teacher education than the average for all teacher educators. Teacher educators, who have been less than nine years in teacher education, expressed a greater need to strengthen their skills in internal cooperation with other professional groups than teacher educators, compared to those who have been in teacher training for more than 15 years.
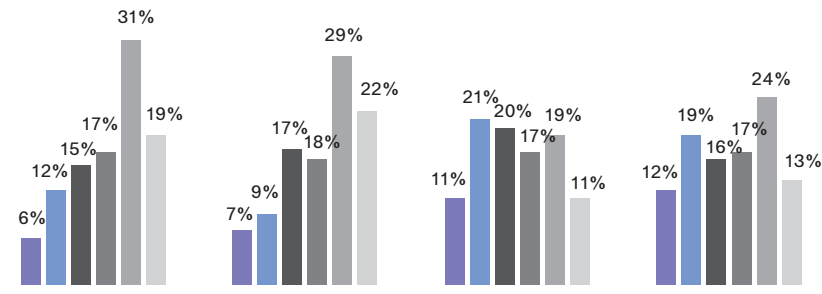

Very large extent

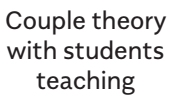

teaching

practice

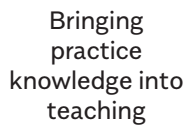

Learning

materials

used in

basic schools

Subject

didactics

Large extent

Some (higher) extent

Some (lower) extent

Small extent

Not at all

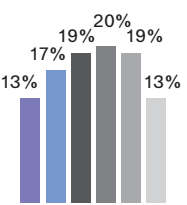

Co-operation with other professional groups

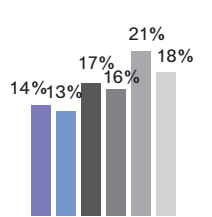

$$
\begin{aligned}
& \text { Co-operation } \\
& \text { with own } \\
& \text { subject group }
\end{aligned}
$$

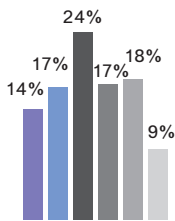

Co-operation with practice teachers

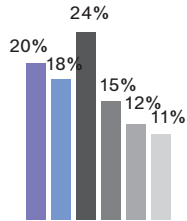

Co-operation with university scholars

Figure 6: Competence needs about practice, subject didactics and cooperation

\section{Equipped to new elements of the basic school reform}

A picture of a larger need for competence development stands out when it comes to competences demanded by the reform of the public school. 
It is elements or themes such as the open school, supportive teaching, co-operation with other professionals about supportive teaching, how schools can be conducive to reduce the importance of social heritage/ social inequality, how schools can compensate for students' various social learning conditions, the use of the new Common Objectives, early foreign language teaching, and the use of "attention points" as a tool to ensure that all students acquire the necessary prerequisites for further learning. For all of these elements/themes the survey study showed, that only about a third of the respondents to a very large and large extent found themselves equipped to teach the students in these elements. Almost half of the teacher educators responded that they to some extent found themselves equipped to teach these elements, while a fifth of the respondents indicated that they only to a small extent or not at all found themselves equipped for these tasks.

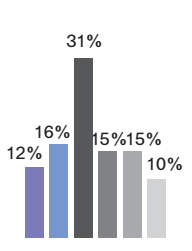

Open school

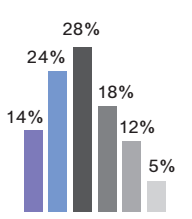

Compensate for students' various learning conditions

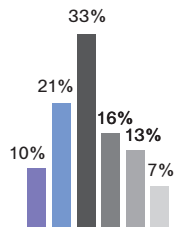

$$
\begin{aligned}
& \text { Supportive } \\
& \text { teaching }
\end{aligned}
$$
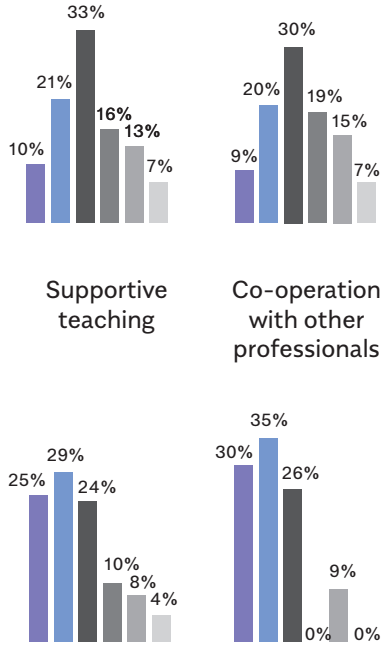

$$
\begin{aligned}
& \text { Use of new } \\
& \text { Common } \\
& \text { Objectives }
\end{aligned}
$$

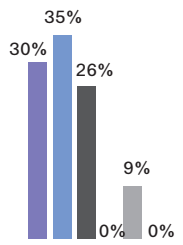

$$
\begin{aligned}
& \text { Early foreign } \\
& \text { language } \\
& \text { teaching }
\end{aligned}
$$

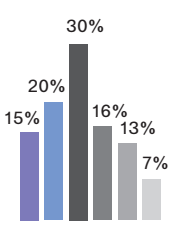

Reduce social inequality

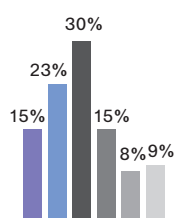

Use "attention points"
Very large extent

Large extent

Some (higher) extent

Some (lower) extent

Small extent

Not at all

Figure 7: Competence needs about new elements in the Folkeskole reform 


\section{Conclusion}

The failure or success of a teacher education reform can be attributed to at least three factors: the student teachers, the teacher educators and the reform itself. It can be said, that if a few students fail the new program, then they themselves are to blame, while if many students fail the programme, then the teacher educators are to blame, and if a major part of the teacher educators fail to teach the programme, then the programme is to blame.

Concerning the teacher educators, we see that they widely practise the kind of teaching the teacher education reform sets the scene for. According to their answers, they do practise management by objectives as it is intended by the reform. It happens, however, with some variation regarding the different elements of this kind of teaching. Some elements are practised more than others. The teacher educators also teach professional key elements such as differentiated instruction, classroom management, teaching that accommodates linguistic diversity and also but to a lesser degree elements such as special education, inclusive education and dual-language teaching.

At the same time the study also shows that a great number of the respondents signal a substantial need for competence development in key elements that are the same in the teacher education reform and the basic school reform, i.e. management by objectives, introduction of research in the curriculum, formative assessment and systematic feedback, as well as differentiated instruction, classroom management, dual-language teaching and inclusion. They also express a need for competence development regarding other new elements in the two reforms such as innovation and entrepreneurship.

What can be learned from the survey study is that the teacher educators do not lack will and motivation to teach the new elements in the reforms of teacher education and the public school, but quite many of them indicate that they do need more and better competences. The success of the reform then seems to be dependent on comprehensive, systematic support to teacher educators in terms of capacity building and competence development. 


\section{References}

$\rightarrow$ European Commission (2013). Supporting teacher educators for better learning outcomes. Retrieved from http://ec.europa.eu/education/policy/ school/doc/support-teacher-educators_en.pdf

$\rightarrow$ European Commission (2014). Conference: “Education: Policy support for teacher educators". Retrieved from http://ec.europa.eu/education/ events/2012/educator_en.htm

$\rightarrow$ Finne, H., Mordal, S. \& Stene, T. M. (2014). Oppfatninger av studiekvalitet i lærerutdanningene 2013. SINTEF. Trondheim. Retrieved from http://ivu.sintef. no/dok/sintef_1127901.pdf

$\rightarrow$ Fullan, M. (2006). Turnaround leadership. San Francisco: Jossey-Bass.

$\rightarrow$ Hattie, J. (2009). Visible Learning. A synthesis of over 800 meta-analyses relating to achievement. London: Routledge.

$\rightarrow$ Helmke, A. (2010). Unterrichtsqualität und lehrerprofessionalität. Diagnose, evaluation und verbeserung des unterrichts (3 ed.). Seelze-Velber: KlettKalmeyer.

$\rightarrow$ Levin, B. (2010). How to change 5000 schools: A practical and positive approach for leading change at every level (2 ed.). Cambridge, MA: Harvard Education Press.

$\rightarrow$ Lunenberg, M. \& Korthagen, F. A. J. (2005). Breaking the didactic circle: Study on some aspect of the promotion of student-directed learning by teachers and teacher educators. European Journal of Teacher Education, 28(1), 1-22.

$\rightarrow$ Rasch-Christensen, A. \& Rasmussen, J. (2014). Kompetencemål i den nye læreruddannelse. Paideia(7), 15-25.

$\rightarrow$ Rasmussen, J., Pedersen, E. F. \& Stafseth, V.T. (2015). Læreruddannerkompetencer: En undersøgelse af danske læreruddanneres kompetencer og behov for kompetenceudvikling Retrieved from http://edu.au.dk/fileadmin/edu/Aktuelt/ Laereruddannerkompetencer.pdf

$\rightarrow$ Smith, K. (2005). Teacher educators' expertise: What do novice teachers and teacher educators say? Teaching and Teacher Education, 21(2), 177-192.

$\rightarrow$ Timperley, H. (2008). Teacher professional learning and development. Retrieved from http://www.orientation94.org/uploaded/MakalatPdf/ Manchurat/EdPractices_18.pdf 


\section{Biographical note:}

Jens Rasmussen, $\mathrm{PhD}$, is professor in Educational Sociology at Department of Education, Aarhus University, Denmark. His research areas are learning theory, the sociology of modernity and comparative educational policy studies particularly on primary and secondary education and teacher training. He has been Fulbright Visiting Professor at College of Education, University of Georgia, USA and visiting professor at Institut für Bildungswisseschaft, University of Vienna, Austria. Among his recent research projects are comparative studies of teacher education and teacher recruitment in the Nordic countries, content in teacher education in Canada, Denmark, Finland and Singapore and the national curricula for basic school in selected countries. He has published several articles, reports and books on the above mentioned topics. He is member of national and international committees on school, curriculum and teacher education development and he has been national curriculum development advisor of Vietnam. 



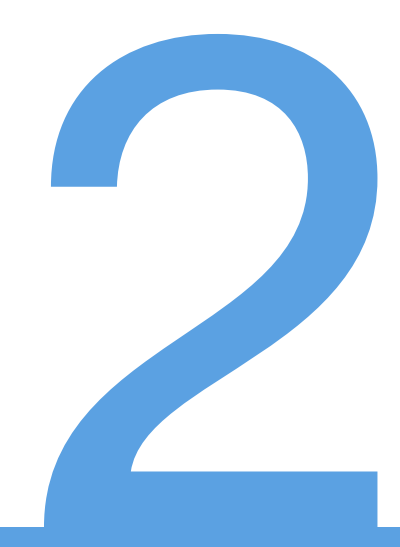




\section{Initial and Continuing Teacher Education - Towards Professionalism and Quality}




\title{
Access to learning within Further and Higher educational levels
}

\author{
Liliana Marić \\ University of Malta
}

\section{Abstract}

This research problematised the quality of Inclusive Education (IE) within Further and Higher educational institutions. Dewey's (1938) pragmatic theory of experience was utilised to explore how young people with physical and sensorial disabilities in Malta experienced access or lack of access to learning. The research analysed experiences and reflections about environmental, social and educational enabling and disabling factors from the perspective of disabled students and other stakeholders namely academics, lecturers, administrators and representatives of entities related to IE and disability. Evidence was collected by a mixedmethods research design and my position was partisan to disabled persons. Reflections on the lived experiences of different stakeholders enlightened whether current implementation of IE in the local milieu emanates democracy and social justice. These experiences and reflections are useful in creating teacher education programmes and professional development courses that respond to student diversity from a rights-based standpoint. The findings indicated that social attributes in developing a pro-inclusion culture that enforces the right of education affect the provision or lack of environmental and educational accessibility. 


\section{Introduction}

The research findings presented in this chapter focus on the experience of young people with physical and sensorial disabilities of inclusive education (IE) in Malta at Further (FE) and Higher Education (HE) or post-secondary and tertiary levels respectively. Data collection occurred between 2012 and 2014 from disabled students, academics, lecturers teaching at FE level, administrators and representatives of entities related to IE and disability. This paper aims to give an insight into the importance of environmental, educational and social accessibility.

Since 1995, Malta implements an IE policy in state schools and has developed resource centres (Ministry of Education, Culture, Youth and Sport, 2005). Influential international developments were: The Salamanca Statement (UNESCO, 1994) and The Bologna Declaration in 1999 as it envisaged "equality of opportunities in higher education, in terms of: access, participation and successful completion of studies; studying and living conditions; guidance and counselling; financial support, and student participation in higher education governance" (The Bologna Process/Social Dimension n.d., 1; The Bologna Declaration, 1999). Since the 1990s, attention was given to develop IE that reflects quality in education and celebrates diversity. However, less than $1 \%$ of student population attend FE and HE institutions (KNPD, 2010, p. 18). The research was developed using a mixed-methods methodology.

\section{Methodology}

Dewey's (1938) pragmatic theory of experience was utilised to explore how disabled young people in Malta experienced in/accessibility to learning. The selected research design to inquiry was a mixed-methods methodology as the research was developed with a "pluralistic", "realworld practice oriented" methodology (Creswell \& Plano Clark, 2011, p. 41) and employed a "what works" approach (Creswell, 2007, p. 22). The "diversity at all levels of the research enterprise" which is a main characteristic of mixed methods research helped me to obtain a greater insight into how environmental, social and educational enabling and disabling factors affect the experience of IE (Teddlie \& Tashakkori, 2010, p. 809). The evidence and methodology presented a novel way in the local and international sphere in identifying and understanding the enabling/disabling factors to IE at secondary level in view of the upcoming transition to FE level and at FE and HE levels by using 
deductive and inductive research instruments. A "convergent parallel design" (Creswell \& Plano Clark, 2011, p. 69) was selected on the basis that the level of interaction of the quantitative and qualitative strands was an independent one during data collection and data analysis. The two paradigms merged during the general interpretation of findings. The sample of the participants included learners and educators and IE supporters. Due to the small samples involved, no generalisations could be made, but the evidence representing the stories of individuals contributes to the advocacy of a much larger collective story in creating knowledge about the experience of IE at FE and HE.

A questionnaire was distributed among secondary students with physical and sensory disabilities during their Form 4/Grade 11. The aims were to explore their experiences and expectations of IE at FE level and to find frequencies of enabling/disabling factors in secondary schools. For ethical purposes, the questionnaire was distributed to the respondents by the school administrators. The total number of potential participants was 39 , but only 14 questionnaires were filled and fit the criteria of this research. Although the low response rate was quite surprising, the fact that I did not meet the students, the level of trust in the research was lowered.

For the qualitative strand, semi-structured interviews were conducted with 12 adult disabled students who followed courses at $\mathrm{FE} / \mathrm{HE}, 11$ academics, nine administrators and eight representatives of entities related to IE and disability. As Cousin (2009, p. 71) elucidates, "by collecting and transcribing interview talk, the researcher can produce rich empirical data about the lives and perspectives of individuals." A narrative inquiry was developed with four young disabled adolescents who were following a course at FE/HE level. Seven sessions over two year consisting of semi-structured interviews were carried out. The aim was to collect the participants' "oral history and testaments" (Plummer, 2001, p. 28). Eleven lecturing staff at FE level participated in four inperson focus groups. The aim was to listen, gather information and understand how service providers feel or think about their experiences of the phenomenon under study (Cousin, 2009). When contrasting the one-off time experiences in data collection to the longitudinal narrative inquiry, although both provided rich data and there was triangulation across the findings, the narratives provided a more personal account of events and explained the impact of such events on the participants' 
wellbeing and identity development. The fact that over time certain stories were repeated, the validity of such events in highlighting how in/accessibility affected their life was increased.

\section{Theoretical framework}

Since the 2000s, disability is being advocated by an anti-discrimination legislation (Laws of Malta, 2000) whereby it is aimed that "all Maltese have equal opportunities to be educated to their highest potential throughout their lifetime" (NCHE, 2009, p. 23). Such legislation increased the recognition of the rights of disabled people to education and training (ANED, 2010). Efforts from the state, National Commission for the Rights of Persons with Disability (CRPD), non-governmental organisations and disability activists contributed to such an achievement (Ministry of Education, Culture Youth and Sport, 2005). There were also various attempts to improve the quality of IE at FE and HE levels in assessment procedures (Education Act, 1988; University of Malta, 2007; University of Malta, 2009; University of Malta, 2011; University of Malta MATSEC Support Unit, 2016). In following international trends, disabled young persons are encouraged to enrol in courses as access is being widened to academic and vocational courses (Ministry of Education, Youth and Employment - Policy Unit, 2005; Master of Arts in Disability Studies n.d.; Camilleri, 2006; NCHE 2007; ACCESS: Disability Support Unit; University of Malta, 2007 n.d, p. 9; Schmitt \& Priestley, 2011). While acknowledging the work that has been carried out so far, the external audit carried out by the European Agency for Special Needs and Inclusive Education (2014) indicated three aspects that could affect the quality of IE in Malta. There has to be a discussion and agreement among stakeholders on key issues for IE; an audit on the use of present resources and identify more flexible resourcing options; and develop pilot projects to examine the implementation of IE.

In addressing inclusion, Azzopardi (2009, p. 255) contends that "schools are idiosyncratic communities" and need to develop flexible patterns by involving the students. Malta needs to create a "collective agenda" of political inventiveness to enforce the rights of students (ibid., pp. 256-257). Portelli (2010) claims that the Maltese educational system should honour the principles of democracy and social justice by valuing equity and proposes critical open discussions rather than silencing people. Pinto et al. (2012), explain the notions of equity, 
diversity and social justice that are inherent to critical democracy. They argued that "critical democracy necessarily leads to requirements of inclusion and empowerment, with particular attention to those who are often marginalised" (ibid., p. 2). Dewey (1930, p. 206) also explains that, "openness of mind means accessibility of mind to any and every consideration that will throw light upon the situation that needs to be cleared up, and that will help determine the consequences of acting this way or that." Therefore, the transformation of an educational system into an inclusive one depends upon the extent there is a culture of plurality, diversity, flexibility and accessibility.

Ainscow (2008) proposes a transformative approach to inclusion where the education system is more capable of developing its capacity to reach out to all learners in an ongoing process. Ideologically, FE and HE institutions need to be proactive rather than reactive in mainstreaming IE. This implies a reconstruction of the "learning landscape" which "includes the physical architecture, the formal and informal relationships, the processes of teaching, learning and assessment, the deployment of technology and the other factors that combine to shape the nature of the student experience in higher education" (Stevenson \& Bell, 2009, p. 1).

In enhancing accessibility, the framework of Universal Design for Learning (UDL), enables disabled students to have equal and equitable means of accessing content at the same time as their peers. They also have the opportunity to experience academic and social growth in ways that work best for them (Burgstahler, 2010; Burgstahler \& Cory, 2010; Hall, Meyer \& Rose, 2012). Investment in building accessibility for students with disabilities from the start of programmes by means of "educational technology" that includes assistive technology, digital curricula and universal design is essential (Rose, 2009, p. 85; Sopko, 2009). Supportive administrators, motivated and creative lecturers, professional development and the recruitment of a number of trainers, coordinators and technology specialists (Sopko, 2009; Spencer \& Romero, 2010; Burgstahler \& Cory, 2010) who inform and collaborate with other educators are necessary to increase sustainability and feasibility in implementing UDL (Behling \& Hart, 2010). Collegial collaboration and ongoing commitment between Departments and Academic Faculties can determine the most effective instructional and support strategies to reduce environmental, educational and 
social disabling barriers (Finn et al., 2010). The next section presents the environmental, social and educational factors that enhance or limit accessibility at FE/HE in Malta.

\section{Findings}

The results obtained from different stakeholders were broadly consistent. For ethical purposes, the participants' quotes are listed with a pseudonym. The main elements are discussed below.

\section{Environmental enabling and disabling factors}

Respondents of the questionnaires claimed that they would like to attend FE institutions that are environmentally accessible so that they would be able to participate in activities. Parking places outside or inside the campus reserved for disabled badge holders were considered essential. Accessible public transport enhances one's independence.

The student interviewees claimed that lack of environmental accessibility limited them from being independent and affected their dignity. It also made them self-conscious of the limitations caused by their impairment, particularly during adolescence which was considered as a sensitive age in developing one's identity. Buildings were not built in line with the principles of Universal Design. Changes in the environment were generally made in reaction to the novel situation they posed to educational institutions, or because non-disabled persons consulted them about what should be done for the environment to meet their needs, or because non-disabled persons tried to position themselves in the shoes of persons with activity limitations:

"The lift was not installed. I was with young girls, and sort of with kids and young boys all right, but then you'll start growing, you'll start feeling self-conscious. My friends used to carry me upstairs." (Rupert)

"Going around the university, $\ldots$ a person who is visually impaired will be disoriented or ends up bumping into a column.... In classes, the sunlight control is very poor.... On the doors, there should be Braille signs or embossed letters." (Martin) 
The narrative stories showed that sensitivity towards the needs of different individuals affected the extent environmental, social and educational disabling barriers were removed. Due to environmental inaccessibility, the participants claimed that they were not able to attend social and educational events. Inaccessibility affected their wellbeing, social inclusion and cohesion. Their participation put pressure upon administrators to comply to their rights. Travelling with the ferry to obtain certain medical assistance or educational services increases stress levels to Gozitan students:

"We have a presentation. The place where we hold the lectures it's like a theatre and with steps. ... When I told them and they made accommodations for me, I felt included." (Melanie)

"I won't be able to go most of the outings as they are not held in accessible places."

(Alessia)

The academic participants stressed the importance that disabled persons become independent and there should be a smoother transition across educational levels. Environmental accessibility reduces the need for students to be dependent on others or give up by the first year:

"I'm afraid that if the campus is not going to become more user friendly we keep on not seeing students with disability who will continue until the last year. They tell you that they always had an LSA. When they came to university they felt totally lost. Maybe there should be a transition."

(Veronica)

The administrators argued that they faced financial and logistical difficulties in making the campus more accessible. Environmental inaccessibility hampers the extent a student can live the life of a student as one's peers:

"We're not geared up for physical disability. This is due to certain limitations and restrictions we have in terms of physical 
environment. As you can understand this requires resources, investment, employment, training."

(Anthony)

The focus group members pointed out that environmental disabling barriers such as lack of resources on campus inhibit lecturers to implement teaching strategies that reflect IE. When lecturers organise outdoor activities like fieldworks, the natural environment of the small islands of Malta also creates an accessibility problem. Inaccessibility to individuals with diverse disabilities propagates social exclusion and disrespects one's dignity:

"The building is old. The classes aren't all equipped with the overhead projector. We don't have internet. We don't have speakers."

(Manuel)

"In the new places, the walls are single walls. You'll switch on a bit the sound, it will be heard from the class next to you. I can't stay next to her all the time so that she'll hear me. From the other side, I get heard with an echo."

(Carl)

"Having the ramp at the back, excuse the expression, it's like you're getting him from the maid's door! Which is to say the least, humiliating."

(Sean)

\section{Educational enabling and disabling factors}

The findings of the questionnaire indicated that the school personnel provided support, gave them individual attention and liaised with parents. Some respondents did not consider that examinations were designed to meet their educational needs. They preferred having summative and formative examinations. Eleven respondents $(78.5 \%)$ preferred that the administration discloses their impairment to their teachers. Eleven respondents $(78.5 \%)$ recognised the use of information technology.

Deaf student interviewees claimed that access to education is affected by the extent there is information accessibility. This is enhanced 
by learning how to lip read, peripatetic teachers and educators who try to overcome barriers. More sign language interpreters are needed. Friends of good-will reduce the need of Learning Support Assistants (LSAs). The development of a smooth transition from secondary to $\mathrm{FE} / \mathrm{HE}$ institutions helps students to settle in the new environment. Designing courses and exams which are flexible and using pedagogies that are student-centred help students to complete courses at their own pace. When a scribe is not knowledgeable of the subject a candidate is sitting for, lack of communication increases stress. The participants argued that any person would get mentally tired after three hours and for persons with visual impairment, the challenge is even harder. These struggles reduce the effectiveness of extra time given as an access arrangement and put disabled students at a disadvantage. Technology increases physical and information accessibility for persons with different disabilities. Lack of assistive technology and distance learning facilities in local FE/HE institutions were regarded as a deficit:

"Deaf students have always struggled during their education since they cannot be informed of what is happening around them." (Gerald)

"A group of students is audio recording the lectures for me. There should be the structures for the university to have distance learning. They are doing it on voluntary basis. ... There were arrangements so that the exam was held here where I live, at the same time it was taking place at university." (Clark)

"In Philosophy, you have a part which is logic. I started saying a word to the scribe, and she was writing it as a normal word in English when it was supposed to be written as a symbol." (Kristof)

The narrative participants were in favour that the school administration discloses their educational needs to their respective educators. However, this should not imply a different treatment or a negative disability identity. Planning and training enable stakeholders to become conscious of the students' needs. Lecturers were 
considered as the main stakeholders in facilitating academic success and promoting the principles of IE. Good tactics in developing group dynamics, two-way communication and partnership between students and lecturers were regarded effective in identifying the plan of action to be implemented. The availability of home-tutoring services, assistive technology on the market and in schools were considered necessary for disabled students to complete tasks at par to non-disabled peers in a dignified way. During the decision-making process for access arrangements, the participants requested to be consulted as they would experience the consequences of the decisions taken. Generally, the participants were satisfied with the access arrangements that their respective school and the local Matriculation and Secondary Education Certificate (MATSEC) Board provided. However, they experienced a struggle to present the statement of needs report every two years to prove that they could sit for the exams or to verify that they were eligible for access arrangements:

"I should tell them that I am visually impaired. They'll be alerted so that they'll be able to prepare from beforehand. ... I went to the library of here and the university. They neither have audio books nor eBooks.... l just needed extra time and a computer that reads for me the paper.... The system that I am following now, it beats a scribe. The scribe literally is seeing what I'm writing and I'm like with a rope around my neck."

(Marie)

"The problem is that I won't always have an operation in the same hospital as sometimes I will need to travel to Malta. To my knowledge, there isn't the service of home tutoring at post-secondary level. ... The Board decides upon the report of the doctors. I won't tell what I need. I won't have a choice. ... A normal girl won't have these things and papers and certificates that you need to do. ... I think that the people who can speak mostly are the LSA, the school, as the student is at school not with the psychologist. "

(Alessia) 
"Certain teachers don't expect to see a person with disability. ... There are ones who don't provide slides or leave the slides flipping and he talks on something else.... For the statement of needs, I did tests. If you needed it two years ago, there isn't the possibility that you won't need it."

(Melanie)

The academic participants argued that positive stories of inclusion are dependent on the educators' commitment to overcome problems that students face due to their impairment and the environment they are in. There is the need for more investment in assistive technology and sign language interpreters even while Deaf students are conducting research. For disabled students to complete courses, FE and HE institutions need to widen their accessibility in the courses offered. Administrators, lecturers and parents need to be trained on how they can support students appropriately. The service of having LSAs and/or teacher assistants at FE and $\mathrm{HE}$ was debatable, but there was consensus that at $\mathrm{HE}$ level, students need to become autonomous learners. Environmental inaccessibility, social disabling barriers such as negative attitudes from non-disabled persons and lack of information accessibility enable disabled students to drop out of courses particularly after the first year. Large groups of students and lack of information about students' educational needs limit the extent educators can reach out to students. Flexibility in courses, blended learning, distance learning and the UDL framework were considered effective in complementing IE on a theoretical and practical level. Extensive and rigid entry requirements at FE/HE limit the possibility for certain students to enter a course. Fixed examination procedures also restrict students from pacing their own learning. Persons with activity limitations have the highest chance to access the curriculum as very little reasonable adjustments need to be done while persons with visual and hearing impairment are second in the hierarchy. Persons with intellectual disability and learning difficulties are further down the ladder. The participants agreed that the integrity of the subject and Examination Boards have to be maintained, however widening access complements the current IE policy:

"Each one of us should have access to the curriculum so that we learn in the mode that suits us most.... We have a very rigid 
educational system, even here at university. We have to get the technology in place. Even culturally we need to open up especially the entry requirements need to be flexible."

(Eleonora)

"Students with disability are not entering university. The way courses are designed, they don't help those who have a disability. We have to be convinced that people deserve the chances and everyone has his own way and rhythm. We won't have one model of inclusive education that fits at primary, at secondary, at university. There has to be flexibility. The Universal Design is a concept that is being introduced in Malta slowly."

(Alan)

The administrators argued that flexibility in the type of support students can receive particularly at FE enables students to develop agency and yet have their needs met. Lecturers should adapt to student diversity. Accessibility in teaching and learning is enhanced if there is investment in resources, ongoing training and evaluation to ensure quality education. Administrators of academic institutions remarked that if a student distracts the class, the individual risks being socially excluded. Small classes enhance learning and social cohesion. Examination Boards limit the extent and the type of access arrangements administration can grant students for school-based exams. Different means of assessment should be provided to all students so that they can choose the mode of assessment that fits their leaning style:

"All the support is optional. ... None of the LSAs gets a student out of class to do a session with him. As soon as we'll mention LSA, the student would think, I'm going to miss certain lessons from my friends and I'm going to be alone. They don't want it." (Jarod)

"There should be more training and learning for teachers and LSAs. More audio visual and multi-sensory educational resources. Evaluation is crucial so that the service is improved." (Gordon) 
"There's a very vast syllabus that has to be covered in one year, six months. Students look up to students with a disability as long as they're not being affected. ... Ideally, you'll have a mixture of formative, summative. But that doesn't depend on us, it depends upon the MATSEC system."

(Johnatan)

The representatives of entities argued that IE is still being provided in a reactive rather than in a proactive way. Although students' needs are generally seen to, for quality IE, there should be standardisation on the services offered. At FE/HE, it is more difficult for students with complex limitations to be in mainstream classes throughout the day. The participants indicated that the University of Malta is falling behind in the provision of accessibility in assessment, distance learning and blended learning that reach out to diverse students:

"When it comes to post-secondary and tertiary, the cohort is still new to a certain extent. We're still learning the wheel. They would be very willing to help the student, but it's more of an ad hoc system rather than having a structure and everyone is working along that structure."

(Alice)

"It's inclusion for the child who has disability but it doesn't mean at the expense of the class.... I don't believe that you can put different disabilities in the same class because the approach is different. There are kids that can cope in mainstream, but there are those that cannot cope or aren't accepted because they aren't understood." (Daniela)

"Accessibility is not only ramps but it is accessibility in pedagogy, in the curriculum and in assessment."

(Edmond)

The focus group members argued that lack of expertise in knowing how to teach a student with a specific impairment has an impact on the effectiveness of the lecturer's teaching. Lack of resources to support lecturers is another limiting factor. The teacher education programme and professional development courses need to underline the principles 
of IE and instruct how to facilitate information accessibility to diverse learners. The participants agreed that there is the need for a clear vision of IE with a set of practical strategies whereby the principles of IE are valued, understood and owned. The presence of learning support personnel in class posed political decisions in relation to power and roles. The extent lecturers can adapt to meet students' needs is restricted as exams control what and how lecturers teach. The type of exams offered should consolidate IE. The use of technology was regarded as problematic due to lack of standardisation, a positive attitude towards its use, and training in how educators can use new technologies that enhance teaching and assessment. It was pointed out that both students and lecturers have to adapt to each other to create a successful experience of IE. Dialogue, active participation and collaboration improve group dynamics. Disruptions during lectures should be minimised and addressed for the syllabus to be finished on time:

"If training is done it shouldn't be done after working hours or there would be certain days allocated for it, maybe in September before the students start."

(Matthias)

"I think at university before they go out, inclusive education shouldn't be an option."

(Audrey)

"When I had the LSA, the roles were defined. I' $m$ the teacher and he is helping the student."

(Manuel)

"As assessment methods, those that he finds himself most comfortable in by speaking or writing. He is the principal, he has to lead. I do what he wants."

(Arnold)

"I used to catch myself, for example, All of you open page 15, or, Look at the board. I felt my lack of professionalism to meet her 
needs, but eventually I tried to cater as much as I could. I think, we ought to be trained."

(Rupert)

\section{Social enabling and disabling factors}

The participants of the questionnaire believed that it was their right to attend mainstream education. They indicated that the school personnel were approachable and valued the need to consult them during decision-making. In and out of class activities need to be planned better to ensure that all students can participate. Thirteen students $(92.8 \%)$ stated that they spent break time with their peers. Ten respondents $(71.4 \%)$ acknowledged that they were not bullied at school. Nine respondents $(64.2 \%)$ were in favour of going out of class for tutorials.

The student interviewees underlined the importance for disabled persons to become autonomous, assertive and develop self-help and self-advocacy skills. They remarked that while overprotection and paternalism limits one's growth, support and encouragement empowered them to overcome barriers that are created by society and by one's impairment. Peer support has an emancipatory impact as other disabled and nondisabled persons become more conscious of someone else's reality. The allocation of an Access Disability Support Unit on campus was regarded critical for them to obtain information and guidance. Disposition from non-disabled persons towards developing collaboration with disabled persons promoted social inclusion, social cohesion and enhanced the implementation of IE. Support made the participants feel secure, that they belonged to a group or an entity, and helped them to develop resilience and perseverance especially during the first year of a course. However, support was given on voluntary basis rather than standardised from a rights-based approach:

"I worked twice as hard as hearing students as I wanted to succeed and achieve. ... At post-secondary school and university, I did not have a facilitator/LSA. I had to depend on friends. I had to copy or borrow notes from friends." (Ann) 
"At university, there is a unit that assists. During the first year, it's very important, you'll arrange lectures, you'll integrate with society, how to apply for exams."

(John)

The narratives revealed that nurturing a rights-based approach from childhood empowered the participants to take up their responsibilities, develop self-advocacy and agency. Conforming to what other students tend to do increased their chances to be socially included. This entailed not distracting the class and being independent. The participants expressed an inner mission statement to improve accessibility to other disabled people and the student cohort in general:

"To make my voice heard, apart from being a right, I think that it's my duty as even if I'm not going to use it myself, someone else is going to use it. ... I wished to be independent. I wished to be like others. No one has an LSA and why should I be different, not having my liberty, independence and privacy."

(Melanie)

"Previous students with disability sort of pave the way for someone else. Inclusivity is a culture, sort of the habits of people. I feel, that because I am asking for help, I am at a lesser level than someone else as the others just cope with what they have to do." (Elena)

The academic participants maintained that there is a lack of consistency among educators in promoting a pro-inclusion culture. This social disabling barrier affects the extent educational and environmental disabling barriers are removed. Educators' motivation, expertise and attitude towards disability and IE affects how IE is implemented. Human rights, democracy and social justice were considered salient throughout the educational system in terms of IE policy and implementation. Lack of human capital who are specialised in IE is a weakness in the infrastructure and this affects the quality of the services that are provided: 
"Attitude can be a huge barrier that prevents even physical barriers from being removed. You will find really good examples of inclusion. There is still a significant chunk of not so good examples which need to be addressed."

(Alexandra)

"On a philosophical level, we have many people who don't believe in inclusion, then you have a level of competence that is lacking, the level of specialised training which is lacking, and the aspects that few are the ones who are truly competent, trained and are specialised, but are buried with work."

(Charles)

The administrators debated that while the main advantages of IE are social development and the fostering of good citizenship, students with low self-esteem, self-confidence and who lack social skills experience great challenges to experience inclusion in mainstream FE/HE classes. Students with complex disabilities face more difficulties in mainstream classes. Lecturers are at the front line in meeting students. So, their role in enhancing access to learning was considered salient. Unless they embrace a pro-inclusion culture, their educational service could have a negative impact on the students' learning. One of the main challenges of IE is finding a balance between reaching out to the individual, catering for the common good of the class, and managing the academic pressures within FE and HE institutions. Career guidance was deemed essential to minimise that students would be disappointed if they cannot follow a course in the way it is offered at present. Peer support was considered more beneficial than LSAs as students would develop social capital and learn how to develop coping skills to fend for themselves:

"Mixed ability classes? Yes, as you learn how to live, how to work, to be in an environment that not everyone is like you, not lesser than you. I keep on saying up to a certain level of physical needs." (Timothy)

"At university, there are still lecturers who resist from sending material so that the student would be able to prepare himself 
and during the lecture he'll be able to interact with his friends. We cannot oblige someone to send something." (Marica)

"The institution has to adapt to the needs of the student. The students around them also in a way adapt and care more. There is an element of adapting that the student needs to do because just like the student has a right, the others have the right. So, the difficulty is finding the balance. And the needs of everybody including the teachers, to carry on with the syllabus."

(Graziella)

"The most problematic is where there are diagrams especially when the person is visually impaired. That's why career guidance is important so that suitable subjects are chosen and the student would know what's in the exam."

(James)

The representatives of entities related to IE and disability indicated the attitude of the Head of an educational institution was regarded critical in enhancing or limiting access to disabled students amongst other minority groups. Disabled persons need to develop self-help strategies to gain independence. The teacher education programme was criticised on the extent it prepares educators to the reality of IE in different sectors of education. Collaboration of different entities could enhance the fusion between theory and practice:

"If you're not independent at university level or at post-secondary, then when are you going to become independent? LSAs are hindering the person from socialising with the others." (Alice)

"The attitude. If the Head has a good idea, it would rub off onto the teacher, and the teacher would rub it onto the LSA and the teacher and LSA would rub it off to the whole class. ... It's the empowerment, let's listen to them, and see what they have to say." (Daniela) 
"The B.Ed (Bachelor in Education) is still not giving the right amount of content on inclusion to address the issue of attitude." (Mariella)

The focus group members argued that by means of IE from the early years and group work, students develop mutual support and community building. Dissemination of information from administrators about students' learning needs was inconsistent and adolescents did not always disclose their needs. These factors limited the extent lecturers could meet students' needs:

"It's a question of attitude and starting from having inclusive education from when they are young. The best is if you have students helping other students."

(Maureen)

"Students who aren't in the mainstream, they would never be in the norm. It's always the case of us and them. When you are including people, you learn to see beyond yourself, both for the student with disability and not."

(Christine)

\section{Discussion}

The results show that social enabling and disabling factors affect the extent environmental and educational accessibility are enhanced or restricted. Triangulation of results was not surprising as each stakeholder was involved in the context of education and disability. The difference was in the way they were experiencing the enabling and disabling factors. The issues identified by the participants have been on the agenda in education and the disability sectors for many years. However, this lack of novelty to individuals who are familiar to discourse in these sectors, emphasises that a rights-based standpoint should be enforced across the educational and examination system so that the principles of social justice and democracy would also be implemented. Although the participants' reflections revealed the reality they experienced at a given time, their criticism is contentious. Different political decisions across different sectors involving different individuals with diverse insights about IE should be taken so that the value of 
accessibility from a rights-based perspective is enforced without marring the integrity of any educational institution or examination body.

\section{Conclusion}

The local situation corresponds to Graham and Slee's (2008, p. 80) argument that although IE is a relatively recent concept about schooling and pedagogy, "it is a rapidly establishing movement simultaneously reflected in and refracted by education policy, research and scholarship." There was a strong triangulation in the evidence provided by the participants representing the learners and learning providers and IE supporters. Enforcement of the right of education and consultation with disabled persons and other stakeholders how IE policies can be implemented effectively are essential to create a praxis in the learning landscape. The organisation of a social support network that fosters community building and nurtures self-help strategies would help disabled students to experience positive transitional periods between educational sectors. Inclusive pedagogies such as the UDL would facilitate access to learning. Although a lot of investment has been put towards creating an inclusive educational system, a pro-inclusive culture from a rights-based standpoint which is socially constructed affects the extent environmental, educational and social accessibility are enhanced or limited. Recognition of this deduction in the teacher education and professional development programmes could enhance the quality of IE. 


\section{References}

$\rightarrow$ Academic Network of European Disability experts (ANED). (2010). ANED Country report on equality of educational and training opportunities for young disabled people. Country: Malta. Accessed on July 29, 2013. Available at: www. disability-europe.net/countries/malta.

$\rightarrow$ ACCESS: Disability Support Unit (2007). Accessed on July 20, 2010. Available at: http://www.um.edu.mt/about/services/support/access.

$\rightarrow$ Ainscow, M. (2008). Profile. In P. Clough \& J. Corbett (Eds.), Theories of inclusive education: A student's guide (pp. 39-42). London Paul Chapman Publishing.

$\rightarrow$ Azzopardi, A. (2009). Reading stories of inclusion - Engaging with different perspectives towards an agenda for inclusion. Germany: VDM Verlag Dr. Müller.

$\rightarrow$ Behling, K. \& Hart, D. (2010). Universal course design: A model for professional development. In S. E. Burgstahler \& R. C. Cory (Eds.), Universal design in higher education: From principles to practice (pp. 109-125). Cambridge: Harvard University Press.

$\rightarrow$ Burgstahler, S.E. (2010). Universal design of instruction: From principles to practice. In . In S. E. Burgstahler \& R. C. Cory (Eds.), Universal design in higher education: From principles to practice (pp. 23-43). Cambridge: Harvard University Press.

$\rightarrow$ Burgstahler, S. E. \& Cory, R. C. (2010). Indicators of institutional change. In S. E. Burgstahler \& R. C. Cory (Eds.), Universal design in higher education: From principles to practice (pp. 247-253). Cambridge: Harvard University Press.

$\rightarrow$ Camilleri, J. M. (2006). The genesis of disability studies in Malta. Available at: from www.knpd.org/pubs/opus/0609_lancaster_camilleri.pdf.

$\rightarrow$ Cousin, G. (2009). Researching learning in higher education: An introduction to contemporary methods and approaches. London, UK: Routledge.

$\rightarrow$ Creswell, J.W. (2007). Qualitative inquiry and research design: Choosing among five approaches ( $2^{\text {nd }}$ ed.). Thousand Oaks, CA: Sage. 
$\rightarrow$ Creswell, J. W. \& Plano Clark, V. L. (2011). Designing and conducting mixed methods research. ( $2^{\text {nd }}$ ed.). London: SAGE Publications.

$\rightarrow$ Dewey, J. (1930). Democracy and education: An introduction to the philosophy of education. New York, NY: The Macmillan Company.

$\rightarrow$ Dewey, J. (1938). Experience and education. New York, NY: Touchstone - Simon \& Shuster.

$\rightarrow$ Disability Studies Unit. n.d. Accessed on August 3, 2013. http://www.um.edu. $\mathrm{mt} / \mathrm{socialwellbeing/disabilitystudies.}$

$\rightarrow$ European Agency for Special Needs and Inclusive Education. (2014). Education for all: Special needs and IE in Malta: External Audit Report. Accessed on April 24, 2016. Available at: https://education.gov.mt/en/Documents/ Special\%20Needs\%20and\%20Inclusive\%20Education \%20in\%20Malta\%20 \%C2\%AD-\%20External\%20Audit\%20Report.pdf.

$\rightarrow$ Finn, D. E., Evans G., El., Asselin, S. B. \& Reilly, V. (2010). Implementing universal design: Collaborations across campus. In S. E. Burgstahler \& R. C. Cory (Eds.), Universal design in higher education: From principles to practice (pp. 267-277). Cambridge: Harvard University Press.

$\rightarrow$ Graham, L. J. \& Slee, R. (2008). Inclusion? In S. Gabel \& S. Danforth (Eds.), Disability $\&$ the politics of education: An international reader (pp. 81-100). Oxford: Peter Lang.

$\rightarrow$ Hall, T. E, Meyer, A. \& Rose, D. H. (2012). An introduction to universal design for learning: Questions and answers. In T. E. Hall, A. Meyer \& D. H. Rose (Eds.), Universal design for learning in the classroom: Practical applications (pp. 1-8). London: The Guilford Press.

$\rightarrow$ Kummissjoni Nazzjonali Persuni B'Diżabilità (KNPD) (2010). National policy on disabled persons and employment. Accessed on April 26, 2016. Available at: http:// www.knpd.org/wp-content/uploads/2016/03/002-Employment-Policy-EN.pdf.

$\rightarrow$ Laws of Malta (1988). Education Act. Accessed on January 4, 2012. Available at: http://planipolis.iiep.unesco.org/upload/Malta/Malta_EducationAct2007.pdf.

$\rightarrow$ Laws of Malta (2000). Equal opportunities (Persons with disability) Act. Accessed on February 16, 2016. Available at: http://docs.justice.gov.mt/lom/ legislation/english/leg/vol_13/chapt413.pdf and http://www.knpd.org/pubs/ CHAPT413_EOA.pdf.

$\rightarrow$ Master of Arts in Disability Studies. n.d. Accessed on March 31, 2016. Available at: http://www.um.edu.mt/news_on_campus/features/2012/new_master_of_ arts_in_disability_studies.

$\rightarrow$ Ministry of Education, Culture, Youth and Sport (2005). Inclusive and special education review. Accessed on March 31, 2016. Available at: http://www. education.gov.mt/ministry/doc/pdf/inclusive_edu.pdf. 
$\rightarrow$ Ministry of Education, Youth and Employment - Policy Unit (2005). For all young persons to succeed: A network organisation for quality education in Malta. Accessed on September 15, 2009. Available at: http://www.education. gov.mt/ministry/doc/pdf/for_all_children_to_succeed.pdf.

$\rightarrow$ Ministerial Committee on Inclusive Education (MCIE). (2000). Inclusive education policy regarding students with a disability. Accessed on February 16, 2016. Available at: https://www.education.gov.mt/Page. aspx?pid=211\&depid=2\&pageid=14.

$\rightarrow$ National Commission for Higher Education (NCHE) (2007). A quality assurance framework for further and higher education in Malta. Report by the National Commission for Higher Education to the Minister of Education, Youth and Employment. Accessed on July 15, 2009. Available at: https://secure2.gov.mt/ NCHE/mediacenter/PDFs/1_NCHEQuality\%20Report\%20on\%20MEYE\%20 website.pdf.

$\rightarrow$ National Commission for Higher Education (NCHE). 2009. Further and higher education strategy 2020. Accessed on July 4, 2010. Available at: https://www. nche.gov.mt/page.aspx?pageid=51.

$\rightarrow$ Pinto, L. E., Portelli, J. P., Rottnam, C., Barrett, S. E. \& Mujuwamarija, D. (2012). Social justice: The missing link in school administrators' perspectives on teacher induction. Canadian Journal of Educational Administration and Policy, 129, 1-22.

$\rightarrow$ Plummer, K. (2001). Documents of life: An invitation to critical humanism. London, UK: SAGE Publications.

$\rightarrow$ Portelli, J. P. (2010). Inclusive education. Accessed on October 27, 2012. Available at: http://www.academia.edu/397579/Inclusive_Education.

$\rightarrow$ Rose, D. H. (2009). There is a way to "Leave no child behind". In D. T. Gordon, J. W. Gravel \& L. A. Schifter (Eds.), A policy reader in universal design for learning (pp. 47-54). Cambridge: Harvard Education Press.

$\rightarrow$ Rose, D. H., Hasselbring, T. S., Stahl, S. \& Zabala, J. (2009). Assistive technology, NIMAS, and UDL. In D. T. Gordon, J. W. Gravel \& L. A. Schifter (Eds.), A policy reader in universal design for learning (pp.133-154). Cambridge: Harvard Education Press.

$\rightarrow$ Schmitt, M. J. \& Priestley, M. (2011). Inclusive education for young disabled people in Europe: Trends, issues and challenges - a synthesis of evidence from ANED country reports and additional sources. Accessed on July 29, 2013. Available at: http://www.disability-europe.net/.

$\rightarrow$ Sopko, K. M. (2009). Universal design for learning: Policy challenges and recommendations. In D. T. Gordon, J. W. Gravel \& L. A. Schifter (Eds.), A policy 
reader in universal design for learning (pp. 93-107). Cambridge: Harvard Education Press.

$\rightarrow$ Spencer, A. M. \& Romero, O. (2010). Engaging higher education faculty in universal design: Addressing needs of students with invisible disabilities. In S. E. Burgstahler \& R. C. Cory (Eds.), Universal design in higher education: From principles to practice (pp.145-156). Cambridge: Harvard University Press.

$\rightarrow$ Stevenson, H. \& Bell, L. (2009). Introduction - Universities in transition: Themes in higher education policy. In L. Bell, H. Stevenson \& M. Neary (Eds.), The future of higher education: Policy, pedagogy and the student experience (pp. 1-16). London: Continuum.

$\rightarrow$ Teddlie, Ch. \& Tashakkori, A. (2010). Overview of contemporary issues in mixed methods research. In A. Tashakkori \& Ch. Teddlie (Eds.), SAGE handbook of mixed methods in social \& behavioural research (pp.1-41). London: SAGE Publications.

$\rightarrow$ The Bologna Declaration (1999). Accessed on April 24, 2016. Available at: http:// www.ond.vlaanderen.be/hogeronderwijs/bologna/documents/MDC/BOLOGNA_ DECLARATION1.pdf.

$\rightarrow$ The Bologna process: Social dimension. n.d. (2016). Accessed on April 24, 2016. http://www.ond.vlaanderen.be/hogeronderwijs/bologna/actionlines/ socialdimension.htm.

$\rightarrow$ United Nations Educational, Scientific and Cultural Organisation (UNESCO) (1994). The Salamanca statement and framework for action on special needs education. Accessed on April 24, 2016. Available at: http://www.unesco.org/ education/pdf/SALAMA_E.PDF.

$\rightarrow$ United Nations Convention on the Rights of Persons with Disabilities (UNCRPD) (2006). Accessed on February 16, 2016. Available at: http://www.un.org/ disabilities/convention/conventionfull.shtml.

$\rightarrow$ University of Malta (2007). The University of Malta and students with disability. Accessed July 14, 2009. Available at: http://www.um.edu.mt/_data/assets/ pdf_file/0011/3899/ access_booklet.pdf.

$\rightarrow$ University of Malta (2009). Disability support services and examination access arrangements. Accessed on July 14, 2009. Available at: http://www.um.edu.mt/ news_on_campus/features/2009/?a=74537.

$\rightarrow$ University of Malta (2011). University of Malta guidelines to MATSEC examinations access arrangements. Accessed on August 4, 2013. Available at: www.um.edu.mt/_data/assets/pdf_file/.../disabilitybooklet2011.pdf.

$\rightarrow$ University of Malta, MATSEC Support Unit (2016). Access arrangements support assistants handbook. Accessed on May 12, 2017. Available at: https://www. um.edu.mt/_data/assets/pdf_file/0003/277905/AASAshandbook-2016.pdf. 


\section{Biographical note:}

Liliana Marić taught at secondary, postsecondary and tertiary level over the past twenty-two years. She teaches Home Economics at the University of Malta, Junior College. At University, she contributed in giving lectures about inclusive education, teaching strategies and narrative inquiry. She was a tutor in practice placement of Learning Support Assistants as well as being a member on dissertation examining boards related to disability, Home Economics and inclusive education. Liliana submitted her Ph.D. thesis. Her research focused on the experience of inclusive education of disabled persons with physical and sensory impairment at further and higher education levels. She is interested in researching and contributing to the field of inclusive education. 



\title{
Reform of Initial Teacher Education in Wales: \\ taking an analytical approach \\ to the issues using activity theory
}

\author{
Jan Barnes \\ University of Wales Trinity Saint David \\ Jane Waters \\ University of Wales Trininty Saint David
}

\section{Abstract}

This chapter is set within the context of systemic change within a national education system concerned to ensure each and every learner grows 'as a capable, healthy, well-rounded individual who can thrive in the face of unknown future challenges' (Donaldson, 2015, p. 5). Wales, as a devolved government within the United Kingdom, is in the early stages of dramatic educational change including radical curriculum reform from 3-16 years, an overhaul of assessment and reporting arrangements, and a re-visioning of professional teacher standards, initial preparation and continued professional learning. The chapter explains the national context and locates a specific research project within it; the research project considers the change process inherent in the requirements for new kinds of provision for Initial Teacher Education (ITE) across the country. Using cultural historical activity theory (Engeström, 1996) as the analytical tool, within a socio-cultural theoretical framework, we seek to explore current challenges within the system that will need to be addressed in order to ensure that the change process might be successful in the longer run.

\section{Keywords: \\ Initial teacher education \\ reforms \\ cultural activity theory \\ partnerships \\ Wales}




\section{Introduction}

This paper is set within the context of systemic change within a national education system concerned to ensure each and every learner grows 'as a capable, healthy, well-rounded individual who can thrive in the face of unknown future challenges' (Donaldson, 2015, p. 5). Wales, as a devolved government within the United Kingdom, is in the early stages of dramatic educational change including radical curriculum reform from 3-16 years, an overhaul of assessment and reporting arrangements, and a re-visioning of professional teacher standards, initial preparation and continued professional learning. The chapter explains the national context and locates a specific research project within it; the research project considers the change process inherent in the requirements for new kinds of provision for Initial Teacher Education (ITE) across the country. Using cultural historical activity theory (Engeström, 1996) as the analytical tool, within a socio-cultural theoretical framework, we seek to explore current challenges within the system that will need to be addressed in order to ensure that the change process might be successful in the longer run.

\section{National context}

Wales sits within the United Kingdom. Wales has a population of just over three million people (Welsh Government, 2016a) and, of these, 18 per cent are children aged 0-15 years. In the 2011 census 19 per cent of the Welsh population reported being able to speak Welsh (Welsh Government, 2012a), a drop of 2 per cent from the 2001 census. The development of Wales as a bilingual nation is a central WG policy focus (e.g. Welsh Government, 2011; 2016b) and the study of Welsh is compulsory in all maintained educational settings until learners are 16 years of age. 23 per cent of people live in households in relative income poverty and 29 per cent of children live in households in relative income poverty (Welsh Government, 2017a). 15 per cent of children are in material deprivation and low income (defined as below 70 per cent of contemporary income median, before housing costs). This is higher than the equivalent figures for England, Scotland and Northern Ireland (13,11 and 13 per cent respectively) (Welsh Government, 2017a). 
The Welsh Government (WG) ${ }^{1}$ came into being after the first Welsh general election on 6 May 1999, following a referendum on 19 September 1997 in which there was a narrow majority in favour of the devolution of Wales from UK central government. This signified the devolution of responsibility for education within Wales from the UK to the Welsh Government. Now administered by the Department for Education and Skills (DES), ${ }^{2}$ education policy for the first decade of devolution was informed by the vision document The Learning Country (NAfW 2001), which signalled, amongst other things, a significant change in policy and provision for children in the early years of schooling. The Foundation Phase Framework for children aged 3-7 years (Welsh Government, 2015a) was rolled out as the statutory early years curriculum from 2008 (see Waters, 2016).

The broader context of WG's overall vision for children and young people as described in The learning country 2: Delivering the promise (Welsh Government, 2006) is based around seven core aims developed from the United Nations Convention on the Rights of the Child (UNCRC) which are still used by WG in its most recent Programme for Government for Children, (Welsh Government, 2015b). In contrast to recent UK wide developments, the UNCRC has been vigorously taken up in post-devolution policy and law in Wales. WG's stance on children's rights has been described as emblematic (Rees, 2010) of Welsh devolution (see also Lewis et al under review/accepted for publication). A central tenet of Welsh Government education policy is related to raising standards of pupil outcomes and breaking the link between attainment and poverty (Welsh Government, 2014).

It is within this context of ambitious and emancipatory vision for Wales' children and young people that significant change is being taken forward within Wales' education system. A significant driver for educational change has been the falls in the attainment of Wales' young people in the International PISA performance tables between 2006 and 2013 (Wheater et al., 2013). This drop in performance has continued in the most recent PISA results with the comparatively low performance

1. Previously the National Assembly for Wales (NAfW) then the Welsh Assembly Government (WAG).

2. Previously ACCAC (Awdurdod Cymwysterau Cwricwlwm ac Asesu Cymru: the Welsh Assembly Government Department for Curriculum and Qualifications) and Department for Children, Education and Lifelong Learning and Skills (DCELLS). 
of Wales' high achieving pupils in mathematics, reading and science has been identified a significant weakness of the Welsh education system (Jerrim \& Shure, 2016). WG review of education has involved a wholehearted consideration of the Welsh curriculum including associated assessment and reporting processes, and the systemic review of provision for initial teacher education (ITE). Both reviews took place during 2014-15 and the final reports, 'Successful Futures' (Donaldson, 2015) and 'Teaching Tomorrow's Teachers' (Furlong, 2015) make reference to each other.

The proposals inherent in the curriculum review included a radical overhaul of the way in which the curriculum - the learning experiences of all pupils - is realised. The notion of 'subsidiarity' (Donaldson, 2015) was introduced to the system. Subsidiarity is described as follows: 'Subsidiarity means that power stays as close as possible to the action. Rather than relying on a set of rules, which suggest a lack of confidence and can breed corruption, subsidiarity is dependent on mutual trust and confidence which supports positive disagreement and argument. Subsidiarity is about ensuring that power is where it belongs - rather than about empowerment which involves someone in power giving something away' (ibid., p. 99).

In the review of ITE, Furlong noted that, in current provision: "Because of the dominant focus on what newly qualified teachers must be able 'to do' at their end of their programmes, there is virtually no explicit recognition of the role of research or critical reflection in teachers' professional learning. As a consequence, newly qualified teachers are not conceptualised nor is there a requirement that they are prepared to be active professionals, with their own judgements to make and with their own responsibilities as leaders of children's learning" (Furlong, 2015, p.12).

The notion of subsidiarity, alongside the notion of research literacy the intention that in future "student teachers [ought] to be both critical consumers of as well as participants in research" (Furlong, 2015, p. 32) - require significant changes to the way in which teacher education at initial and continuing stages of teacher development is conceptualised in Wales. This observation, as well as recognition of weaknesses in the provision for ITE more generally (e.g. Tabberer, 2013), has led to a process of re-accreditation for programmes of ITE across Wales. 
Alongside the notion of subsidiarity, the fundamental purposes of education for the future, set out by Donaldson (2015) and accepted by Welsh Government (2015c), require a shift of focus from instrumental outcomes by pupils to their wellbeing, engagement and preparation for life. This shift, arguably a culture shift in education in Wales, will make very different demands on the teaching profession in Wales in the future; in order to meet such demands new pathways into the profession are required. The four purposes of the new curriculum, which resonate strongly with the Welsh Government's stance on children rights as detailed above, are summarized as:

The purposes of the curriculum in Wales should be that children and young people develop as:

$\rightarrow$ ambitious, capable learners, ready to learn throughout their lives

$\rightarrow$ enterprising, creative contributors, ready to play a full part in life and work

$\rightarrow$ ethical, informed citizens of Wales and the world

$\rightarrow$ healthy, confident individuals, ready to lead fulfilling lives as valued members of society (p. 29).

Alongside the process of re-accreditation and the publication of the new curriculum proposals (Welsh Government, 2015c), the Welsh Government has set out an over-arching vision for learners in Wales: "Qualified for life sets out our vision that learners in Wales will enjoy teaching and learning that inspires them to succeed, in an education community that works cooperatively and aspires to be great, where the potential of every child and young person is actively developed" (WG, 2014, p. 4). One arm of the delivery of the vision is related to the development of the workforce throughout the education system and it is within this national context also that the re-accreditation of ITE is taking place.

Currently in Wales, 96 per cent of ITE is provided through a series of undergraduate and post-graduate programmes of University-based study that include significant periods of time in school at each level of study, and lead to the recommendation for the award of Qualified Teacher Status (QTS). There are also two small school-based graduate programmes that lead to QTS; the graduate teacher programme (GTP) and the 'Teach first' programme. University-based ITE is currently delivered though three Centres of ITE that work broadly across three 
(overlapping) regions of the country. The Higher Education Funding Council for Wales (HEFCW) allocates annual intake targets for each Centre of ITE that are informed by Welsh Government's internal teacher supply modelling processes. For the past 4 years (that is, intake September 2014 -September 2017) the intake targets have remained generally stable, with a total of 871 intended secondary students, 86 at Undergraduate level and 785 at Post-graduate level and 750 intended primary students, 300 at Undergraduate level and 450 at Post-graduate level. In the past two years (i.e. entry 2015 and 2016) recruitment targets for secondary programmes have been hard to meet in some subjects, most notable, Design Technology, Computing/ICT, Chemistry, Physics and Modern Foreign Languages.

The content of programmes of ITE are currently focussed, at primary level, across the curriculum with specialism generally offered in early years (Foundation Phase: WG, 2015), secondary programmes are subject-related and range across all secondary school subjects. University-based programmes typically include blocks of theoretically based instruction and preparation for the blocks of practically-oriented learning that occurs typically through two long placements of about 8-10 weeks in partnership schools. During placement, also known as school experience, primary students are usually allocated to a class and secondary students allocated a subject timetable. Students work closely with school-based mentors, who are teachers in the school, and are visited around twice per placement by a university tutor. Wales is a bilingual nation with English medium, Welsh medium and bilingual school contexts; 33 per cent of primary 24.5 per cent of secondary schools in Wales are Welsh medium (Welsh Government, 2017b). ITE students are placed in a professional school context according to their language ability and ITE pathway. Students studying through the medium of Welsh will generally be placed in Welsh medium, or bilingual schools.

Furlong (2015) identifies a need for new relationships and practices to be developed between the universities currently providing ITE, and their partnership schools in the development of new teachers. Included in these models for new working practices is the development of the use of clinical practice. Clinical practice models are those in which there is a greater status given to the role of the partnership schools in the development of teachers; where closer relationships exist between the 
university-based learning and the school-based learning in programmes of ITE. In particular there is great emphasis on the development of "strong links between theory and practice, in a way that helps students to understand and explore the interconnectedness of educational theories and classroom practices" (Furlong, 2015, p.17). In order for this model to successfully evolve there is a need for co-production (also called co-construction) of the ITE programmes between the schools and the universities in order to build stronger 'bridges' between the different forms of professional knowledge available (that is, theoretical input, research and practice in the classroom). To this end 'clinical practice' in ITE incorporates opportunities for the student teacher to be able to undertake guided reflection on their own professional development building on their own practice, university-based learning, school-based learning and their own developing theories of practice.

\section{Local context}

The research study took place within the context of one provider of ITE, based in South and West Wales, working collaboratively with one of the four regional consortia in Wales that are tasked with improving standards in the education system. A series of pilot projects, designed and negotiated through partnerships between university-based tutors and school-based mentors took place over one academic year which were intended to explore 'clinical practice' opportunities within current programmes of ITE at primary and secondary level. The research study focusses in the secondary pilot projects. Each of the six secondary projects included collaborative planning to build 'bridges' between the university- and school-based learning in order to help the student teachers integrate theory and practice.

\section{Research Study}

\section{Theoretical frame}

The study adopts a socio-cultural theoretical framework and Cultural Historical Activity Theory (CHAT) (Engeström, 1996) as the analytical tool. Commonly shortened to 'Activity theory', this is a developmental resource, which is growing in popularity in education (Barnes \& Kennewell, 2017; Douglas, 2014). 
The foundation of activity theory is that human activity consists of much more than mere action, but is a socially-situated phenomenon. It is a framework that examines practice, placing that practice within an environment, whilst investigating not just the process of the practice but also the purpose of that practice (Daniels et al., 2010). This perspective attempts to interpret the complexity of real-time activity, investigating factors that influence the activity such as the beliefs and perceptions of those central to the activity. Engeström et al. (1999) believe that activity theory has much to contribute to research as it allows for analysis of the micro, meso- and macro-environs in which the activity takes place. This examination of activity or practice in a hierarchy of related environments, allows the researcher to pay particular attention to external influences such as cultural or social stance and political imperative. It is the recognition of these external influences and their impact on education, and in turn initial teacher education, that is likely to bring about change.

An activity setting can be described as a model of the relationships between mediating factors which influence activity outcomes (Engeström, 2007; see fig 1), for example, how the culture of the organisation or the individual involved in the activity impacts on the outcome(s) of the activity. Engeström (2007) also discusses disturbances or contradictions within the activity setting which impact upon the effective desired outcomes of the activity. These contradictions are not necessarily conflicts, but characterise strains which may exist within the activity. These exist on a number of levels, within a single activity setting, within concurrent or indeed historical activity settings. In this study we are mainly concerned with those contradictions which exist within a single activity setting, either within one mediating artefact, a primary contradiction, or within differing mediating artefacts of the same setting, a secondary contradiction. An example of a contradiction in the current context might be where an activity setting within ITE may be oriented towards student attainment of instrumental standards, where the intention of the ITE programme has shifted towards students developing professionally reflective dispositions towards pedagogic improvements. Another example may be where the expectations of the ITE programme are to produce research-active students, however the programme content does not support the research skill development required to fulfil that outcome. 


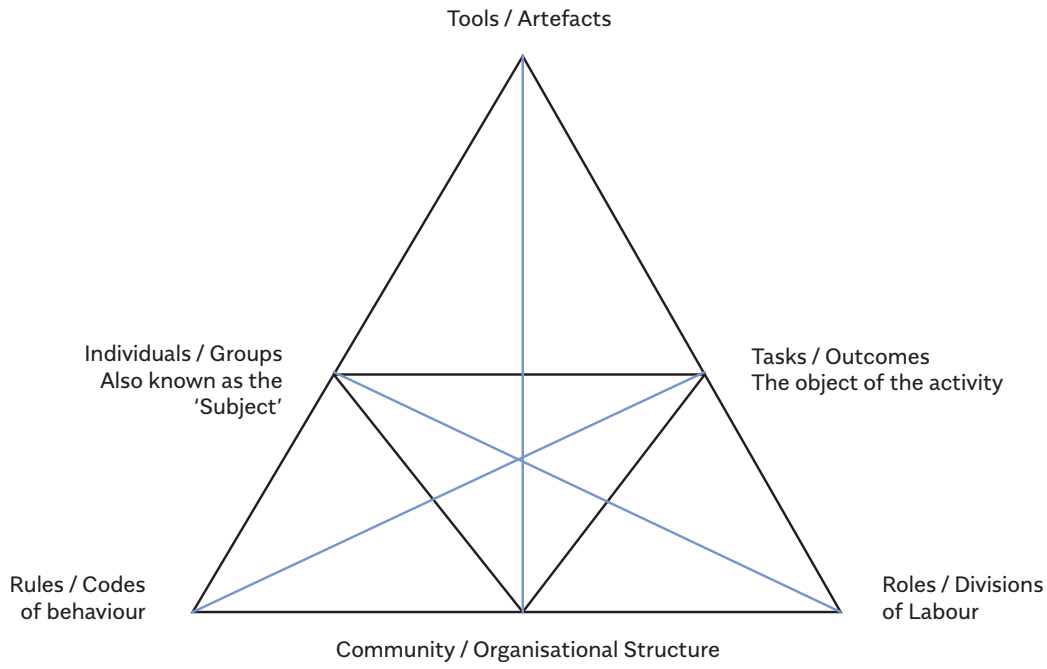

Figure 1. Activity Setting, prepared on the basis of Engeström, 2000.

It is a contradiction of this sort within the activity setting which will highlight a need for change and the adjustment to this contradiction will bring about the transformation which is essentially the point of this form of analysis. This recognition should lead to an evolution of a new activity setting where the influencing factors are no longer in dissonance allowing for new and improved practices to take place. However, there may be a danger that the contradiction will either not be recognised or will be discarded as irrelevant. Returning to the previous analogy regarding research-active students, there are a number of options that could be taken following recognition of the contradiction. The first is that the support for research-based practice is improved in the taught programme, removing that contradiction and creating an effective activity. A further option would be to change the outcome, here the goal of a research-active student is altered; this change would however produce a new contradiction between the outcome and the community where there is an expectation of researchcapable practitioners (Furlong, 2015). The final option is to ignore the 
contradiction, in this case no change is made and the continuation of ineffective activities occurs.

\section{Method}

Data was collected via online questionnaires to stakeholders in the process of ITE, namely ITE students and school-based senior mentors, using open questions requiring a text-based response. Senior mentors are those within each school who have oversight of all the ITE students placed there; they are typically experienced and well-placed to respond. The questions focused on learning needed in order to become a teacher, the relationships between theory and practice and the perceived status of the theory and the practice of that theory. The first phase of study involved student teachers and school-based senior mentors on the Secondary PGCE programme and was conducted through both English and Welsh medium. The online questionnaire was sent to 210 students and 45 senior mentors. The participants were those student teachers and mentors involved in the pilot projects as well as those who were not participating in the pilot projects. The questionnaire was distributed electronically via the programme's virtual learning environment which was accessible by all student participants and via email to schoolbased mentors.

One of the key purposes of this research is to explore perceptions, and evaluate or discover commonalities between school-based mentors' perceptions of what it means to develop an effective teacher. Another purpose was to interpret student teachers' perceptions of what it means to become an effective teacher. Thematic analysis was used to identify patterns of meaning in the response dataset related to aspects of the activity setting. In this sense the aspects of the activity setting were pre-defined codes into which the data was sorted, however perceptions that did not readily align to the pre-defined codes were also noted. This method of analysis is innovative and supports the application of activity theory to the field of education (Barnes, 2015; Barnes \& Kennewell, 2017). The identification of common themes concerning the attitudes of the participants highlighted the most salient meanings present in that dataset, it is within these common themes where contradictions tended to emerge. For example when analysing data pre-coded to "Roles and Divisions of Labour" it emerged there were differences in the perceptions regarding the status of the school-based and university- 
based learning. The themes which emerged were then associated with the mediating factors of the activity setting for analysis. The mediating factors of the actual setting were interpreted and contradictions noted. The implications of these contradictions were then discussed in order to inform future change.

\section{Findings}

The response rate of the students involved in the study amounted to $55 \%$, and was greater than that of the mentors, at around $10 \%$. Whilst the response rate of the school-based mentors was small, it was felt that the responses themselves were significantly varied that they indicated a range of perceptions held within the environment of ITE. The ratio of participants responding to the questionnaire who were involved in pilot projects amounted to $10 \%$ of the overall respondents.

\section{Contradictions for student teachers}

There were a number of contradictions existing between the mediating artefacts within the activity setting of 'Student Teachers' Perception'. These exist at both primary and secondary levels. The first is a primary contradiction and this exists in both mediating artefacts 'Tools and Artefacts' and 'Rules and Codes of Behaviour'. The contradiction is that there is a difference of opinion regarding the relevance of the tools used to develop as a teacher. Some of the student cohort believe that the most important tools are operational in nature and might be described as: Tips for Teachers. Other students appear to recognise the underpinning theoretical ideas as tools for practical applications in their teaching. This contradiction also leads to a secondary contradiction in that there is a clear recommendation from the ITE review that there is a requirement that initial teacher education produces research-capable teachers. However the views of some students imply that they felt that the theoretical ideas they met in University did not necessarily relate to their practice in the classroom. However, it is important to note that whilst a proportion of the general cohort recognised the links between underpinning theoretical ideas as tools for practical applications in their teaching; all those students who had been involved in the pilot projects made this link.

Another contradiction within this activity setting relates to the role and status of university-based learning and the role and status of 
school-based learning. There are a number of students who made the connection between the university-based learning and school-based practice, recognising that the theory underpins the practice; however there were also students who felt that the status of the school-based practice was more relevant to their future employment and therefore of higher status than the university-based learning. In this instance, those student teachers who were involved in the pilot projects perceived the university based learning and school-based learning as being of equal import and status.

The final contradiction that related to the student teachers' perceptions, was that some students identified a form of progression or hierarchy between the blocks of university-based learning and school-based practice. A perception emerged that one undertook the university-based learning and school-based practice in sequence, but that these blocks of learning existed almost in isolation from each other.

\section{Contradictions for school-based mentors}

It is worth remembering that the respondents to the voluntary survey within this category were limited in number, however, because this study included those within and outside the pilot project schools, the data was varied and thought to cover a range of perceptions within the possible sample.

There was no strong evidence of contradictions concerning the learning needed to become a teacher, unlike that of the student teachers. Many of the tools highlighted as being necessary to the development of student teachers are at an operational level, for example the need to be aware of government requirements, the need to be able to create a learning environment.

There is, however, a possible contradiction between schoolbased mentor perception and the future of education in Wales. The expectations outlined by Donaldson (2015) and Furlong (2015) are that student teachers will gain research skills implementing practicebased research within the classroom. The ability to conduct classroombased research with an aim to improving the learning taking place requires a broader skillset than, as stated by the respondents, the ability to recognise and implement government requirements at an operational level. 


\section{Alignment}

Contradictions appear to arise concerning the roles of the stakeholders in initial teacher education, and it is here that there is an indication of the need for future alignment. Whilst a majority of respondents indicate that they feel that the relationships between the universitybased learning and the school-based learning is strong and not in need of change, a few of school-based mentors who stated that changes in roles may "plug any gaps"; or that they would welcome greater involvement with the university and closer working relationships.

There is a further, linked, contradiction which arises between the roles of the stakeholders and the organisational structure of the environment. If there is greater emphasis, in future, on the universitybased tutor being more involved with school-based learning, the need for a greater collaboration between the partnership schools and the university within ITE is satisfied. However, this change in role for the university-based tutor may initiate contradictions in their working activity, in that the Higher Education Institution requires that they engage in scholarly research-focussed activity above and beyond that which may be inherent in an ITE programme.

The main areas of contradiction appear to exist between the separate parallel activity settings of the student teacher and the school-based mentor. There are two key contradictions. The first is between the "Tools and Artefacts" of the two activity settings; the student teachers are looking at the tools needed to develop as a teacher and are distinguishing between practical tools and theoretical underpinning. However, the school based mentors generally group all the tools as operational. An example is the use of "two ticks and a wish" as a feedback mechanism and assessment for learning technique which is used when pupils are peer-assessing work. The pupils are asked to recognise two aspects of the work they are assessing which meets success criteria (two ticks) and an aspect which could be improves (a wish). The school-based mentors perceive the ability to use techniques such as this within the classroom as important, however, seem less concerned with the student teachers' understanding of why or even how using these techniques benefit learning. Furthermore, the student teachers appear to recognise the tools solely from a teaching perspective, focusing on their own actions, whereas the school-based 
mentors regard the tools from the perspective of pupil learning as well in that they are linked to the creation of positive learning environments.

The second key contradiction relates to the perceived status of school-based learning and university-based learning by the student teachers and the perceived need for closer working practices by the school-based mentors. Resolving this contradiction is likely to impact upon the activity setting of the student teacher and involves resolving the tensions regarding the perceived difference in status of the following:

$\rightarrow$ theoretical study and practical application,

$\rightarrow$ university-based study, and

$\rightarrow$ school-based study.

\section{Implications for the future}

The findings and interpretations from this study have implications for the future implementation of ITE in Wales. In light of the changes proposed by both Donaldson (2015) and Furlong (2015) for education in Wales it will be vital that the existing provision of ITE also changes in order to create teaching practitioners able to take those recommendations forward in the near future. In order to do this effectively, we suggests that the key contradictions indicated above need to be resolved.

One of the initiators of change in the system is related to Donaldson's notion of subsidiarity, and the need to tailor a curriculum that meets the needs of the learners at a local level. However, teachers in Wales, like England, have been practicing within the confines of a National Curriculum, which has been centrally prescribed, since 1988. It is prudent to speculate that the skills needed for curriculum design to enable subsidiarity may no longer exist within the workforce. It is imperative therefore, that these skills re-emerge through initial teacher education. However, for this to take place there needs to be a change in perception of existing teachers in recognising the importance of this skill. The study highlighted that the school-based mentors' perceptions were that those tools important in becoming an effective teacher were largely at an operational level. Students who had been involved in the pilot projects tended to rate operational skills and research-related theoretical knowledge similarly, though those students who had not been involved tended to rate operational practice-focussed skills as 
more valuable. Skills of this type, whilst important, are unlikely to bring about subsidiarity as Donaldson sees it. It is important that practitioners are proactive as effective, research-informed designers of curricular experience to bring about meaningful knowledge creation for their pupils. This being the case, it is suggested that the success of future initiatives in education may require the teaching workforce, including those entering it, to recognise a need for change in their perception of different forms of professional knowledge.

Further implications for future change in the design of initial teacher education relate to the way in which the status of the university-based learning and the school-based learning is viewed by stakeholders. There is a need for greater collaboration between the university and the mentoring schools in order that all stakeholders recognise the need for equal status between different forms of knowledge and partnership between those providing access to them. In this way it is likely that that there will be greater recognition that theory and research do not exist as separate entities from practice, but that they underpin and interweave with pedagogic decision making and provision in the classroom.

There is also a case for evaluating the ITE curriculum design with a view to altering the way in which the programmes are presented. ITE is generally delivered in blocks of university based leaning followed sequentially by blocks of school-based learning. It is this format and division of labour which, arguably, perpetuates the student teachers' perception that the learning in each block is separate and distinct. In order for transformative learning, of the sort required in effective ITE, to take place the learning needs to relate to a "coherent body of experience" (Mezirow, 1997, p. 5). This study indicates that currently many student teachers perceive that their ITE learning is separated into theoretical and practice-based blocks, separated temporally, spatially, geographically and, most significantly, cognitively; such separations present a barrier to transformative learning.

Implications for change also focus on possible difficulties which may be faced by university-based lecturers operating in a university culture which has traditionally associated value to theoretical research rather than practical application. The opportunities for the university-based tutor to build a classroom-based research culture within partnership schools may be limited unless the value of practice-oriented research activity is recognised, as indicated by Furlong's (2015) in the call 
for the inclusion of clinical practice in the development of future student teachers.

To that end we would suggest that if an enquiry-based profession is to be achieved then university-based tutors need to have 'a foot in each camp' and blend the requirements of sets of skills and knowledge associated with both research enquiry and practical application, in order to design and maintain a model of clinical practice in the initial education of teachers of the future.

\section{Concluding note}

This piece of work, undertaken in 2015-16, has helped shape the development of the Centre's partnership activity and the design of its ITE programmes. All existing ITE programmes, primary and secondary phase, undergraduate and post-graduate routes, have been revised to ensure that there are blurred edges between theoretical and practical aspects of learning. This blurring has been supported by engaging students in co-constructed episodes of learning in which schoolbased mentors and university-based staff jointly design an element of ITE curriculum. In such co-constructed elements there are activities that act as the bridges between different forms of knowledge. Central to such bridges are cycles of reflection embedded in the ITE student learner journey, through which the explicit reflection on both practicebased and theoretically-informed forms of knowledge is supported. The blurring has also applied to the blocks of university-based and schoolbased learning, there are now weeks of shared activity where bridging work takes place between the two sites of learning; and different forms of knowledge are explicitly drawn upon across both sites. To date, such development has been warmly received by all stakeholders in our wider community; we have on-going evaluation projects to ascertain the impact of such changes on ITE student outcomes. 


\section{References}

$\rightarrow$ Barnes, J. M. I. (2015). Changing perceptions of ICT at KS3: A critical investigation using Activity Theory. PhD dissertation. Cardiff: University of Wales, Trinity Saint David.

$\rightarrow$ Barnes, J. \& Kennewell, S. (2017). Investigating teacher perceptions of teaching ICT in Wales. Education and Information Technologies, 22 (5), 2485-2497.

$\rightarrow$ Daniels, H., Edwards, A., Engeström, Y., Gallagher, T. \& Ludvigsen, S. R. (2010). Activity Theory in practice. Oxon: Routledge.

$\rightarrow$ Donaldson, G. (2015). Successful futures: Independent review of curriculum and assessment arrangements in Wales. Cardiff: Welsh Government.

$\rightarrow$ Douglas, A.S. (2014). Student teachers in school practice: An analysis of learning opportunities. Hampshire: Palgrave Macmillan.

$\rightarrow$ Engeström, Y. (2007). Enriching the theory of expansive learning: Lessons from journeys toward configuration. Mind, Culture, and Activity, 14 (1-2), 23-39.

$\rightarrow$ Engeström, Y. (2001). Expansive learning at work: Toward an activity theoretical reconceptualization. Journal of Education and Work, 14 (1), 133-156.

$\rightarrow$ Engeström, Y. (2000). Activity Theory as a framework for analyzing and redesigning work. Ergonomics, 43(7), 960-974.

$\rightarrow$ Engeström, Y. (1996). Interobjectivity, ideality, and dialectics. Mind, Culture, and Activity, 3 (4), 259-265.

$\rightarrow$ Engeström, Y., Miettinen, R. \& Punamäki, R-L. (1999). Perspectives on Activity Theory. Cambridge: Cambridge University Press.

$\rightarrow$ Furlong, J. (2015). Teaching tomorrow's teachers. Options for the future of initial teacher education in Wales. Report to Huw Lewis, AM, Minister for Education and Skills. Oxford: University of Oxford.

$\rightarrow$ Jerrim, J. \& Shure, N. (2016). Achievement of 15 year olds in Wales: PISA 2015 National Report. London: UCL Institute of Education.

$\rightarrow$ Lewis, A., Sian, S., Tyrie, J., Waters, J. \& Williams, J. (2017). Exploring the extent of enactment of young children's rights in the education system in Wales. Wales Journal of Education, in press.

$\rightarrow$ Mezirow, J. (1997). Transformative learning: Theory to practice. New Directions for Adult and Continuing Education, 74, 5-12.

$\rightarrow$ National Assembly for Wales (2001). The learning country: A paving document. Cardiff: NAfW. 
$\rightarrow$ Rees, O. (2010). Dealing with individual cases: An essential role for national human rights institutions for children? The International Journal of Children's Rights, 18 (3), 417-436.

$\rightarrow$ Tabberer, R. (2013). A review of initial teacher training in Wales. Cardiff: Welsh Government.

$\rightarrow$ UN Committee (2008). Concluding observations on the third and fourth combined state party reports of the United Kingdom under the Convention on the Rights of the Child. CRC/C/GBR/CO/4.

$\rightarrow$ Waters, J. (2016). The foundation phase in Wales-time to grow up? Wales Journal of Education, 18 (1), 179-198.

$\rightarrow$ Wheater, R., Ager, R., Burge, B. \& Sizmur, J. (2013). Achievement of 15-Year-Olds in Wales: PISA 2012 National Report. Accessed on August 01, 2017. Available at: http://www.nfer.ac.uk/publications/PQUK02

$\rightarrow$ Welsh Government (2017a). National Statistics: Households below average income. Cardiff: Welsh Government.

$\rightarrow$ Welsh Government (2017b). National statistics: Address list of schools. Cardiff: Welsh Government.

$\rightarrow$ Welsh Government (2016a). Mid-year population estimates June 2015. Cardiff: Welsh Government.

$\rightarrow$ Welsh Government (2016b). Welsh-medium education strategy: Next steps. Cardiff: Welsh Government.

$\rightarrow$ Welsh Government (2015a). Foundation phase framework: Revised. Cardiff: Welsh Government.

$\rightarrow$ Welsh Government (2015b). Programme for government for children. Cardiff: Welsh Government.

$\rightarrow$ Welsh Government (2015c). A curriculum for Wales - A curriculum for life. Cardiff: Welsh Government.

$\rightarrow$ Welsh Government (2014). Qualified for life. Cardiff: Welsh Government.

$\rightarrow$ Welsh Government (2012). Census 2011: Number of Welsh speakers falling. Cardiff: Welsh Government.

$\rightarrow$ Welsh Government (2011). Our Welsh language scheme. Cardiff: Welsh Government.

$\rightarrow$ Welsh Government (2006). The learning country 2: Delivering the promise. Cardiff: Welsh Government.

$\rightarrow$ Welsh Government (2004). Rights to action. Cardiff: Welsh Government.

$\rightarrow$ Williams, J. (Ed.) (2013). The United Nations Convention on the Rights of the Child in Wales. Cardiff: University of Wales Press. 


\section{Biographical notes:}

Dr Jan Barnes is a senior lecturer in the Athrofa, University of Wales Trinity Saint David. Jan's doctoral research focused on the relationship between teacher perceptions \& practice using Cultural Historical Activity Theory. Jan's research interests include the pedagogical use of technology, and the development of the use of CHAT in education as a means of pedagogical analysis. Jan also sits on the board of the Association of Information Technology in Teacher Education (ITTE), and the Welsh Government National Network of Excellence in Science and Technology (NNEST). Jan is also involved in the CAMAU Project (collaborating with the University of Glasgow), facilitating 'pioneer' schools in Wales in the development and design of progression frameworks in the innovative new Welsh Curriculum.

Dr Jane Waters is the Assistant Dean Research in the Athrofa: Institute of Education, University of Wales Trinity Saint David. Having worked as a primary school teacher and lecturer in Early Childhood Studies and Initial Teacher Education, she now works most closely with postgraduate research students. Jane is involved in research activity and networks related to initial teacher education, early childhood education and professional learning in a period of significant systemic change in Wales. Jane co-leads the CAMAU project, part funded by Welsh Government, in collaboration with University of Glasgow exploring the articulation of progression in children's learning within a new and innovative curriculum framework. Jane also sits on the Welsh Government's Foundation Phase expert group. 



\title{
What skills do contemporary teachers need? The need to improve \\ emotional intelligence and self- regulation in the opinion of teachers preparing for the job
}

\author{
Katarzyna Szorc \\ University of Białystok \\ Agnieszka Iłendo-Milewska \\ Private University of Pedagogy in Białystok
}

\section{Abstract}

Teaching young children self-regulation requires strong teacher selfregulation first. Children learn to regulate thoughts, feelings, behaviour and emotion by watching and responding to adults' self-regulation. Referring to motivational regulation, Galinsky notes, "Adults foster children's motivation by being motivated themselves" (2010, p. 11). By demonstrating appropriate behaviour, teachers show children how to accomplish a task and use the self-regulation needed to complete it. When teachers use simple directions, gestures and touch, they provide young children with valuable cues about how and when to regulate their emotions, attention and behaviour. Teachers can help children regulate attention by pointing to or commenting on important or interesting aspects. Kramarski and Michalsky (2009) found that teachers' ability to self-regulation was associated with their pedagogical knowledge as well as with their beliefs on student-centered learning. The article confirmed or supplemented the psychological and pedagogical knowledge presenting interrelation between the level of self-regulation and sex, 
education and type of education. There is also the observation that the higher level of emotional intelligence among teachers preparing for their professional role, the higher level of autonomous self-regulation.

\footnotetext{
Keywords:

emotional intelligence

self-regulation

prospective teachers
} 


\section{Introduction}

Recently, more and more interest has been focused on the issues of self-regulation and emotional intelligence which can constitute important factors in the quality of education. Researches have been systematically identifying elements supporting the education process, recognising quality of relationships important to the self-regulation process and analysing undertaken activities aimed to improve quality of education process (Schunk, 2005, p. 173-177). It is evident that the said quality depends largely on teachers themselves. Although many renowned researchers refer to role of teachers' self-regulation, only a limited amount of publications have depicted the teachers' own orientation toward autonomy, supportive or controlling students, as its main topic of study (Dembo, 2001; Randi, 2004). Consequently, there is a clear need to advance research around the recognition of the level of teachers' self-regulation and the level of teachers' emotional intelligence in their own perception.

Theoretical consideration in this article emphasises that teachers play a crucial role in promoting self-regulation. Self-regulated teachers attune their instructional approach to their own self-regulation skills, better understand self-regulation processes and become more effective in self-regulation promotion. According to Perry (Perry, Hutchinson, Thauberger, 2008), most teachers agree with the concept to support their students to become self-regulated learners; but many of the teachers reported to feel unsure about how to do that.

Based on an extensive literature review, the main goal of the present study was to recognise the relation between the level of emotional intelligence and the level of self-regulation among adults who are learning to become teachers. This consideration requires a connection with the theory describing the self-regulation - The Self-Determination Theory by Deci and Ryan (Deci, Ryan, 2000). This theory differentiates types of behavioural regulation in terms of the degree to which they represent autonomous versus controlled functioning.

\section{Theoretical approach}

\section{The significance of emotional intelligence}

Since the term emotional intelligence is still causing numerous controversies (Salovey, Mayer, 1990; Goleman, 1997, 1999; Bar-On, 
1997, 2001) and available theoretical data are still full of blanks or even contradictions, it is hard to determine whether to qualify it as an ability, competence, skill or a set of convictions. Due to the lack of unequivocal opinion there are various perspectives and theoretical attempts which translate into evident shortage of systematical comparison of particular trends. No wonder, then, that emotional intelligence has not been given unequivocal and coherent definition.

The most frequent models of emotional intelligence that can be found in various papers are an ability model of J. Mayer and P. Salovey (1990) or so called mixed models promoted by D. Goleman $(1997,1999)$ and R. Bar-On (1997, 2001).

In the emotional intelligence structure Salovey and Mayer initially identified three (1990, p. 185-211) and then four-component groups pointing to development aspects next to identified group of competences constituting emotional intelligence. The components exist in a hierarchical structure where at the bottom are basic perceptive abilities as well as abilities to express emotions. The top level is associated with a conscious and insightful regulation of emotions that allows for personal understanding and development.

According to the authors, acquiring emotional skills is a lifetime process and each skill of emotional intelligence model requires constant effort and devotion. It seems, however, that people of high emotional intelligence are able to pass stages of acquiring consecutive skills faster, as well as assimilate more of them.

It should be noted that despite numerous doubts (proven by empirical data) as to the coherence of presented model (see Day \& Carroll, 2004; Mayer at al., 2003; Ciarrochi, Chan, Caputi, 2000) it is probably the only one that can be called intelligence. It is supported by the following criteria: possibility of operationalisation of particular components understood as abilities; fulfill the correlative criterion with a standardized intelligence measure; improved level of intelligence with age (Mayer, 2001; Mayer, Caruso, Salovey, 2000).

Another theoretical concept of emotional intelligence called the mixed model was presented by D. Goleman. In his bestselling book he admits that emotional intelligence conveys such abilities as: motivation and endurance in acquiring particular goals despite failures, impulse control and postponing their fulfillment, ability to regulate the mood and resistance to worries that impede on ability to reason, ability to 
feel other peoples' moods and optimistic expectations for the future (Goleman, 1997, p. 67).

It is called a mixed model because it includes various aspects: cognitive, personal, motivational and emotional. A model presented in such a way is not recognised as a scientific theory by critics but as a set of information concerning the possibility of the best life through improvement of emotional potential.

The model presented by Bar-On is also recognised as a mixed one. Emotional intelligence is defined as a set of extra-cognitive abilities, competences and skills which allow an individual effective coping with society imposed expectations and pressures (Bar-On, 1997, p. 3). Basic components of that model are self-awareness, understanding of one's strengths and recognition of weaknesses as well as ability to express one's emotions and thoughts. The interpersonal platform focuses on the ability to recognise emotions, feelings and needs of others combined with the skill to create and sustain satisfactory interpersonal relationships. Emotional intelligence in Bar-On understanding stresses effective managing changes occurring in personal and professional life due to being flexible and creative in various life situations.

Research into those phenomena so far has been directed into looking for connections between emotional intelligence and academic success in college and the first year of universities (see Schutte at al., cited in Jaworowska \& Matczak, 2001). Research among professional groups (managers, psychotherapists) confirms that emotionally intelligent people have more success in professional life (Cooper, Sawaf, 2000; Goleman, 1999). Special significance of emotional intelligence is associated with jobs that require interpersonal relationships based on communication. Therefore without a doubt, it is a crucial component of a teacher competence. Emotional intelligence channels emotional energy amplifying communication and interpersonal competence as well as motivates decision making in socially important areas (Salovey, Sluyter, 1999, p. 335-339). Emotionally competent teachers would be able to appreciate and reward abilities and achievements of their pupils and be of service in their intellectual progress. They would also be engaged in an intellectual exploration and would be an example to students. Such teachers could also understand various opinions and see how diversity of opinion can be a driving force in their progress. 


\section{The importance of self-regulation}

Self-regulation is a complex concept, including various features of the learner and their environment that have an impact on the learning process (Zimmerman, 1989). The Self-Regulation Theory by Deci and Ryan (1985) emphasises that child attributes or inner resources that are expectably influenced by teachers are those involving self-regulation and self-evaluation capacities. One of the most significant affective goals of education is the capacity to be self-regulating or autonomous with respect to the learning process and to one's own behaviour.

Trying to answer a question "what factors determine that some people enjoying themselves make progress and work with devotion while others just count the hours before the weekend?" we came up with a theory consisting of two concepts: motivation and basic psychological needs. Autonomic motivation focuses on behaviours undertaken by the persons themselves and which have a set value assigned by their choice. Controlled motivation, as opposed to the first one, focuses on behaviours undertaken in order to avoid punishment or to gain a reward. Research shows that the autonomic motivation encourages productive thinking and better health, the quality of undertaken task by the student is higher and the student acts with more creativity and engagement (Deci, Ryan, 2008; Stone, Deci \& Ryan, 2009, p. 75-91). In other words, Ryan and Deci (Deci, Ryan, 2000) prove that perseverance and effectiveness is determined by the level of autonomy experienced in action.

The aim of this brief introduction to internal self-regulation is to stress and remind teachers that given optimal conditions, students could meet the set norms and values only when the three universal psychological needs are met as well: the need to belong, the need of autonomy and of competence (Gagne, Deci, 2005; Boekaerst, 2014, p. 2-28). The teacher can and should accompany the student in the process.

The more students' needs for autonomy are met, the more persistent they are in action and the higher the results, they also feel more responsible for achieving better results as well (Deci, Ryan, 2000). They have more satisfaction from their work at the same time. Moreover, the more they are aware of being autonomous the more willing they are for action and the results are corresponding as well (Miserandino, 1996 , p. 88). Therefore a hypothesis is assumed that supporting 
autonomy among students will cause them to increasingly engage in school activities and will enable them to use self-regulation strategy more. According to Deci and Ryan, context determines the type of experience the students have. Optimal learning effects appear when the school environment creates possibilities to develop the awareness of self-competence and autonomy and creates a space for positive interpersonal relations (Deci, Ryan, 1985). Theory presumes that the more the students perceive that the school meets their psychological needs, the higher their engagement (Connell, Wellobortn, 1990).

Dealing with the area of self-regulation of students in a school environment, it is necessary to explain the latter concept. The school environment consists of all institutional, didactical and personal factors that one can find at school. The quality of relations of students with their teachers is an indicator of a better knowledge of their functioning in the school environment; it also provides us with information about the level of their dysfunction (Gryniuk \& Tuszyńska-Bogucka, 2004, p. 127-142). This chapter deals with this relationship between the student and the teacher because teachers having high self-regulation levels are able to teach that to their students.

The question then arises whether the teachers can shape the process of self-regulation in students. What is the opinion in that matter among people that are preparing for the teaching profession?

\section{Methodological aids}

\section{Subjects}

The main scientific problem defined in this article has taken the form of the following question: what is the level of emotional intelligence and self-regulation among a group of adults who are studying to be teachers?

It thus requires a reference for indicators of the independent variables - the level of emotional intelligence and the level of selfregulation as well as indicators of the dependent variable - the declaration of the respondents.

We hypothesised that there is a correlation between teachers' level of self-regulation and their level of emotional intelligence. We wanted to recognise the level of teachers' self-regulation and the level of teachers' emotional intelligence in their own perception. 
To investigate this hypothesis, we ought to identify relevant dimensions of teachers' level of self-regulation: high autonomy support $(\mathrm{HA})$, moderately autonomy supportive (MA), moderately controlling $(\mathrm{MC})$, and highly controlling $(\mathrm{HC})$.

The emotional intelligence indicator is then the sum of all available points for completing the questionnaire INTE (165 points). Among questions, according to the primary assumption based on the emotional intelligence model of Salovey and Mayer (1990), 13 concern perception, evaluation and expression of emotion, 10 concern the regulation of emotion and another 10 concern using them in thinking and acting.

\section{Participants}

The questionnaire was completed by 50 adults who are studying in order to become teachers, however, only 49 were possible to analyse. The group consisted of 50 adults where 40 adults were female, 9 adults were male, which over represents the percentage of female adults, as only $18.4 \%$ of respondents were male.

One person had postgraduate education, there were 3 people with MA degrees and 45 (91.8\%) with a Bachelor's degree.

$24.5 \%$ of people studied human sciences and the same percentage studied IT/Mathematics, while $25 \%$ studied natural sciences (Biology).

Table 1. Structure of the test group (according assumed independent variables)

\begin{tabular}{|c|c|c|c|c|c|c|c|c|c|c|}
\hline & \multicolumn{2}{|c|}{ SEX } & \multicolumn{3}{|c|}{ LEVEL OF EDUCATION } & \multicolumn{4}{|c|}{ PROFILE } & \\
\hline & 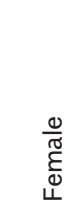 & $\frac{0}{\frac{\pi}{\pi}}$ & 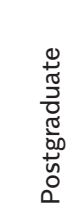 & 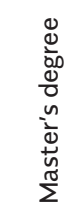 & 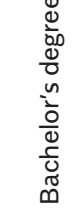 & 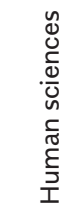 & 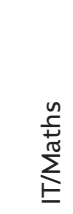 & 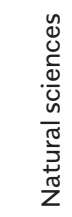 & $\frac{\pi}{4}$ & TOTAL \\
\hline $\mathrm{N}$ & 40 & 9 & 1 & 3 & 45 & 12 & 12 & 25 & 0 & 49 \\
\hline$\%$ & 81.6 & 18.4 & 2 & 6.1 & 91.8 & 24.5 & 24.5 & 51 & 0 & 100 \\
\hline
\end{tabular}




\section{Measures}

The research took place at the University of Bialystok in January 2017. To determine the level of adults' self-regulation, The Problems in Schools Questionnaire (PIS) by Deci, Schwartz, Sheinman, Ryan (1981) were used. Respondents rate the degree of appropriateness of each of the four options (on a seven-point scale) for each of the eight situations. There are a total of 32 ratings. Respondents completed the scale about their own orientation toward motivating students. The questionnaire assesses whether individuals in a position of authority, whose job is, in part, to motivate others, tend to be oriented toward controlling the behaviour of those others versus supporting their autonomy.

Participants were also informed that there are no right or wrong ratings, that people's styles differ and we are simply interested in what you consider appropriate given your own style. Some of the stories ask what you would do as a teacher. Others ask you to respond as if you were giving advice to another teacher or to a parent.

The emotional intelligence level was analysed using Emotional Intelligence Questionnaire (INTE) of N.S. Schutte, J.M. Malouff, L.E. Hall, D.J. Haggerty, J.T. Cooper, Ch.J. Gloden, L. Dornheim in a Polish rendition by Anna Ciechanowicz, Aleksandra Jaworowska and Anna Matczak (2000). INTE consists of 33 descriptive points, of which veracity the participants evaluate on a five-degree Likert scale.

\section{Statistical Power}

In the statistical analysis of the data:

$\rightarrow$ a T-test for independent groups was used to compare averages,

$\rightarrow$ the one-way analysis of variance ANOVA was used to determine whether there are any statistically significant differences between the means of three and four unrelated groups,

$\rightarrow$ the $r$-Pearsons correlation for association between paired samples was also used.

All analyses were done in the SPSS 23.0 programme. The hypotheses were verified at a significance level of 0.05 . 


\section{Results}

The analysis of research was performed using selected data to describe indicators associated with the level of emotional intelligence and selfregulation level among people who are preparing to become teachers.

Assessing opinions of such people, a zero hypothesis was formulated. It is assumed that there is a high level of emotional intelligence and self-regulation among people aspiring to became teachers. It was also assumed that there is a significant statistical difference in the level of emotional intelligence and self-regulation between males and females.

\section{Results in the field of self-regulation}

The analysis of research was made on the basis of selected data that will be used to describe the indicators associated with the level of selfregulation among the adults who are studying to become teachers.

To make a recognition of the adults' perception in the field of their level of self-regulation, a T-test for independent groups was used.

Table 2. The level of respondents' self-regulation

(The PIS questionnaire, the statistic for the group of gender)

\begin{tabular}{|c|c|c|c|c|c|c|c|c|}
\hline \multirow{2}{*}{$\begin{array}{c}\text { THE LEVEL } \\
\text { OF SELF-REGULATION }\end{array}$} & \multicolumn{2}{|c|}{ WOMEN } & \multicolumn{2}{|c|}{ MEN } & \multicolumn{2}{|c|}{ TOTAL } & \multicolumn{2}{|c|}{$\begin{array}{c}\text { COMPARISONS } \\
\text { BETWEEN GROUPS } \\
\text { WOMEN / MEN }\end{array}$} \\
\hline & $\mathrm{N}=40$ & $\%$ & $N=9$ & $\%$ & $\mathrm{~N}=49$ & $\&$ & $\mathrm{t}$ & p.i. \\
\hline High level of control & 1 & 2.5 & 0 & 0 & 1 & 2.04 & .282 & n.i. \\
\hline Average level of control & 31 & 77.5 & 7 & 77.8 & 38 & 77.5 & .018 & n.i \\
\hline $\begin{array}{l}\text { High level } \\
\text { of autonomous }\end{array}$ & 25 & 62.5 & 9 & 100.0 & 34 & 69.3 & 1.282 & 0.01 \\
\hline $\begin{array}{l}\text { Average level } \\
\text { of autonomous }\end{array}$ & 30 & 75.0 & 3 & 33.3 & 33 & 67.3 & .618 & n.i. \\
\hline
\end{tabular}

Source: own research

Data shows that $77.5 \%$ of women describe themselves as an average level of control self-regulation when $100 \%$ of men described their orientation as high level of autonomous self-regulation.

Applying the results to the theoretical considerations means that while men refer to regulation by the self, in contrast, woman refer to 
regulation that occurs without self-endorsement. This reflects the recognition that, when autonomously functioning, men are more deeply engaged and productive, generating human capital and wellness (Gough, McGregor, 2007).

The following table presents the means in different groups based on gender that confirms these trends.

Table 3. The means of level of respondents' self-regulation

(The PIS questionnaire, the statistic for the group of gender)

\begin{tabular}{|c|c|c|c|c|c|c|}
\hline \multirow{2}{*}{$\begin{array}{c}\text { THE LEVEL } \\
\text { OF SELF-REGULATION }\end{array}$} & \multirow{2}{*}{ GENDER } & \multirow{2}{*}{ THE MEAN } & \multirow{2}{*}{$\begin{array}{l}\text { STANDARD } \\
\text { DEVIATION }\end{array}$} & \multicolumn{3}{|c|}{ COMPARISONS BETWEEN GROUPS } \\
\hline & & & & $\mathrm{t}$ & df & p.i. \\
\hline \multirow{2}{*}{ High level of control } & Women & 1.9250 & .34991 & \multirow[t]{2}{*}{.282} & \multirow[t]{2}{*}{47} & \multirow[t]{2}{*}{.907} \\
\hline & Men & 1.8889 & .33333 & & & \\
\hline \multirow{2}{*}{$\begin{array}{l}\text { Average level } \\
\text { of control }\end{array}$} & Women & 2.2250 & .42290 & \multirow[t]{2}{*}{.018} & \multirow[t]{2}{*}{47} & \multirow[t]{2}{*}{.972} \\
\hline & Men & 2.2222 & .44096 & & & \\
\hline \multirow{2}{*}{$\begin{array}{l}\text { High level } \\
\text { of autonomy }\end{array}$} & Women & 2.6250 & .49029 & \multirow[t]{2}{*}{1.607} & \multirow[t]{2}{*}{47} & \multirow[t]{2}{*}{.001} \\
\hline & Men & 2.3333 & .50000 & & & \\
\hline \multirow{2}{*}{$\begin{array}{l}\text { Average level } \\
\text { of autonomy }\end{array}$} & Women & 2.2000 & .46410 & \multirow[t]{2}{*}{1.282} & \multirow[t]{2}{*}{47} & \multirow[t]{2}{*}{.618} \\
\hline & Men & 2.0000 & .00000 & & & \\
\hline
\end{tabular}

Source: own research

Data presented in the Table 3 shows statistically significant results in the area of high level of self-regulation $\left(t_{(47)}=1.607 ; p<0.05\right)$. It means that the field of autonomous self-regulation differentiates in a statistically significant way the data which focus on the division between genders. The men have much higher level of autonomy self-regulation than women. In other areas the result are not statistically significant. The next table shows data related to the level of education. 
Table 4. The level of respondents' self-regulation

(The PIS questionnaire, the statistic for the level of education)

\begin{tabular}{l|c|c|c|c|c|c|c|c}
\multirow{2}{*}{$\begin{array}{c}\text { THE LEVEL } \\
\text { OF SELF-REGULATION }\end{array}$} & \multicolumn{2}{c|}{ MASTER'S DEGRE } & \multicolumn{2}{c}{ BACHELOR'S DEGREE } & \multicolumn{2}{c}{ TOTAL } & \multicolumn{2}{c}{$\begin{array}{c}\text { COMPARISONS } \\
\text { BETWEEN GROUPS }\end{array}$} \\
\cline { 2 - 9 } & $\mathrm{N}=3$ & $\%$ & $\mathrm{~N}=45$ & $\%$ & $\mathrm{~N}=49$ & $\%$ & $\mathrm{t}$ & p.i. \\
\hline $\begin{array}{l}\text { High level } \\
\text { of control }\end{array}$ & 0 & 0 & 1 & 2.2 & 1 & 2.04 & -1.297 & n.i. \\
\hline $\begin{array}{l}\text { Average level } \\
\text { of control }\end{array}$ & 0 & 0 & 35 & 77.8 & 35 & 71.4 & -.906 & 0.01 \\
\hline $\begin{array}{l}\text { High level } \\
\text { of autonomy }\end{array}$ & 3 & 100.0 & 24 & 53.3 & 27 & 55.1 & 1.586 & 0.00 \\
\hline $\begin{array}{l}\text { Average level } \\
\text { of autonomy }\end{array}$ & 2 & 66.7 & 37 & 82.2 & 39 & 79.5 & -2.160 & n.i.
\end{tabular}

Source: own research

Results in Table 4 show that $100 \%$ of people with the M. A. degree declare themselves as a high level of autonomous self-regulation ( $t(49)$ $=1.586 ; p<0.05), 77.8 \%$ participants with a Bachelor's degree declare an average level of control self-regulation $\left(t_{(49)}=-.906 ; p<0.05\right)$. The results are confirmed in the next table.

Table 5. The means of level of respondents' self-regulation

(The PIS questionnaire, the statistic for the level of education)

\begin{tabular}{|c|c|c|c|c|c|c|}
\hline \multirow{2}{*}{$\begin{array}{c}\text { THE LEVEL } \\
\text { OF SELF- } \\
\text { REGULATION }\end{array}$} & \multirow[b]{2}{*}{ LEVEL OF EDUCATION } & \multirow[b]{2}{*}{ THE MEAN } & \multirow{2}{*}{$\begin{array}{l}\text { STANDARD } \\
\text { DEVIATION }\end{array}$} & \multicolumn{3}{|c|}{ COMPARISONS BETWEEN GROUPS } \\
\hline & & & & $\mathrm{t}$ & df & p.i. \\
\hline \multirow{2}{*}{$\begin{array}{l}\text { High level } \\
\text { of control }\end{array}$} & Master's degree & 1.6667 &, 57735 & \multirow[t]{2}{*}{-1.297} & \multirow[t]{2}{*}{46} & \multirow[t]{2}{*}{.103} \\
\hline & Bachelor's degree & 1.9333 & .33029 & & & \\
\hline \multirow{2}{*}{$\begin{array}{l}\text { Average level } \\
\text { of control }\end{array}$} & Master's degree & 2.000 & .00000 & \multirow[t]{2}{*}{-.906} & \multirow[t]{2}{*}{46} & \multirow[t]{2}{*}{.015} \\
\hline & Bachelor's degree & 2.2222 & .42044 & & & \\
\hline \multirow{2}{*}{$\begin{array}{l}\text { High level } \\
\text { of autonomy }\end{array}$} & Master's degree & 3.0000 & .00000 & \multirow[t]{2}{*}{1.586} & \multirow[t]{2}{*}{46} & \multirow[t]{2}{*}{.000} \\
\hline & Bachelor's degree & 2.5333 & .50452 & & & \\
\hline \multirow{2}{*}{$\begin{array}{l}\text { Average level } \\
\text { of autonomy }\end{array}$} & Master's degree & 1.6667 & .57735 & \multirow[t]{2}{*}{-2.160} & \multirow[t]{2}{*}{46} & \multirow[t]{2}{*}{.307} \\
\hline & Bachelor's degree & 2.5333 & .38665 & & & \\
\hline
\end{tabular}


It turns out that the results divide the group as to their education level. Participants with a Master's degree declare themselves as a high level of autonomous self-regulation $\left(t_{(46)}=1.586 ; p<0.05\right)$, while with Bachelor's degree declare an average level of control self-regulation $\left(t_{(49)}=-.906 ; p<0.05\right)$. The next table shows self-regulation in relation as to the type of education.

Table 6. The level of respondents' self-regulation

(The PIS questionnaire, the statistic for the level of studies' profile)

\begin{tabular}{|c|c|c|c|c|c|c|c|c|c|c|}
\hline \multirow[t]{2}{*}{$\begin{array}{c}\text { THE LEVEL OF } \\
\text { SELF-REGULATION }\end{array}$} & \multicolumn{2}{|c|}{$\begin{array}{l}\text { HUMAN } \\
\text { SCIENCES }\end{array}$} & \multicolumn{2}{|c|}{$\begin{array}{c}\text { MATHEMATICS } \\
\text { IT }\end{array}$} & \multicolumn{2}{|c|}{$\begin{array}{l}\text { NATURAL } \\
\text { SCIENCES } \\
\text { (BIOLOGY) }\end{array}$} & \multicolumn{2}{|c|}{ TOTAL } & \multicolumn{2}{|c|}{$\begin{array}{c}\text { COMPARISONS } \\
\text { BETWEEN } \\
\text { GROUPS }\end{array}$} \\
\hline & $\mathrm{N}=12$ & $\%$ & $\mathrm{~N}=12$ & $\%$ & $\mathrm{~N}=25$ & $\%$ & $\mathrm{~N}=49$ & $\%$ & $\mathrm{~F}$ & p.i. \\
\hline $\begin{array}{l}\text { High level } \\
\text { of control }\end{array}$ & 0 & 0 & 0 & 0 & 1 & 4.0 & 1 & 2.04 & .540 & n.i. \\
\hline $\begin{array}{l}\text { Average level } \\
\text { of control }\end{array}$ & 9 & 75.0 & 10 & 83.3 & 19 & 76.0 & 19 & 38.7 & .146 & n.i. \\
\hline $\begin{array}{l}\text { High level } \\
\text { of autonomy }\end{array}$ & 10 & 83.3 & 6 & 50.0 & 12 & 48.0 & 16 & 32.6 & 2.306 & n.i. \\
\hline $\begin{array}{l}\text { Average level } \\
\text { of autonomy }\end{array}$ & 11 & 91.7 & 9 & 75.0 & 19 & 76.0 & 20 & 40.8 & .451 & n.i. \\
\hline
\end{tabular}

Source: own research

The data of the means of level of respondents' self-regulation divided by the level of studies' profile are not statistically significant. They show that $91.7 \%$ participants with education in human sciences declare an average level of self-regulation control, $83.3 \%$ participants with IT/Mathematics type of education declare an average level of self-regulation control, while people educated in the area of natural sciences (Biology) declare both average level of self-regulation control and average level of autonomous self-regulation.

\section{Results in the field of emotional intelligence}

The significance of emotional intelligence cannot be overestimated in the present time. Although, the family is where an individual learns to socialise their emotions (see Oatley, Jenkins 2005, p. 81-82), more and more often it is argued that emotional education should take place at 
school by properly prepared, competent personnel (compare Salovey, Sluyter 1999, p. 253). It is worth analysing, in this context, whether the teacher candidates possess high level of emotional competence which would translate into building proper relationships with the students and helping them to develop emotional intelligence in turn.

Table 7. The level of emotional intelligence

(The INTE questionnaire, the statistic for the level of gender)

\begin{tabular}{|c|c|c|c|c|c|c|c|c|}
\hline \multirow{2}{*}{$\begin{array}{l}\text { THE LEVEL OF } \\
\text { EMOTIONAL } \\
\text { INTELLIGENCE }\end{array}$} & \multicolumn{2}{|c|}{ WOMEN } & \multicolumn{2}{|c|}{ MEN } & \multicolumn{2}{|c|}{ TOTAL } & \multicolumn{2}{|c|}{$\begin{array}{c}\text { COMPARISONS } \\
\text { BETWEEN GROUPS } \\
\text { WOMEN / MEN }\end{array}$} \\
\hline & $\mathrm{N}=40$ & $\%$ & $N=9$ & $\%$ & $\mathrm{~N}=49$ & $\%$ & Sig. & p.i. \\
\hline High level & 6 & 15 & 1 & 11.1 & 7 & 14.3 & & \\
\hline Average level & 28 & 70 & 6 & 66.7 & 34 & 69.4 & .595 & n.i. \\
\hline Low level & 6 & 15 & 2 & 22.2 & 8 & 16.3 & & \\
\hline
\end{tabular}

Source: own research

The data points out that women present higher level of emotional intelligence $(3.9 \%$ more). It is in accordance with a theory of lateralisation processes in human brain, which claims that men should be characterised by a lower level of emotional intelligence. The lateralisation of the brain in males is stronger, moreover, the left hemisphere is dominant (which is responsible for verbalising emotions) where emotion recognition is done chiefly by the right hemisphere. Women, in turn, with their brain less lateralised and with no significant dominance of either hemisphere should have better awareness of their subjective and somatic conditions (Maruszewski, Ścigała 1998). It should be noted that the low level of emotional intelligence is higher among men what seems to confirm the aforementioned theory. 
Table 8. The level of emotional intelligence

(The INTE questionnaire, the statistic for the level of education)

\begin{tabular}{|c|c|c|c|c|c|c|c|c|c|c|}
\hline \multirow{2}{*}{$\begin{array}{c}\text { THE LEVEL } \\
\text { OF EMOTIONAL } \\
\text { INTELLIGENCE }\end{array}$} & \multicolumn{2}{|c|}{$\begin{array}{l}\text { POSTGRADUATE } \\
\text { STUDIES }\end{array}$} & \multicolumn{2}{|c|}{$\begin{array}{c}\text { MASTER'S } \\
\text { DEGREE }\end{array}$} & \multicolumn{2}{|c|}{$\begin{array}{l}\text { BACHELOR'S } \\
\text { DEGREE }\end{array}$} & \multicolumn{2}{|c|}{ TOTAL } & \multicolumn{2}{|c|}{$\begin{array}{l}\text { COMPARISONS } \\
\text { BETWEEN } \\
\text { GROUPS }\end{array}$} \\
\hline & $N=1$ & $\%$ & $N=3$ & $\%$ & $N=45$ & $\%$ & $N=49$ & $\%$ & Sig. & p.i. \\
\hline High level & 0 & 0 & 1 & 33.3 & 6 & 13.3 & 7 & 14.3 & \multirow{3}{*}{.211} & \multirow{3}{*}{ n.i. } \\
\hline Average level & 0 & 0 & 1 & 33.3 & 33 & 73.3 & 34 & 69.4 & & \\
\hline Low level & 1 & 100 & 1 & 33.3 & 6 & 13.3 & 8 & 16.3 & & \\
\hline
\end{tabular}

Source: own research

The results prove that a high level of emotional intelligence is displayed by the teacher candidates with a Bachelor's degree (13.3\%) and with a Master's degree (33, 3\%). Surprisingly, postgraduate participants display low levels of emotional intelligence. Higher levels of academic education do not automatically translate, then, into high competence in the emotional area.

Table 9. The level of emotional intelligence

(The INTE questionnaire, the statistic for the levels of studies' profile)

\begin{tabular}{|c|c|c|c|c|c|c|c|c|c|c|}
\hline \multirow{2}{*}{$\begin{array}{c}\text { THE LEVEL } \\
\text { OF EMOTIONAL } \\
\text { INTELLIGENCE }\end{array}$} & \multicolumn{2}{|c|}{$\begin{array}{l}\text { HUMAN } \\
\text { SCIENCES }\end{array}$} & \multicolumn{2}{|c|}{$\begin{array}{c}\text { MATHEMATICS } \\
\text { AND IT }\end{array}$} & \multicolumn{2}{|c|}{$\begin{array}{l}\text { NATURAL } \\
\text { SCIENCES } \\
\text { (BIOLOGY) }\end{array}$} & \multicolumn{2}{|c|}{ TOTAL } & \multicolumn{2}{|c|}{$\begin{array}{c}\text { COMPARISONS } \\
\text { BETWEEN } \\
\text { GROUPS }\end{array}$} \\
\hline & $\mathrm{N}=12$ & $\%$ & $N=12$ & $\%$ & $N=25$ & $\%$ & $\mathrm{~N}=49$ & $\%$ & $\mathrm{~F}$ & p.i. \\
\hline High level & 1 & 8.3 & 1 & 8.3 & 5 & 20.0 & 7 & 14.3 & \multirow{3}{*}{.578} & \multirow{3}{*}{ n.i. } \\
\hline Average level & 8 & 66.7 & 10 & 83.3 & 16 & 64.0 & 34 & 69.4 & & \\
\hline Low level & 3 & 25.0 & 1 & 8.3 & 4 & 16.0 & 8 & 16.3 & & \\
\hline
\end{tabular}

Source: own research

Looking at the empirical data it is evident that the level of emotional intelligence of the future teachers is affected by the variable of the education profile (Table 9). Natural sciences (Biology) dominate over representatives of other profiles $(20 \%$ of that group have high level of 
emotional competence, while only $8.3 \%$ from other profiles i.e. human sciences and Mathematics/IT).

\section{Correlation between the level of self-regulation and the level of emotional intelligence}

To show full results of the undertaken research there must also be data gathered by correlation between variables formulated in the article. The following table shows correlation between the level of self-regulation and the level of emotional intelligence.

Table 10. Pearson's correlation between different dimensions: the level of self-regulation and the level of emotional intelligence

\begin{tabular}{|c|c|c|c|c|c|}
\hline & $\begin{array}{l}\text { HIGH LEVEL } \\
\text { OF CONTROL }\end{array}$ & $\begin{array}{l}\text { AVERAGE LEVEL } \\
\text { OF CONTROL }\end{array}$ & $\begin{array}{l}\text { HIGH LEVEL } \\
\text { OF AUTONOMY }\end{array}$ & $\begin{array}{l}\text { AVERAGE LEVEL } \\
\text { OF AUTONOMY }\end{array}$ & $\begin{array}{c}\text { THE LEVEL } \\
\text { OF EMOTIONAL } \\
\text { INTELLIGENCE }\end{array}$ \\
\hline $\begin{array}{l}\text { High level } \\
\text { of control }\end{array}$ & - & $.129 ;$ n.i. & $.035 ;$ n.i. & $.235 ;$ n.i. & $.100 ;$ n.i. \\
\hline $\begin{array}{l}\text { Average level } \\
\text { of control }\end{array}$ & .129; n.i. & - & $.071 ;$ n.i. & .140; n.i. & -.069; n.i. \\
\hline $\begin{array}{l}\text { High level } \\
\text { of autonomy }\end{array}$ & 0.35; n.i. & $.071 ;$ n.i. & - & $.238 ;$ n.i. & $.192 ;$ n.i. \\
\hline $\begin{array}{l}\text { Average level } \\
\text { of autonomy }\end{array}$ & $.235 ;$ n.i. & $.140 ;$ n.i. & $.238 ;$ n.i. & - & $.102 ;$ n.i. \\
\hline $\begin{array}{l}\text { The level } \\
\text { of emotional } \\
\text { intelligence }\end{array}$ & $.100 ;$ n.i. & -.069; n.i. & $.192 ;$ n.i. & $.102 ;$ n.i. & - \\
\hline
\end{tabular}

Source: own research

In Table 10 one can see a correlation between the two tests used in the research. We were interested in whether there is a connection between the level of self-regulation and the level of emotional intelligence among adult candidates for the teaching profession. However, the analysis shows no statistically significant data. There is, however, an observation that the higher the level of emotional intelligence among the candidates, the lower the level of self-regulation control. Linear regression analysis and Paired Samples Correlation confirmed this interdependence. 
Detailed analysis using partial correlation aimed to identify controlled variables which could affect the level of self-regulation and the level of emotional intelligence. It turns out, however, that sex, level of education and profile of education are of no significance. The research should be continued, though, as the data show that given the bigger group with the level and profile of education among people declaring high level of autonomous self-regulation could be correlated with the level of emotional intelligence. The following table presents averages of the analysed variables.

Table 11. The means of correlation between the level of self-

regulation and the level of emotional intelligence

\begin{tabular}{l|c|c|c}
\multicolumn{1}{c|}{ THE VARIABLES } & MEAN & STD. DEVIATION & N \\
\hline High level of control & 1.9184 & .34380 & 49 \\
\hline $\begin{array}{l}\text { Average level } \\
\text { of control }\end{array}$ & 2.2245 & .42157 & 49 \\
\hline $\begin{array}{l}\text { High level } \\
\text { of autonomy }\end{array}$ & 2.5714 & .50000 & 49 \\
\hline $\begin{array}{l}\text { Average level } \\
\text { of autonomy }\end{array}$ & 2.1633 & .42558 & 49 \\
\hline $\begin{array}{l}\text { The level of emotional } \\
\text { inteligence }\end{array}$ & 1.9796 & .55864 & 49
\end{tabular}

Source: own research

People from the test group most often declare high level of autonomous self-regulation.

\section{Concluding remarks and practical implications}

Teachers of young children play a vital role in helping children to develop foundational self-regulation skills. When teachers deliberately teach self-regulation as a part of everyday experiences, they help children to become actively engaged learners, laying the foundation for years of future success in school and life. But it will only be possible when teachers could have a high level of their own self-regulation sills. In light of theoretical foundations, the results of undertaken research are particularly interesting due to their practical implications. The 
results of our research which constitute the first part of a project demonstrated that:

$\rightarrow$ most of the women $(77.5 \%)$ describe their orientation as an average level of control self-regulation

$\rightarrow$ all of the men describe their orientation as a high level of autonomous self-regulation. The men have a much higher level of autonomous self-regulation than the women,

$\rightarrow 100 \%$ participants with high education declare their orientation as high level of autonomous self-regulation, though $77.8 \%$ participants with a Bachelor's degree declare having an average level of self-regulation control,

$\rightarrow$ most of the participants $(91.7 \%)$ with education in human sciences declare an average level of their own autonomous self-regulation, $83.3 \%$ participants with the Mathematics/IT education declare an average level of self-regulation control,

$\rightarrow$ women present higher level of emotional intelligence (15\%),

$\rightarrow 33 \%$ participants with a Master's degree declare high level of emotional intelligence, while only $13.3 \%$ of people with a Bachelor's degree reach the high level (no one of postgraduate education has reached the high level),

$\rightarrow$ high level of emotional intelligence was displayed in the greatest proportion $(20 \%)$ by participants with the background in natural sciences (Biology)

$\rightarrow$ the higher the level of emotional intelligence among the teachers preparing for their professional role, the lower the level of selfregulation control.

Theoretical consideration shows that at the level of personality functioning, people can be distinguished by individual differences in their tendencies toward autonomous functioning across specific domains and behaviours. The men, who have a Master's degree in human sciences will organise their behavioural regulation by taking reflective interest in possibilities and choices. They are more flexible and creative. Women with a Bachelor's degree in natural sciences, those who are control oriented, tend to regulate behaviour by focusing on perceived or ambient social contingencies, such as salient rewards and punishments, the controlling contexts yield negative effects on wellness. 
As for the adults who are studying to be a teacher, the problem may be in teachers' attitude or lack of knowledge as to how to support students' self-regulation effectively. However, it is clear that the teacher plays a crucial role in predicting teachers' promotion of self-regulation in their classrooms. Helping teachers to develop an effective way of integrating self-regulation into their teaching would have to be started by creating awareness of both ways to foster self-regulation. Moreover, a lot of studies showed that the high level of teachers' self-regulation can influence and support high level of students' self-regulation.

The presented study is subjected to some limitations. The small sample size does not allow for generalisation to adults at large. Respondents who were willing to participate were probably already motivated and interested in the topic. Thus, the general picture on adults' perception of self-regulation might be less promising.

A second limitation is the assessment of teachers' perception by means of self-report. Adults who are learning to be teachers might want to produce a more positive picture so that their self-report could be subject to social desirability. In contrast, the SDT-based scales referred to as Perceived Autonomy Support: The Climate Questionnaires were designed to be completed by people being motivated - that is, by the students about their teachers' autonomy support versus control orientation.

As a conclusion to these considerations, it should be stated that teachers might appreciate the idea of self-regulation, but if they do not feel capable of managing more student autonomy or if they have a control level of their own self-regulation, they won't integrate it into their teaching. As Kramarski and Revach (2009) concluded, based on teacher training that they had conducted to help teachers' integrating self-regulation in their classrooms, teachers' self-efficacy might be related to teachers' professional development and might cause teachers not to implement what they had learned during training.

This research should be continued, though, as the data show that given the bigger group, the level and profile of education among people declaring high level of autonomous self-regulation could be correlated with the level of emotional intelligence. The results of this study can produce many new questions. Why teachers do not instruct self-regulation and where researchers and educators would have to 
start in order to enable teachers to promote self-regulation effectively. When looking at teachers' ideas of the enhancement of self-regulation among their students, it becomes clear that the area of direct strategy instruction has somehow got lost in teachers' behaviour. 


\section{References}

$\rightarrow$ Apter, M. J. (Ed.) (2001). Motivational styles in everyday life: A guide to Reversal Theory. Washington, D.C.: American Psychological Association.

$\rightarrow$ Apter, M. J. (2007). Reversal Theory: The dynamics of motivation, emotion and personality. Oxford: Oneworld Publications

$\rightarrow$ Bar-On, R. (1997). The Emotional Quotient Inventory (EQ-i): Technical manual. Toronto, Canada: Multi-Health Systems, Inc.

$\rightarrow$ Bar-On, R. (2001). Emotional intelligence and self-actualization. In J. Ciarrochi, J.P. Forgas \& J. D. Mayer (Eds.), Emotional intelligence in everyday life: A scientific inquiry (pp. 82-97). Philadelphia: PA, Psychology Press.

$\rightarrow$ Baumeister, R. F. \& Vohs, K. D. (Eds.) (2004). Handbook of self-regulation: Research, theory, and applications. New York: Guildford Press.

$\rightarrow$ Baummeister, R.F. \& Vohs K. D. (2007). Self-regulation, ego depletion, and motivation. Social and Personality Psychology Compass, 1(1), 115-128.

$\rightarrow$ Boekaerst, M. (2014). Motivation to learn. International Academy of Education, http://unesdoc.unesco.org/images/0012/001280/128056e.pdf

$\rightarrow$ Brammer, L. M. (1984). Kontakty służq̨ce pomaganiu. Warszawa: PTP.

$\rightarrow$ Ciarrochi, J. V., Chan A.Y. C. \& Caputi, P. (2000). A critical evaluation of the emotional intelligence construct. Personality and Individual Differences, 28, 539-561.

$\rightarrow$ Connell, J. P. \& Wellborn, J. G. (1990). Competence, autonomy and relatedness: A motivational analysis of self-system processes. In M. R. Gunnar \& L. A. Sroufe (Eds.), Self processes in development: The Minnesota Symposium on Child Psychology. Hillsdale (pp. 43-77). Hillsdale, NJ: Erlbaum.

$\rightarrow$ Cooper, R. K. \& Sawaf, A. (2000). EQ. Inteligencja emocjonalna w organizacji i zarzq̨dzaniu. Warszawa: Studio Emka.

$\rightarrow$ Day, A. L. \& Carroll, S. A. (2004). Using an ability-based measure of emotional intelligence to predict individual performance, group performance and group citizenship behaviors. Personality and Individual Differences, 36, 1443-1458. 
$\rightarrow$ Deci, E. L. \& Ryan, R. M. (1985). Intrinsic motivation and self-determination in human behavior: Perspective in social psychology. New York, NY: Springer Science \& Business Media.

$\rightarrow$ Deci, E., Ryan, R. M. (1996). Elements within the competitive situation that affect intrinsic motivation. Personality and Social Psychology Bulletin, 22, 24 33.

$\rightarrow$ Deci, E. L. \& Ryan, R.M. (2000). What is the self in self-directed learning? Findings from recent motivational research. In G. Straka (Ed.), Conceptions of self-directedlLearning: Theoretical and conceptual considerations (pp. 75-92). LOS. Münster: Waxmann.

$\rightarrow$ Deci, E.L. \& Ryan, R. M. (2008). Self-determination theory: A macrotheory of human motivation, development, and health. Canadian Psychology, 49, 225232.

$\rightarrow$ Deci, E. L., Schwartz, A. J., Sheinman, L. \& Ryan, R. M. (1981). An instrument to assess adults' orientations toward control versus autonomy with children: Reflections on intrinsic motivation and perceived competence. Journal of Educational Psychology, 73, 642-650.

$\rightarrow$ Dembo, M.H. (2001). Learning to teach is not enough: Future teachers also need to learn how to learn. Teacher Education Quarterly, 28(4), 23-35.

$\rightarrow$ Duckworth, A. L. \& Seligman, M. E. P. (2005). Self-discipline outdoes IQ in predicting academic performance of adolescents. Psychological Science, 16(12), 939-944.

$\rightarrow$ Gagne, M. \& Deci, E. L. (2005). Self-determination theory and work motivation. Journal of Organizational Behavior, 26, 331-362.

$\rightarrow$ Galinsky, E. (2010). Mind in the making: The seven essential life skills every child needs. New York, NY: Harper Collins.

$\rightarrow$ Gaś, Z. B. (2004). Badanie zapotrzebowania na profilaktykę w szkole. Poradnik dla szkolnych liderów profilaktyki. Lublin: Wydawnictwo UMCS.

$\rightarrow$ Gaś, Z. B. (2006). Profilaktyka w szkole. Warszawa: WSiP.

$\rightarrow$ Goleman, D. (1997). Inteligencja emocjonalna. Poznań: Media Rodzina.

$\rightarrow$ Goleman, D. (1999). Inteligencja emocjonalna w praktyce. Poznań: Media Rodzina.

$\rightarrow$ Gough, I. \& McGregor, A. J. (Eds.) (2007). Well-being in developing countries: New approaches and research strategies. Cambridge: Cambridge University Press.

$\rightarrow$ Gryniuk, I. \& Tuszyńska-Bogucka, W. (2004). Psychorysunek tematyczny jako narzędzie diagnozy sytuacji szkolnej i rodzinnej ucznia. In Z. B. Gaś (Ed.), Badanie zapotrzebowania na profilaktykę w szkole. Poradnik dla szkolnych liderów profilaktyki. Lublin: Wydawnictwo UMCS. 
$\rightarrow$ Iłendo-Milewska, A. (2009). Dysfunkcjonalność uczniów gimnazjum. Warszawa: Difin.

$\rightarrow$ Janowska, J. (2000). Samoaktualizacja w teorii i praktyce kształcenia nauczycieli. Lublin: Wydawnictwo UMCS.

$\rightarrow$ Jaworowska, A. \& Matczak, A. (2001). Kwestionariusz inteligencji emocjonalnej INTE. N. S. Schutte, J. M. Malouffa, L. E. Hall, D. J. Haggerty'ego, J. T. Cooper C. J. Goldena, L. Dornheim. Warszawa: Pracownia Testów Psychologicznych Polskiego Towarzystwa Psychologicznego.

$\rightarrow$ Kozioł, E. (1994). Rola zawodowa wychowawcy klasy w świadomości nauczycieli szkół podstawowych. Zielona Góra: Wydawnictwo Wyższej Szkoły Pedagogicznej.

$\rightarrow$ Kramarski, B., Michalsky, T. (2009). Investigating preservice teachers' professional growth in self-regulated learning environments. Journal of Educational Psychology, 101 (1), 161-175.

$\rightarrow$ Kuchcińska, M. (1997). Od edukacji dyrektywnej do emancypacyjnej. Dylematy w edukacji za pośrednictwem zadań. Bydgoszcz: Wydawnictwo Wyższej Szkoły Pedagogicznej.

$\rightarrow$ Maruszewski, T. \& Ścigała, E. (1998). Emocje-aleksytymia - poznanie. Poznań: Wydawnictwo Fundacji Humaniora.

$\rightarrow$ Mayer, J.D., Salovey, P., Caruso, D. R. \& Sitarenios, G. (2003). Measuring emotional intelligence with the MSCEIT V2.0. Emotion, 3(1), 97-105.

$\rightarrow$ Mayer, J. D. (2001). A field guide to emotional intelligence. In J. Ciarrochi, J. P. Forgas \& J. D. Mayer (Eds.), Emotional Intelligence and Everyday Life (pp. 3-26). New York: Psychology Press.

$\rightarrow$ McCluskey, C. P., Bynum T. S. \& Patchin J. W. (2004). Reducing chronic absenteeism: An assessment of an early truancy initiative. Crime \& Delinquency, 50, 2, 214-234.

$\rightarrow$ Miserandino, M. (1996). Children who do well in school: Individual differences in perceived competence and autonomy in above average children. Journal of Educational Psychology, 88, 203-214.

$\rightarrow$ Porzak, R. (1994). Wychowanie jako proces tworzenia warunków do rozwoju. In Z. B. Gaś (Ed.), Wspomaganie rozwoju dziecka. Lublin: Pracownia Wydawnicza Fundacji "Masz Szansę".

$\rightarrow$ Perry, N. E., Hutchinson, L. \& Thauberger, C. (2008). Talking about teaching self-regulated learning: scaffolding student teachers' development and use of practices that promote self-regulated learning, International Journal of Educational Research, 47 (2), 97-108. 
$\rightarrow$ Randi, J. (2004). Teachers as self-regulated learners. Teacher College Record, 106(9), 1825-1853.

$\rightarrow$ Roeser, R. W., Eccles, J. S. \& Sameroff A. J. (1998). Academic and emotional functioning in early adolescence: Longitudinal relations, patterns, and prediction by experience in middle school. Development and Psychopathology, 10, 321-352.

$\rightarrow$ Rogers, C. (2002). Sposób bycia. Poznań: Rebis.

$\rightarrow$ Rokeach, M. (1973). The nature of human values: Individual and societal. New York: The Free Press.

$\rightarrow$ Rosenberg, M. (1965). Society and the adolescent self-image. Princeton, NJ: Princeton. University Press.

$\rightarrow$ Salovey, P. \& Sluyter, D. J. (1999). Rozwój emocjonalny a inteligencja emocjonalna. Poznań: Dom Wydawniczy Rebis.

$\rightarrow$ Salovey, P. \& Mayer, J. D. (1990). Emotional intelligence. Imagination, Cognition, and Personality, 9, 185-211.

$\rightarrow$ Szorc, K. (2014). Inteligencja emocjonalna nauczycieli gimnazjów. Kraków: Impuls.

$\rightarrow$ Schunk, D. H. (2005). Commentary on self-regulation in school contexts. Learning and Instruction, 15, 173-177.

$\rightarrow$ Stone, D. N., Deci, E. L. \& Ryan R. M. (2009). Beyond talk: Creating autonomous motivation through self-determination theory. Journal of General Management, 34, 75-91.

$\rightarrow$ Zimmerman, B. J. (1989). Models of self-regulated learning and academic achievement. In b. J. Zimmerman \& D. H. Schunk (Eds.), Self-regulated learning and academic achievement: Theory, research and practice. (pp. 1-25). New York: Springer-Verlag.

$\rightarrow$ Zimmerman, B. J. \& Schunk, D. H. (Eds.) (1989). Self-regulated learning and academic achievement: Theory, research and practice. New York: SpringerVerlag. 


\section{Biographical notes:}

Katarzyna Szorc, PhD in pedagogy, assistant professor in the Faculty of Pedagogy and Psychology of University in Białystok. She deals with the issues of teachers' emotional intelligence. The author of Inteligencja emocjonalna nauczycieli gimnazjów, Kraków, 2013. Author and coauthor of numerous scientific and methodological articles in the field of teachers' education and their competencies. The member of the Polish Educational Research Association, assistant editor of the Journal Parrhesia. Pedagogues Forum at the Committee on Pedagogical Sciences of PAN (National Academy of Sciences).

Agnieszka Iłendo-Milewska, PhD in psychology, assistant professor, deputy head of the Department of Psychology of Private University in Białystok. Director of the Private Primary School. She deals with the issues of the quality of relations between national minority groups and self-regulation among students. The author of the book 'Dysfunctionality of junior high school pupils', Warsaw, 2009 and 'School environment in the student's experience: trends of change' Cracow, 2016. Author and co-author of numerous scientific and methodological articles in the field of social psychology and educational psychology. 



\title{
Teacher team's maturity as the basis for a learning school
}

\author{
Bożena Tołwińska
}

University of Białystok

\section{Abstract}

In this chapter I assume that only teacher teams that have reached the maturity phase can introduce changes in a subjective way, changes which transform the school culture positively and make it a learning organisation through expansive learning (Engeström \& Sannino, 2010). Both the teachers involved in the teaching process and the managerial staff need to be prepared for this process. The aim of this chapter is to present a fragment of data from a pilot study concerning teachers' functioning from the principals' perspective. This research was carried out in 2015 with the method of questionnaire-based diagnostic poll. The questionnaire was distributed among the principals of 30 schools of different levels and locations (a village, a town, and a city), with different work experience and different experiences in the managerial position. The analysis is quantitative, and the data are interpreted from the perspective of the learning organisation model. The data demonstrate that many norms of behaviour that are common in teachers disprove their maturity. Although the concept of a learning organisation is present in publications, there is still a lot to do in practice. Having said that, we can see examples of staff who, from the perspective of principals, have the characteristics of mature teams and who can make an environment conducive to learning together.

\section{Keywords:}

school as a learning organisation

teacher team's maturity

teacher-principal relations

relations between teachers 


\section{Introduction}

The developing information society implies the need to cope with the dynamics of changes in all areas of life. The development of contemporary organisations in accordance with the learning organisation model is the response to that. It is a challenge for educational institutions to display the characteristics of learning organisations too. In many publications, M. Fullan expresses his belief that the quality of school work can be raised thanks to teachers and principals who collaborate to improve it. School management should concentrate on building the culture of learning organisation at school, manifested in a profound change in the character of interpersonal relations (Fullan, 2001, 2011). According to P.M. Senge, the originator of the learning organisation model, teams are currently the basic link of the learning process (Senge, 1990).

The aim of this chapter is to present data from a pilot study concerning teachers' everyday functioning from the principals' perspective in the context of assumptions of the learning organisation model. I wanted to find out to what degree the characteristics proving team's maturity based on the assumptions of the model occur in teachers' everyday work at schools from the perspective of their principals. The obtained data were used to show the strong points and the deficits of the teams' work, facilitating or preventing learning together. My intention is to highlight the problem of proper understanding of the characteristics of a mature team and the need to develop abilities of managerial and teaching staffs as well as student teachers in order to build such teams.

In the text, I assume that only teacher teams that have reached the maturity phase can introduce changes in a subjective way, changes which transform the school culture positively and make it a learning organisation through expansive learning (Engeström \& Sannino, 2010). Both the teachers involved in the teaching process and the managerial staff need to be prepared for this process.

I decided to study this area because the process of building a learning school involves the introduction of many changes which require all the participants (teachers, principals) to learn continuously. For many years, Polish schools have been undergoing continuous changes in all the functioning areas to improve the quality of education. Nevertheless, data from many empirical studies indicate that the Polish school is a place where "time has stopped" (Krzychała \& Zamorska, 2011, p. 530). Looking at schools from outside, we can notice many changes, 
but those that are most desirable - transformations in the school culture-are not common enough. The reasons for this are both external, connected with the character of changes imposed by the educational policy, and internal, resulting from the school conditions. Teacher teams have different characteristics, and principals' management styles can also make their progress to maturity either easier or more difficult.

All of us realise the need for lifelong learning, but individuals' learning, although necessary, does not guarantee the development of school as an organisation (Fullan, 2003; 2011; DuFour, 2004). Creating a team of teachers whose members are able to learn together is a great challenge, due to the clash of school culture norm, saying that a good teaching staff is made up of compatible and easy-going people, and the norm popular in the contemporary world, saying that you should first of all care about your individual benefits and your own position on the labour market. Although teamwork is often encouraged, employees are evaluated and awarded individually; competition is also used by organisations to enhance effectiveness. This does not help one engage in collaborative projects for the common good and increase social capital.

Research by H. Kędzierska and M. Maciejewska (2014) shows that teachers have the need to compete, they feel lonely, and they fear the loss of their jobs; actually, even working as part of teams that are formally established at schools does not mean they become educational communities. Another case study shows that teachers employed at school do not make a harmonious, united group but are divided into many groups, which engage in different activities, have different goals, and do not collaborate with each other (Borukało \& Kiciński, 2012, pp. 311-312). Similar conclusions resulted from research by $A$. Korzeniecka-Bondar. Her thesis, based on qualitative research involving teachers is that: "nowadays' communities are created for the purpose of a temporary initiative, a one-off event. The bonds created in such circumstances are not permanent or engaging. Instead of cooperation, there are one-off 'actions', which will later be followed by another action, etc. There is a need for change, as indicated by the teachers taking part in the study, however it is not possible without long-term involvement, common goal which would be more important than everyday benefits" (Korzeniecka-Bondar, 2013, p. 50).

Such diagnoses cause the need for further analyses, looking for factors, and taking activities that can facilitate teachers' teamwork, 
especially that many studies confirm that it helps improve students' learning processes (Stoll et al., 2006). My research follows this trend and fills in a gap, since it provides the uncommon perspective of the principals.

Dynamic changes in the environment cause different responses, from enthusiasm up to resistance. It is especially difficult to accept the sense of instability and uncertainty. Being part of a mature staff facilitates overcoming difficulties related to the process of changes (Mills, 1995), which are inevitable in organisational life. "When the team really learns, this not only allows its extraordinary performance but also helps its members develop more quickly" (Senge, 2006, p. 25). Unfortunately, at times, working in a team causes a loss of energy and produces poorer results than individual work (Wenger cited in: Madalińska-Michalak, 2016, p. 59). What conditions, then, are associated with a good team?

\section{Maturity of the teaching staff in a learning school - theoretical background for the study}

\section{Characteristics of a mature team}

Staff maturity involves the ability to cope with typical limitations of teamwork, such as group polarity, social loafing, or group thinking (Oyster, 1999), all of which prevent learning and implementation of changes. Aiming at unanimity in order to avoid conflict is often mistaken for group cohesion or maturity. It can be illustrated with a sentence uttered by a teacher: "There should be no conflicts among educated people1." When applying defensive responses to conflict, which is traditionally perceived as solely negative, the team avoids deeper analysis and realising that it is their own actions that cause problems, not some other factors. One of the pillars of the "learning organisation" concept developed by Peter Senge is systemic thinking, only possible in mature teams capable of insight and problem solving (Senge, 2006, p. 268). However, the author is of the opinion that it is still the weak point of contemporary organisations. The ability to learn in teams requires constant analyses and description. P. Senge also adds that

1. A teacher's utterance obtained in the course of my previous study: B. Tołwińska (2013). Kompetencje społeczne dyrektorów szkół. Kraków: Oficyna Wydawnicza "Impuls". 
what characterises a really learning team is not unanimity but rather the divergence of views and the presence of conflicts, which are very important in the creative process. In immature teams, discrepancies are concealed, because they are regarded as destructive (Senge, 2006, p. 280).

W. Daniecki (2004) also points to the criterion of team maturity for successful changes and organisational development. As he sees it, "group maturity" is "one of the most important criteria of team analysis." In an immature group, goals are not clear yet and not approved by all members; the social structure (of communication, prestige, influences and roles, including the role of the leader) is still undergoing clarification. The sense of psychological security is not strong enough, so some of the members do not dare behave authentically and are not ready to take the responsibility for the group, while anxiety and guilt associated with that make them express the 'siege mentality'. It involves sealing group boundaries, severely punishing those that violate these boundaries and the group's non-consolidated norms, as well as looking for scapegoats. This, in turn, is a barrier to the formation of authentic internal bonds and external relations. Such groups do not let their members make any personal changes and do not authentically engage in organisational development (Daniecki, 2004, p. 57).

Only mature groups provide the conditions for subjective participation in changes and learning together. In such groups, the goals, roles and norms are clearly established. Their members feel secure, the level of trust is high, and communication is open and authentic. Group members do not feel the need to secretly fight for power; cooperative behaviours and mutual support are natural. Difficult and sensitive issues are mentioned within the group. Such group characteristics are necessary for their members to participate in the process of changes in a subjective way, which ensures real organisational and personal change (Daniecki, 2004, pp. 56-58).

S. Mills (1995) describes the characteristics of mature teaching staff. Aiming at maturity, teams go through different phases: from immaturity, through the phase of experimenting and consolidation, up to maturity. In the immature phase, team members always agree with the opinion of the superior, decisions are unquestionable, everybody wants to attract attention, and changes are perceived as something negative. A mature team, on the other hand, is able to draw conclusions from 
the mistakes made, its members respect each other, try to achieve the goals together, nobody wants to dominate or compete with others, they are proud of others' accomplishments, communicate openly and express their opinions freely, they create good atmosphere and are ready to make changes.

\section{The attitude of the leader in building mature teams}

A mature team is able to use two forms of communication and understand the differences between them. These forms are dialogue and discussion (Senge, 2006, p. 271). The aim of dialogue is for each person to freely express his/her thoughts and go beyond his/her individual understanding of facts, thus accessing "the pool of shared meanings." The objective is not the victory of a certain view but the exchange of views, so that we can "observe" our own thinking, which may let us - as participants - notice its inconsistency and reveal it without fear (Bohm, cited in: Senge, 2006, p. 271). We do not have to agree with and share the views of others. Thus, the essence of mature teams is the sense of security and trust within them. Referring to Bohm's views, Senge points out how difficult it is to implement dialogue in organisations where hierarchy exists. In the traditional superiorsubordinate relationship, a lot depends on the superior's approach: if he cares about his privileges and likes to dominate, there is no room for dialogue. If the subordinate refrains from expressing his views because of being in a lower position, there will be no dialogue, either. The fear of saying something improper, judging the views of others and failure to reveal one's own views make it impossible to work on difficult problems or to understand them (Senge, 2006, p. 276). These organisational conditions inhibit the building of mature teams. Among the main internal organisational factors connected with the level of innovativeness, Beata Przyborowska identifies the type of organisational culture, and one of the many characteristics she mentions is the right to make mistakes (Przyborowska, 2013, p. 15). What about teachers, then? Do they treat admitting to a mistake as a failure, weakness and incompetence, or as strength, courage and an opportunity to find a new solution? "In a dialogue, people really feel they are building something. And they do build: a new, deeper, mutual understanding" (Senge, 2006, p. 275). Dialogue can be supplemented with discussion. This form is 
inevitable whenever we have to make a decision. Then, it is necessary to present arguments and defend them (Senge, 2006, p. 278).

The leaders who fail to see the benefits of a mature teaching staff for the development of the school but who want to retain their dominant position behave in a domineering way, thus suppressing the teachers' will to reveal their views, even if they verbally encourage this. The courage to publicly express a different view may have sad consequences. That is why team members may apply a set of defensive procedures, e.g. fail to express their anxiety or views, hide divergent opinions or criticise the views of others. As for the leaders hiding behind the screen of confidence and omniscience, they never have doubts, they always know what decision to take, so they do not need to confront them with others (Senge, 2006, pp. 281-283).

Teams who have made the effort to reach maturity are more lasting and can achieve better effects not only on one occasion but also in the long run, because each activity reinforces the next one. But a team cannot be forced to work this way, so legally establishing teachers' teamwork (Dziennik Ustaw 2015, item 1214) is not going to make them engage in it; to the contrary, it may lead to disappointment if the teachers perceive it as a duty and something artificial. External pressure will never induce internal engagement but may weaken it instead.

\section{Examples}

Learning as teams is not a common practice at schools and it requires continuous analyses, but many activities are taken both by theoreticians and by practitioners to develop different forms of teachers learning together. The belief underlying these activities is that school will never become a better place for students to learn unless teachers develop individually and as a team (DuFour, 2004). "Learning can no longer be left to individuals. To be successful in a changing and increasingly complex world, it is suggested that whole school communities need to work and learn together to take charge of change, finding the best ways to enhance young people's learning" (Stoll et al., 2006, pp. 221-221).

A study showing the specificity of teamwork was carried out by $A$. Borukało and A. Kiciński (2012). The authors emphasise that this form is important for all teachers, but especially valuable for the younger ones with short working experience. Working together as a team does not only involve doing the task but also allows to gain extra benefits: to learn 
something new about yourself, to find out how others work and study, or even - like in typical support groups - to discuss topics connected with personal experiences. It gives the opportunity to talk about problems and look for ways to cope with difficult situations; teachers think together how to improve lesson materials, how to motivate students to be active, or even how to persuade them to attend classes (Borukało \& Kiciński, 2012). B. Zamorska (2008) points to yet another aspect of learning as a team. Teachers who participated in her qualitative research share their daily matters, look for joint solutions, and meet a variety of views and perspectives of a problem. Actually, they make a support group. Their discussions always include the subject of failures, both their students' and their own. They can see that both successes and failures are important experiences in professional development and both deserve to be discussed together. Therefore, they share their failures and they experience "togetherness" (Zamorska, 2008).

Examples of selected schools in Slovenia (8 schools) that took part in the project 'The Learning Schools Network' can also serve as an inspiration of good practices. Before the schools began to work in accordance with the concept of learning community, teamwork and sharing knowledge had been exceptions, not the standard. Teachers who took part in the project reported it was the first time they could see how their colleagues worked, they discussed difficult issues that had been ignored before, they looked for solutions together, they acquired skills they had not had before, and - what is especially valuable - enhanced their self-esteem, developing the belief that their activities were good and helped improve the quality of work of the whole school, they experienced friendly atmosphere and learnt to present their opinions in public freely and to recognise different views. The analysis of weak points of teamwork showed several aspects: a lot of time required, resistance to learning together (expressed by one fifth of the respondents, who doubted the value of their ideas and felt embarrassed to reveal them; some of them did not want to reveal their problems publicly to be discussed by the team) (Erculj, 2013).

British experiences in team learning and changing the school culture into a learning community described by J. Jones (2013) stress the need to change the roles of the teacher and the student. In the described school the students' views, consulting the ways of learning with them and encouraging students to express constructive criticism 
were a natural element of organising school work. Teachers, in turn, could experiment, they were interested in observing the work of other teachers, they included new methods and did research on their benefits for students in accordance with the concept of a reflective practitioner. The identified difficulties with team learning were the reluctance of some teachers to assume the role of the leader, and frequent misunderstandings.

A thorough review of literature concerning teachers' professional development shows the following positive changes in teachers' behaviour as a result of collaborative learning: "greater confidence; enhanced beliefs among teachers of their power to make a difference to pupils' learning; development of enthusiasm for collaborative working, despite initial anxiety about classroom observation; and, greater commitment to changing practice and willingness to try new things." These changes triggered others, the most important in the work of a school, "the positive impact on students included enhanced motivation and improvements in performance" (Stoll et al., 2006, p. 230).

\section{Study design}

The fragment of data presented here is part of a broader research project. Its aim is to find out to what extent the assumptions of the learning organisation model are reflected in school daily life from the perspective of school principals. The aim of the analysis is to find out to what degree the characteristics of a mature team occur in teachers' everyday work at school from the perspective of their principals. The research was quantitative, carried out with the method of questionnaire-based diagnostic poll, in the pilot phase involving a small sample in 2015. I selected a random sample of 30 school principals from the eastern and southern regions of Poland. The participants were the principals of primary, junior secondary and secondary schools located in villages, small towns and big cities. The participants were both males and females, with the majority of females. The principals' work experience as teachers varied from 13 to 35 years, and the management position experience from 1 year to 29 years. All the principals had higher education. The presented findings are part of the collected data which will be interpreted in terms of the assumptions of the learning organisation model (see also: Tołwińska, 2016). 


\section{Research results}

The principals participating in the study pointed out to what extent each assumption was popular in the schools they managed, using the following scale: all teachers do so, most teachers do so, half of the teachers do so, few of the teachers do so, or none of them do so.

Table 1. Specificity of teamwork from the principals' perspective

\begin{tabular}{|c|c|c|c|c|c|c|}
\hline \multirow[b]{2}{*}{ No } & \multirow[b]{2}{*}{ CATEGORY } & \multicolumn{5}{|c|}{ NUMBER OF ANSWERS $(\mathrm{N}=30)$} \\
\hline & & $\begin{array}{c}\text { ALL } \\
\text { OF THE } \\
\text { TEACHERS }\end{array}$ & $\begin{array}{c}\text { MOST } \\
\text { OF THE } \\
\text { TEACHERS }\end{array}$ & $\begin{array}{c}\text { HALF } \\
\text { OF THE } \\
\text { TEACHERS }\end{array}$ & $\begin{array}{c}\text { FEW } \\
\text { OF THE } \\
\text { TEACHERS }\end{array}$ & $\begin{array}{l}\text { NONE } \\
\text { OF THE } \\
\text { TEACHERS }\end{array}$ \\
\hline 1. & $\begin{array}{l}\text { When the principal admits } \\
\text { to the mistakes s/he has made, } \\
\text { the teachers perceive it } \\
\text { as incompetence }\end{array}$ & 0 & 10 & 2 & 13 & 5 \\
\hline 2. & $\begin{array}{l}\text { The teachers would consider me } \\
\text { as incompetent if I didn't know } \\
\text { how to solve a problem and asked } \\
\text { them for advice }\end{array}$ & 0 & 9 & 4 & 13 & 4 \\
\hline 3. & $\begin{array}{l}\text { The teachers expect the principal } \\
\text { to always be ready to solve } \\
\text { a problem }\end{array}$ & 3 & 16 & 0 & 8 & 3 \\
\hline 4. & $\begin{array}{l}\text { The teachers tend to blame each } \\
\text { other when a problem arises }\end{array}$ & 0 & 7 & 2 & 12 & 9 \\
\hline 5. & $\begin{array}{l}\text { The teachers are able to admit } \\
\text { to their mistakes and remedy them }\end{array}$ & 4 & 10 & 7 & 9 & 0 \\
\hline 6. & $\begin{array}{l}\text { The teachers value their own } \\
\text { competencies; they never / hardly } \\
\text { ever use the knowledge and skills } \\
\text { of their colleagues }\end{array}$ & 3 & 8 & 4 & 12 & 3 \\
\hline 7. & $\begin{array}{l}\text { The teachers are open } \\
\text { to constructive feedback } \\
\text { concerning their work (received } \\
\text { from colleagues, students and } \\
\text { parents) }\end{array}$ & 4 & 11 & 3 & 12 & 0 \\
\hline 8. & $\begin{array}{l}\text { The teachers tend not to reveal } \\
\text { their views }\end{array}$ & 3 & 7 & 3 & 14 & 3 \\
\hline 9. & $\begin{array}{l}\text { The teachers are mutually inspired } \\
\text { by their innovative activities }\end{array}$ & 4 & 12 & 4 & 10 & 0 \\
\hline 10. & $\begin{array}{l}\text { The teachers would work in teams } \\
\text { even if this was not necessary }\end{array}$ & 5 & 10 & 3 & 12 & 0 \\
\hline 11. & $\begin{array}{l}\text { The teachers rejoice together } \\
\text { and celebrate the successes } \\
\text { of each one of them }\end{array}$ & 8 & 11 & 3 & 8 & 0 \\
\hline
\end{tabular}


As the gathered data show, from the perspective of principals many aspects of team work which determine the maturity of the staff, necessary for the creation of learning schools, still need to be improved in many schools. According to the principals of 10 schools, most teachers would perceive the principal's admitting to mistakes as incompetence (no 1.); in two other schools, half of the staff would think so. As a result, 12 out of 30 principals agreed with the statement that can be a barrier to learning together and the reason for hiding failures. If the leaders popularise this as normal behaviour, it will also become common among the teachers. This way of working of the teaching staff and the underlying beliefs should also be presented to the teachers and discussed together.

The principals' belief that they need to hide behind "the screen of self-confidence and omniscience", reflected in the assumption that: the teachers would consider me as incompetent if I didn't know how to solve a problem and asked them for advice (no. 2), does not help the staff reach for maturity. Almost in half of the schools (13 out of 30), most teachers (in 9 schools) or half of them (in 4 schools) would consider the principal as incompetent if $s / h$ had no ready solution and had to ask others for advice.

Furthermore, in most schools $(3+16)$ the teachers expect the principal to always be ready to solve a problem (no. 3). Only in 3 schools no staff member expects this, and in 8, few of them do.

A problem situation is a special test for the staff. If a problem is treated as a sign of incompetence and weakness, there will be attempts to hide it and someone will have to be blamed for it. If revealing problems is treated as an expression of proactive approach and constructive coping with the complicated school reality, the staff will collaborate to look for solutions. For most principals, the situation at their schools was positive: they did not see teachers looking for someone to blame in a problem situation or could see only few of them doing so. But most teachers in 7 schools and half of them in 2 other schools (in total, nearly $1 / 3$ of all the schools in the study) blame each other for any emerging problem (no. 4). In the opinion of 10 principals, most teachers in their schools are able to admit to mistakes and correct them; only four participants indicated that all the teachers did so, and 16 principals do not see this as a typical behaviour. According to 7 of them, only half of the teachers do so, and according to 9 others, few (no. 5).

Only 3 principals responded that in their schools no teacher was open to the knowledge and skills of their colleagues, and 12 of them 
found this approach in few teachers. As for the other participants, who account for half of the group, they agreed that most teachers (8 responses), half of them (4 responses), or even all of them (3 responses) value their own competencies and do not use (or hardly ever use) the knowledge and skills of their colleagues (no. 6).

Better effects of work are only possible thanks to open, bilateral communication about how teacher's actions are evaluated by recipients, what actions are worth maintaining, and what should be avoided. Only 4 principals answered that in their schools all teachers were open to constructive feedback concerning their work from colleagues, students and parents; 11 said that the majority of the staff had this attitude, and according to half of the principals $(3+12)$ this referred to half (in 3 schools) or few of the teachers (in 12 schools) (no. 7).

A mature teaching staff creates good atmosphere, works together to achieve its goals, and its members do not try to dominate or compete with each other but rather to learn from each other. How do the principals participating in the study perceive teachers in this context? Only 3 principals responded that in their schools no teacher tended to conceal their views, and 14 of them thought that few teachers did so. Data received from 13 principals $(3+7+3)$ show that there is a problem with open communication in their schools. In the opinion of 7 principals, most teachers tend not to reveal their views, 3 of them think that half of the teachers do so, and 3 more, that all of them do (no. 8).

Only 4 principals saw that the assumption: The teachers are mutually inspired by their innovative activities applied to all the teachers in their schools (no. 9). According to the principals of 12 schools, this refers to most of the teachers. Sadly, in half of the schools this is not the case. 4 principals are of the opinion that half of their teams do so, while as many as 10 of them think that only few teachers use the skills of other staff members as a source of inspiration.

Teamwork gives the best results when it is not an administrative duty forced by the authorities but taken voluntarily with the awareness of all its benefits. This assumption is still not common in school reality. Only 5 principals think that all teachers in their schools can see its advantages for of work, and they would still work in teams even if this was not necessary. 10 participants think that the majority of their staff would do so. But half of the respondents are not so optimistic. 3 principals suppose only half of their teachers would work in teams 
out of their will, and as many as 12 (out of 30) principals cannot see their teachers attaching great importance to teamwork, since only few of them would choose this form of work (no. 10).

Another thing that indicates the constructive atmosphere of the team, the sense of security and maturity, is celebrating successes together, and expressing joy is a sign of support and motivates the person to further efforts. Do the teams, managed by the participating principals, create such an atmosphere? Most of the respondents answered yes, in 8 out of 30 schools all the teachers are happy when one of them achieves a success, and according to 11 principals, the majority of teachers do so. However, in $1 / 3$ of the schools $(3+8)$ this is not normally observed. According to 8 principals only few teachers in their schools are able to express happiness when a colleague has achieved a success, and in the opinion of 3 of them, only half of the teachers are (no. 11).

\section{Discussion and conclusions}

A mature teaching staff creates an atmosphere in which even sensitive issues can be mentioned, e.g., its members can admit to mistakes, or openly ask others for advice without the fear of being judged as weak and incompetent. Another characteristic of such a team is looking for solutions together instead of blaming each other when a problem arises. Besides, there is communication within the staff, which allows its members to share feedback, openly express their views, and take advantage of other people's potential. In such a team we receive support and motivation to further efforts, and we can celebrate successes together instead of hiding them from the group for fear of their jealousy. Moreover, a success can become an inspiration and a source of experience for others, so it is an opportunity to develop too.

On the basis of empirical data, it can be concluded that from the perspective of principals in many schools the sense of security and trust needs to be strengthened for the team members to behave authentically and avoid defence strategies in relation with each other. Using the team resources is not popular, either; in this matter, traditional attitudes to teacher's work as exclusively individual work are clearly seen. Principals are also typically convinced that they have to offer ready solutions to problems. J. S. Czarnecki $(2010$, p. 98) calls this belief the "organisational goldfish" stereotype. The principal assumes 
the responsibility for the school, relieving all the other staff members from it. Similar conclusions were drawn in studies by M.-N. Beaudoin and M. Taylor (2004). Data analysis led the authors to the conclusion that everyday reality of school principals is dominated by three kinds of experience: "Being mistaken for God; doing more, more, more; being everything for everyone all the time" (ibid., p. 4). If the principal is mistaken for God, the implications are as follows: "you become trapped into a role where you cannot be your preferred self and must instead: never make mistakes, know all the answers, be able to solve everything, control everything at will, predict the future (e.g., school enrolment or even the weather)" (ibid., 2004, p. 5).

The situations observed by the researchers result from excessive expectations of the authorities and from the team's immaturity caused by the lack of social competencies.

If we look at the study results from the perspective of the presented assumptions of learning organisation, the data received from 30 principals demonstrate that many norms of behaviour that are common in teachers disprove their maturity. Out of the 11 aspects of staff maturity analysed here, 5 had poor scores in half or even more of the schools. The weak points are: expecting solutions from the principal, teachers' failure to admit to mistakes, failure to take advantage of staff members' potential because of belief in one's own competencies, the lack of openness to feedback, and treating teamwork as a necessity rather than as one's own choice. In the other 6 aspects, the unfavourable result only refers to a small minority of the schools ( 3 aspects: no. 2 , no. 8, no. 9 ) or $1 / 3$ of the schools ( 3 aspects: no. 1 , no. 4 , no. 11).

In the learning organisation concept, mature teams are the basic link of the learning process, but their formation requires changes in interpersonal relations. However, we cannot analyse interpersonal relations inside an organisation without considering the influences of the macrosystem and culture norms common in the global perspective. The fact that all the areas of life are dominated by the market promotes competitiveness, while collaboration and teamwork are treated as merely temporary tactics applied as long as they produce the expected benefits (Bauman, 2007). In the culture of individualism, developing social capital is very difficult and triggers a lot of controversies (Potulicka, 2012). The authors of educational change theories who develop the concept of school in accordance with the learning organisation model 
see the competencies of the management staff as the source of change of social relationships in a school. According to M. Fullan, some schools have succeeded in it, and they are a good example to follow. However, contemporary school systems do not provide the management staff with the right conditions for such work (Fullan, 2003). Analysing the educational policies of countries without educational successes in international tests of educational accomplishments, e.g. PISA, M. Fullan points out that they have chosen the wrong drivers in reforming education, those that involve great promises but actually do not lead to goal achievement (Fullan, 2011). Hence, it is a mistake to apply them. If their dominance is the result of the assumption that intensified internal pressure will produce internal motivation, this assumption is definitely a wrong one. The author identifies four wrong drivers, one of which is concentrating on the quality of work of individual teachers and leaders, promoting individuals instead of solutions for entire groups 2 . He justifies his view with reference to a report by McKinsey \& Company, describing 20 improved educational systems all over the world (Mourshed et al., 2010). Data therein show that good quality educational systems are much more concentrated on building the potential, which means investing in the practice of collaboration and supporting professional development rather than external tests, lesson observations and writing reports. Fullan also points out the right drivers: building the potential, concentrating on teaching methods, systemic solutions and, last but not least, team work. These factors can change the school culture. The countries that have successes in education and are improving their educational systems concentrate on those drivers and try to develop the culture of cooperation at schools (Fullan, 2011). Teamwork enhances responsibility, whereas assessing teachers and punishing those who lag behind are fatal for the system. Another study that M. Fullan refers to, one by professor Carrie Leana (2011), demonstrates that teachers with poor skills had better work results than average teachers if they worked at schools with strong social capital. The best results were achieved by teachers with high human and social capital, but the strength of

2. The other three drivers he mentions are: "accountability: using test results, and teacher appraisal, to reward or punish teachers and schools vs capacity building; technology: investing in and assuming that the digital world will carry the day vs instruction; and fragmented strategies vs integrated or systemic strategies." 
social capital was greater for the achieved effects. According to $\mathrm{C}$. Leana, poor social working conditions make teachers less efficient, and those with lower competencies reduce the quality of their work. It happens otherwise if teachers talk to each other about teaching in the atmosphere of trust and friendliness (Leana, 2011, cited in: Fullan, 2011). A culture of cooperation motivates and allows mutual learning; "high social capital is a powerful strategy to leverage human capital" (Fullan, 2011, p.11).

Pedagogists in Poland have also strongly expressed their opinions involving deep attention to the social climate of schools "immersed" in neoliberal ideology (e.g. Dudzikowa et al., 2011; Kwiatkowska, 2012; Potulicka \& Rutkowiak, 2010; Potulicka, 2012; Rutkowiak, 2012). Externally forced competition between schools fosters fights between individuals for the best positions within the schools. This prevents the sense of community, open exchange of experiences, mutual inspiration and sharing the joy of success. The pursuit of top ranking positions leads to leaving behind the care for humanistic values, which are needed to build mature teams.

Although the concept of a learning organisation is present in publications, there is still a lot to do in practice. Thus, there is room for twofold changes. First, changes are necessary in educational policy, involving the departure from assessing and ranking. Inside schools as humanistic institutions, there must be proper conditions for people not to treat each other as rivals who fight for the best ranking position. Drawing on Putnam's views, what we can see in the public domain, i.e. politics, school, self-governments etc., is of key importance for the building of community and social capital resources, fostering the development of whole societies (Putnam, 2000). However, as we can read in Social Diagnosis 2015, it is hard now to find examples of encouragement to collaboration. Unfortunately, educational institutions do not provide good conditions for such activities, either (Czapiński \& Panek, eds., 2015, p. 345). The implementation of market mechanisms and economic growth are not accompanied by social growth, and this phenomenon can be seen in many countries as a result of globalisation processes and information revolution (Raport Polska 2050, p. 29).

Yet, there is also another necessary direction in which to go. On the basis of quoted studies by other authors and my own research, we can see examples of staff who from the perspective of principals have 
the characteristics of mature teams and can make an environment conducive to learning together. It is necessary to look for and advocate the examples of good practices in such institutions, which have managed to balance the individualistic tendencies and the care for the good of the school in general (see: Madalińska-Michalak, 2012).

Teacher and educational leaders education should involve, to a greater degree, the development of social competencies (Tołwińska, $2011,2013)$. It is important to discuss the issue of forming teams and learning the conditions in which they can achieve the phase of maturity to practise expansive learning. It is necessary to refer to the common norms of behaviour motivating to concentrate on oneself and the ways of fighting this. One of them may be analysing case studies during university education to show the innovative effects of synergy of teamwork at schools, as well as preparing practical team projects.

Professional successes and failures are both opportunities to learn, if the person is sure that he or she will not meet negative assessment and can freely talk about the situation, that it will not be an expression of their weakness but to the contrary, of courage in looking for solutions and using the potential of other people. Based on the presented data it is clear that these norms of behaviour need to be popularised at school, and a lot depends on the attitude of the leaders. They can also see the individualistic attitude of teachers, manifested in the fact that teamwork is treated as an obligation, not chosen because of belief in possibly better solutions.

A mature teaching staff can be created if teacher candidates learn the specificity of teamwork thoroughly, and are able to overcome its limitations such as imposing solutions by some people in the group and the others not expressing their opinions (group thinking), if they accept the differences and perceive mistakes as opportunities to learn. Similarly, they will see the successes of others as an opportunity to learn from them.

Learning the multiple benefits that can be achieved in a mature team, exceeding the tangible effect and involving the experience of "togetherness" and support, the sense of security and trust in looking for new solutions (expansive learning) may be an inspiration to create better workplaces in the future, where the humanistic values are really upheld, not only declared. 


\section{References}

$\rightarrow$ Bauman, Z. (2007). Liquid times: Living in an age of uncertainty. Cambridge: Polity Press.

$\rightarrow$ Beaudoin, M.N., \& Taylor, M. (2004). Creating a positive school culture: How principals and teachers can solve problems together. Thousand Oaks, CA: Corwin Press.

$\rightarrow$ Borukało, A., \& Kiciński, A. (2012). Jaką społecznością uczącą się są nauczyciele? Forum Oświatowe, 1, 302-316.

$\rightarrow$ Czapiński, J. \& Panek, T. (Eds.) (2015). Social diagnosis 2015: Objective and subjective quality of life in Poland. Warszawa: Rada Monitoringu Społecznego.

$\rightarrow$ Czarnecki, J. S. (2010). Stereotypy w zarządzaniu szkołą. In S. M. Kwiatkowski, J. M. Michalak (Eds.), Przywództwo edukacyjne w teorii i praktyce (pp. 93-118). Warszawa: Fundacja Rozwoju Systemu Edukacji.

$\rightarrow$ Daniecki, W. (2004). Strategie zmian: Teorie i rekomendacje praktyczne. Warszawa: Wyd. ACADEMICA SWPS.

$\rightarrow$ Dudzikowa, M., Jaskulska, S., Wawrzyniak-Beszterda, R., Bochno, E., Bochno, I., Karina Knasiecka-Falbierska, K. \& Marciniak, M. (2011). Kapitał społeczny w szkołach różnego szczebla: Diagnoza i uwarunkowania. Kraków: Oficyna Wydawnicza "Impuls".

$\rightarrow$ DuFour, R. (2004). What is a professional learning community? Educational Leadership, 61 (8), 6-11.

$\rightarrow$ Engeström, Y. \& Sannino, A. (2010). Studies of expansive learning: Foundation, findings and future challenges. Educational Research Review, 5, 1-24.

$\rightarrow$ Erculj, J. (2013). Sieć Uczących się Szkół. In D. Elsner (Ed.), Sieci współpracy i samokształcenia. Teoria i praktyka (pp. 194-214). Warszawa: Wolters Kluwer Polska SA.

$\rightarrow$ Fullan, M. (2001). Leading in a culture of change. San Francisco: Jossey-Bass.

$\rightarrow$ Fullan, M. (2003). The moral imperative of school leadership. Thousand Oaks, CA: Corwin Press. 
$\rightarrow$ Fullan, M. (2011). Choosing the wrong drivers for whole system reform, Centre for Strategic Education Seminar Series Paper No. 204. Accessed on July 4, 2014. http://michaelfullan.ca/wp-content/uploads/2016/06/13396088160.pdf

$\rightarrow$ Fullan, M., \& Langworthy, M. (2014). A rich seam: How new pedagogies find deep learning. London: Pearson.

$\rightarrow$ Jones, J. (2013). Tworzenie uczącej się społeczności w szkole i w sieci. Doświadczenia brytyjskie. In D. Elsner (Ed.), Sieci współpracy i samokształcenia. Teoria i praktyka (pp. 122-135). Warszawa: Wolters Kluwer Polska SA.

$\rightarrow$ Kędzierska, H. \& Maciejewska, M. (2014). Odpowiedzialny nauczyciel - (nie) odpowiedzialna wspólnota: Co pomaga, a co przeszkadza w budowaniu nauczycielskich wspólnot praktyków. In G. Mazurkiewicz (Ed.), Edukacja jako odpowiedź. Odpowiedzialni nauczyciele w zmieniającym się świecie (pp. 83-95). Warszawa - Kraków: Wydawnictwo Uniwersytetu Jagiellońskiego.

$\rightarrow$ Korzeniecka-Bondar, A. (2013). Time for community at school or community for the time being? In E. Bochno (Ed.), School in community: Community in school (pp. 39-50). Toruń: Wydawnictwo Adam Marszałek.

$\rightarrow$ Krzychała, S. \& Zamorska. B. (2011). Zamknięte i otwarte zmiany kultury szkoły. In M. M. Urlińska, A. Uniewska, J. Horowski (Eds.), Po życie sięgać nowe ... Teoria a praktyka edukacyjna (pp. 531-549) . Toruń: Wydawnictwo Adam Marszałek.

$\rightarrow$ Madalińska-Michalak, J. (2012). Skuteczne przywództwo w szkołach na obszarach zaniedbanych społecznie. Studium porównawcze. Łódź: Wyd. Uniwersytetu Łódzkiego.

$\rightarrow$ Madalińska-Michalak, J. (2016). Wspólnoty praktyków a granice uczenia się nauczycieli w szkole. Rola dyrektora szkoły. In A. Minczanowska, A. SzafrańskaGajdzica, M. J. Szymański (Eds.), Szkoła. Wspólnota dq̨żeń? (pp. 48-61). Toruń: Wydawnictwo Adam Marszałek.

$\rightarrow$ Mills, S. (1995). Managing people through change: A guide for schools and colleges. Framework Press.

$\rightarrow$ Oyster, C. K. (1999). Groups: A user's guide. New York City: McGraw-Hill.

$\rightarrow$ Potulicka, E. \& Rutkowiak, J. (2010). Neoliberalne uwikłania edukacji. Kraków: Oficyna Wydawnicza "Impuls".

$\rightarrow$ Potulicka, E. (2012). Kształtowanie kapitału społecznego w szkole wprowadzenie do problemu. Studia Edukacyjne, 22, 97-107.

$\rightarrow$ Przyborowska, B. (2013). Pedagogika innowacyjności:. Między teoriq̨ a praktyka. Toruń: Wydawnictwo Naukowe Uniwersytetu Mikołaja Kopernika.

$\rightarrow$ Putnam, R. D. (2000). Bowling alone: The collapse and revival of American community. New York: Simon \& Schuster. 
$\rightarrow$ Raport Polska 2050, Polska Akademia Nauk. http://rp2050.czasopisma.pan.pl/ index.php?option=com_content\&view=article\&id=271:raport-polska-2050\&ca tid=103: wydania\&Itemid $=228$

$\rightarrow$ Rozporządzenie Ministra Edukacji Narodowej z 6 sierpnia 2015 r. w sprawie wymagań wobec szkół i placówek, DzU 2015, poz. 1214 http://dziennikustaw. gov.pl/du/2015/1214/1

$\rightarrow$ Rutkowiak, J. (2012). Jak kształtować kulturę zaufania i odpowiedzialności w szkole w warunkach promowania rywalizacji przez neoliberalizm? Studia Edukacyjne, 22, 127-138.

$\rightarrow$ Senge, P. M. (2006), Piq̨ta dyscyplina: Teoria i praktyka organizacji uczących się. Translated by Helena Korolewska-Mróz. Wydanie V. Kraków: Oficyna Ekonomiczna.

$\rightarrow$ Senge, P. M. (1990). The fifth discipline: The art and practice of the learning organization. 1990. New York: Doubleday.

$\rightarrow$ Stoll, L., Bolam, R., McMahon, A., Wallace, M. \& Thomas, S. (2006). Professional learning communities: A review of the literature. Journal of Educational Change, 7, 221-258.

$\rightarrow$ Tołwińska, B. (2011). Kompetencje społeczne dyrektorów szkół. Kraków: Oficyna Wydawnicza "Impuls".

$\rightarrow$ Tołwińska, B. (2013). Head teachers' social competence as a condition for the creation of school community. In E. Bochno (Ed.), School in community: Community in school (pp.79-89). Toruń: Wydawnictwo Adam Marszałek.

$\rightarrow$ Tołwińska, B. (2016). Overcoming organisational silence: Looking for opportunities to change school culture. In L. Daniela, L. Rutka (Eds.), Selected papers of the Association for Teacher Education in Europe. Spring Conference 2015 (pp. 209-221). Cambridge: Cambridge Scholars Publishing.

$\rightarrow$ Zamorska, B. (2008). Nauczyciele. (Re)konstrukcje bycia-w-świecie edukacji. Wrocław: Wydawnictwo Naukowe Dolnośląskiej Szkoły Wyższej. 


\section{Biographical note:}

Bożena Tołwińska (PhD) is an assistant professor at the Faculty of Pedagogy and Psychology of the University of Bialystok. She is a holder of the Academic Tutoring Certificate issued by Collegium Wratislaviense. She focuses on the subjects of school management and school organisational culture, especially the model of school as a learning organisation. She is actively involved in popularising the idea of humanistic management, based on the idea that interpersonal relations foster mutual development of the interaction partners. She has authored a number of articles concerning this subject, and a monograph: Kompetencje społeczne dyrektorów szkót, [Social Competencies of School Principals] Oficyna Wydawnicza IMPULS, Kraków 2011, ISBN 978-83-7587-487-7. She is a member of the Polish Educational Research Association (Polskie Towarzystwo Pedagogiczne). 



\title{
Teachers' digital competence \\ from a global perspective
}

\author{
Marthese Spiteri \\ Stockholm University \\ Shu-Nu Chang Rundgren \\ Stockholm University
}

\section{Abstract}

This chapter introduces the concept of digital competence, as a teachers' prerequisite for today's education in a globalised world. Digital technology is widely available, and if used well, better learning opportunities could be provided for the students, especially when they come from different backgrounds and have various educational needs. In this globalised world, students daily encounter diversity and mobility and understanding this concept of digital competence could provide a more holistic and humane approach to address the teachers' role when teaching and learning with evolving technologies. More specifically it addresses the factors which affect the use of digital technology by the teachers, such as their attitudes and beliefs, their pedagogical knowledge and their technological skills. These factors influence the teachers' daily use of digital technology when they use it to safely manage information, communicate, create content and solve problems at schools. In outlining these digital competence areas, some recommendations are suggested to enhance students' performance in education and their future social inclusion needs.

\section{Keywords: \\ digital competence \\ digital technology \\ teacher education \\ prospective students' educational needs \\ globalised world}




\section{Introduction}

In the current Information Age, finding out what it means to be a digitally competent teacher and trained in this area could contribute towards effective global teaching with technology. This is due to the affordability and pervasiveness of technology, which provides better learning opportunities globally, especially where students come from different backgrounds and have various educational needs. Digital Competence (DC) offers this possibility to further connect and expose the students to a larger diverse population of ideas and cultures, since they can reach out beyond the classroom walls for information and communicate with other students, teachers and the community. Nowadays teachers' use of technology is no longer a choice or a willingness to try and use it, but it is expected from teachers to use technology in their practice. Law (2007) stated that the two widespread needs of $21^{\text {st }}$ century educational reforms require better curriculum planning for the Knowledge Society and the realisation that these reforms can only be achieved through changes in teaching methods. Understanding teachers' DC in the context of globalisation can contribute towards new teaching methods with technology, to enhance students' performance in education and their future needs.

\section{Digital competence and the use of}

\section{technology from a global perspective}

DC is one of the eight life-long learning competencies, needed by every citizen (EC, 2006) and was defined as: "the knowledge, skills and attitudes (KAS)...required when using Information and Communication Technology (ICT) and digital media to perform tasks; solve problems; communicate; manage information; collaborate; create and share content; and build knowledge ..." (Ferrari, 2012, p. 43).

From this definition, the seven main areas of DC can be identified (Ferrari, 2012), which were later narrowed down to five areas: Information Management, Communication, Content Creation, Safety and Problem Solving (Ferrari, 2013). These main DC areas could provide guidance to the teachers' daily practice with technology, where they manage information, to safely communicate and solve problems with their colleagues and their students, and create new content and knowledge.

When technology is planned collegially, to support the students' learning, it is more used in schools (EC, 2014) since both technological 
and pedagogical experiences and expertise can be shared by teachers (Thompson, Schmidt \& Davis, 2003; Wake \& Whittingham, 2013).

From a global perspective, the potential of technology to enhance and support learning had been well documented (Hernández-Bravo et al., 2016; McNamara, 2016; Zaranis, 2016), and when students discussed the information found on the Internet, their writing was enhanced and they were more productive in their writing (Doult \& Walker, 2014). Additionally, the students worked more independently and telling them that their work might be published on the school website, motivated them to correct their work (Al-Qallaf \& Al-Mutairi, 2016; Karchmer, 2001; Wang et al., 2011).

Still, some teachers are skeptical about its usefulness for educational purpose and some use it even less to communicate the students' learning developments with their parents (EC, 2014; Keengwe, Onshwari \& Wachira, 2008). There are various challenges that the teachers encounter when using technology, for example it demands new classroom management and new roles, since more interactions are taking place; it demands the constructivist approach to teaching and learning (Vygotsky, 1978). Yet, knowledge in the classroom is still transmitted by the teacher, rather than constructed with the students, which indicates that teachers need space to reflect on new conceptions of constructive teaching and learning (De Aldama \& Pozo, 2016).

\section{The importance of teachers' $D C$ and current issues}

In today's Information Age, children encounter daily new challenges and new technologies, which could result in new opportunities if technology is used well. They are growing up in a globalised world where they daily experience diversity and mobility. This confirms the importance of the teachers' contribution to practice DC in their daily work at school not only for the students' better educational performance but also for the students' future employability and contribution in society (EC, 2006, 2014).

A digitally competent teacher can facilitate communication, especially with migrant students who do not speak the local language or students with special needs. It allows for continuity in one's learning, both life long and life wide (Niemi, Kynäslahti \& Vahtivuori-Hänninen, 2013), and can contribute towards aligning and achieving each students' individual educational needs during their compulsory years and 
beyond. From a global perspective, technology can facilitate teaching and learning to all students, with different backgrounds, abilities and reachability. When using technology at school, students are given the opportunity to share their already mastered digital skills with their peers and their teachers (Spires at al., 2012). Predictors leading to high levels of DC among students, include among others the students' background and the availability of digital technology at home (Hatlevik, Ottestad \& Throndsen, 2015) and providing students with opportunities to increase their level of DC is important in preventing the digital divide (Karabacak, 2016).

In European countries technology is available in schools for more than four out of five students and almost all teachers in this region, use technology to prepare lesson (EU, 2013). At the primary school level, the EU average of teachers' use of ICT in more than $25 \%$ of the lessons was $29 \%$ and the students had the highest level of ICT use when the teacher was confident using it (EU, 2013). However, the outcome of this increased availability and use of technology in schools is not giving better results in respect to the students' learning progress. Education indicators across Europe state that basic skills such as reading, mathematics and science are poorly achieved and affect one-fifth of EU students (OECD, 2014).

The International Computer and Information Literacy Study (ICILS) (EU, 2014), showed that many digital native students are not digitally competent and highlighted the importance of teacher's role to transfer this DC. It was also noted that in all the EU countries involved in the study, the innovative potential of technology is still undervalued and there was a gender gap in computer and information literacy, where girls did better than boys (EC, 2014). Teacher training must be ongoing and teachers are advised to work collaboratively so as to boost their confidence when sharing their practices with technology (EC, 2014). Training should also be targeted towards the various needs and backgrounds of the teachers, for instance one must distinguish between pre-service and in-service training, where the former are the digital natives (EC, 2014; Orlando \& Attard, 2016).

\section{Factors affecting the use of technology by the teachers}

When using technology, the school has the responsibility to provide time and space for the teachers to collaboratively reflect and provide 
feedback on new applications of technology (De Aldama \& Pozo, 2016; Campbell \& Abd-Hamid, 2012; Getenet, Beswick \& Callingham, 2016; Thompson et al., 2003). The collaborative use of technology within the school can also support the teachers' community where new knowledge is sustained and improved with time (Campbell \& Abd-Hamid, 2012; Higgins \& Spitulnik, 2008; Niemi et al., 2013). The teachers' attitudes towards the use of technology were also affected by the school culture (Apeanti, 2016), since teachers were more motivated to use it when they felt respected and valued for their work (Tondeur et al., 2016). Additionally, technical support, consistent encouragement and digitally competent leaders encourage the use of technology more (Uluyol \& Sahin, 2016; Kim \& Keller, 2011; Niemi et al., 2013; Omwenga, Nyabero \& Okiomo, 2016).

As Zhao and Frank (2003) pointed out, the process of technology integration is an evolutionary one and is developed with the adaptation of new technologies in the school culture. The factors affecting the teacher's use of technology at school can be categorised into three: the teachers' attitudes and beliefs, the teachers' pedagogical knowledge and the teachers' technological skills (Zhao \& Frank, 2003). These factors are further discussed hereunder.

\section{The teachers' attitudes and beliefs}

The teachers' attitude towards the use of technology is influenced by various aspects such as the teacher's age, familiarity with technology, expertise and gender, and conversely the teacher's attitudes towards the use of technology in the classroom influences the students' motivation to learn (Mustafina, 2016). However, in real classroom situations, using digital technology takes more time and this was perceived by the teachers as a drawback (Prieto-Rodriguez, 2016). Successful technology integration, which empowers the teachers, requires from them dedication in their work and willingness to participate and share their expertise with other teachers (Niemi et al., 2013). There was a significant correlation between teachers who find the use of digital technology important and those who demand higher order tasks from their students (Prieto-Rodriguez, 2016). Furthermore, the teachers' positive attitude towards training in this area nurtures higher levels of students' DC (Hatlevik, Ottestad \& Throndsen, 2015). 
Teachers' attitude towards the use of technology is also related to its availability in schools (Aydin, Gürol \& Vanderlinde, 2016; Dastjerdi, 2016). Zyad (2016) found that although teachers were willing to use technology it was still under used because of several barriers, which included the school infrastructure and inadequate resources (Mirzajani et al., 2016). However, the teacher's attitudes and confidence to use technology is not subject only to its availability, since confident teachers can adapt whatever technology is available to support the students' learning needs (Wastiau et al., 2013). The two main qualities which influence the teachers' use of technology, are their confidence and their belief that technology is beneficial for the students' educational development (Wastiau et al., 2013). Furthermore, it might be advantageous if preservice teachers' self-efficacy beliefs are examined since these could give insight on better teacher training to build their confidence for their future use of technology (Lemon \& Garvis, 2015). On the other hand, effective teacher training, enhances the teachers' positive attitudes and perceptions on technology integration (Apeanti, 2016).

\section{The teachers' pedagogical knowledge}

However, teachers need pedagogical knowledge on how to use technology in their practices (Kihoza et al., 2016; Liang, Ebenezer \& Yost, 2010; Markauskaite, 2007; Mirzajani et al., 2016; Mishra \& Koehler, 2006). It is not enough to provide teachers with new technologies; they also need to know how to use them. Teachers need to know how to meet the needs of various students, for example how students with reading difficulties can find online information (Karchmer, 2001); or how to facilitate sharing of experiences (Aesaert et al., 2013) so as to encourage equal participation in the classroom (Aesaert et al. 2013; Karchmer, 2001).

Mishra and Koehler (2006) suggested the technological, pedagogical and content knowledge (TPACK) framework, where effective technology integration occurs when the teacher applies technology knowledge (TK), pedagogy knowledge (PK) and content knowledge (CK) to design a learning activity. Training teachers on the application of the TPACK framework can be achieved when they observe each other and work collaboratively. Participation in these TPACK workshops improve the teachers' ability to integrate technology with their teaching activities, where they reflect on their efforts when designing lessons 
with technology and on how to instruct the class in such digital environment (Getenet, Beswick \& Callingham, 2016). Teachers tend to be more involved in these workshops and change from passively absorbing information to producing new teaching activities, such as the use of digital storytelling, where it was perceived as encouraging the students to talk more and actively construct new knowledge (De Aldama \& Pozo, 2016; Istenic et al., 2016).

\section{The teachers' technological skills}

When using technology, the teachers need the right skills to exploit the use of technology to its full potential (Mirzajani et al., 2016). It was indicated that teachers lack the skill to find and select the best information from the Internet (Al-Qallaf \& Al-Mutairi, 2016), where both the teachers and the students need to master this skill to search and choose the right information and be able to create new content and communicate their conclusions with others (Hinostroza et al., 2016).

It is challenging for the teachers to use technology in their daily practices (Prieto-Rodriguez 2016) and require a different approach to teaching than that traditionally practiced (De Aldama \& Pozo, 2016; Getenet, Beswick \& Callingham, 2016; Istenic et al., 2016) and these changes also depend on the kind of technology being used (Orlando \& Attard, 2016). For example, one can distinguish between technology which is located in a particular space in the classroom such as the Interactive Whiteboard (IWB) and the portable technology such as tablets. The IWB can be used with traditional teaching methods, but the tablets, since one can move while using them, require different organization of the classroom and different roles from the teacher and the students (Orlando \& Attard, 2016). However, teaching with technology is still teacher-centered, where knowledge is transmitted to the students and they passively consume knowledge rather than construct knowledge together (De Aldama \& Pozo, 2016). This skill of constructive teaching requires reflection from the part of the teachers where new roles demand a new approach to teaching and learning (De Aldama \& Pozo, 2016).

It was also noted that pre-service teachers' skills to integrate technology is very basic, mainly for demonstrations (Aslan \& Zhu, 2016) and they know less how to use certain programmes, like database and webpage design (Markauskaite, 2007). Although digitally native pre- 
service teachers are familiar with various technologies, they are not necessarily experts in technology integration (Kontkanen et al., 2016) and they experience device conflict as they learn how to use it for teaching purpose (Orlando \& Attard, 2016).

Both in-service and pre-service teachers have some expertise to share and collaborative teacher training allow them to share new digital skills when they work in projects using the new technologies (Getenet, Beswick \& Callingham, 2016; Markauskaite 2007; Rye, Landenberger \& Warner, 2012) which training can take place both in the school environment and online (Liang, Ebenezer \& Yost, 2010).

\section{Discussion and recommendations}

The above three factors which affect the teacher's use of technology at school: the teachers' attitudes and beliefs, the teachers' pedagogical knowledge and the teachers' technological skills (Zhao \& Frank, 2003), are in line with Ferrari's (2012) definition of DC where it was stated that a digitally competent citizen must have the knowledge, attitudes and skills when using technology to safely manage information, communicate, create content, and solve problems. One can devise some guidelines or a framework on how best to offer professional development for both pre- and in-service teachers, on how technology could be used for teaching and learning. Applying these areas to the teacher's daily use of technology, some practical suggestions could be devised.

\section{Information management}

Information is ubiquitous and the teachers need to know how to make use of the global information available on the Internet. To manage the information one need to ask the right questions and search from best sources, where then it is evaluated, synthesised and discussed with others (Leu et al., 2004). Training teachers in this DC area will help students learn how to search for information, which requires them to make use of various search engines and read several articles, and finally evaluate was is significant for them (Kinzer, 2010). When teachers together with students manage information on the Internet, the students are learning how to think critically about it. Research indicates that teachers and students lack this skill (Hinostroza et al. 2016) and it is one of the factors contributing to a meaningful use of 
technology during the teaching and learning process (Dastjerdi, 2016). It could contribute towards better acquisition of DC (Hatlevik, Ottestad \& Throndsen, 2015) and practising this skill could diminish the digital divide among students (Karabacak, 2016). Thus, it is the responsibility of the teacher to practise this area of DC at school, so training must be provided. Teaching and learning in information management improves life choices and allows a more secure environment. When managing information, one must also consider the multimodal aspect of information. Information from the Internet is not only textual, it has changed from the printed text to multiple modes of communication and includes the images, sounds, video clips, text and kinesthetic (Istenic et al., 2016; Kress, 2003) and different modality can have different learning effects on the students (Kinzer, 2010). Our students encounter new technologies and new opportunities for learning on a daily basis. Teachers need to realise this potential for learning, when through different modes such as images, sound, videos and text, they seize the students' individual interests and needs. Information management, as suggested in TPACK, also requires from the teacher to choose the right technology and apply the strategies, to learn the new content (Mishra \& Koehler, 2006).

\section{Communication}

In the $D C$ area of communication, it is a requirement for quality teaching, to interact with others while using technology, to share ideas and work collaboratively (EC, 2014; Darling-Hammond, 2013; Getenet, Beswick \& Callingham, 2016; Thompson, Schmidt \& Davis, 2003). Communication can take place both online and on the school premises, with other staff and with the students' parents and when using various technologies.

From a global perspective technology encourages more diversity of ideas and more understanding, for example it allows migrant children to share their life experiences and different cultures. When using technology in the classroom, more interactions are encouraged and teachers tolerate more talking among students (Istenic et al., 2016; Vygotsky, 1978). The role of the teacher changes from a traditional one, where the students expect all the knowledge from their teacher to a more constructive one, where both the teacher and the students learn from each other, thus training is recommended on the constructivist concept of teaching and learning. 
The effectiveness of the use of technology also depends on the school culture, where the school leaders offer encouragement and technical aid when needed (Aydin, Gürol \& Vanderlinde, 2016; Niemi et al 2013; Uluyol \& Sahin 2016). It is recommended that teachers communicate and share their experiences with their colleagues; this sense of belonging makes them feel more confident to try new approaches in their practices with technology (Getenet, Beswick \& Callingham, 2016). Niemi, Kynäslahti and Vahtivuori-Hänninen (2013) called this an open school culture where teachers are encouraged to take risks when integrating evolving technologies in their practices. The result is that they feel part of a community where their work is appreciated as they work towards the students' needs (Niemi et al., 2013). This reflective approach can also allow teacher to appreciate new concepts of constructivist teaching and learning and eventually practise the new teaching roles that such concept underlies (De Aldama \& Pozo, 2016).

In education students' parents are a great human resource, especially when they collaborate with the school and share responsibilities. Through sharing of school activities and communication, the teachers become acquainted with the students' background which is valuable for their learning (Aesaert et al., 2013). Various means of communication can be used, such as the school learning platform, mobile phones and other social media. This is a great opportunity for the teachers to connect and extend their work done at school and interest shown from the family members could cultivate more sharing of ideas and help the student concretize their learning experience. This is even more important when students come from a different culture or speak a different language, since the misunderstandings can be compensated with the use of technology. Online interactions offer global solutions and students have the opportunity to work with others across the globe and appreciate diversity.

\section{Content creation}

In the third area of DC, content creation, it is required that teachers develop the subject content (Ferrari, 2013). Various studies indicated the importance of innovation when using digital technology (De Aldama \& Pozo, 2016; Istenic et al., 2016; Campbell \& Abd-Hamid, 2012; Doult \& Walker, 2014; Hinostroza et al, 2106). The TPACK framework was 
suggested (Mishra \& Koehler, 2006) to plan teaching activities with technology and thus create new content. This TPACK knowledge allows the teacher the framework to integrate technology in their practice when applying the technology, pedagogy and content knowledge to design the best learning experiences with technology for the students. Teacher training on the application of TPACK can allow innovative use of technology, since teaching and learning with technology changes not only how the teacher teaches but the content as well (Mishra \& Koehler, 2006). Furthermore, better results in technology integration can be achieved when teachers observe their colleagues and try the framework together (Getenet, Beswick \& Callingham, 2016). Creating content requires from the teacher a constructivist approach where the teacher and the students are learning and developing the curriculum together (Istenic et al., 2016). The teacher needs to be aware that since the information from the Internet is constantly changing, the teaching strategies need to be adapted accordingly and with new technologies one can create new content. It is recommended that beside interactive games on iPads and the use of IWB a variety of technologies can be used.

\section{Safety}

A digitally competent teacher is required to consider safety when using technology, which incorporates taking care of the devices, protecting the information, protecting one's health and the environment. Practising teachers must be sensitive to legal frameworks so as to act ethically and responsibly, and training should be ongoing with evolving technology and supported by the school (Aydin, Gürol \& Vanderlinde, 2016; Niemi et al., 2013). Concerns over Internet safety can be minimized when the teachers are provided with the right information and support to enhance the use of technology (Uluyol \& Sahin, 2016). The school management are responsible to filter unwanted material, including website. Nevertheless, in this digital environment the teachers can be trained to discuss safety issues with their students. The school might be the only place where such discussions on Internet safety can be held, and students could be guided on to how to proceed once a difficulty is encountered. This approach will better safeguard our students from bad experiences on the Internet in their future. The school together with the local community can organize meetings were all those involved with the students' education will be invited and the school's ICT policies 
will be made explicit. With these boundaries, everyone can feel safer when using technology.

\section{Problem solving}

Most teachers recognise the importance of technology in the students' life and the potential of technology to use it as a tool to further develop the students' learning needs (EC, 2014; De Aldama \& Pozo, 2016; Hatlevik, Ottestad \& Throndsen, 2015; Istenic et al., 2016; Karabacak, 2016; Kinzer, 2010). Teaching and learning when working on projects allow the students to interact more and they have more control on their learning, when together they evaluate their work (Karabacak, 2016; Vygotsky, 1978). Teachers can make use of various digital activities to encourage problem solving; such as computer simulations, scenarios, blogs, coding, storytelling and other inquiry activities (Istenic et al., 2016; Rye, Landenberger \& Warner, 2012; Al-Qallaf \& Al-Mutairi, 2016). Teacher training in this area of problem solving is required to prepare the students to manage their digital lifestyle and to practice their thinking skills. The students' familiarity with computer games can further encourage other problem-solving skills, in computer programming, like coding. Relevant preservice teacher training can guarantee better skilled teachers with the right attitudes to develop the curriculum using these digital skills (Apeanti, 2016; Aslan \& Chang, 2016; Kontkanen et al., 2016).

Since technology is continuously changing, constant training must be provided so as teachers adapt their teaching with new digital tools. This is quite challenging for teachers and they require the knowledge, the skills and the right attitudes to use technology creatively (Dastjerdi, 2016; Getenet, Beswick \& Callingham, 2016; Kihoza et al., 2016; Niemi et al., 2013) and the disposition to experiment with new technologies so as to capture the interests of all the class students (Kinzer, 2010).

\section{Conclusions}

Training teachers in these areas of DC could further enhance the potential of technology to contribute towards students' performance in education and their future needs. In this global digital environment, students need to know more than the programming language and how computers and technical systems work. When practising these 
DC areas at school, teachers are integrating digital technology more fully and the approach more humane, since students are safely learning to collaborate and communicate when using their capacities to create new knowledge (Spiteri \& Chang Rundgren, 2017).

Globally when the teachers practice these areas in their daily school activities, through online projects, they are collaboratively creating new solutions to various topics and the students are learning to appreciate diversity. Technology also allows other people from the community, such as the parents to be involved, which could contribute towards reaching more children.

More research on the teachers' daily use of technology is recommended including comparative studies on each area of DC in various contexts and on the teachers' $\mathrm{DC}$ as a whole. Eventually these five areas could serve as a framework where teacher training on DC could be designed and provided. 


\section{References}

$\rightarrow$ Aesaert, K., Vanderlinde, R., Tondeur, J. \& van Braak, J. (2013). The content of educational technology curricula: a cross-curricular state of the art. Education Technology Research and Development, 61 (1), 131-151.

$\rightarrow$ Al-Qallaf, C. L., \& Al-Mutairi, A. S. R. (2016). Digital literacy and digital content supports learning. The impact of blogs on teaching English as a foreign language. Electronic Library, 34 (3), 522-547.

$\rightarrow$ Apeanti, W. O. (2016). Contributing factors to pre-service mathematics teachers' e-readiness for ICT integration. International Journal of Research in Education and Science (IJRES), 2 (1), 223-238.

$\rightarrow$ Aslan, A. \& Chang, Z. (2016). Influencing factors and integration of ICT into teaching practices of pre-service and starting teachers. International Journal of Research in Education and Science, 2 (2), 359-370.

$\rightarrow$ Aydin, M. K., Gürol, M. \& Vanderlinde, R. (2016). Evaluating ICT integration in Turkish K-12 schools through teachers' views. EURASIA Journal of Mathematics, Science and Technology Education, 12 (4), 747-766.

$\rightarrow$ Campbell, T. \& Abd-Hamid, N. H. (2012). Technology use in science instruction (TUSI): Aligning the integration of technology in science instruction in ways supportive of science education reform. Journal of Science Education and Technology, 22 (4), 572-588.

$\rightarrow$ Darling-Hammond, L. (2013). Getting Teacher Evaluation Right: What Really Matters for Effectiveness and Improvement. New York: Teachers College Press.

$\rightarrow$ Dastjerdi, N.B. (2016). Analysing the opportunities and challenges to use of information and communication technology tools in teaching-learning process. Australian Educational Computing, 31 (1).

$\rightarrow$ De Aldama, C. \& Pozo, J. I. (2016). How are ICT used in the classroom? A study of teachers' beliefs and uses. Electronic Journal of Research in Educational Psychology, 14 (2), 253-286. 
$\rightarrow$ Doult, W., \& Walker, S. A. (2014). He's gone and wrote over it: The use of Wikis for collaborative report writing in a primary school classroom. Education, 42 (6), 601-620.

$\rightarrow$ EC (European Commission) (2013). Survey of schools: ICT in education. Benchmarking access, use and attitudes to technology in Europe's schools. Belgium: European Union.

$\rightarrow$ EC (European Commission) (2014). The International Computer and Information Literacy Study (ICILS). Main findings and implications for education policies in Europe. URL: http://ec.europa.eu/education/library/study/2014/ec-icils_en.pdf

$\rightarrow$ EC (European Commission) (2006). Recommendation of the European Parliament and the Council of 18 December 2006 on key competences for lifelong learning. Official Journal of the European Union, L394/310.

$\rightarrow$ Ferrari, A. (2012). Digital competence in practice: An analysis of frameworks. Seville: Joint Research Centre. URL: http://ftp.jrc.es/EURdoc/JRC68116.pdf

$\rightarrow$ Ferrari, A. (2013). DIGCOMP: A framework for developing and understanding digital competence in Europe. Seville: Joint Research Centre. URL: http:// publications.jrc.ec.europa.eu/repository/bitstream/JRC83167/lb-na-26035enn.pdf

$\rightarrow$ Getenet, S. T., Beswick, K. \& Callingham, R. (2016). Professionalizing inservice teachers' focus on technological pedagogical and content knowledge. Education and Information Technology, 21 (1), 19-34.

$\rightarrow$ Hatlevik, O.E., Ottestad, G. \& Throndsen, I. (2015). Predictors of digital competence in 7th grade: A multilevel analysis. Journal of Computer Assisted Learning, 31 (3), 220-231.

$\rightarrow$ Hernández-Bravo, J. R., M., Cardona-Moltó, C. \& Hernández-Bravo, J. A. (2016). The effects of an individualized ICT-based music education programme on primary school students' musical competence and grades. Music Education Research, 18 (2), 176-194.

$\rightarrow$ Higgins, T. E. \& Spitulnik, M. W. (2008). Supporting teachers' use of technology in science instruction through professional development: A literature review. Journal of Science Education and Technology, 17(5), 511-521.

$\rightarrow$ Hinostroza, J. E., Ibieta, A. I., Claro, M. \& Labbé, Ch. (2016). Characterisation of teachers' use of computers and Internet inside and outside the classroom: The need to focus on the quality. Education and Information Technologies, 21(6), 1595-1610.

$\rightarrow$ Karabacak, K. (2016). Evaluation of faith project in the frame of digital divide. Turkish Online Journal of Educational Technology, 15 (2), 61-72. 
$\rightarrow$ Karchmer, R. (2001). The journey ahead: thirteen teachers report how the Internet influences literacy and literacy instruction in their $\mathrm{K}-12$ classrooms. Reading Research Quarterly, 36 (4), 442-466.

$\rightarrow$ Keengwe, J., Onchwari, G. \& Wachira, P. (2008). Computer technology integration and student learning: Barriers and promise. Journal of Science Education and Technology, 17 (6), 560-565.

$\rightarrow$ Kihoza, P., Zlotnikova, I., Bada, J. \& Kalegele, K. (2016). Classroom ICT integration in Tanzania: Opportunities and challenges from the perspectives of TPACK and SAMR models. International Journal of Education and Development using Information and Communication Technology, 12 (1), 107-128.

$\rightarrow$ Kim, C. M \& Keller, J. M. (2011). Towards technology integration: The impact of motivational and volitional email messages. Educational Technology Research and Development, 59 (1), 91-111.

$\rightarrow$ Kinzer, Ch. K. (2010). Considering literacy and policy in the context of digital environments. Language Arts, 88 (1), 51-61.

$\rightarrow$ Kontkanen, S., Dillon, P., Valtonen, T., Renkola, S., Vesisenaho, M., \& Väisänen, P. (2016). Pre-service teachers' experience of ICT in daily life and in educational contexts and their Proto-Technological Pedagogical Knowledge. Education and Information Technologies, 21 (4), 919-943.

$\rightarrow$ Kress, G. (2003). Literacy in the new media age. London: Routledge.

$\rightarrow$ Law, N. (2007). Comparing pedagogical innovations. In M. Bray (Ed.), Comparative education research: Approaches and methods (pp. 315-337). China: Springer.

$\rightarrow$ Lemon, N. \& Garvis, S. (2015). Pre-service teacher self-efficacy in digital technology. Teachers and Teaching, 22 (3), 387-408.

$\rightarrow$ Leu, D. J. Jr., Kinzer, Ch. K., Coiro, J. L. \& Cammack. D. W. (2004). Towards a theory of new literacies emerging from the Internet and other information and communication technologies. In R.B. Ruddell \& N. J. Unrau (Eds.), Theoretical models and processes of reading (pp.1570-1611). Newark, NJ: International Reading Association.

$\rightarrow$ Liang, L., Ebenezer, J. \& Yost, D. S. (2010). Characteristics of pre-service teachers' online discourse: The study of local streams. Journal of Science Education and Technology, 19 (1), 69-79.

$\rightarrow$ Markauskaite, L. (2007). Exploring the structure of trainee teachers' ICT literacy: The main components of, and relationships between, general cognitive and technical capabilities. Education Technology Research and Development, 55 (6), 547-572. 
$\rightarrow$ McNamara, A. (2016). Digital gesture-based games: An evolving classroom. International Journal of Game-Based Learning, 6(4), 52-72.

$\rightarrow$ Mirzajani, H., Rosnaini, M., Ayub, A. F. M \& Wong, S. L. (2016). Teachers' acceptance of ICT and its integration in the classroom. Quality Assurance in Education: An International Perspective, 24 (1), 26-40.

$\rightarrow$ Mishra, P. \& Koehler, M. J. (2006). Technological pedagogical content knowledge: A framework for teacher knowledge. Teachers College Record, 108 (6), 10171054.

$\rightarrow$ Mustafina, A. (2016). Teachers' attitudes toward technology integration in a Kazakhstani secondary school. International Journal of Research in Education and Science, 2 (2), 322-332.

$\rightarrow$ Niemi, H., Kynäslahti, H. \& Vahtivuori-Hänninen, S. (2013). Towards ICT in everyday life in Finnish schools: Seeking conditions for good practices. Learning, Media and Technology, 38 (1), 57-71.

$\rightarrow$ OECD. (2014). PISA 2012 results in focus. What 15-year-olds know and what they can do with what they know. OECD: Paris.

$\rightarrow$ Omwenga, E., Nyabero, Ch. \& Lazarous, O. (2016). Assessing the influence of the PTTC Principal's competency in ICT on the teachers' integration of ICT in teaching Science in PTTCs in Nyanza Region, Kenya. Journal of Education and Practice, 6 (35), 142-148.

$\rightarrow$ Orlando, J. \& Attard, C. (2016). Digital natives come of age: The reality of today's early career teachers using mobile devices to teach mathematics. Mathematics Education Research Journal, 28 (1), 107-121.

$\rightarrow$ Prieto-Rodriguez, E. (2016). It just takes so much time! A study of teachers' use of ICT to convey relevance of mathematical content. International Journal for Technology in Mathematics Education, 23 (1), 13-24.

$\rightarrow$ Rye, J., Landenberger, R. \& Warner, T. A. (2012). Incorporating concept mapping in project-based learning: Lessons from Watershed investigations. Journal of Science Education and Technology, 22 (3), 379-392.

$\rightarrow$ Spires, H. A., Hervey, L. G., Morris, G. \& Stelpflug, C. (2012). Energizing projectbased inquiry: Middle-grade students read, write, and create videos. Journal of Adolescent \& Adult Literacy, 55 (6), 483-493.

$\rightarrow$ Spiteri, M. \& Chang Rundgren, S.-N. (2017). Maltese primary teachers' digital competence: Implications for continuing professional development. European Journal of Teacher Education (CETE), 40(4), 521-534.

$\rightarrow$ Thompson, A., Schmidt, D., D. A. \& Davis, N. E. (2003). Technology collaboratives for simultaneous renewal in teacher education. Education Technology Research and Development, 51 (1), 73-89. 
$\rightarrow$ Tondeur, J., Forkosh-Baruch, A., Prestridge, S., Albion, P. \& Edirisinghe, S. (2016). Responding to challenges in teacher professional development for ICT integration in education. Educational Technology \& Society, 19 (3), 110-120.

$\rightarrow$ Uluyol, Ç. \& Sahin, S. (2016). Elementary school teachers' ICT use in the classroom and their motivators for using ICT. British Journal of Educational Technology, 47 (1), 65-75.

$\rightarrow$ Vygotsky, L. (1978). Mind in society. London: Harvard University Press.

$\rightarrow$ Wake, D. \& Whittingham, J. (2013). Teacher candidates' perceptions of technology supported literacy practices. Contemporary Issues in Technology and Teacher Education, 13 (3), 175-206.

$\rightarrow$ Wang, Ch.-H., Ke, Y.-T., Wu, J.-T. \& Hsu, W-H. (2011). Collaborative action research on technology integration for science learning. Journal of Science Education and Technology, 21 (1), 125-132.

$\rightarrow$ Wastiau, P., Blamire, R., Kearney, C., Quittre, V., van de Gaer, E. \& Monseur, Ch. (2013). The use of ICT in education: A survey of schools in Europe. European Journal of Education, 48 (1), 11-27.

$\rightarrow$ Zaranis, N. (2016). The use of ICT in kindergarten for teaching addition based on realistic mathematics education. Education and Information Technologies, 21 (3), 589-606.

$\rightarrow$ Zhao, Y. \& Frank, K. A. (2003). Factors affecting technology uses in schools: An ecological perspective. American Educational Research Journal, 40 (4), 807-840.

$\rightarrow$ Zyad, H. (2016). Integrating computers in the classroom: Barriers and teachers' attitudes. International Journal of Instruction, 9(1), 65-78. 


\section{Biographical notes:}

Marthese Spiteri obtained her Master's degree in International and Comparative Education from Stockholm University. Her main research interests include teachers' training on digital competence (DC) and the potential of technology for the students' life; how it affects their learning and social inclusion. She is currently involved in a research group on Competence for Modern Citizenship (CMC).

Shu-Nu Chang Rundgren is a professor at Stockholm University and focuses on teaching and learning of socioscientific issues (SSI) and informal argumentation. SSI includes science/technology (S), environment $(E)$, economy $(E)$, social culture $(S)$, ethics $(E)$ and policy (P). In 2010 the model term SEE-SEP had been developed. Currently she focuses on Competence for Modern Citizenship (CMC) concerning scientific and media literacy for responsible citizenship. 



\title{
The learning outcomes approach: reflections from two Maltese trainers
}

\author{
Doreen Said Pace \\ Ministry for Education and Employment, Malta \\ Anita Seguna \\ University of Malta
}

\section{Abstract}

Currently, in Malta, the Learning Outcomes Framework (LOF) is the most widely discussed topic between Maltese educational practitioners. This national systematic shift from a content based to an outcomesbased approach requires a refinement of one's beliefs about the philosophy of teaching and learning. This chapter briefly outlines the seminal work of the learning outcomes and its effect in the Maltese educational sphere. We define terms such as aims, objectives, and outcomes. Then, we move on to discuss the alignment of these three elements with assessment as the crucial ingredients for an effective lesson embedded within a learning outcomes approach. One of the key aspects for this implementation is planning characterised by what Biggs $(2003 a, b)$ calls "constructive alignment." This has implications on the teacher's and learners' roles within teaching and learning. Engagement on its own is not a guarantee of learning. Therefore, the quality and level of engagement are crucial. Success in the learning outcomes approach is thus achieved when good teachers adopt child-centred approaches. Heads of schools are also catalysts in the successful implementation of this approach. The importance of constructive alignment in one's teaching as well as a shift in the approach taken during teacher training courses, from professional development to professional learning, are crucial for a change in mindset. 
Keywords:

learning outcomes

objectives

mind-set

constructive alignment

professional learning training 


\section{Introduction}

This chapter presents the conceptual perspective of two Maltese Learning Outcomes Framework (LOF) trainers who had the possibility of working alongside as well as reflecting with other Maltese trainers from all educational sectors. Although our educational background differs, these differences have encouraged us to reflect upon and discuss the implications of the learning outcomes process to share the enthusiasm and new knowledge gained. The reflective stance that we take offers a multi-level reflective process from a theoretical and practical point of view.

A conceptual perspective has been adopted since empirical research in the LOF is still underway. Projections for the launching of the learning outcomes were September 2016. Therefore, LOF training for trainers took place between October and December 2015 with over seventy trainers graduating. Professional learning sessions were intended soon after but were halted by the Malta Union of Teachers (2016) in order to allow for more discussions and understanding to take place. This temporary interruption encouraged us to join forces and reflect upon how this interlude could affect us both in our professional roles and as LOF trainers.

Despite this halt in the State and Church Sectors, Independent schools wishing to run professional learning sessions with the teaching staff were still able to do so. In light of this, professional learning sessions were held at two independent schools. As an LOF Trainer and Head of Curriculum Design, Seguna had the opportunity of implementing professional training with the teachers within these schools thus putting the theoretical training obtained into practice. This leveraged our position to reflect on the teachers' responses and to offer practical recommendations for professional learning sessions within other educational institutions in Malta. This learning from practice, and listening to teachers' voices will be of assistance to other LOF trainers, when planning and implementing the professional learning of teachers in Malta. Generalisability is not possible since empirical research has only been carried out in two schools. However, our paper will suggest some transferability in terms of the process which may be undertaken by other trainers. The sharing of various methods, which had positive effects on the professional staff in these schools, encouraged us to reflect and share this experience with others. 
This professional development contrasted with the current topdown approach adopted in professional development training in Malta. The European Agency for Special Needs and Inclusive Education (2014) has reaffirmed this through an external audit commissioned by the Ministry of Education. It identified that "no stakeholder group considers that the initial or in-service training for SMTs, teachers, LSAs or other educational professionals fully meets the demands that these professionals face in schools" (p. 49). As LOF trainers we both believe in the social constructivist paradigm of learning, wherein knowledge is socially constructed and our actions shape the realities we are part of (Vygotsky, 1978). Seguna, therefore, capitalised upon this social nature of knowledge and reality and through the professional learning training sessions, she provided teachers with opportunities for the deconstruction and co-construction of knowledge.

Several studies (Wain et al., 1995; Bezzina \& Camilleri, 2001; Bezzina, 2002), amongst others, were influential on subsequent policy reforms in Malta. The NCF, too, contributed to the necessary change that professional development needs to undergo in Malta. Therefore, what Seguna engaged in was novel from a practical rather than a theoretical perspective. Hence, the examples we offer in this paper are authentic examples from practice about what the theory of contemporary professional development has been advocating. Consequently, our reflections support the ongoing emphasis for a revamped form of professional development and enrich the current literature by local exemplars from practice.

Several Maltese studies, amongst which are Wain et al. (1995), Bezzina and Camilleri (2001), Bezzina (2002), had already influenced policy reforms, particularly the NCF and had indicated the necessary changes in professional development. International authors (Fullan, 1991, Martinez, 2011), among others, were also influential in the professional development approach Seguna decided to adopt. Therefore, Seguna's approach, which had already been proven from a theoretical perspective, was being put to the test in a practical situation. Hence, the examples we offer in this paper are authentic examples from practice about what the theory of contemporary professional development had been advocating.

Modern professional learning should offer teachers a bottom-up experience placing them in a learner-centred position which they should adopt within their own classrooms. The Ministry of Education 
and Employment (2012), through the NCF legal document, reiterates this need to rethink the professional development of teachers. Particularly, it states that:

"to be successfully implemented the sustained and continued up skilling and re-skilling of educators' competencies to deliver the new pedagogies requires a structured professional development programme that goes beyond what the current structure for training permits (xvi)."

This gave rise to the setting up of the Institute for Education (IfE) ${ }^{1}$, an educational hub, which provides customised professional learning for individual schools and teachers. It aims at offering professional learning, through a blended approach, in order to provide the essential knowledge, skills, competences and attitudes of the 21 st century. In turn, it is hoped, teachers should then be able to share and cultivate these through their teaching and learning approaches.

\section{The Maltese educational background context}

One of the crucial questions which dominated our reflections has been whether the LOF was just another reform or a gradual build-up. Over the years there was a theory-practice gap, as the European Agency for Special Needs and Inclusive Education (2014) has pointed out in its report on the Maltese current educational practices, and therefore practitioners have been seeing this framework as another reform. It appears that this perception could have contributed to the framework's current temporary halt. From our end, we feel that the LOF should have been perceived as a natural step following the number of reforms which were put into place since 1995.

A brief outline of the major reforms which led to the LOF will be delved into to substantiate our claim.

\section{Major educational reforms}

We believe that major reforms in Malta emanated through Wain et al.'s (1995) report, Tomorrow's Schools: Developing Effective Learning Cultures, which proposed very sound ideas. Amongst its recommendations, the notion of a quality education for all through the entitlement of the individual learner, the development of the school as learning communities and the importance of conducive

1. http://instituteforeducation.gov.mt/en/Pages/default.aspx 
learning environments were focused upon. These recommendations necessitated the review of the 1988 National Curriculum leading to the new curriculum by the Ministry of Education (1999).

The updated curriculum was structured around a set of principles based on the philosophy of social justice. In a nutshell, these principles focused upon both the physical and the pedagogical aspects of inclusion, thus providing an inclusive learning experience in its wider sense. The restructuring of the secondary schools was immediately taken up resulting in the document For all children to succeed by the Ministry of Education, Youth and Employment (2005). Ten state colleges were established facilitating the continuity between the cycles of compulsory schooling and emphasising the idea of networking.

This offered a new challenge to teachers, especially those who were accustomed to teaching in grammar schools since they were not used to such a wide variety of learning needs. Subsequently, the current National Curriculum Framework for All (NCF) launched by the Ministry of Education and Employment (2012) suggested Assessment for Learning (AfL) as one of the pedagogical approaches offering a meaningful learning experience for all. Furthermore, the NCF proposed a learning approach based on outcomes rather than content. AfL fits perfectly in this recommendation as through its success criteria strategy it complements this outcomes approach. For learning experiences to become more meaningful, the Ministry for Education and Employment, together with the Directorate for Quality and Standards in Education (2015), launched the Learning Outcome Framework (LOF).

\section{The Learning Outcome Framework}

The LOF aims at offering a developmental approach to learning through an outcomes-based system. This requires future LOF practitioners to question their philosophy of teaching and learning. It also necessitates practitioners to question and reflect on their own working paradigm and analyse whether it is based on the behavioural or constructivist framework. The LOF, similarly to AfL, is not only based on the social constructivist paradigm, but it also shares a similar working language.

In AfL, the working language is one of learning intentions or goals, success criteria, which are the broken-down outcomes, effective questioning, feedback, self and peer assessment. With LOF, the working language is one of aims, objectives, outcomes, and assessment. 
Kennedy $(2006,2015)$, one of our international trainers, distinguishes between aims, objectives and outcomes, as follows:

$\rightarrow$ an aim is like an umbrella. It provides the bigger picture of what a topic aims to achieve;

$\rightarrow$ an objective, on the other hand, is a specific, concise and clear statement of what the teacher hopes to achieve by the end of the lesson; and

$\rightarrow$ an outcome is a "statement of what a student should know, understand and/or be able to demonstrate after completion of a process of learning" (European Union, 2011).

This implies that during the planning of one's lessons, a teacher should break down the objective into measurable learning outcomes. By doing so, the assessment procedures would be facilitated for both the teachers and the learners, as they would both know what to look for. The use of either self, peer or teacher assessment fits very well within this objective-outcome approach. The synchronisation of these four elements - aims, objectives, outcomes and assessment - is crucial for a successful lesson with an outcomes approach.

The LOF portrayed a change in the local teaching and learning approach which consequently triggered a change in the system's assessment procedures. For this purpose, each subject, in addition to its learning outcomes, was supplied by an educators' guide for pedagogy and assessment. Each guide places the learner at the centre by focusing upon an inclusive pedagogy and a variety of assessment strategies. This approach encourages teachers to tweak their approach unless they have already done so. In order to emphasise this aspect, in a personal communication addressed to the LOF trainers, we can emphasise that for a number of teachers who were already using child-centred pedagogies like (inquiry-based learning, AfL, Let Me Learn, ongoing assessment techniques, right questioning techniques ...) the changes brought about will be minimal. These approaches are based on a constructivist teaching and learning philosophy. Hence, proponents of each are already practising the learning intention/goal/objective and success criteria. Therefore, practitioners who are using these approaches in the way that they should be used are already a step ahead in the adoption and implementation of LOF. 
What might be different from the present practice is the approach to lesson planning. Several questions need to be asked during this phase. These include:

$\rightarrow$ What do I want the learners to learn?

$\rightarrow$ How will I know that my learners have reached the lesson's goal?

$\rightarrow$ What diversification of outcomes are needed to reach all the levels of ability in my class?

These questions might contrast with the current approach to planning which starts with the planning of the activity. Rather, the activity should be thought of as the last thing. McTighe and Thomas (2003) refer to this as the backward design to learning. Class practitioners need to ask themselves, "Am I using a forward or backward design to learning?" Upon answering this question, the change or refinement of practice commences.

Since assessment is central to the teaching and learning activity, it follows, that assessment should take a significant role in planning too. This is addressed by another question during the planning stage: "What kind of assessment tasks can help me (the teacher) to gather the evidence of learning, and for the learners, to judge their learning?" The convergence of goals, outcomes and assessment has been referred to by Biggs (2003b) as constructive alignment.

Table 1 below illustrates the planning a class teacher could adopt for a literacy lesson.

Table 1. An example of a literacy lesson

\section{Objective}

to give an opportunity to make predictions from the book cover as reference point.

\section{Assessment \\ oral assessment (answering and pointing) Writing}

\author{
Learning Outcomes \\ Identify the author's and illustrator's name. \\ Define the role of the author. \\ Define the role of the illustrator. \\ Answer questions about the front cover \\ (author, illustrator, title) \\ Talk about/Act out the time, setting and \\ characters in the story \\ Explain what is going to happen. \\ Design/Write the prediction in their booklet.
}

Resources: booklets for children, blue tack, cardboard to hide picture on front cover 


\begin{tabular}{l|l|}
\hline Learning Activity 2 & Tap into children's prior knowledge \\
\hline Learning Activity 3 & $\begin{array}{l}\text { Reveal the front picture } \\
\text { Discuss what the story might be about }\end{array}$ \\
\hline Learning Activity 4 & Discuss the characters, the setting and the time \\
\hline Learning Activity 5 & Refer to the author and illustrator \\
\hline Learning Activity 6 & $\begin{array}{l}\text { Group the children in 3s and ask them to write all their predictions on } \\
\text { the given booklets. }\end{array}$
\end{tabular}

Such approach to teaching and learning ensures that teachers are adopting a developmental and readiness approach according to their learners' needs. Planning and teaching from a readiness perspective is in line with both the NCF and LOF rationale whose aim is to free teachers from prescriptive syllabi. In turn, this implies that teachers are not bound by the syllabi content but by the set of outcomes within a performance level. This allows teachers to better control the teaching and learning episodes. Although this might be a welcome move by some teachers, the cultural shift from the current comfort zone to the new expected working zone is quite significant. Bezzina and Camilleri (2001, p. 159) had reflected upon reforms taking place nearly two decades ago: "The reforms we have been witnessing over the years has failed to address the major goal of reform: that of improving the quality of schooling. Our history of education revolves around a series of reforms and counter reforms mainly provoked by political and ideological polarisation and consequently by the absence of consensual and organic planning."

We therefore reflect that if the meting out of the LOF is not addressed appropriately, a similar level of uneasiness will be felt. Borg and Giordmaina (2012, pp. 4-5), also reiterate this point since they believe that teachers do not see reforms as "... a form of regeneration,... progress, (or) ... a source of empowerment."

\section{A Change in mind set}

What has been discussed, in the previous section, suggests a change or refinement in one's modus operandi. However, this cannot take place unless one starts to change one's mind-set, that is, the thinking about the LOF.

In our training, we have been strongly advised that this mind-set could be facilitated if the teachers' learning is a model of the learners' learning in class. Therefore, the teachers' professional learning sessions 
should be based on the same lesson structure of aims, objectives and outcomes that they are expected to plan within the LOF.

As illustrated in Table 1 above, each learning outcome commences with a verb showing the thinking behaviour that underlies every action. Bloom (1956) classifies these behaviours in three categories, namely, the cognitive, affective and psychomotor. Each category can manifest itself across six distinct levels of thinking ranging from knowing to evaluating a task. This therefore implies that teaching needs to cater for every learner's level of thinking and style of learning.

This is also being reiterated in European workshops about school based professional development. During a recent Council of Europe Pestalozzi programme workshop (2016, pp. 1004-1007) attended by Said Pace, Rolands Ozols, Chairman of the Board of the Institute for Lifelong Learning and Culture in Latvia, sustained that teachers must go through the same process as the learners especially where higher order thinking opportunities are involved.

As to the style of learning, this can be tapped using multiple intelligences (MI) within the training and the classroom. This can be done, first and foremost, by using $\mathrm{Ml}$ as hooks to engage the learners and put them centrally within the topic. An array of multiple intelligences can also be used throughout the training and in one's teaching so that the diverse learners' needs are taken into consideration. Hyland (2000) sustains that the use of multiple intelligences allows teachers to use different methods to unlock diverse gateways to learning. This is in line with the Faculty Development and Instructional Design Centre's (2009) explication of multiple intelligences. In an adaptation of Gardner's theory of multiple intelligences, in businessballs.com (n.d.), the Faculty Development and Instructional Design Centre (2009) defines Ml as the human potential which can be tied to one's preferences to learning; thus, Gardner's focus on human potential lies in the fact that people have a unique blend of capabilities and skills (intelligences). This model can be used to understand "overall personality, preferences and strengths."

The Faculty Development and Instructional Design Centre's (2009) asserts that according to Gardner people who have an affinity toward one of the intelligences do so in concert with the other intelligences as "they develop skills and solve problems" (businessballs.com, 2009). To reiterate this point, as seen in Table 1 above, various intelligences were 
used in an English literacy lesson. The teaching, during this exemplar, did not tap only into the learners' verbal intelligence but allowed space for other intelligences such as the kinaesthetic, visual/spatial and musical/rhythmic.

\section{Professional development in Malta}

Professional development in Malta was introduced in 1988 soon after teaching grades were awarded the status of professionals. This meant that teachers had to seek for professional opportunities with the assistance of the Head of School and the local education authority. Heads of Schools, on the other hand, had the dual role of providing for their own and their teachers' professional development. To facilitate this provision, an agreement was reached between the Malta Union of Teachers (MUT) and the Ministry of Education Youth and Employment (2007) on behalf of the Government. Since then, professional development within the state sector consists of six two-hour sessions during and after school hours. Over and above these sessions, many teachers may be called for additional three half-days of in-service training. Any other professional opportunities for growth are upon the discretion and willingness of the individual. In the independent sector, each school has its own framework for the professional development of its teachers.

For professional development to be effective, teachers need to feel the need for and see relevance in the training that is offered to them. Relevance can be seen if the professional development sessions mirror what the teachers should do in class. The basic premise of in-class teaching and learning is to reach the full potential of every student. Likewise, professional development sessions should reach each teacher's potential. This potential can be tapped into through the inclusion of Multiple Intelligences which not only delve into the traditional types of intelligences like the verbal and visual but more importantly invoke inter- and intra-personal reflection. This kind of reflection is crucial during the teachers' lesson planning as it directs the teacher to focus on the use of different intelligences to reach out to a diverse classroom set-up.

If an understanding of multiple intelligences is delved into during professional learning sessions, teachers will be made aware of their students' different intelligences and how to cater for them. If they 
are also utilised during the professional learning sessions, teachers will stand to benefit even more. The teachers are the "learners" during these sessions and therefore, whilst getting to use their different intelligences, they also get to experience the hands-on sessions which will consequently help them understand how to include them in their lesson planning.

Seguna took up this belief and devised a professional learning plan for the Senior Leadership Team, teachers and LSAs within the independent schools she works in. Table 2 outlines such example. This is, of course, one way of approaching such sessions. Other approaches and ways could and should be tapped into. The most important aspect to consider during the training sessions is that they are as practical and hands-on as possible so that all learning is linked to the teachers' everyday experiences in the subjects they teach. To demonstrate how this can be put into practice, a professional learning session was based on the theoretical underpinnings of Biggs' (2003b) constructive alignment and sought to ensure that all sessions and focus points were practical in nature.

Table 2. An example of a professional learning session on multiple intelligences.

\begin{tabular}{|c|c|c|}
\hline OBJECTIVES & STRATEGIES/RESOURCES & LEARNING OUTCOMES \\
\hline $\begin{array}{l}\rightarrow \text { To define } \\
\text { multiple intelligences } \\
\rightarrow \text { To see how multiple } \\
\text { intelligences can be used as } \\
\text { hooks/entry points. } \\
\rightarrow \text { To provide an opportunity } \\
\text { of using multiple intelligences } \\
\text { during the lesson }\end{array}$ & $\begin{array}{l}\rightarrow \text { Creation of a poster } \\
\rightarrow \text { Science experiment set up } \\
\rightarrow \text { Video of a maths lesson } \\
\rightarrow \text { Background music } \\
\rightarrow \text { PowerPoint presentation }\end{array}$ & $\begin{array}{l}\rightarrow \text { I can define } \\
\text { multiple intelligences } \\
\rightarrow \text { I can explain what hooks/ } \\
\text { entry points are } \\
\rightarrow \text { I can assess a given lesson/ } \\
\text { activity and identify what } \\
\text { multiple intelligences are } \\
\text { being used } \\
\rightarrow \text { I can modify an activity } \\
\text { using multiple intelligences }\end{array}$ \\
\hline
\end{tabular}

$\rightarrow$ Create a poster

$\rightarrow$ Evaluate the Maths lesson

$\rightarrow$ Analyse own lesson and update it to include multiple intelligences

The professional learning sessions were practical in nature and linked to the teachers' area of expertise and experiences within the classroom. Following the sessions, written evaluative feedback was obtained. Teachers commented that they felt more engaged, not spoken down to, actively involved, and had been provided with an opportunity for deeper intrapersonal reflection. Additionally, they commented that 
"The session was always linked to what we do in class, so one could see the relevance of this." Furthermore, they affirmed that, "I've actually started to think about my own lesson plans and how I can include more aspects from different intelligences" and, hoped for, "... more of these practical sessions, where practical ideas are discussed and feedback on our lessons is given."

The provision of meaningful teaching and learning experiences are possible if professional learning sessions provide opportunities of dialogue and reflection upon one's work (Hyland 2000) which will hopefully lead to the teachers' personal and professional growth. Moreover, professional learning sessions need to help restore and recover the teachers' personal and professional identities which, according to Pattie (2009), might have been disturbed by the educational reforms.

Providing such opportunities for social learning offers teachers a safe environment within which they are able to discuss, reflect and consider changing their practices, thereby moving away from their longestablished ones (Birenbaum et al., 2009). This, according to Helsing (2007), often brings about fear and anxiety which can be mitigated when colleagues work together in their own school environment about issues which are directly relevant to their everyday classroom experiences. Through professional learning sessions, teachers are offered the possibility of sharing their ideas, offering suggestions and trying these out in class. When these trials are shared in the subsequent professional learning sessions, teachers will be more willing to accept shared ideas since they would have been, as Haggarty and Postlethwaite (2003) argue, "tried and tested" by their own colleagues who share the same environment. If the period between professional learning sessions is enhanced through peer observation, teachers will be able to observe each another and build trusting relationships through which they are able to discuss their successes and failures. This, therefore, entails not only the re-structuring but also the re-culturing of the learning organisation (Fullan, 1993).

Reflection on practice needs time and space. Schools already have their allocated timed sessions but these are not enough. For professional learning to become embedded, Stoll (2015) argues that school leaders need to become creative with the time and space available. Furthermore, Stoll provides practical advice such as "covering classes themselves ... 
rearrange timetables ... [bringing in] retired teachers ... or finding other ways to free staff" (ibid., pp. 5-6).

Although teachers reacted positively to the training provided by Seguna, a fear emerged about not having enough time to be creative within one's planning and lessons. Such a battle against time is often brought up by teachers as their current priority is syllabus coverage and student preparation for mid and final year exams. This is especially true of secondary teachers who also have the national SEC exams looming on them. Educating students within an exam-oriented system, constraints teachers to adopt and focus on the methodological approach instead of the conceptual one. Hence, students are becoming good at being technical reproducers of a method rather than the ability to analyse and evaluate what is being asked of them. Teachers, therefore, fear a change in strategy which might have previously brought about the success in their learners' exam results. Unfortunately, the Maltese educational system and society judge teachers by the quantitative achievements of their students. Very recently, this has been acknowledged and firmly sustained by the Hon. Minister of Education and Employment Evarist Bartolo who claimed that the Maltese educational system is not preparing students for work and life as it is too focused on exams (Pace, 2016). Hyland (2000) has highlighted that a strong focus on exams "paradoxically" impinges upon any innovations in the educational sphere. Recommendations by the most recent Maltese educational policies, namely the NCF and the LOF, have been received in a similar manner.

Similarly, the pressure of exams affects Heads of School. As much as teachers are judged by the performance of their students, Heads of School are judged by the global performance of their school. It follows that exams are having an impact on both the teachers' and the Heads of School's priorities. This implies that exams might be hindering Heads of School in initiating, fostering and monitoring the recommended policy changes. Apart from exams, administrative demands also impinge upon the Heads' priorities. The Head of school's priority should be the teaching and learning. Therefore, the Head should continue to ensure that one of the school development plan's targets focuses upon this and appears in the professional training plan. Apart from feeling the need for the training, Heads of School also need to be trained first as well as attend the training with staff. To ensure success Heads of School need to be part of the whole process so that they too take ownership 
of the training and are better able to follow up with the training in the teachers' day-to-day teaching. Such an idea is strongly reiterated by Borg and Giordmaina (2012, pp. 4-5) who believe that "Having on board key players such as teaching personnel and school management teams is crucial for the success of any educational reform, anywhere."

Heads of School could be better supported with the assistance of a professional in curriculum matters. This "expert" could be part of the school staff who shares the same successes and challenges of the teachers thus making his/her professional input easily accepted by the teachers. Having a professional focused on curriculum matters does not demean, in any way, the professional responsibility of the Head of School in monitoring and supporting the teachers' learning. Instead, this "expert" can offer more sustainability and consistency so that together they would have the opportunity of discussing the professional learning of the teachers and ensure that actual school needs are being met.

National documents and policies have advocated the need for collegiality and collaboration, spearheaded by the SMT. One such example was the document Knowing our school (2004) which provided the school's leadership team with a golden opportunity to engage in a School Evaluation and Development Process through which it could identify and highlight its training needs. Likewise, the NCF (2012) has also recommended a structured professional development programme which would go "beyond what the current structure for training permits" (NCF, 2012, p. xvi). It reaffirmed that professional development needed to be continuous and not a one-off session. Thus, in collaboration with the teaching staff, the SMT will be able to ensure that the school development plan facilitates "the implementation and pursuance of the learning outcomes framework in view of the differing contexts of every school and the particular needs of its students" (Ministry For Education and Employment, 2016). This planning links to the training needs analysis that each school should undergo in preparation for the school's development. The emergent needs could then be catered for through in-house trainers, the Institute for Education or any other professional trainer that the school wishes to engage.

A School Development Plan, in terms of a learning outcomes approach, can be planned through aims, objectives and outcomes. The SDP report plan could mirror the same structure of professional learning sessions and class lessons that are being advocated by the 
LOF. Constructive alignment can therefore be taken to the macrolevel in planning rather than remaining at the micro-level of lesson planning. Our reflections have taken us a step forward to the creation of a three-tiered constructive alignment model (see Figure 1) between the teacher's lesson planning, the professional learning training and the school development plan.

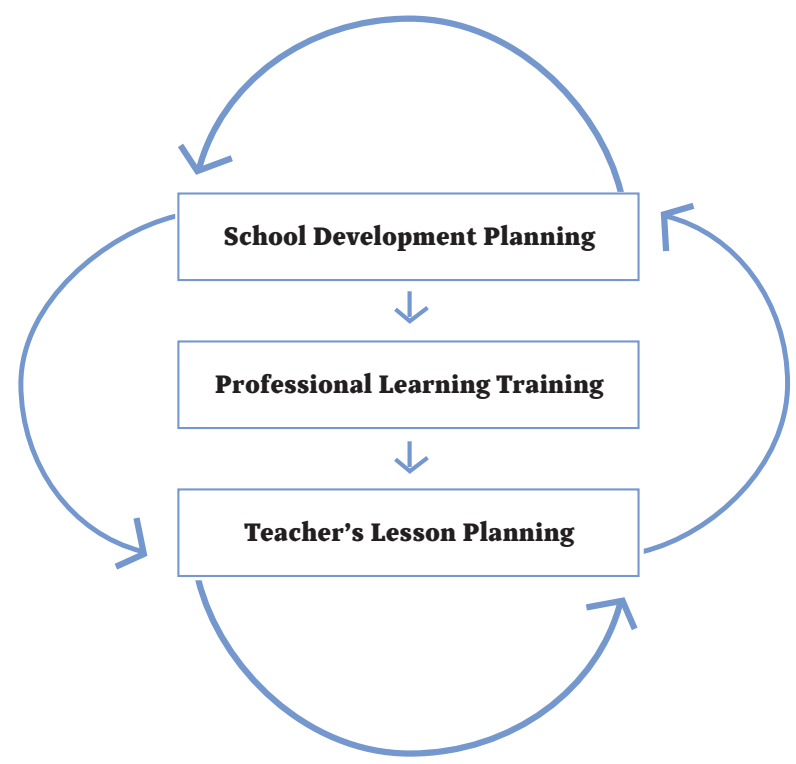

Figure 1. Our model for a holistic constructive alignment

Our model is a result of a long process of reflection based on the intensive training that we received as LOF trainers, the reactions to the initial dissemination professional meetings as well as the most recent public consultation document on the new proposed Education Act. We feel that when identifying the school development planning, professional learning is given its due importance not proceeding but as part and parcel of the SDP document. Since teachers contribute towards the writing of the SDP, they will be able to identify the learning that they wish to undergo to reach the outcomes in the SDP. If teachers take a learner-centred approach for their own professional learning, greater ownership and participation in these sessions will be enhanced. This will imply that the professional learning plan would therefore need to be relevant to the teachers' self-identified learning needs. If this 
relevance is felt, teachers will be better able to transfer what they have experienced into their planning and classrooms. This will, in turn, affect the evaluation of the SDP and impinge upon the targets for the following year.

The Ministry for Education and Employment (2016, p. 7) sustains the crucial role of School Development Plans when stating that "It shall be the duty of schools ... to ensure that the National Curriculum Framework is translated into appropriate curricula, programmes, pedagogies and assessments for the students through an adequate school development plan and that these are implemented." If this is the Ministry's belief, it is therefore advisable that before imposing topics of national priority to be included in the schools' SDP, it either finds other means to disseminate its national priorities or informs schools well in advance so that these national priorities are included in the schools' SDPs.

\section{Conclusions and implications}

In the above discussion, we have outlined a series of policies and reforms, drawn up, over the years, by the Ministry for Education (Malta), which have ultimately led to an outcomes-learning approach. An initial huge investment in trainers was carried out to ensure appropriate training prior to the inception of the learning-outcomes framework. It is therefore crucial that all the educators, teachers and school administrators alike, involved in the successful implementation of this approach, do not see this as another reform thus missing out on the golden opportunity of a more meaningful learning experience which this approach presents.

Apart from the need for this approach to take flight, a bottom-up approach in teacher training also needs to be invested in. Teachers need to feel part and parcel of the professional learning that takes place within their schools. Therefore, reliable and consistent structures need to be put into place where professional development activities, related to a particular topic, are not just one-off events. Instead, it is advisable that a topic is drip-fed throughout all the sessions along the year. This has also been affirmed in the current public consultation document of the revised Education Act by the Ministry for Education and Employment $(2016$, p. 8) where one of the changes that is being proposed is the promotion of "continuous professional development of educators." 
Professional learning needs to be engaging enough in a way to attract the teachers' interest and enhance their willingness and readiness. The role of a professional in curriculum matters is also of the asset since they would be familiar persons whom the teachers can relate to and trust, giving professional learning the thrust it needs. Through this professional curriculum leader leading the plan in collaboration with the Head of School who is wholly engaged in the whole process, as well as a bottom-up approach throughout the sessions, teachers will be better engaged in their learning. The LOF will be consequently be embedded through the right ingredients, within the necessary supportive learning environment. 


\section{References}

$\rightarrow$ Bezzina, C. (2002). Rethinking teachers' professional development in Malta: Agenda for the twenty-first century. Journal of In-Service Education, 28 (1), 57-78.

$\rightarrow$ Bezzina, C. \& Camilleri, A. (2001). The professional development of teachers in Malta. European Journal of Teacher Education, 24(2), 157-170.

$\rightarrow$ Biggs, J. (2003a). Aligning teaching and assessment to curriculum objectives: Imaginative curriculum project. LTSN Generic Centre 12.

$\rightarrow$ Biggs, J. (2003b). Aligning teaching for constructing learning. The Higher Education Academy, 1-4.

$\rightarrow$ Birenbaum, M., Kimron, H., Shilton, H. \& Shahaf-Barzilay, R. (2009). Cycles of inquiry: Formative assessment in service of learning in classrooms and in school-based professional communities. Studies in Educational Evaluation, 35 (4), 130-149.

$\rightarrow$ Bloom, B. S. (1956). Taxonomy of educational objectives: The classification of educational goals. New York: Longmans, Green.

$\rightarrow$ Borg, M. \& Giordmaina, J. (2012). Towards a quality education for all: Every teacher counts. Malta: The Malta Union of Teachers.

$\rightarrow$ European Agency for Special Needs and Inclusive Education (2014). Education for all. Special Needs and Inclusive Education in Malta. External Audit Report. Brussels.

$\rightarrow$ European Union (2011). Using learning outcomes framework. European Qualifications Series: Note 4. Luxembourg: Publications Office of the European Union.

$\rightarrow$ Faculty Development and Instructional Design Center (2009). Howard Gardner's theory of multiple intelligences. Access on November 4, 2016. Available at: http://www.niu.edu/facdev/_pdf/guide/learning/howard_gardner_ theory_multiple_intelligences.pdf. 
$\rightarrow$ Fullan, M. (1993). Change forces: Probing the depths of educational reform. London: The Falmer Press.

$\rightarrow$ Haggarty, L. \& K. Postlethwaite (2003). Action research: A strategy for teacher change and school development? Oxford Review of Education, 29 (4), 423-448.

$\rightarrow$ Helsing, D. (2007). Regarding uncertainty in teachers and teaching. Teaching and Teacher Education, 23 (8), 1317-1333.

$\rightarrow$ Hyland, Á. (2000). Multiple intelligences, curriculum and assessment project: Final report: NAIRTL.

$\rightarrow$ Kennedy, D. (2006). Writing and using learning outcomes: A practical guide. Cork: University College Cork.

$\rightarrow$ Kennedy, D. (2015). Writing and using learning outcomes: The key concepts. Cork: University College Cork.

$\rightarrow$ Malta Union of Teachers (2016). LOF implementation to be postponed and PD sessions on subject temporary stopped. Malta.

$\rightarrow$ McTighe, J. \& Ronald S. T. (2003). Backward design for forward action. Educational Leadership, 60 (5), 52-55.

$\rightarrow$ Ministry For Education and Employment (2016). Bridging education in the 21st Century. Sliema, Malta: Salesian Press.

$\rightarrow$ Ministry For Education and Employment, and Directorate for Quality and Standards in Education (2015). About the learning outcomes framework. Sliema, Malta: Salesian Press.

$\rightarrow$ Ministry of Education (1999). Creating the future together: National Minimum Curriculum. Sliema, Malta: Salesian Press.

$\rightarrow$ Ministry of Education and Employment (2012). A National Curriculum Framework for all. Sliema, Malta: Salesian Press.

$\rightarrow$ Ministry of Education Youth and Employment (2005). For all children to succeed. Sliema, Malta: Salesian Press.

$\rightarrow$ Ministry of Education Youth and Employment (2007). Agreement between the Government and the Malta Union of Teachers, Fov-mut. Directorate for Quality and Standards in Education and Directorate for Educational Services. Malta.

$\rightarrow$ Pace, Y. (2016). Education system not preparing children for life - Evarist Bartolo. Maltatoday. Accessed on October 28, 2016. Available at: http:// www.maltatoday.com.mt/news/budget-2017/71071/education_system_not_ preparing_children_for_life_evarist_bartolo\#.WBdA5iQ3Ifv . 
$\rightarrow$ Pattie, L.F. \& Yuk, Y. (2009). Teachers' stress and a teachers' development course in Hong Kong: Turning 'deficits' into 'opportunities'. Professional Development in Education, 35 (4), 613-634.

$\rightarrow$ Stoll, L. (2015). Using evidence, learning and the role of professional communities. In C. Brown (Ed.), Leading evidence use in schools (pp. 54-65). London: IOE Press.

$\rightarrow$ Vygotsky, L. S. (1978). Mind in society: The development of higher mental process. Cambridge, MA: Harvard University Press.

$\rightarrow$ Wain, K., Attard, P., Bezzina, C., Raymond, C., Darmanin, M., Farrugia, C., Psaila, A., Sammut, J., Sultana, R. \& Zammit, L. (1995). Tomorrow's schools: Developing effective learning cultures. Malta: Ministry of Education and Human Resources. 


\section{Biographical notes:}

Doreen Said Pace is a Head of Department (HOD-Assessment) within the Maltese Educational Assessment Unit and a part-time lecturer at the Institute for Education, Malta. In the past eighteen years, she held various roles in the domains of inclusion and assessment. In teacher education, Doreen supports undergraduate students during their teaching practicum and has also shared her doctoral work in progress with Masters Students studying comparative educational studies. Her research area is about the relationship between teachers' beliefs and practices about AfL and the influence of collaborative action research on the beliefs to practice relationship. Recently, she has participated in several conferences, TEPE 2016, ICERI 2016 and INTED 2017, all of which led to the publication of the conferences proceedings.

Anita Seguna is Head of Curriculum Design and Professional Learning at St. Martin's College, Malta. She lectures and mentors students at the University of Malta and the Institute for Education. Following a Masters in Education Degree, and obtaining the National Professional Qualification for Headship (NPQH) qualification from the Institute of Education, London, she served as Head of School for twelve years. Anita is currently reading a PhD at the Friedrich-Alexander University Erlangen-Nürnberg, Germany with a special focus on the internationalisation of secondary schools in Malta. She has participated in conferences such as TEPE 2016 and WCES 2017, which have led to the publication of her papers. She has also published several reading books for children aged five to thirteen.

hh 


\title{
Teacher CPD needs: perspectives from teachers in Malta and the Republic of Ireland
}

\author{
Michelle Attard Tonna \\ University of Malta \\ Timothy Murphy \\ University of Limerick \\ Cathal de Paor \\ Mary Immaculate College
}

\section{Abstract}

Much research has been done on how best teachers' professional development can be supported. However, for it to be effective, CPD provision needs to target the right content areas or topics and also be directed at the right levels. Planning for such provision is normally undertaken by providers with a role in supporting professional development in schools, or by centralized education authorities. A range of evidence exists which highlights how teachers' learning can be best supported. For example, it is over twenty years since research has shown that CPD provision should be experiential, grounded in enquiry, collaborative, sustained and derived from teachers' work with their students (Darling-Hammond \& McLaughlin, 1995; Stoll et al., 2006). However, while much research on CPD and teachers' learning has focused on how this can be best supported (Avalos, 2011), there has been less attention on what the focus of such learning should be (see for example EL-Deghaidy, Mansour, \& Alshamrani, 2015; Mansour et al., 2014). Yet, if it is to be effective, CPD provision also needs to target the right content areas or topics, in accordance with the needs and priorities among teachers (Geldenhuys \& Oosthuizen, 2015). This study presents an overview of a Training Needs Analysis which was carried out among teachers in two different geographical contexts, Ireland and 
Malta. An investigation of the priorities of the learning needs of these teachers is provided, together with an outline of how these priorities differ, but also converge, across contexts and levels. The identification of differences can serve to inform future CPD provision and enhance the understanding of teachers' learning needs for particular contexts.

\section{Keywords:}

teacher professional learning

learning needs

training needs analysis

Malta

Ireland 


\section{Introduction}

Education documents that have been published by national governments, as well as various bodies of the European cooperation structures, clearly evidence that the conditions for teaching are changing rapidly (Burns \& Shadoian-Gersing, 2010; Guerriero, 2017). The struggle to keep abreast of economic and industrial developments have had a fundamental influence on the changes that are taking place in societies, and especially in their education systems (Vonk, 1997).

Each country's education system is characterised by its own culturally defined teaching tradition within its own particular social context (Vonk, 1997). Notwithstanding this, it is also evident that there is an increasing convergence of pressures that extend beyond the national context which have an impact on the direction and development of individual systems of education. Within the European context, for example, we are familiar with the impact of the European Union (EU) and the Organisation for economic co-operation and development (OECD) on the direction and impact of education policy across the member states of the EU (Dale \& Robertson, 2009; Lawn \& Grek, 2012). Livingston (2003) has explored the future of national policy making in the context of an enlarged and increasingly influential European Union. She claimed that there is no doubt that the power and responsibility of the EU in educational matters is growing and there is increasing pressure on Member States to work towards achieving the concrete objectives set and to adopt the European benchmarks (2003, p. 597). All of this is increasing the pressure on teachers and requiring them to work at maximum effectiveness.

It is therefore important for education systems to conduct audits on the professional profile of their teachers, particularly on their existing skills, as well as the areas in which training may be required in order to better respond to the changing realities of their classrooms. These audits provide detailed and comprehensive information on the demographic characteristics of teachers and students, in addition to teacher salaries as well as other educational financial issues. These studies offer invaluable information about the composition of the teaching working force, the supply of and demand for teachers, the conditions under which they work, and other background details which are considered useful to provide a better understanding of teachers and teaching. 
Targeting the specific training needs of teachers however can benefit from the conduct of a Training Needs Analysis (TNA). Such studies acknowledge the influence of context on teacher learning and development. This is what the authors are attempting to do in this chapter. Two different contexts, each with their own training needs analysis, will be explored. A number of implications concerning teachers' continuing professional development (CPD) will be discussed, together with recommendations for how such CPD can address the learning needs which teachers in each of the respective countries have identified.

\section{The contexts}

\section{Ireland}

One of the main differences between the two contexts being researched is their size and their population. Ireland currently has a population of 4.76 million $^{1}$ which amounts to 67.9 persons per square kilometre, compared to 1,369 persons in Malta. In the Republic of Ireland there are 3, 262 primary (first level) schools and 735 second level schools, comprising 375 secondary schools, 265 vocational and 95 community and comprehensive. These schools serve 553,380 students and 345,550 students, and are staffed by 34,576 teachers and 26,805 teachers respectively (DES, 2016).

For the past several years, the Department of Education and Skills (DES) has, together with the National Council for Curriculum and Assessment (NCCA) been involved in a significant overhaul of the Junior Cycle Curriculum (JCC) which covers the first three years of second level schooling. The recommended reforms attempted to shift the perception of the JCC as a 'dress-rehearsal' for the summative examinations at the end of senior cycle (NCCA, 2010), so that the JCC would be recognised as having value in and of itself. In 2010, the NCCA developed Towards a Framework for Junior Cycle: Innovation \& Identity, as part of the preliminary work, leading later on to the publication of, A Framework for Junior Cycle (Department of Education and Skills, 2012). The proposed framework pivoted around specified principles, including: quality, wellbeing, creativity and innovation, choice and

1. Information source: (www.cso.ie) and http://ec.europa.eu/eurostat/tgm/table. do?tab=table\&init=1\&plugin $=1 \&$ pcode=tps00003\&language=en. 
flexibility, engagement and participation, inclusive education, continuity and development, and learning to learn (ibid., p. 4). It was intended that regular in-class assessment by teachers themselves would replace what was deemed an over-reliance on the terminal examinations at the end of the third year. As a result of ongoing consultations between the Department of Education and Skills and the teachers, together with the teacher unions, a revised Framework for Junior Cycle was published in 2015 (Department of Education and Skills, 2015b). The then Minister for Education, Jan O'Sullivan acknowledged that the new JCC Framework 'places the student at the centre of the learning process and envisages a modernised curriculum across all subjects. It allows for new ways of learning and a broader range of skills to be properly assessed' (Donnelly, 2015, p. 2). O'Sullivan, McMillan and McConnell (2011) also acknowledged the pivotal role that CPD would play in the ultimate success of the reforms, stating that she was committed 'to ensuring that the Junior Cycle is well supported and resourced and that the continuing professional development for school leaders and teachers will be of a very high quality' (Donnelly, 2015, p. 2).

Previous studies on the continuing professional development (CPD) of teachers in Ireland have drawn attention to its functionalist tendencies, being more about 'building teacher skills rather than capacity' (O'Sullivan et al., 2011, p. 8). Jeffers (2006, p. 188) suggested that such an orientation to CPD invited a 'top-down' perspective 'that holds many attractions, not least the possibility of devising inservice packages that can be rolled out to large numbers of teachers.' An example of this was provided by Murchan, Loxley and Johnston's (2009) study on the Primary Curriculum Support Programme (PCSP) in Ireland which was established by the Department of Education and Science (DES) in 1998. The data for the study were drawn from a large national evaluation of the PCSP which ran from 2003 to 2005. The authors noted that 'there is some risk that such approaches can engender a dependency culture whereby teachers feel incapable of embracing reforms and adjusting professional practice without first receiving externally provided PD' (Murchan, Loxley \& Johnston, 2009, p. 468). Smith's study (2015) on the Western Seaboard Science Project (WSSP) offered an alternative perspective on CPD in Ireland, which was more the exception rather than the rule. It provided opportunities for teachers to use their professional judgements and determine 
their own professional development needs. It also aimed 'to build the capacity of teachers to become authors of their own work' (Smith, 2015 , p. 233). Providing such opportunities was found to be beneficial for the professional development of teachers in a study conducted by McMillan, McConnell and O'Sullivan (2016). Teachers in their study 'expressed a preference both to seek out and to pursue CPD areas that they valued for their own personal reasons and in response to their own personal and/or professional' (McMillan, McConnell \& O'Sullivan 2016, p. 157). They further suggested that as the Teaching Council in Ireland moves toward an approach to CPD that will require teachers to provide evidence of such engagement, that the Teaching Council 'would do well to take account of the factors that motivate and inhibit teacher engagement in CPD' (ibid., p. 151).

\section{Malta}

Malta is the most densely populated country in the European Union, with more than 400,000 people living on $316 \mathrm{~km}^{2}$ of land. Of these, around 9,600 of them are teachers or teaching staff working at compulsory education level (National Statistics Office, 2014). In Malta, teachers at the pre-primary, primary and secondary levels of state education, as well as teachers in church schools and some independent schools, are required to regularly engage in Continuing Professional Development (CPD). They are obligated by a collective agreement between the Government and the Malta Union of Teachers to attend three-day sessions annually involving a total of twelve hours. Teachers in Malta tend to engage mostly in the INSET (abbreviation of In-Service Training) type of CPD, since this leads to a formal recognition of their professional development in terms of knowledge and skills.

One of the primary policy documents which governs teaching and learning in Maltese schools is The National Curriculum Framework (NCF) document which was launched in 2012. The NCF claims to have universal appeal as it is 'a response to the changing demands of individuals and society, rapid changes in our education system driven by globalisation, ICT development, competition, shift of traditional values and new paradigms' (Ministry of Education and Employment, 2012, p. iii). The document envisages a paradigm shift away from a prescriptive curriculum towards a framework based on learning outcomes which allows for internal flexibility and attractiveness to 
lifelong learning (ibid., p. xiii). The aims of education, as articulated in this national curriculum document: "... seek to prepare all children to become lifelong learners, who are confident, successful, creative, connected and engaged in the community and the world around them and who are able to secure social justice. Their education should enable them to acquire the knowledge, skills, values and attitudes that make them capable of sustaining their life chances in the changing world of employment, and to become actively engaged citizens" (Ministry of Education and Employment, 2012, p. 32).

The document also anchors the discourse for a reform in national assessment which mirrors the changes in pedagogy being envisaged.

The Framework for the Education Strategy for Malta (2014-2024) document is further testimony that the Education Ministry has positioned itself at the forefront of the efforts to provide present and future generations of students with the necessary skills and talents for employability and citizenship in the 21st century. This strategy document aims to improve the quality and effectiveness of the country's opportunities and to develop a society which is competent, resourceful, critically conscious and competitive in a global economy driven by information, knowledge and innovation. Other objectives include the provision of a relevant curriculum which is characterised by a learning outcomes approach, a variety of learning experiences and qualifications anchored to the Malta Qualifications Framework, to ensure that every learner becomes an active member of a democratic society. The Qualifications Framework itself is characterised by different tracks and opportunities in order to maximise relevance for the labour market and to optimally prepare learners for highly skilled jobs.

It is evident from the NCF and The Framework for the Education Strategy for Malta (2014-2024) documents, combined with other recently developed education policies in Malta, that there is a strong focus on school effectiveness, promoting improved management and school development planning. It is also evident that there is a demand for $21^{\text {st }}$ century skills and the associated teaching methods. The teaching-to-the-test approach which involves such practices as filling out worksheets and answering tests leaves little time for inquiry-based learning, collaborative explorations of questions, or real-world problems, that have the potential to engage students in their learning. 


\section{A need for CPD}

The contextual realities evident in both Ireland and Malta strongly suggest that teachers will benefit from Continuing Professional Development opportunities, particularly those of a curricular nature. They will increase the capacities of the teachers to inaugurate the required changes in their classroom practices to align with their respective educational policies. Such opportunities are all the more necessary when we consider that good education follows improvement in the collective capacity of the entire teaching staff and not merely in the exceptional attainment of a few highly motivated teachers (Bullough, 2009). Teachers then are crucial to policy implementation, which further underscores the importance of relevant and meaningful CPD for them. Indeed, CPD is often purported as having a number of functions to this effect:

$\rightarrow$ Aligning teachers' practice with educational policies.

$\rightarrow$ Improving the learning outcomes of students by improving the performance of teachers.

$\rightarrow$ Enhancing the status and profile of the teaching profession (Day \& Sachs, 2004).

Similarly, Grundy and Robison (2004) draw attention to the three interconnected purposes of CPD: extension, growth and renewal. CPD then has the potential to extend a teacher's repertoire with the introduction of new knowledge and skills, which in turn facilitates the enactment of greater levels of expertise, which has the potential to transform practice. The extent to which this is possible is often dependent on the extent to which resources are made available for it.

It is also helpful to bear in mind that teachers have a diverse range of opportunities for learning, which can embrace a wide variety of activities, both formal and informal. They learn through: their own practice (Opfer \& Pedder, 2011), conversations with their colleagues, observing their peers, being mentored, and also through reading, attending conferences, workshops and courses, and in all sorts of other ways. Teachers' motives for participating in CPD also differ and are influenced on the type of training available and how it is received. For instance, the tradition of CPD as involving one-shot, outside expert, presentations and brief workshops endures in many countries, including Ireland and Malta. However, such courses generally fail to adequately respond to 
the serious and growing challenges facing teachers. The perpetuation of the 'delivery' model of teaching which positions teachers as the uncritical implementer of outside policies is not effective in developing a well-educated teaching force (Dadds, 2014).

So, a new generation of CPD activities is emerging. The most successful schools are those which utilise a range of CPD strategies, taking the needs of both the school and teachers into account. There is also an increasing emphasis on teachers assuming responsibility for their own development (Fullan \& Hargreaves, 2013) through policies that support and sustain teacher learning and development. Active participation of teachers, focusing on classroom practice, leads to changes in classroom practices. Teachers undergo a variety of complex processes as they continue to learn about their work and struggle with the difficulties of the change process (Dadds, 2014). Thus, a suitable working and learning context for teachers may be a school that is organised as a learning environment for both students and teachers; wherein teachers collaborate with their peers; where teachers are supported to be innovative; and where they are enabled to have professional autonomy and decision making.

As a final point to this section on CPD and its recommended models, the authors also wish to stress that not all teachers engage in CPD in the same way. It is hence important to conceptualise teachers' needs and design CPD experiences from an individual's learning perspective, rather than global prescriptions of systemic needs and forms of provision. This is precisely why the Training Needs Analysis carried out in both countries can yield important insights into the ways teacher learning should be organised.

\section{Methodology}

The need analysis for CPD carried out in Ireland was in preparation for the development of the new National Institute for Studies in Education (NISE) in the Republic of Ireland. The data which provide the basis for the needs analysis were collected over a number of weeks in Spring 2014 using an online survey of 591 education professionals. The questionnaire contained a total of 20 items, both open-ended and closed-ended, and sought information from education professionals on different aspects of their engagement in CPD, views, preferences, 
etc. A review of key issues with regard to teachers' CPD, nationally and internationally informed the design of the questionnaire.

Following a pilot study, invitations to participate in the main survey were sent to the email addresses for all recognised primary and postprimary schools throughout the Republic of Ireland, amounting to 3866 addresses in total (3145 addresses for primary and special schools, and 721 addresses for post-primary schools). The recipient of the email (whether principal, school secretary, etc.) was asked to forward the survey link to staff members within the school to enable their participation. In addition, an invitation to participate was emailed to a number of other education and teacher associations so that they in turn could forward it to their members and other interested parties. This included the primary and post-primary sector, as well as early childhood, further education, and higher education. However, for the purposes of the current chapter, only the results for teachers working in the primary and post-primary sectors are being presented as it is the views of these teachers that the chapter seeks to explore. While the TALIS study (OECD, 2014) involved lower secondary teachers only, the inclusion of results for primary school teachers in this study will enable certain inter-sectoral comparisons to be made. This resulted in a convenience sample of 507 teachers, comprising 233 primary teachers (46\%) and 274 post-primary teachers (54\%).

The survey was anonymous, with no person, school, etc. identifiable in any of the data collected. The first item asked respondents for their consent to the use of their responses in any subsequent publication. Respondents were also invited to supply an email address where they were willing to participate in any follow-on focus group, which might be organised to further explore issues raised in the initial survey.

The methodology for the study in Malta adopted a similar approach. The questionnaire was posted on SurveyMonkey ${ }^{\odot}$ website. The associated online tool was activated to connected potential participants to engage with the Training Needs Analysis activity. All educators in the pre-primary, primary and secondary levels were invited to participate. Responses were therefore collected from teachers, kindergarten assistants, learning support assistants and members of the School Leadership Team. The items on the questionnaire were designed to ensure that the research aims were met, namely: to identify qualifications and demography of educators; to establish the extent of 
their knowledge, skills and training needs, as articulated in the Learning Outcomes Framework; and to identify professional development practices and opportunities congruent with those outcomes for educators in Malta.

The necessary permissions were obtained from the Research and Policy Development Department within MEDE in order to conduct the associated research in the State Schools sector. The Church and Independent School Sectors were also contacted to brief them on the intended research. An information was also developed to fully inform on potential participants on the nature and purpose of the intended TNA research. This information sheet, with an embedded URL link to the online questionnaire and an accompanying covering note, was disseminated to all Heads of Schools in a school circular which was issued by the education authorities. The Heads of Schools were invited to relay the information sheet to their respective staff. Adopting this approach increased the likelihood that the TNA invitation would be extended across all the relevant sectors in Malta.

Questionnaire responses were collected online in the period between September and October 2015. The responses were automatically generated to IMCS from the Survey Monkey website. The response rate was monitored on a regular basis. A total of 1227 responses were obtained. Quantitative data were analysed using Microsoft Excel and SPSS. The data received from the online questionnaire were complimented by the data which were obtained from the five focus groups. The focus involved participants from the compulsory schooling sectors, as well as the school administration and policy sectors. The focus group participants were invited to respond to questions which were broadly similar to those developed for the TNA questionnaire. They had the added advantage however of providing opportunities for the participants to expand on their responses where appropriate. All of the participants for the focus group interviews were presented with information sheets and consent forms.

\section{Findings}

The results related to both studies will be presented in this section. A number of common themes have been identified and these themes, and the discussion around them, will help readers understand the professional learning needs of teachers in both countries. 
In the Irish TNA, teachers at primary and post-primary level were asked to indicate the extent to which they would prioritise CPD from a list of given learning areas. In the second item respondents had an opportunity to propose their own priority areas. Both sets of results can be considered in tandem. Tables 1 and 2 present the results for primary teachers and post-primary teachers separately.

In the case of primary teachers, the learning areas prioritised the most included:

$\rightarrow$ technology (as a major priority or priority by $78 \%$ )

$\rightarrow$ special educational needs (as a major priority or priority by $70 \%$ )

$\rightarrow$ assessment (as a major priority or priority by $68 \%$ )

$\rightarrow$ differentiation (as a major priority or priority by $67 \%$ )

$\rightarrow$ school/curriculum leadership (as a major priority or priority by $67 \%$ ).

Table 1. Priorities of primary teachers for undertaking CPD

in a given list of areas over the next two years - Ireland

\begin{tabular}{|c|c|c|c|c|}
\hline ANSWER OPTIONS & $\begin{array}{l}\text { MAJOR } \\
\text { PRIORITY }\end{array}$ & PRIORITY & $\begin{array}{l}\text { NOT } \\
\text { A PRIORITY }\end{array}$ & TOTAL \\
\hline Assessment & $\begin{array}{l}45 \\
20 \%\end{array}$ & $\begin{array}{l}105 \\
48 \%\end{array}$ & $\begin{array}{l}71 \\
32 \%\end{array}$ & 221 \\
\hline Special educational needs & $\begin{array}{l}53 \\
24 \%\end{array}$ & $\begin{array}{l}101 \\
46 \%\end{array}$ & $\begin{array}{l}67 \\
30 \%\end{array}$ & 221 \\
\hline $\begin{array}{l}\text { Differentiation (e.g., linguistic diversity, } \\
\text { educational disadvantage, individual difference) }\end{array}$ & $\begin{array}{l}53 \\
24 \%\end{array}$ & $\begin{array}{l}96 \\
43 \%\end{array}$ & $\begin{array}{l}72 \\
33 \%\end{array}$ & 221 \\
\hline Specific curriculum subjects & $\begin{array}{l}57 \\
26 \%\end{array}$ & $\begin{array}{l}96 \\
43 \%\end{array}$ & $\begin{array}{l}70 \\
31 \%\end{array}$ & 223 \\
\hline Action research or other practitioner enquiry & $\begin{array}{l}17 \\
8 \%\end{array}$ & $\begin{array}{l}49 \\
23 \%\end{array}$ & $\begin{array}{l}151 \\
70 \%\end{array}$ & 217 \\
\hline School / curriculum leadership & $\begin{array}{l}70 \\
31 \%\end{array}$ & $\begin{array}{l}81 \\
36 \%\end{array}$ & $\begin{array}{l}73 \\
33 \%\end{array}$ & 224 \\
\hline Relationships and working with others & $\begin{array}{l}39 \\
18 \%\end{array}$ & $\begin{array}{l}82 \\
37 \%\end{array}$ & $\begin{array}{l}101 \\
45 \%\end{array}$ & 222 \\
\hline Mentoring other colleagues & $\begin{array}{l}33 \\
15 \%\end{array}$ & $\begin{array}{l}81 \\
37 \%\end{array}$ & $\begin{array}{l}106 \\
48 \%\end{array}$ & 220 \\
\hline Technology and learning & $\begin{array}{l}62 \\
28 \%\end{array}$ & $\begin{array}{l}111 \\
50 \%\end{array}$ & $\begin{array}{l}49 \\
22 \%\end{array}$ & 222 \\
\hline Personal well-being & $\begin{array}{l}57 \\
26 \%\end{array}$ & $\begin{array}{l}91 \\
41 \%\end{array}$ & $\begin{array}{l}73 \\
33 \%\end{array}$ & 221 \\
\hline Health education and promotion & $\begin{array}{l}40 \\
18 \%\end{array}$ & $\begin{array}{l}93 \\
43 \%\end{array}$ & $\begin{array}{l}84 \\
39 \%\end{array}$ & 217 \\
\hline
\end{tabular}


Among post-primary teachers, the most prioritised learning areas included:

$\rightarrow$ technology (as a major priority or priority by $87 \%$ );

$\rightarrow$ specific curriculum subjects $(82 \%)$;

$\rightarrow$ assessment (as a major priority or priority by $73 \%$ );

$\rightarrow$ differentiation (as a major priority or priority by $71 \%$ );

$\rightarrow$ special educational needs $(63 \%)$.

Table 2. Priorities of post-primary teachers for undertaking CPD

in a given list of areas over the next two years - Ireland

\begin{tabular}{|c|c|c|c|c|}
\hline ANSWER OPTIONS & $\begin{array}{c}\text { MAJOR } \\
\text { PRIORITY }\end{array}$ & PRIORITY & $\begin{array}{c}\text { NOT } \\
\text { A PRIORITY }\end{array}$ & TOTAL \\
\hline Assessment & $\begin{array}{l}86 \\
34 \%\end{array}$ & $\begin{array}{l}98 \\
39 \%\end{array}$ & $\begin{array}{l}69 \\
27 \%\end{array}$ & 253 \\
\hline Special educational needs & $\begin{array}{l}52 \\
21 \%\end{array}$ & $\begin{array}{l}106 \\
42 \%\end{array}$ & $\begin{array}{l}95 \\
38 \%\end{array}$ & 253 \\
\hline $\begin{array}{l}\text { Differentiation (e.g., linguistic diversity, } \\
\text { educational disadvantage, individual } \\
\text { difference) }\end{array}$ & $\begin{array}{l}74 \\
30 \%\end{array}$ & $\begin{array}{l}100 \\
41 \%\end{array}$ & $\begin{array}{l}72 \\
29 \%\end{array}$ & 246 \\
\hline Specific curriculum subjects & $\begin{array}{l}117 \\
46 \%\end{array}$ & $\begin{array}{l}93 \\
36 \%\end{array}$ & $\begin{array}{l}47 \\
18 \%\end{array}$ & 257 \\
\hline $\begin{array}{l}\text { Action research or other practitioner } \\
\text { enquiry }\end{array}$ & $\begin{array}{l}34 \\
14 \%\end{array}$ & $\begin{array}{l}61 \\
25 \%\end{array}$ & $\begin{array}{l}153 \\
62 \%\end{array}$ & 248 \\
\hline School/curriculum leadership & $\begin{array}{l}61 \\
24 \%\end{array}$ & $\begin{array}{l}85 \\
33 \%\end{array}$ & $\begin{array}{l}108 \\
43 \%\end{array}$ & 254 \\
\hline Relationships and working with others & $\begin{array}{l}51 \\
20 \%\end{array}$ & $\begin{array}{l}84 \\
34 \%\end{array}$ & $\begin{array}{l}114 \\
46 \%\end{array}$ & 249 \\
\hline Mentoring other colleagues & $\begin{array}{l}48 \\
19 \%\end{array}$ & $\begin{array}{l}82 \\
33 \%\end{array}$ & $\begin{array}{l}119 \\
48 \%\end{array}$ & 249 \\
\hline Technology and learning & $\begin{array}{l}110 \\
43 \%\end{array}$ & $\begin{array}{l}111 \\
44 \%\end{array}$ & $\begin{array}{l}33 \\
13 \%\end{array}$ & 254 \\
\hline Personal well-being & $\begin{array}{l}74 \\
29 \%\end{array}$ & $\begin{array}{l}101 \\
40 \%\end{array}$ & $\begin{array}{l}77 \\
31 \%\end{array}$ & 252 \\
\hline Health education and promotion & $\begin{array}{l}51 \\
20 \%\end{array}$ & $\begin{array}{l}95 \\
38 \%\end{array}$ & $\begin{array}{l}103 \\
41 \%\end{array}$ & 249 \\
\hline
\end{tabular}

Taken together, there are some marked similarities and differences between the priorities of both primary and post-primary teachers. Those areas which teachers from both sectors prioritised most included: assessment; special educational needs; differentiation; technology and learning; and personal well-being. 
However, the results show that differences exist, even if these are quite subtle in some cases. Thus, while both sectors identify assessment, differentiation, and technology as priorities, they are rated as greater priorities by post-primary teachers. For example, while $73 \%$ of postprimary teachers considered assessment either a "major priority" or a "priority", the figure was lower for primary teachers, i.e., $68 \%$. Specific curriculum subjects are also more of a priority for post-primary teachers than for primary. For example, while it is either a "major priority" or a "priority" for $82 \%$ of post-primary teachers, the figure is $69 \%$ in the case of primary teachers. This reflects the nature of the primary curriculum as an integrated construct with teachers being responsible for teaching all subjects of the curriculum.

On the other hand, the results show that school or curriculum leadership is a slightly greater priority among primary teachers, with $31 \%$ of primary teachers deeming it a "major priority" as against $24 \%$ of post-primary teachers. It should be acknowledged that when those teachers who deemed it a "priority" are included, the difference between both sectors is negligible, with the figure for both groups being $67 \%$.

An analysis of the qualitative data helps to provide context to the quantitative results presented above. In one of the open-ended items, teachers were invited to specify areas that they would prioritise for their own CPD in the next two years: "What areas of practice would you like to prioritise for your own CPD in the next two years?" Teachers had the option of identifying more than one learning area in their comments. The teachers' responses were analysed and coded into a number of recurring content areas as presented in Table 3.

While the proposed priorities are wide-ranging, they all closely related to teachers' work in classrooms. Before examining the actual nature of the responses, it is worth noting the similarities with the quantitative results presented earlier. As with the quantitative results, there are many similarities in how teachers prioritise the content areas. Among the three most frequent topics that feature in the teachers' comments, two are common to both sectors, i.e., teaching/learning/ assessment $(13.8 \%$ of primary teachers and $18 \%$ of post-primary teachers), and curriculum (12.8\% of primary teachers and $21.4 \%$ of post-primary).

And yet, while this suggests certain congruence, the differences are also noteworthy, for example, the differential of over $8 \%$ in the 
case of curriculum. There are also various differences with regard to other sectoral priorities. For example, leadership is identified by $14.8 \%$ of primary teachers as a priority, while it is just $7.9 \%$ in the case of post-primary teachers. On the other hand, $15.6 \%$ of post-primary teachers identify technology as a priority, while it is $9.1 \%$ in the case of primary teachers (it should be noted that this priority among postprimary teachers cannot simply be explained as being due to an overrepresentation of technology teachers in the sample, given that the results show that there was in fact only one teacher out of the sample who indicated technology as a teaching subject).

It is significant that these results on sectoral differences correspond to the other results presented above, which invited teachers to indicate priorities from a given list. Both sets of results show that CPD in assessment, technology and learning and curriculum subjects was deemed a greater priority by post-primary teachers than primary, while the opposite was the case for CPD in curriculum/school leadership.

Table 3. Areas for CPD suggested in comments from primary and post-primary teachers - Ireland

\begin{tabular}{|c|c|c|c|c|c|}
\hline $\begin{array}{l}\text { PRIMARY TEACHER PRIORITY } \\
\text { AREAS FOR CPD }\end{array}$ & No. & $\%$ & $\begin{array}{l}\text { POST-PRIMARY TEACHER PRIORITY } \\
\text { AREAS FOR CPD }\end{array}$ & No. & $\%$ \\
\hline Leadership/Management & 75 & 14.8 & Curriculum & 89 & 21.4 \\
\hline Teaching/Learning/Assessment & 70 & 13.8 & Teaching/Learning/Assessment & 75 & 18.0 \\
\hline Curriculum & 65 & 12.8 & Technology & 65 & 15.6 \\
\hline Literacy & 55 & 10.8 & Differentiation/SEN/Inclusion & 44 & 10.6 \\
\hline Well-being & 52 & 10.3 & Leadership/Management & 33 & 7.9 \\
\hline Differentiation/SEN/Inclusion & 51 & 10.1 & Wellbeing & 26 & 6.3 \\
\hline Technology & 46 & 9.1 & Other & 18 & 4.3 \\
\hline Numeracy & 31 & 6.1 & Teacher research & 14 & 3.4 \\
\hline Behaviour & 18 & 3.6 & Mentoring/Coaching & 13 & 3.1 \\
\hline School evaluation & 16 & 3.2 & Literacy & 12 & 2.9 \\
\hline Mentoring/Coaching & 12 & 2.4 & Numeracy & 11 & 2.6 \\
\hline Parents & 7 & 1.4 & Behaviour & 8 & 1.9 \\
\hline Teacher research & 6 & 1.2 & School evaluation & 7 & 1.7 \\
\hline Other & 3 & 0.6 & Parents & 1 & 0.2 \\
\hline Total & 507 & 100 & & 416 & 100 \\
\hline
\end{tabular}


The kinds of comments which teachers provided are also insightful. As noted, the priorities which were coded as "curriculum," accounted for the greatest priority among post-primary teachers (21.4\%). Their comments included: "Own subject area updates", "Short courses within each subject area" and "Subject specific training". Particular curricular areas or subjects for development included "Art history", "New English Course for Junior Cycle", "Project Maths Curriculum" and "Designing Curriculum Content for the New Junior", "Certificate Programme in Science". Issues relating to curriculum and specific subject areas featured to a lesser extent in the responses of primary teachers (12.8\%). These included generic suggestions for curricular development e.g. "Curriculum based courses", "Specific curriculum subjects" and "Effective planning in primary schools". Other primary teachers suggested particular curricular areas or subjects for development leading to large list of subjects being mentioned e.g. "Literacy", "Gaeilge", "Music", "SESE", "Science", "Arts education", "PE", "Visual Arts", "SPHE", etc.

The second major priority identified in teachers' responses was teaching, learning and assessment. Almost $14 \%$ of primary teachers offered suggestions in the area of teaching, learning and assessment, while the figure was $18 \%$ in the case of post-primary teachers. Primary teachers' responses ranged from general comments on strategies for enhanced learning e.g. "Problem solving in the classroom" and "Active learning \& collaborative methodologies" to comments directly related to "assessment" and "Assessment Approaches and Strategies". Comments from post-primary teachers included "Cooperative learning strategies in the classroom" and "Making students independent learners". Similar to comments from primary teachers, there were a number of comments directly related to "assessment" and "Assessment for learning".

A total of $15 \%$ of primary teachers mentioned items relating to leadership, management and staff relations as areas for development. Many simply responded with the word "leadership" while others elaborated slightly with comments such as "school leadership" and "distributed leadership". Other comments related to procedures around management e.g. "Building capacity to manage and effect educational change within school systems with ever dwindling resources", "management team development", "Timetabling" with a focus on working with and leading others, e.g. "motivation of staff", 
and on relations in the workplace "Leadership - how to effect change and a collaborative reflective culture in schools" and "building positive relationships in the workplace". This topic occurred less frequently in the comments of post-primary teachers $(7.9 \%)$. Where it did occur, the comments referred to "conflict resolution strategies", "dealing with disillusioned staff" and "Mediation, restorative practices".

Over $15 \%$ of post-primary teachers suggested technology as an area for CPD. A large number of respondents focus on technology in the classroom, as can be seen in comments such as "Using technology in the classroom (Tablet computers in use in school with no specific training)", "ICT- interactive boards", "More ways to use ICT in the classroom", "Integration of ICT into subject areas" and "E learning and technology". Other comments indicate the need for up skilling in the use of IT more generally "Software training", "Technology skills", "IT Media" and "Digital Training". Technology was less of a priority among primary teachers $(9.1 \%)$. In their comments, primary teachers referred to "Incorporating IT into teaching and learning" and "Using technology in the classroom (Tablet computers in use in school with no specific training)".

The fourth most-frequently occurring priority among post-primary teachers was coded as differentiation/SEN/inclusion. A total of $10.6 \%$ of post-primary teachers, and $10.1 \%$ of primary teachers mentioned teaching strategies and differentiation as priorities for CPD. Primary teachers submitted comments such as "Teaching techniques", "collaboration in teaching (how to team teach effectively)" and "collaborative methodologies". A large number of responses simply state "differentiation" or specific instances of differentiation e.g. "Multi Grade Teaching", "Differentiation in a busy and crowed classroom; especially in mixed-ability groups" and "developing outcomes for different levels". Some comments from post-primary teachers referred specifically to Special Educational Needs, ranging from "Special Educational Needs" to more specific areas for development within SEN, e.g. "Students with Dyslexia", "Helping children with Dyscalculia/ math learning difficulties", "children with emotional and behavioural difficulties: behaviour management approach" and "Autism training for whole staff".

Other significant differences among the priorities identified by teachers include literacy. This was the fifth most-frequently occurring 
priority for primary teachers $(10.8 \%)$, while it was just $2.9 \%$ in the case of post-primary teachers.

A different, but quite similar focus, was applied in the Maltese TNA. One of the questions invited the Maltese teachers to identify their preferred CPD learning method. For this question, they had to choose one item from a given list. The most preferred method, at $26 \%$, was group-based learning activities involving peers from the same school. The second most preferred option was face-to-face training activities at $23 \%$. Although to a lesser extent, seminars and INSET courses (In-service education and training) were also quite popular at $17 \%$. A similar percentage (16\%) expressed a preference for researching and studying individually. Both online learning methods and mentoring/ coaching registered on the lower end of the preference scale, each at $9 \%$ respectively. Table 4 below presents the preferred learning method for primary and post-primary teachers and the corresponding number of participants for each option.

Table 4. Preferred learning method for primary and post-primary teachers - Malta

\begin{tabular}{l|l|l}
\multicolumn{1}{c|}{ ANSWER CHOICES } & \multicolumn{2}{c}{ RESPONSES } \\
\hline Researching and studying individually & $16.02 \%$ & 148 \\
\hline Group-based learning activities (peer-based) & $25.65 \%$ & 237 \\
\hline Face-to-face training activities & $22.94 \%$ & 212 \\
\hline Online learning methods & $9.20 \%$ & 85 \\
\hline Seminars/INSET courses & $17.42 \%$ & 161 \\
\hline Mentoring/Coaching & $8.77 \%$ & 81 \\
\hline Total & & 924
\end{tabular}

Maltese teachers were also asked to specify, from a list of given options, the types of collaborative activities that they have a preference for engaging in as part of their professional practice in schools. It is evident from Table 5 below that most of the participants (35\%) indicated a preference for planning lessons and related activities. This was followed in terms of preference by professional collaboration within subject or teaching area at $30 \%$. 
Table 5. Teachers' preferred collaborative activity at primary and post-primary level - Malta

\begin{tabular}{l|l|l}
\multicolumn{1}{c|}{ ANSWER CHOICES } & \multicolumn{2}{c}{ RESPONSES } \\
\hline Planning of lessons and activities & $34.74 \%$ & 321 \\
\hline Peer teaching & $6.82 \%$ & 63 \\
\hline Having a 'critical friend' & $11.47 \%$ & 106 \\
\hline Networking within the same school & $8.98 \%$ & 83 \\
\hline Networking across different schools & $1.95 \%$ & 18 \\
\hline Networking both within and across schools & $6.17 \%$ & 57 \\
\hline Professional collaboration within subject or teaching area & $29.87 \%$ & 276 \\
\hline Total & & 924
\end{tabular}

When these same teachers were asked if they reflect upon their teaching and whether they self-evaluate their practice, an encouraging number of them said that they do. $29 \%$ indicated that they do so to a moderate degree (at a weekly to monthly basis), while $37 \%$ indicated that they do so to a high degree (on a weekly basis). Additionally, a further $28 \%$ stated that they do so very (on a daily basis). They were also asked to rank, in order of preference, their reasons for taking up new learning / professional development opportunities (see Table 6 below). The majority of the participants ( $58 \%$ ) stated that they did so for their own self-fulfillment and personal satisfaction.

Table 6. Teachers' motivations for taking up new learning/professional development opportunities ranked by order of preference ( 1 is the highest, 4 is the lowest) - Malta

\begin{tabular}{l|c|c|c|c}
\multicolumn{1}{c|}{ RESPONSES } & $\mathbf{1}$ & $\mathbf{2}$ & $\mathbf{3}$ & $\mathbf{4}$ \\
\hline Career advancement opportunities & $15.32 \%$ & $20.95 \%$ & $26.01 \%$ & $37.73 \%$ \\
\hline Further options for different roles in current grade & $6.64 \%$ & $20.50 \%$ & $41.78 \%$ & $31.08 \%$ \\
\hline Specialisation in subject area & $19.71 \%$ & $36.94 \%$ & $21.96 \%$ & $21.40 \%$ \\
\hline Self-fulfilment/Personal satisfaction & $58.33 \%$ & $21.62 \%$ & $10.25 \%$ & $9.8 \%$
\end{tabular}

Maltese teachers were also asked to identify the degree to which CPD opportunities are available locally; the degree to which they think that these activities are supported by their school principal; the degree to which professional learning communities are nurtured in their school; the degree to which virtual learning platforms are catering for their PD needs; and the degree to which they think they can dedicate time for 
their PD activities. The data from these responses will assist in better understanding the teachers' dispositions toward professional learning, and, also, with better understanding why preference is attached to certain activities or experiences over others. Additionally, the TNA study also recognized that it would be beneficial to assess the level of existing support structures in schools to promote and develop the various professional learning activities. Table 7 below presents findings in respect of this.

Table 7. Teachers' experiences in and dispositions to professional learning - Malta

\begin{tabular}{|c|c|c|c|c|c|}
\hline RESPONSES & NOT AT ALL & $\begin{array}{l}\text { SMALL } \\
\text { DEGREE }\end{array}$ & $\begin{array}{l}\text { MODERATE } \\
\text { DEGREE }\end{array}$ & $\begin{array}{c}\text { HIGH } \\
\text { DEGREE }\end{array}$ & $\begin{array}{l}\text { VERY HIGH } \\
\text { DEGREE }\end{array}$ \\
\hline $\begin{array}{l}\text { Professional development } \\
\text { opportunities which fulfil your } \\
\text { needs are available locally }\end{array}$ & $7.05 \%$ & $32.61 \%$ & $41.82 \%$ & $15.91 \%$ & $2.61 \%$ \\
\hline $\begin{array}{l}\text { Professional development } \\
\text { is supported by your School } \\
\text { Management Team / Directors }\end{array}$ & $3.64 \%$ & $13.64 \%$ & $30.80 \%$ & $38.41 \%$ & $13.52 \%$ \\
\hline $\begin{array}{l}\text { Professional learning } \\
\text { communities are nurtured in your } \\
\text { school / department }\end{array}$ & $8.64 \%$ & $21.59 \%$ & $39.43 \%$ & $23.18 \%$ & $7.16 \%$ \\
\hline $\begin{array}{l}\text { Virtual platforms meet your } \\
\text { professional development needs }\end{array}$ & $15.02 \%$ & $32.88 \%$ & $37.43 \%$ & $11.83 \%$ & $2.84 \%$ \\
\hline $\begin{array}{l}\text { You have time to engage in } \\
\text { professional development } \\
\text { activities }\end{array}$ & $13.54 \%$ & $37.32 \%$ & $38.57 \%$ & $8.42 \%$ & $2.16 \%$ \\
\hline
\end{tabular}

\section{Discussion}

The Irish teachers' preference for CPD in the area of Special Educational Needs (SEN)-Differentiation, evident from the study, is an acknowledgement of the changed composition of the profile of students in Irish schools. This was prompted by the Persons with Special Educational Needs Act (Government of Ireland 2004) which focused attention on the need to create inclusive learning environments in our schools. Shevlin, Winter and Flynn (2013) drew attention to the critical role played by teachers in creating these environments. They acknowledged that it is generally accepted "that inclusive practice relies to a large extent on teacher knowledge, skills, understanding, 
capacity and attitudes" (ibid., p. 1119). Teachers were therefore aware of the responsibility incumbent upon them to upskill in the area of SEN and differentiation. Technology and ICT was also an area of interest to teachers in Ireland when it comes to CPD. This interest is congruent with the policy push in this area at the level of the EU and the OECD (see Wastiau et al., 2013). At a national level, respective Governments have embedded this policy shift into their strategic plans for education. In Ireland for example the Department of Education and Skills (2015a) unveiled the Digital Strategy for Schools 2015-2020: Enhancing Teaching, Learning and Assessment. It is quite understandable then why teachers would want to prioritise this area as part of their CPD. Furthermore, the enhancement of teaching, learning and assessment is another area that the teachers in the study prioritised as part of their preferred CPD. As outlined earlier in this chapter, the introduction of the new Junior Cycle framework in Ireland focused attention on new assessment strategies which invited a shift away from the traditional focus on examinations, from assessment of learning to assessment for learning. This invited new repertoires of skills and capacities in teachers around assessment and helps to explain the priority given to assessment in our study.

The TNA results in Ireland show that certain commonalities exist in the needs identified by teachers across both sectors, with pedagogical content knowledge, technology, and assessment being among the main priorities. However, there are also some sectoral differences in the extent to which these are prioritised. Areas such as assessment, differentiation and technology were rated as greater priorities by postprimary teachers, while school/curriculum leadership was a greater priority among primary teachers. It is also noteworthy how the responses of post-primary teachers illustrate the centrality of their subject(s) in how they understand their work as teachers. The importance placed on differentiation by post-primary teachers in the present study, with $71 \%$ of post-primary teachers considering it as a major priority or priority, corresponds to the TALIS study where teaching students with special needs (22\% of teachers) was the most significant need (OECD 2014). The next most important areas identified in the TALIS study were ICT skills $(19 \%)$, and using new technologies in the workplace $(18 \%)$. This finding also corresponds with the findings in the present study, with 
$87 \%$ of post-primary teachers considering "technology and learning" a major priority or priority.

The findings above are significant in the context of planning provision for CPD. In the Republic of Ireland, the Teaching Council is at an advanced stage in the development of a CPD framework and identified a number of priority areas based on existing national priorities at a system level: inclusion, literacy, numeracy, ICT (The Teaching Council 2015). However, while the Teaching Council (2015) document envisages teachers' learning as, "including but not limited to, the Priority Learning Areas identified" (p.15), it is worth emphasising that, given the diverse nature of teachers' work, priorities for teachers may also differ greatly (Bartell, 2005; Rodríguez \& McKay, 2010). Sectoral differences are one way in which this diversity can be manifested. The results presented as part of this study can therefore be useful in supporting CPD planning and provision in catering for teachers in particular settings. Some of these may emanate from curriculum reforms that may be particular to one sector only, rather than both.

The results from the Maltese TNA, on the other hand, indicate that teachers in both primary and post-primary levels value collaborative learning and face-to-face training sessions. This suggests that they have a preference for models of CPD that they already have a degree of familiarity with. The findings also indicate that they have least preference for models of CPD that they are not so familiar with, such as mentoring and use of virtual platforms. It is not too surprising then that the CPD activities which Maltese teachers value are those which are embedded as part of their natural routines as teachers, across both primary and post-primary sectors. These activities are already in a sense quite institutionalised across the schooling sector in Malta. It is encouraging to note that such activities are supported in terms of CPD. It is not clear however whether participation in such activities promotes the enactment of teacher autonomy on account of the extent to which such practices are already in a sense embedded as part of school culture. Therefore, it is also questionable whether participation in such activities will promote the development of professional learning communities amongst teachers in Malta. In fact, the findings indicate that networking within and across schools in Malta is still very poor. CPD provision then should focus on supporting schools in developing strategies to help 
different groups of teachers (not merely those linked by subject or year group) to work and learn together.

The data from Malta also indicate that the majority of teachers engage CPD for self-fulfillment purposes. While this is a positive, it would also be helpful to assess the extent to which other CPD related activities are also being implemented. The latter might include CPD for teachers' advancement and progression, as well as CPD that would be relevant for the teachers' day-to-day teaching practices. The benefits which CPD opportunities ought to provide should not stop at fulfilling teachers' personal needs. Rather, are the CPD opportunities which teachers engage in leading to changes in pupils', teachers' and school practices? Are they enhancing the status of teaching and career prospects? These considerations are tied in with understandings of CPD effectiveness. Although certain activities which teachers engage in may be deemed relevant from the perspective of the policy-makers, the practising teachers may have a different point of view. These perspectives of the teachers may have a bearing on whether they assess particular CPD activities effective or not. It is also important to recognise that teaching and learning are contextually situated and it is helpful to allow CPD activities to build on teachers' own knowledge and beliefs, perceived problems and classroom practices (Opfer \& Pedder, 2011).

\section{Conclusion}

Both the Irish and Maltese TNA studies highlight the benefits of a clear and robust national plan that recognises the continuing needs of teachers as learners in a continuously changing societal context. Multiple and complex social change places multiple demands on teachers. A well-educated, flexible and highly competent teaching force is required to handle these changes and to foster practices which are responsive to the educational needs of all children. CPD can respond to this challenge, but the individual needs of teachers need to be prioritised since the impetus for change originates within the personal aspect of professional learning, which was especially evident from the Maltese findings. It is therefore important that when CPD policies are being developed, that they take into consideration the motivational factors of those involved, as well as their viewpoints, namely, the teachers. 
Indeed, the analysis of the TNA in both countries has led the authors to conclude that while it is useful to address the CPD needs of teachers cross-sectorally, there is also benefit in providing some level of sectoral differentiation so that CPD can be tailored to the actual needs of teachers, as they perceive them. The range of priority areas identified in the Irish TNA and the CPD preferences identified in the Maltese study suggest that any future policy and provision to support CPD for the teaching profession is broad enough to address these different priorities, both within and across sectors. Responding to CPD in this way has the potential to promote ownership of professional learning through understanding specific needs (Timperley \& Alton-Lee, 2008). Responding to such needs, as evidenced in the present study, at an individual and school level, can be the hallmark of effective professional development (Stoll, Harris \& Handscomb, 2012, p. 3). 


\section{References}

$\rightarrow$ Avalos, B. (2011). Teacher professional development in teaching and teacher education over ten years. Teaching and Teacher Education, 27, 10-20.

$\rightarrow$ Bartell, C. (2005). Cultivating High-quality Teaching through Induction and Mentoring. Thousand Oaks, CA: Corwin Press.

$\rightarrow$ Borko, L. (2004). Professional development and teacher learning: Mapping the terrain. Educational Researcher, 33 (8), 3-15.

$\rightarrow$ Bullough, R. V. (2009). The continuing education of teachers: In-service training and workshops. In B. J. Biddle, T. L. Good \& I. F. Goodson (Eds.), International Handbook of Research on Teachers and Teaching (pp. 159-170). Dordrecht, the Netherlands: Springer.

$\rightarrow$ Burns, T. \& Shadoian-Gersing, V. (2010). The importance of effective teacher education for diversity. In OECD (Ed.), Educating Teachers for Diversity: Meeting the Challenge. Paris: OECD Publishing.

$\rightarrow$ Dadds, M. (2014). Continuing Professional Development: Nurturing the expert within. Professional Development in Education, 40 (1), 9-16.

$\rightarrow$ Dale, R. \& Robertson, S. (2009). Globalisation \& Europeanisation in Education. Oxford: Symposium Books.

$\rightarrow$ Darling-Hammond, L. \& McLaughlin, M. W. (1995). Policies that support professional development in an era of reform. The Phi Delta Kappan, 76 (8), 597-604.

$\rightarrow$ Day, C. \& Sachs, J. (2004). Professionalism, performativity and empowerment: Discources in the politics, policies and purposes of continuing professional development. In C. Day \& J. Sachs (Eds.), International Handbook on the Continuing Professional Development of Teachers (pp. 3-32). Berkshire: Open University Press.

$\rightarrow$ De Paor, C. (2016). The impact of school-based continuing professional development: Views of teachers and support professionals. Irish Educational Studies, 35 (3) 289-306. 
$\rightarrow$ Department of Education and Skills (2012). A Framework for Junior Cycle. Dublin: Department of Education and Skills.

$\rightarrow$ Department of Education and Skills (2015a). Digital Strategy for Schools 20152020: Enhancing Teaching, Learning and Assessment. Dublin: Department of Education and Skills.

$\rightarrow$ Department of Education and Skills (2015b). Framework for Junior Cycle 2015. Dublin: Department of Education and Skills.

$\rightarrow$ De Vries, S., van de Grift, J. C. M., Jansen, W. \& Ellen, P. W. A. (2014). How teachers' beliefs about learning and teaching relate to their continuing professional development. Teachers and Teaching, 20 (3), 338-357.

$\rightarrow$ Donnelly, K. (2015). Junior Cert peace plan will see exam split in two. Independent.ie. http://www.independent.ie/irish-news/education/junior-certpeace-plan-will-see-exam-split-in-two-30988573.html

$\rightarrow$ EL-Deghaidy, H., Mansour, N. \& Alshamrani, S. (2015). Science teachers' typology of CPD activities: A socio-constructivist perspective. International Journal of Science and Mathematics Education, 13 (6), 1539-1566.

$\rightarrow$ Fullan, M. \& Hargreaves, A. (2016). Bringing the Profession Back in: Call to Action. Oxford, OH: Learning Forward.

$\rightarrow$ Geldenhuys, J. \& Oosthuizen, L. (2015). Challenges influencing teachers' involvement in continuous professional development: A South African perspective. Teaching and Teacher Education, 51, 203-212.

$\rightarrow$ Government of Ireland (2004). Education for Persons with Special Educational Needs Act. Dublin: The Stationery Office.

$\rightarrow$ Grundy, S. \& Robison, J. (2004). Teacher professional development: Themes and trends in the recent Australian experience. In C. Day \& J. Sachs (Eds.), International Handbook on the Continuing Professional Development of Teachers (pp. 146-166). Berkshire: Open University Press.

$\rightarrow$ Guerriero, S. (2017). Pedagogical Knowledge and the Changing Nature of the Teaching Profession. Paris: OECD Publishing.

$\rightarrow$ Hardy, I. \& Melville, W. (2013). Contesting continuing professional development: Reflections from England. Teachers and Teaching, 19 (3), 11-325

$\rightarrow$ Jeffers, G. (2006). Talking about teaching in non-crisis situations: Learning from a teacher support project. Irish Educational Studies, 25 (2), 187-206.

$\rightarrow$ Kazamias, A. M. (2009). Forgotten men, forgotten themes: The historicalphilosophical-cultural and liberal humanist motif in comparative education. In R. Cowen \& A. M. Kazamias (Eds.), International Handbook of Comparative Education (pp. 37-58). London: Springer. 
$\rightarrow$ Lawn, M. \& Grek, S. (2012). Europeanizing Education: Governing a New Policy Space. Oxford: Symposium Books.

$\rightarrow$ Livingston, K. (2003). What is the Future for National Policy Making in Education in the Context of an Enlarged European Union? Policy Futures in Education, 1(3), 586-598.

$\rightarrow$ McMillan, D., McConnell, B. \& O'Sullivan, H. (2016). Continuing Professional Development - Why bother? Perceptions and Motivations of Teachers in Ireland. Professional Development in Education, 42 (1), 150-167.

$\rightarrow$ Murchan, D., Loxley, A. \& Johnston, K. (2009). Teacher learning and policy intention: Selected findings from an evaluation of a large-scale programme of professional development in the Republic of Ireland. European Journal of Teacher Education, 32 (4), 455-471.

$\rightarrow$ NCCA (2010). Innovation and Identity: Ideas for a new Junior Cycle. Dublin: National Council for Curriculum and Assessment.

$\rightarrow$ NCCA (2011). Towards A Framework for Junior Cycle: Innovation \& Identity. Dublin: National Council for Curriculum and Assessment.

$\rightarrow$ OECD (2014). TALIS 2013 Results: An International Perspective on Teaching and Learning. Paris: OECD.

$\rightarrow$ Opfer, V. D. \& Pedder, D. (2011). Conceptualizing teacher professional learning. Review of Educational Research, 81 (3), 376-407.

$\rightarrow$ O'Sullivan, H., McMillan, D., \& McConnell, B. (2011). Continuous professional development and its impact on practice: A North-South comparative study of Irish teachers' perceptions, experiences and motivation [SCOTENS]. Retrieved from http://scotens.org/wp-content/uploads/Final-Report1.pdf.

$\rightarrow$ Rodríguez, A. G. \& McKay, S. (2010). Professional development for experienced teachers working with adult English language learners. Center for Applied Linguistics. http://www.cal.org/caelanetwork/pdfs/ExpTeachersFinalWeb.pdf

$\rightarrow$ Shevlin, M., Winter, E. \& Flynn, P. (2013). Developing inclusive practice: teacher perceptions of opportunities and constraints in the Republic of Ireland. International Journal of Inclusive Education, 17(10), 1119-1133.

$\rightarrow$ Smith, G. (2015). The impact of a professional development programme on primary teachers' classroom practice and pupils' attitudes to science. Research in Science Education, 45, 215-239.

$\rightarrow$ Stoll, L., Bolam, R., McMahon, A. Wallace, M. \& Thomas, S. (2006). Professional learning communities: A review of the literature. Journal of Educational Change, 7, 221-258. 
$\rightarrow$ The Teaching Council (2015). Cosán: Draft framework for teachers' learning. Department of Education and Skills, Ireland. http://www.teachingcouncil.ie/en/ Publications/Teacher-Education/Cosan-Framework-for-Teachers-Learning.pdf

$\rightarrow$ Timperley, H. \& Alton-Lee, A. (2008). Reframing teacher professional learning: An alternative policy approach to strengthening valued outcomes for diverse learners. Review of Research in Education, 32, 328-369.

$\rightarrow$ Van den Bergha, L., Rosb, A. \& Beijaard, D. (2015). Teacher learning in the context of a continuing professional development programme: A case study. Teaching and Teacher Education, 47, 142-150.

$\rightarrow$ Vonk, J. H. C. (1997). The Changing Social Context of Teaching in Western Europe. In B. J. Biddle, T. L. Good \& I. F. Goodson (Eds.), International Handbook of Teachers and Teaching (pp. 985-1051). Dordrecht, the Netherlands: Springer.

$\rightarrow$ Wastiau, P., Blamire, R., Kearney, C., Quittre, V., Van de Gaer, E. \& Monseur, C. (2013). The Use of ICT in Education: a survey of schools in Europe. European Journal of Education: Research, Development and Policy, 48(11), 11-27. 


\section{Biographical notes:}

Michelle Attard Tonna is an academic member of staff at the Faculty of Education, University of Malta, coordinating school-based mentoring on a national level. This role oversees the mentoring of student-teachers during their field placement. Her primary research interests include the professional development of teachers and comparative studies of the way teachers learn. She has contributed to various European-wide studies in the area of teacher learning and also participated in various conferences and European networks in which she has presented her research. She has completed a PhD with the University of Aberdeen, UK, focusing her research on professional teacher learning in Malta.

Dr Cathal de Paor is a Senior Lecturer and Director of Continuing Professional Development in the Faculty of Education, Mary Immaculate College, Limerick. His research work focuses on teacher induction, professional development, and programme evaluation.

Timothy R. N. Murphy obtained his Doctorate in Education from Teachers College, Columbia University, New York. He is a Lecturer in Educational Research and Policy in the School of Education at the University of Limerick, Ireland. He was previously a Senior Lecturer in Education Studies at Leeds Beckett University in the United Kingdom. His research areas include education policy and reform, equity and disadvantage in education, active learning methodologies and teacher well-being. He has co-authored a report CPD for Education Professionals: Existing Provision and a Needs Analysis (de Paor and Murphy 2014). This involved a needs assessment of current CPD provision and demand across the Mid-West region of Ireland and nationally. 



\title{
Personal and Social Development practice within a European neoliberal Maltese education system
}

\author{
Amanda Bezzina
}

University of Malta

\section{Abstract}

Personal and Social Development (PSD) is a statutory subject in Maltese schools. Whilst PSD does not exist as a subject in Maltese higher education, PSD practice is present within the academic content as well as the co-curricular and extra-curricular activities. Its claimed purpose is to support the students' personal and social dimension. This study explores stakeholder perceptions of PSD practice within the University of Malta (UoM) undergraduate experience and its contribution to the wellbeing of undergraduates. From this research it emerges that UoM students from the Science and Social Sciences faculty clusters, those attending the Degree Plus programme together with students engaged in extra-curricular groups, ranked highly the provision of competences that address their personal and social dimension, the emphasis on their active role and the positive impact on their wellbeing, all of which make part of the PSD practice. This chapter suggests that PSD practice at the UoM is not consistent across faculties, but whenever there was PSD practice, students appeared to give it value and recognise its contribution to their wellbeing. Other students suggested that such link is hindered by factors like the traditional education, the influence of the European Union with its economic agenda and a neo-liberal, globalised and capitalist society that glorifies competition, performativity and 
market demands. In conclusion, it is recommended that educators are encouraged to make use of a pedagogy that is based on genuine PSD practice for wellbeing.

\section{Keywords:}

holistic education

personal and social development

wellbeing

teacher education

Malta 


\section{Introduction}

Personal and Social Development (PSD) is a statutory subject in Maltese schools. Whilst PSD does not exist as a subject in Maltese higher education, PSD practice is present within the academic content as well as the co-curricular and extra-curricular activities. Its claimed purpose is to support the students' personal and social dimension.

This study explores undergraduates' perceptions of PSD practice at the University of Malta (UoM), undergraduates' experience and its contribution to their wellbeing. This chapter aims to present the different ways the PSD practice is included at the UoM and the way it impacts the wellbeing of young people. As a result, the chapter attempts to answer the following questions: How is the PSD practice provided at the UoM? Which are the opportunities for PSD practice at UoM? What hinders the PSD practice at the UoM? What is the impact of the PSD practice on the wellbeing of young people? Which are the implications on teacher education?

In order to answer these questions, I conducted a set of semistructured interviews with 23 undergraduates from the UoM, 3 education academics, 8 Faculty Deans, 5 policymakers, the Minister for Education and Employment and the Pro-Rector of the UoM. The semi-structured interview was used as a method because it allows the respondents not to be constrained by fixed answers (Langdridge, 2004) and enhances an informal conversation, shaped partly by the interviewer pre-set questions and partly by the emerging concerns. In addition, an internet search was held to explore ways how the PSD practice is included within the undergraduate courses at the UoM. All names are fictitious to protect the identity of the interviewees. Data was collected between the period of January 2013 and January 2015. Before answering the research questions, I am presenting existent foreign empirical studies that shed light on the impact of an education based on the PSD practice, or as it is referred to by different researchers "holistic education", on the wellbeing of University students. Unfortunately, in the Maltese Islands, this is a research gap because there is no research that focuses on this.

Research shows that UoM students from the Science and Social Sciences Faculty clusters, those attending the Degree Plus programme together with students engaged in extra-curricular groups, ranked highly the provision of competences that address their personal and 
social dimensions, the emphasis on their active role and the positive impact on their wellbeing, all of which make part of the PSD practice.

This chapter suggests that PSD practice at the UoM is not consistent across faculties, but whenever there was PSD practice, students appeared to give its value and recognise its contribution to their wellbeing. Other students suggested that such link is hindered by factors like the traditional education, the influence of the European Union with its economic agenda and a neo-liberal, globalised and capitalist society that glorifies competition, performativity and market demands. In conclusion, it is recommended that educators are encouraged to make use of a pedagogy that is based on genuine PSD practice for students' wellbeing.

\section{Review of existing empirical studies}

Maybury (2013) examines the influence of participation in a positive psychology course that addresses the holistic development of students, on the wellbeing of 23 undergraduates. Similar to what happens in the PSD practice, "positive psychology students frequently consider human character strengths (e.g., bravery, compassion, wisdom) by examining ... the student's own life experiences" (ibid., p. 62). All students, coming from a small liberal arts college in the Northeastern United States, answered a set of questionnaires. Results show that after the course, students gained hope, self-actualization, wellbeing, agency, hopefulness, purpose, and mission in life. Another research held by Clark, Callister and Wallace (2003) confirms the positive contribution of education which is holistic, person-centred and based on the development of the personal and social dimension. From three undergraduate management skills courses, delivered by three different lecturers at Universities in Western United States, 121 students were selected to form an experimental group. The lecturers in each course followed Whetten and Cameron's text (1998) named "Developing Management Skills," which focuses on three intrapersonal (self-awareness, managing stress, creative problem-solving) and six interpersonal competences (communication, gaining power and influence, motivating others, empowering and delegating, managing conflict, and developing effective teams). Lecturers used a pedagogy which is based on their experiences and the application of knowledge to their personal reality. These groups formed the experimental group. 
In the meantime, there was a control group of 113 students taking other business courses, whose content was not based on Whetten and Cameron's 1998 text. Both groups were asked to do a pretest questionnaire to measure their emotional intelligence before the 16week course, and a post-test questionnaire after the course, both of which were about their emotional intelligence. Results showed that the experimental group improved the emotional intelligence scores during the 16-week semester, whereas the control group did not. Both studies held by Maybury (2013) and Clark et al. (2003) are indicative of the positive outcome of holistic education (which in this paper is referred to as "the PSD practice"). Lack of this may even result in drop outs from University. In fact, Goldfinch and Hughes (2007) postulate that "lack of ... self-management skills is one of the common reasons given by students and staff to explain withdrawal or poor performance in first year at University" (p. 261). The authors investigated a large cohort of Scottish undergraduates who started University in 2001/2 and studied programmes ranging from accounting to languages. They were asked to fill in a questionnaire about their personal and social competences and academic performance. Results indicate that students who rated themselves as good in self-reliance, time-management and teamwork were likely to do better in their first year. In addition, the authors said that: "Provision aimed at helping students to develop these skills during first year may help to improve performance overall. In the university where this study took place, it has been found beneficial to alert new students to the importance of these skills" (Goldfinch \& Hughes, 2007, p. 271).

Similarly, Carroll, Cacciattolo and McKenna (2012) sustain that growing evidence shows that character strengths like commitment to learn, positive values, social competence and a sense of purpose were associated with school success and leadership. In addition, Brewster, Curtis, McCarthy, Rodgers and Stoloff (2012) relate the course characteristics and content to student success among students completing psychology programmes at 110 institutions in North America. They correlate student success with a pedagogy that focuses specifically on the undergraduates and their personal experiences. Another inspiring research that discusses this aspect was held by Carroll and colleagues (2012), who used a self-study research methodology. The authors are three teacher educators teaching three different units of academic study in the School of Education at 
Victoria University in Melbourne, Australia. These teacher educators used a positive educational practice, focusing on character strengths, goal setting and mindfulness (being aware of what is happening in the present moment) in addition to the typical content of mathematics education, literacy education and postgraduate research methods. Overall, the results are very positive since the positive educational practice helped the students to pass their test and made them realize that they can use their character strengths in different areas of their life, including education.

Literature presents the need for education to tackle both the skills of achievement as well as the skills of wellbeing (Seligman at al., 2009) and that undergraduate programmes must "develop insight into their own and others' behaviour and mental processes and apply effective strategies for self-management and self-improvement" (American Psychological Association, 2007, p. 20).

\section{The PSD practice at the University of Malta}

The PSD (Personal and Social Development) practice is an educational practice that targets the entire holistic development of the students. It provides a difference from the traditional type of education because there is an emphasis on holistic content and holistic aims, instead of a strict focus mainly on knowledge and qualifications. The term "holistic" derives from the Greek word "holon" which refers to a universe that is made up of integrated wholes that cannot be easily fragmented into parts (Lee, 1988). Similarly, Jung infers that individuals have a drive toward wholeness, where all elements of the person combine to form a larger entity, which is the self (Witmer, 2012). The holistic PSD practice addresses all aspects of the individual, including the personal and social dimension, or as sometimes referred to as "character strengths". Examples include: decision making, self-esteem, communication, leadership, empathy and emotional literacy. The personal dimension refers to an "individual's sense of self-worth and accomplishment" (Hall \& Rueth, 1999, p. 31), whereas the social dimension refers to the "ability to understand and communicate with other persons" (ibid., p. 31). The PSD practice can also be defined as that educational practice that is holistic because it targets the competences (skills, attitudes, values and knowledge) of the student, makes use of empowering learning methods and places the individual at a very central role of the process of education. 


\section{Opportunities for the PSD practice at the University of Malta}

At the UoM, the PSD practice is either offered through specific credits that address competences that develop the personal and social dimension of the students; or embedded within the aims of the credits; or offered through the co-curricular and extra-curricular activities (Figure 1-data elicited from interviews and from the online search through the University website). Empirical evidence suggests that the most faculty clusters that followed the PSD practice were the Science (Faculty of Health Sciences, Faculty of Medicine and Surgery, Faculty of Dental Surgery and Faculty of Science) and the Social Science (Faculty of Laws, Faculty for Social Wellbeing, Faculty of Education, Faculty of Economics, Management and Accountancy and Faculty of Media and Knowledge Sciences). In these faculty clusters, it seems that the students have a more active role, experience circle format and smaller groups, engage in experiential activities as well as lectures and are more assessed formatively.

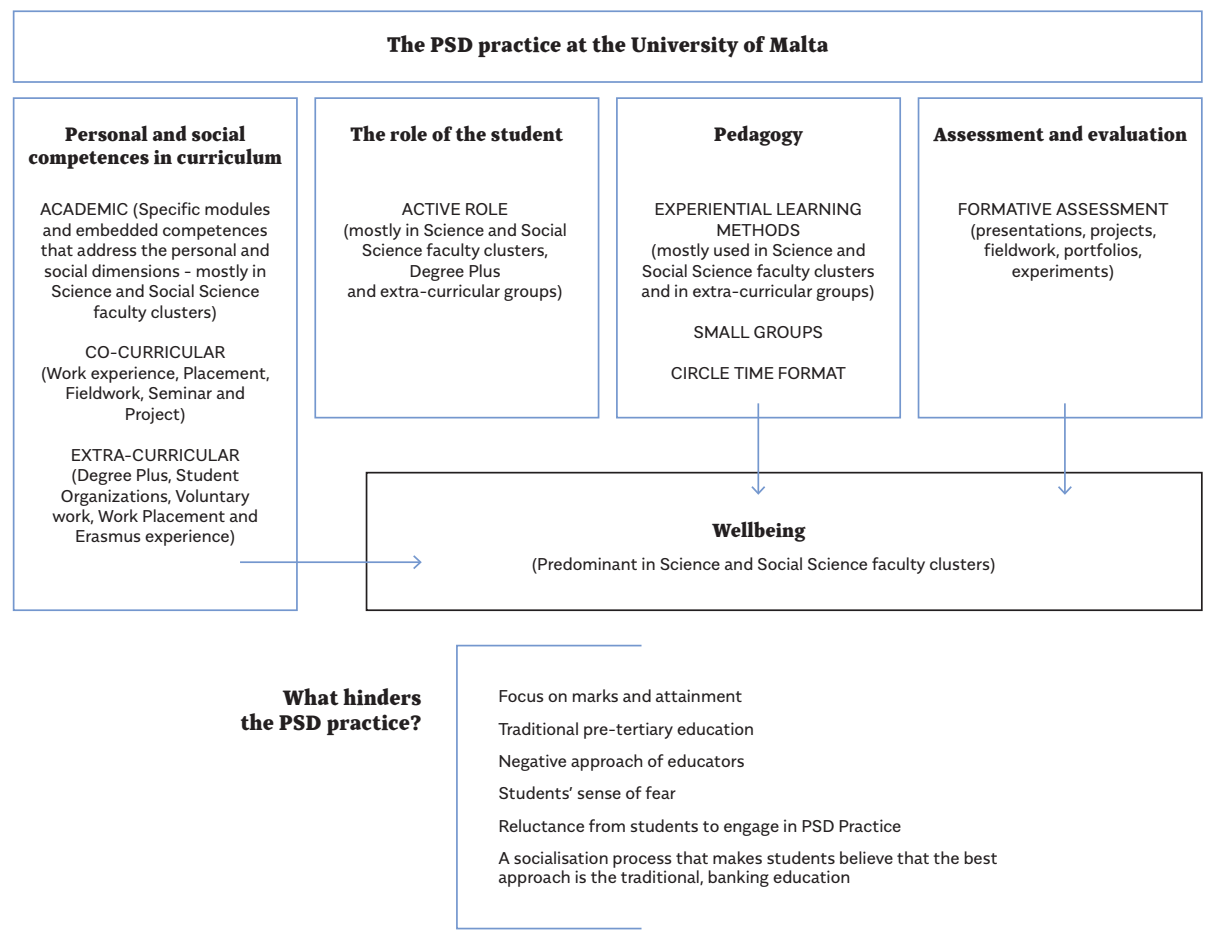

Figure 1. The PSD practice at the University of Malta 
As explained earlier, results from interviews indicate that the UoM provides an opportunity to students to develop their personal and social dimension through extra-curricular activities. This is held through the Degree Plus programme, different student organizations, voluntary work and work placement. The Degree Plus programme is aimed at offering an opportunity to all students at the university, on a voluntary basis, to enrich themselves with personal and social competences through different extra-curricular activities which are person-centred and enhance their active role. The UoM also provides opportunities for voluntary work with the aim of helping students to practice social and teamwork skills, enhancing their ability to plan and manage small scale projects and improving their employability (UoM, 2015). It also offers a range of student organizations and the ERASMUS experience (an EU student exchange programme), which are also aimed to develop the personal and social dimensions of young people, thus enhancing the PSD practice at the UoM.

Despite having these opportunities, the interviewees mentioned a series of aspects which are hindering such practice: namely the traditional education system, the lack of lecturers who make use of it and the summative assessment.

\section{Hindering the PSD practice at University}

Empirical evidence from this study suggests that the traditional academic education system seems to be persisting throughout all educational levels. As literature suggests, traditional education with a focus on the transfer of knowledge and academic content "turns them [students] into 'containers', into 'receptacles' to be 'filled' by the teacher ... Education thus becomes an act of depositing, in which the students are the depositories and the teacher is the depositor... This is the "banking concept of education" (Freire, 1970, p. 52). Accordingly, the traditional approach to education is characterized by the transmission model since knowledge is transmitted to students. The Maltese education system seems to be characterised by this type of approach. This was evident from the data of the semi-structured interviews. Mr Claudio, a policy maker within the Ministry for Education and Employment, argued that whereas policies focus on the holistic aspect of education, in reality this is not always the case: 
"But when it comes to implementation, I still think that we are too much relying on our academic, traditional models. You would find pockets, instances of experiencing education in a particular school that is truly holistic where you do see a teacher, an educator that has embraced so much these values that throughout her professional work she conveys these messages continuously in all her lessons. But this does not mean that it is reflected throughout."

Dr Martin, another policy maker within the Ministry, questioned whether there is enough space for the PSD practice within the Maltese education system in general, including UoM. In fact, Prof. David, from the UoM, identified three models of education: the traditional, which is content-oriented; the interactionist, which is cognitive development oriented and focuses on higher order skills, like critical thinking and problem-solving; and the transformative, which overlaps with the interactionist but with a more social commitment. Prof. David further added that most University students who attend his lectures (who would have followed primary, secondary and post-secondary education) identify themselves with the traditional model. His interpretation of reality shows that through the socialisation process, students are expected "to sit passively, consume knowledge and sit for a summative assessment." Some interviewees said that students are socialised to believe that the best method is the traditional banking education.

As a result, such socialisation process seems to be making students prefer to adhere more to reductionist and mechanistic views of mainstream education (Miller, 2000) where education is a matter of how many qualifications one gets and education is simply transmission of information. In this way, students are socialised to fear and resist problem-posing education, in which they critically perceive the way they exist in the world through a process of reflection (Freire, 1970). Certain interviewees confirmed that this was lacking because students tend to be socialised from their early years to be only acquainted to the traditional, banking, reductionist type of education. Prof. Luca, an education academic, argued that this seems to be leading UoM students who find it hard to be critical and to participate, because they are not used to it and they feel shy. An example was given by Mandy, an undergraduate, who commented that: 
"So in the discussion that we would have in class, sometimes off topic, there would be someone who says Oh I disagree... you know it's interesting that when that happens, you almost feel the tension, all students say oh my God. And I mean that it's a good thing that he disagrees and the lecturer is very happy. But the fact that other students are surprised also shows you that we are not used to it ... but the space was there."

Here Mandy is confirming that students were given the opportunity to have an active role, however it seemed surprising whenever someone participated. This shows that in this example, as well as others shared during the interviews, students feared participation, even though space was provided. On the other hand, those student interviewees who participated in Degree Plus, extra-curricular groups, ERASMUS experience and other activities offered by the UoM, which are in line with the PSD practice, had less fear to participate. In fact, they said that through these opportunities that they had an active role and their personal and social dimensions were developed. Interviewees explained this by referring to the presence of smaller groups and a setting where the leader valued their opinions and beliefs.

As a result, the traditional academic approach to education still persists throughout the Maltese education system in general. This is despite the opportunities for the development of the personal and social dimension. Accordingly, I discussed this contradiction with the interviewees, who argued that, at University, time is limited and the academic curriculum is too vast (Margot - an undergraduate), hence restricting time for holistic development. Other interviewees referred to the socialisation process that makes students believe that the best approach is the traditional, banking method of education, hence making students reluctant to engage in the PSD practice. The latter demands critical thinking and participation. Some interviewees even blamed the large number of students per class. In spite of this, Prof. David argued that:

"Numbers do tend to interfere but if you come to my lectures, my average class is around 100 and I still engage critically with the students. But obviously, I have changed my pedagogy from one which is content-driven, where I am obviously the typical 
traditional lecturer who would be obsessed with covering knowledge to a situation-driven where knowledge is secondary. I can give them the knowledge beforehand to read and then engage on that knowledge so basically that hour I spend with the students is not spent reading from an overhead projector, slides, not spent reading from a powerpoint. That is I share knowledge over a VLE or something else and I spend the whole lecture engaging with them critically so I had to change my pedagogy, in order to change, in order to conform with my vision."

This is related to the "flipped classroom", which is "A new pedagogical method, which employs asynchronous video lectures and practice problems as homework, and active, group-based problem-solving activities in the classroom. It represents a unique combination of learning theories once thought to be incompatible- active, problembased learning activities founded upon a constructivist ideology and instructional lectures derived from direct instruction methods founded upon behaviourist principles" (Bishop \& Verlerger, 2013, p. 2).

As explained by Prof. David, even though he has large number of students at University, he still engages students and makes them feel central to their own learning by involving them and giving them the power to critically analyse the knowledge that they should read at home. Even his assessment system is quite different since he uses the openbook system which helps students to practise higher order thinking skills like rational and critical thinking. As a result, his pedagogy, which is in line with the practice of the flipped classroom, puts the learner at a central role and is followed by a challenging assessment that makes the student think and reflect rather than regurgitate what is learnt. However, he admitted that this was not easy to be done and he had to change his vision, his pedagogy and expectations. He confessed that "it was a personal change in order to accommodate a different view of how to deal with students so the limitations are still there." In line with the argument by Prof. David, Dr John from the Ministry for Education and Employment in Malta, contended that numbers do not necessarily make a difference. Instead, it depends on the preparation of educators and in, at least, managing to create a balance between the traditional approach and the person-centred (hence the PSD practice) approach. 
He argued that as teachers and lecturers, they are "not very much prepared in order to balance and use these two different approaches."

The traditional academic education system, as well as the lack of trained professionals who can educate through the PSD practice, become more complicated when having a mode of assessment throughout the entire Maltese education system, that is mostly summative. Lucia, Marvic and Jonathan, three undergraduates, said that summative assessment puts a lot of stress, assesses on one occasion only and limits the amount of creativity and willingness to participate whereas formative assessment encourages students to really reflect on what they were learning and to focus less on regurgitation of knowledge. Claudia, another undergraduate, was against exams and instead she was in favour of formative and continuous assessment because she thought that:

"Exams are completely unfair because you are examining everyone on the same level when not everyone learns on the same level. For me exams are more a memory test of what you actually know. For example, I prefer assignments to exams even though in an assignment they expect more from you. But in an assignment at least I have time to sort of give my own opinion not just regurgitate what the lecturer taught me. And also ideally it would be almost continuous assessment, not at the end because there is a lot of pressure at the end and in that way you can develop and learn. If they give feedback, then you can learn from it."

However, this seems to be still lacking throughout the Maltese education system in general. Marouska, an undergraduate at UoM, confirmed this argument by saying that: "We were taught in a very capitalist view. We were ... yes... we were taught you have to pass the exam." In turn, this method seems to be limiting the development of higher-order cognitive skills. When asking about this, Prof. David commented that:

"As far as I am concerned usually assessment or at times, let me put it that way, at times assessments are imposed ... Now you cannot give a traditional exam and expect students to have higher order thinking skills. You have to change the nature of the assessment so it all starts with your vision, then it comes down to social relations with 
your students and ultimately yes, a change in the way you assess your students. So, there needs to be coherence between vision, pedagogy and assessment."

As a result, in order to have a proper PSD practice, the vision, the pedagogy and the assessment methods must follow each other. Consequently, the interviewee suggested a review in programmes and self-reflection so as to question how the mode of assessment reflects the competences that go beyond the subject itself.

\section{The impact of the PSD practice on the wellbeing of young undergraduates}

Results from this research show that students from the Science and Social Sciences Cluster, students who attended Degree Plus for more than four years and students who participated in extra-curricular groups ranked highest the provision of the PSD practice, in terms of active involvement, focus on their needs, and development of personal and social dimension. The same interviewees also ranked highest the belief that the PSD practice within their UoM experience had holistic aims in terms of wellbeing. As a result, this encourages the UoM policymakers to invest in this practice and not to rely on sporadic events or personal initiatives. There were interviewed participants who recognised the holistic aims of the PSD practice and therefore, in support of this, it would be beneficial to increase student exposure to the PSD practice as it supports holistic development and it is in line with the mission statement of the UoM.

Marco, an undergraduate, said that a focus on the PSD practice meant that he matured properly and he was able to make effective transitions from one life stage to the other. By equipping students with the necessary focus on the personal and social dimension, Lucia, another undergraduate, learnt how to deal with her ambivalent feelings of remaining a child and not facing adulthood, which brought further responsibilities. In turn, this enhanced her psychological, emotional and subjective wellbeing and health as well as her quality of life. She said that this was difficult for her because she is very close to her parents, who try to give her everything, without allowing her to be responsible for her own self. It is evident that young people are affected by their life transitions and that, in these cases, the PSD practice within the undergraduate experience at the UoM helped them to deal with 
them. Empirical data from interviews reveals that coping well with life transitions seems to be essential because it affects all dimensions of wellbeing (emotional, physical, intellectual, social, spiritual). Different student interviewees mentioned that University life is a period of transitions, even in terms of relationships. Claudia confessed:

"I would say how I was in first year and how I am now there is a difference. In first year, I had a boyfriend and now I am happily single. So, there was a breaking point when my relationship ended and I said let me take a different approach to life so if before it was sort of I graduate, do a Masters, get a job, have a family. Now I would say graduate from University, get a job maybe, travel a bit, live life, enjoy. So, I have gone through a transition phase. The organisations definitely helped me. The reason I joined is that I was bored and I had nothing to do after breaking up and I decided to join. From extra-curricular groups, you learn competences. Your social cycle opens a lot."

Claudia is a student who likes to attend extra-curricular groups since they helped her to overcome her relationship challenges which are a common feature of late adolescents and early adults. This is a developmental task in Erikson's psychosocial life-span stages (Stage 6 - Intimacy versus isolation), whereby individuals may experience a time of termination or modification in meaningful relationships. Such transitions in meaningful relations may lead to growth and development as well as separation or loss, creating ambivalent feelings (Egan, 1984). The importance of interpersonal relationships is one of the seven vectors describing psychosocial development for young people (Chickering, 1969). Margaret argued that for her, making friends and starting to form healthy relationships was very important. Her University experience, which was based on the PSD practice, tackled this aspect and found it very useful for her life since she could tackle her relationship challenges easily. Chloe also said that before the University experience, she used to be shy and quiet but the PSD practice helped her in overcoming her difficult situations, in making new friends, in feeling confident, in modifying her meaningful relationships, thus facilitating her psychological, social and emotional wellbeing and health as well as quality of life. Similarly, Mandy sustained that: 
"Definitely a lot, as a child I was a very shy person. An extreme. That changed before I came to University but it is coming to University that helped me boost my self-esteem, being able to sit down and talk to somebody I don't know. I got to an extent that because I was shy, I was left out. My course is very ... the people there, are very friendly as well. You have a lot of group assignments, communication, talks and it definitely increases my social competences."

Even though interviewees recognised such a link, there were other interviewees who were sceptic about the development of wellbeing through the PSD practice. Although there were students who received help to focus on personal and social dimensions through the PSD practice, the traditional educational system based purely on marks, the influence of the European Union with the economic agenda, a neo-liberal discourse, globalisation and capitalism, all impeded the link between the PSD practice and wellbeing. This was because some educators who engaged in PSD practice directed it towards utilitarian purposes, influenced by current discourse, rather than genuine development of wellbeing. Empirical data from this research suggests that despite the positive practices, the aims of the PSD practice focused more on employment and employability, hence some students were sceptical about the link between PSD practice and wellbeing, because such aims served the purpose of the economy rather than their personal flourishing. This goes against the humanistic (besides utilitarian) purposes mentioned in the mission statement of the UoM.

\section{Implications for teacher education}

This research provides evidence of positive and negative experiences of the PSD practice at the UoM and its impact on the student wellbeing. It is very important to reflect about the implications of this study on the theory, policy and practice of teacher education in Malta. These are grouped in three main categories: "Moving away from traditional education and utilitarian aims", "Facilitative educators at the UoM" and "Education is no panacea to the problems that we have out there", all of which elicited through a process of analysis that followed constructivist grounded theory. 
After collecting data from semi-structured interviews, there was a stage of analysis through a coding process which is the process where data is analysed, interpreted, separated, sorted and synthesized. In this research, I followed the coding process presented by Charmaz (2006), which comprises open, focused, axial and theoretical coding (Urquhart, 2013). After having different transcripts, these were inputted in the NVivo10, so as to facilitate the analysis and the constant comparison of data, which is the constant process of comparing different sections of data (Charmaz, 2006). The coding process started off by open coding, whereby data is "broken down into discrete parts, closely examined and compared for similarities and differences" (Strauss \& Corbin, 1998, p. 102) to build up categories. This process was held until there was theoretical saturation, which is the point where I did not find any new codes (Urquhart, 2013). Once the open coding was done, I carried out focused coding, which was used to identify the main categories from all the open codes. After this step, I engaged in axial coding, which helped me to "uncover relationships among categories" (Strauss \& Corbin, 1998, p. 127). The statements of participants were grouped by the "coding paradigm", thus identifying the:

$\rightarrow$ conditions which are the causal, intervening and contextual factors;

$\rightarrow$ actions or interactions which are the strategies done;

$\rightarrow$ consequences which are the immediate, cumulative, reversible, foreseen and unseen actions.

Finally, all this data was used to produce substantive theory which pertains to the phenomena being studied without making claims to generalise beyond the particular phenomena (Urquhart, 2013).

\section{Moving away from traditional} education and utilitarian aims

All interviewees argued that a change is required at all education levels. They blamed the Maltese Education System in general for the lack of PSD practice and development of student wellbeing. In some cases, the latter lacked even when the education system was based on the PSD practice, since it focused more on employability rather than on wellbeing. To the contrary, the Ministry of Education and Employment for Malta $(2012$, p. 6) warns: "in the event that the education system is 
subservient to the economy then the education system might succumb to displaced priorities and the valuation of utilitarian benefits above the human person." Through this neo-liberal approach "public goods (like education) are converted into consumption goods as the ideology of the marketplace takes hold" (Borg \& Mayo, 2006, p. 2). LeGrand and Bartlett and (1993) warn that if this happens, the system would be 'producing' efficient students who are suitable only for the world of work. Despite this practice, the aims of the Maltese National Curriculum Framework 2012 (Ministry of Education and Employment, 2012), the Framework for the Education Strategy for Malta 2014-2024 (Ministry for Education and Employment, 2014a) and the Respect for All Framework (Ministry for Education and Employment, 2014b) stress the importance of addressing the holistic needs of each individual student and the importance of the active role of the student. This shows that there is a discrepancy in the vision presented in the local education policy documents and the actual practice.

Since empirical evidence indicates that the current education system adheres more to the traditional, banking education (Freire, 1970), serving economical purposes, interviewees noted that there must be an improvement in the Maltese Education System in general. However, a change can be implemented if it is directed towards different aspects in education, including the methodology, the programme and the assessment. This was confirmed by different interviewees. Dr Martin commented in the following way:

"We are still examination obsessed and test driven. Now, one is hoping that this changes with the learning outcomes framework and the type of assessment that will replace tests and exams. Then, what methodology and programmes are used because these have to reinforce each other. If you change the method of assessment, but you do not change the pedagogy, there is the chance that you keep teaching to the test. As a result, changes have to be done in all these factors. You cannot change one thing only."

Dr Martin is suggesting a change in the education system in general. $\mathrm{He}$ also mentioned that in order to enhance the PSD practice, the Ministry is working on a learning outcomes framework with the aim of moving away from a system that is based on "centrally-imposed 
knowledge-centric syllabi", and instead introducing one that gives "the freedom to develop programmes that fulfil the framework of knowledge, attitudes and skills-based outcomes that are considered national education entitlement of all learners in Malta" (Ministry of Education and Employment, 2015, p. 5). Mr Claudio, explained that this is being introduced slowly within the pre-tertiary education levels, with the hope of making education less focused on the academic and more in line with the students' holistic personal and social needs. He further explained that when one speaks about knowledge, attitudes and skills based outcomes, one is already setting a different scenario that is placing the learner at the heart of the education process.

Since the empirical evidence from this research suggests that the traditional education is hindering the PSD practice at all levels of the education, the active role of the student and the development of wellbeing, and since this research, as well as literature (Maybury, 2013; Clark et al., 2003; Goldfinch \& Hughes, 2007; Carroll et al., 2012; Brewster et al., 2012), indicate that the PSD practice or holistic education matters in the development of student wellbeing, respondents argued that it is important that such practice is taken seriously. The learning outcomes framework might be a good solution; however, it needs to be assessed continuously so that policymakers ensure that the PSD practice is not implemented for purposes which serve the economy but for the student's entire life. The latter was also a factor which hindered the link between the PSD practice and wellbeing.

These research findings are an eye-opener to education policymakers and practitioners in Malta and abroad to genuinely believe and implement the PSD practice, since it equips students for their entire life and promotes holistic wellbeing.

\section{Facilitative educators at the University of Malta}

A pertinent implication that emerged from this research was that educators at tertiary education level may require upskilling so that they have a better pedagogical formation and ongoing reflection on their pedagogy. Maria, a University student, argued:

"Teachers who are teaching me at University are boring as hell. They try to tell me to be creative and engaging and then they 
make it boring themselves. Teach by example. Teachers seem not to know how to do the lecture otherwise."

As highlighted in literature, the PSD educator must be well equipped with personal and social competences and must be able to achieve different aims, using different methods (Heron, 1999; Weil \& McGill, 1989). This is an important implication for policymakers and practitioners to ensure that educators are better equipped in providing an education based on the PSD practice. Nevertheless, having the necessary pedagogical training still seems not to be enough because University is not a community of educators working together but a collection of individuals (Prof. Tim, an education academic at the UoM). It seems that at the UoM, educators tend to work on their own, instead of meeting to share good practice as well as to evaluate their work. In turn, this hinders change. He argued:

"We are here like a convent rather than a community so I come in, I sit here, I produce research but most of the time on an individual basis so the community spirit is lacking. That makes change very difficult on an institutional level. There are changes happening but most of those changes are on an individual basis. There are differences between faculties, there is a difference in terms of ethos, expectations, attitude, culture so obviously my comments are general in nature so I know that there are pockets of home within University where things are done differently."

The lack of community aspect results in traditional type of education, as opposed to PSD practice, because there is no communication, feedback and teamwork. Since most of the work carried out by educators is held on an individual basis, such three aspects tend to be hindered. One suggestion made during this research was that the University should continue to provide professional development to educators and that it should find ways of enhancing teamwork between staff within the same department and faculties as well as between different faculties. This links to the research findings about the provision of PSD practice on a sporadic basis, hence not guaranteeing every student to have PSD practice. Prof. Tim sustained that: "There are differences between faculties, there is a difference in terms of ethos, expectations, attitude, culture." If there is more communication and teamwork between faculties, these issues may be discussed more, good 
practices might be shared and there might be a more interdisciplinary approach used by the educators.

\section{"Education is no panacea to the problems that we have out there"}

Education is "no panacea to the problems that we have out there." In his claim, Prof. Tim is showing that the education is only one aspect of the system. This research revealed that even if the PSD practice is provided, it does not necessarily translate into having a different society because education is only one aspect of it. In fact in his interview, Mr Adrian, a policy maker within the Ministry for Education and Employment, commented that:

"Education is a complex process. To try to understand it, you need to adopt the systems approach. It means that you identify the different factors that are part of the system. Those factors include factors beyond school. You have factors within school and factors beyond school."

As a result, one must address other issues, rather than blaming only the tertiary education system, which might not always solve the other existent problems. Some of these might be the home background, the community and even the Maltese context. Empirical evidence shows that the Maltese context presents a certain scenario for PSD practice. Malta is a small island state with limited natural resources, a surface area of $316 \mathrm{~km} 2$ and a resident population of around 400,000. A phenomenon which is particular to the Maltese context is that of young people who have a delayed transition to adulthood and who tend to live longer with their parents. This was stated by the Council of Europe, Directorate of Youth and Sport in 2005 and confirmed by interviewees in this research. This prolonged dependence on the family, the protective family environment coupled with the insular Maltese context seem to lead certain young people to be dependent, to be pampered, to resist any change and to be reluctant to be involved in new experiences and activities. In fact, despite having a series of available University extra-curricular activities that are intended to address the personal and social dimension, few interviewees from the UoM said that they participated in Degree Plus and that they experienced ERASMUS. 
This implies that besides addressing University education to be more in line with the PSD practice, it is suggested that policymakers from different areas discuss genuinely the existent problems within the education system in general, so that they are tackled at grass root level.

\section{Conclusions}

Nowadays, we can observe that the Maltese policies tend to be dominated by a neo-liberal discourse which emphasises the importance of education for employability. This study provides evidence that within the UoM, the PSD practice is implemented on a sporadic basis. This implies that some students have experienced an education that places them at the centre, that addresses their personal and social dimensions and that in turn affects their wellbeing. On the other hand, there were others who commented that there was more links between the PSD practice at the UoM and employability, rather than wellbeing.

The study is an eye-opener for policymakers and stakeholders who regulate teacher education to move away from the traditional system, to genuinely provide PSD practice for wellbeing and to work with other sectors in order to address the problems at grass root level.

As indicated in the aspects which hindered PSD practice, the way the Maltese education system in general is structured is posing a problem to PSD practice at the UoM. Maltese education providers need to revise and critically evaluate the entire Maltese education system so as to ensure that PSD practice is properly implemented in actual practice and that the education is not based on the traditional, didactic approach instead of the facilitative, person-centred approach. Besides an evaluation of the Maltese education system, amongst the factors which hindered PSD practice at the UoM, there was reference to the passivity of students and the sense of fear to engage in this practice, which demands active participation and courage to try new experiences. Such attitude and feelings were related to the Maltese culture and mentality of having an insular as well as protective environment which resists change and new challenges. It was also linked to the persistent priority given to academic accomplishment instead of holistic development. Both aspects related to the Maltese education system in general and the Maltese mentality appear to be hindering PSD practice at the UoM, confirming what Prof. Tim stated: "University is a reflection of society." In addition, there were also other 
factors which hindered such practice and which were directly related to the UoM. These were the knowledge-based courses, summative assessment and predominant use of information-giving. Such results might act as feedback to UoM educators and policymakers to evaluate their practices. They are also an eye-opener to UoM policymakers to equip students with the necessary support structures to be able to interact within PSD practice, thus going against the Maltese mentality. As Prof. David argued, with greater popularisation of tertiary education, the UoM is attracting different students, including those with lack of social capital and who need more assistance. This urges the UoM stakeholders to provide these support structures.

In summary, the research is indicative of the ways PSD practice is included within the undergraduate experience and the ways such practice affects the wellbeing of students. For policymakers, the evidence of this research would suggest that they might usefully consider the aspects related to Maltese mentality and culture, those linked to the Maltese education system in general and those related to the UoM, so as to provide quality holistic education. 


\section{References}

$\rightarrow$ American Psychological Association (2007). APA guidelines for the Psychology Major. Washington, DC: Author.

$\rightarrow$ Bishop, J. L. \& Verleger, M. (2013). The flipped classroom: A survey of the research. ASEE National Conference Proceedings, Atlanta, GA, 30 (9), 1-18.

$\rightarrow$ Borg, C. \& Mayo, P. (2006). Learning and social difference: Challenges for public education and critical pedagogy. Colorado, US: Paradigm Publishers.

$\rightarrow$ Brewster, J., Curtis, N., McCarthy, M., Rodgers, M. \& Stoloff, M. (2012). Characteristics of successful undergraduate psychology programs. Teaching of Psychology, 39 (2), 91-99.

$\rightarrow$ Carroll, J., Cacciattolo, M. \& McKenna, T. (2012). Positive education: The use of self-study research methodology to assess its place in higher education settings. In C. Gale \& S. Steinberg (Eds.), Critical qualitative research: Reader (pp. 512-523). New York, USA: Peter Lang Publishing.

$\rightarrow$ Charmaz, K. (2006). Constructing grounded theory: A practical guide through qualitative analysis. Thousand Oaks, CA: Sage.

$\rightarrow$ Chickering, A. W. (1969). Education and identity. San Francisco: Jossey-Bass.

$\rightarrow$ Clark, S. C., Callister, R. \& Wallace, R. (2003). Undergraduate management skills courses and students' emotional intelligence. Journal of Management Education, 27 (1), 3-23.

$\rightarrow$ Council of Europe Directorate of Youth and Sport (2005). The youth policy in Malta. Strasbourg, France: Council of Europe.

$\rightarrow$ Egan, G. (1984). People in systems: A comprehensive model for psychosocial education and training. In D. Larson (Ed.), Teaching psychological skills: Models for giving psychology away (pp. 21-43). Monterey, CA: Brooks/Cole.

$\rightarrow$ Freire, P. (1970). Pedagogy of the oppressed. New York, USA: Continuum.

$\rightarrow$ Goldfinch, J. \& Hughes M. (2007). Skills, learning styles and success of first-year undergraduates. Active Learning in Higher Education, 8 (3), 259-273.

$\rightarrow$ Hall, S. E., \& Reuth, T. W. (1999). Counsellors in the classroom: A developmental approach to student wellbeing. NASSP Bulletin, 83 (603), 27-33. 
$\rightarrow$ Heron, J. (1999). The complete facilitator's handbook. London, England: Kogan Page.

$\rightarrow$ Langdridge, D. (2004). Introduction to research methods and data analysis in psychology. Essex, England: Pearson Education Limited.

$\rightarrow$ Lee, K. D. (1988). Toward a philosophical framework for holism in education. USA: Arizona State University.

$\rightarrow$ LeGrand, J. \& Bartlett, W. (1993). Quasi-markets and social policy: The way forward? In J. Le Grand \& W. Bartlett (Eds.), Quasi-markets and social policy (pp. 202-220). Basingstoke, UK: Macmillan Press.

$\rightarrow$ Maybury, K. (2013). The influence of a positive psychology course on student wellbeing. Teaching of Psychology, 40 (1), 62-65.

$\rightarrow$ Miller, R. (2000). Beyond reductionism: The emerging holistic paradigm in education. The Humanistic Psychologist, 28 (1-3), 382-393.

$\rightarrow$ Ministry of Education and Employment (2012). A National Curriculum Framework for all. Malta: Salesian Press.

$\rightarrow$ Ministry for Education and Employment (2014a). Framework for the Education Strategy for Malta 2014-2014: Sustaining foundations, creating alternatives, increasing employability. Malta: Ministry for Education and Employment.

$\rightarrow$ Ministry for Education and Employment (2014b). Respect for All Framework. Malta: Ministry for Education and Employment.

$\rightarrow$ Ministry for Education and Employment (2015). Educators' guide for pedagogy and assessment: Using a learning outcomes approach. Malta: Directorate for Quality and Standards in Education.

$\rightarrow$ Seligman, M. E. P., Ernst, R.M., Gillham, J., Reivich, K. \& Linkins, M. (2009). Positive education: Positive psychology and classroom interventions. Oxford Review of Education, 35 (3), 293-311.

$\rightarrow$ Strauss, A. \& Corbin, J. (1998). Basics of qualitative research: Techniques and procedures for developing grounded theory. London: Sage Publications.

$\rightarrow$ University of Malta (2015). Degree Plus: List of courses 2014/2015. University of Malta.

$\rightarrow$ Urquhart, C. (2013). Grounded theory for qualitative research: A practical guide. London: Sage.

$\rightarrow$ Weil, S. W. \& McGill, I. (1989). Making sense of experiential learning: Diversity in theory and practice. Milton Keynes, UK: Society for Research into Higher Education and Open University Press.

$\rightarrow$ Whetten, D. A. \& Cameron, K. S. (1998). Developing management skills. New York, USA: Pearson.

$\rightarrow$ Witmer, M. (2012). Evolution of wellness. In P. F. Granello (Ed.), Wellness counselling (pp. 11-28). New York, USA: Pearson. 


\section{Biographical note:}

Dr Amanda Bezzina is a Personal, Social and Career Development as well as a guidance teacher. She is also a Visiting Assistant Lecturer at the University of Malta and a member of the Board of Governors at the Malta College of Arts, Science and Technology, Malta. Her areas of specialisation are: effective teaching strategies, facilitation, resilience, leadership, professional development, holistic education for wellbeing and employability, formative assessment and teaching skills and strategies. Dr Bezzina is the President of the Malta PSD Association and is committed to organize a series of conferences to enrich the professional development of educators. 



\title{
A Professional Learning Community model for a Maltese Catholic Church Primary School: A Case Study
}

\author{
Christopher Bezzina \\ University of Malta \\ Mark A. Farrugia \\ University of Malta
}

\section{Abstract}

This study explores the culture of a newly established primary school, as it engages in the process of introducing policies, organisational structures and developing pedagogies of teaching and learning. Specifically, it examines the Professional Learning Community (PLC) model which is reported in the literature to create a collaborative culture aimed at improving both the educational environment and students' achievement. The study critically analyses the literature in the field of PLCs, and the principles extracted from it guided the methodological approach adopted in this study. The research approach was action research, with the aim of changing practitioners' practices, their understandings of their practices, and the conditions in which they practise in order to improve the learning experience of the students. Finally, the study outlines the leadership implications to develop and support a PLC in the local setting.

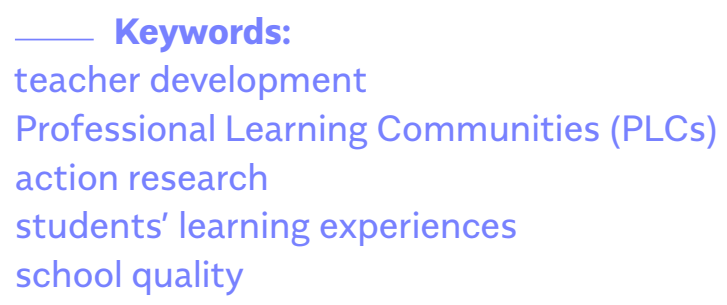




\section{Introduction}

Today, more than ever before, we do appreciate that building a community of learners is essential to any school reform effort. Various national and international documents argue that in order to adequately prepare our children to become productive citizens in democratic societies we need leaders who are committed to continuous schoolwide learning. Building professional learning communities (PLCs) in schools challenges leaders to perform a multitude of roles involving educators within the school and other stakeholders in the pursuit of learning. The personal experience of the main author in various schools has shown that while increased collaboration among teachers is a long, arduous and tortuous journey (Bezzina, 2006, 2008), on the other hand, it can be a powerful vehicle for positive change and development. This paper presents the initial collaboration between the authors, one as a consultant/researcher and the other as the deputy head of the school in their endeavours to introduce a teacher-led approach to school improvement.

\section{Professional Learning Communities}

The main intent behind this research study was to explore how the notion of PLCs might be introduced at St Peter and St Paul Primary School'1. Before looking at the case study we will start off by referring to the PLC literature that has inspired the study. We believe that the findings will be of value to the educational field, both researchers and practitioners, who may be interested in engaging with the factors that aid or inhibit the introduction of collaborative factors within schools.

In recent decades, educational reforms have had one main aim: that of increasing student achievement (InPraxis Group Inc., 2006, p. 7). McLaughlin and Talbert $(2006$, p. 1) identify two pressures that drive today's schools: society's demand to produce students with the complex cognitive skills needed by the 'knowledge society' (Sahlberg \& Boce, 2010, p. 34) and a wish to address the issue of inequity so that all students achieve set standards (OECD, 2008, p. 1). However, these two aspirations may or may not be compatible, most often depending on how policy-makers address reforms (Hargreaves, 2003, p. 14). Research

1. All names referred to in this chapter are pseudonyms. Permission was sought and granted by the school authorities to write about their experience. 
to promote change and reforms thus focused on the important relationship between school organisation, teacher quality and student achievement (Robinson \& Timperley, 2007). It is within this context that PLCs have been found to play a critical role (Hughes \& Kritsonis, 2007). Such a conceptualisation is one of increasing importance because PLCs are considered as a dynamic model to improve education systems (Barber \& Mourshed, 2009). It has particular relevance to new-start schools because it reports how at this stage culture responds to shaping on PLC characteristics.

During the eighties, educators felt the need of regeneration and to move away from traditional schooling to improve 'accountability, collaborative environments and teachers' efficacy' (InPraxis Group Inc., 2006, p. 7). Consequently, research set about scrutinising what was really effective in education and how learning can be sustained. This brought under scrutiny the link between student achievement, "teacher quality, organisational and systemic change and reform" (ibid., p. 7).

By the turn of the $21^{\text {st }}$ century, Senge (2006) had articulated a view of the workplace as a learning organisation for the business world which seemed to propose a solution for the sought after change in education (Feger et al., 2008, p. 3). Senge $(2006$, p. 3) defines PLCs as a place where "people continually expand their capacity to create desired results, where new and expansive patterns of thinking are nurtured, where collective aspiration is set free, and where people are continually learning how to learn together." Within the same context, the National College for School Leadership's definition of school capacity is "the collective comptency of the school as an entity to bring about effective change" (Hopkins \& Jackson, 2003, p. 84). Hopkins and Jackson argue that "capacity is the key construct in creating the conditions within the school to enhance both leading and learning" (ibid., p. 85). This is emphasised since schools become centres of change and need to take control of their own development, which is unsuastainable without a focus on capacity.

Senge's idea was supported by Sergiovanni's (1994) work on 'communities of learning'. Sergiovanni advocated the importance of a school adopting a sense of community, becoming more of a social rather than a formal organisation. He notes that "success seems to be related to the fact that though substance differs, the schools have achieved focus and clarity and have embodied them in a unified practice" 
(ibid., p. 100). Other educational researchers were pooling evidence from the field (Astuto et al., 1994) and eventually the concept was refined to that of PLC by writers such as Hord (1997). While trying to avoid the pitfalls of new buzzwords that often pervade the educational lexicon, recently a new concept of 'intelligent school' has developed that expands on the same basic dimensions of PLC presenting them as multiple intelligences that may be fostered in schools (MacGilchrist et al., 2004).

In many countries, research on PLC's dynamics is at a relatively early stage of development, even though evidence suggests that they have a positive impact on school improvement (Stoll et al., 2006, p. 222). Various efforts can be noted especially in the English-speaking world (Stoll \& Seashore Louis, 2007a, p. 9). In the USA, PLCs have been promoted as a way to facilitate school reforms and a means to manage the challenges of raising student achievement (Cormier \& Olivier, 2009, p. 9). From their study on PLCs, Hughes and Kritsonis (2007) have found that schools that re-culture to PLC give evidence of improved student achievement. In Hong Kong, ACTEQ $(2003$, p. 7$)$ recommends that 'schools should be developed as professional learning communities' and that 'teachers' professional development should be regarded as an important force in school development' establishing the school as a PLC. Moreover, they state that "teachers as professionals also have a responsibility to facilitate the professional growth and development of their colleagues" (ibid., p. 7). In England, it seems that the concept of PLC was also growing in this last decade and that it presented "a means of promoting school and system wide capacity building" (Bolam et al., 2005, p. 10).

Meanwhile, in Malta, policy makers made a conscious effort to move away from a highly centralised and bureaucratic system to a wider participative and collaborative strategy among stakeholders (Bezzina, 2006, p. 160). This vision aimed to empower members of staff in educational decision-making to determine the way forward and develop schools as learning organisations. Consequently, a number of schools in Malta started their journey towards implementing PLC principles (Bezzina, 2008; Bezzina \& Testa, 2005; Salafia, 2003). Yet, in spite of the promotion of PLCs as desirable and valuable, researchers and theorists (Cormier \& Olivier, 2009, p. 19) are still struggling to define a PLC, and Bolam with the colleagues $(2005$, p. 5) signal the breadth 
of interpretation put on it. DuFour $(2004$, p. 1) warns that "the term has been used so ubiquitously that it is in danger of losing all meaning." Schmoker (2006, p. 106) notes that the term has been used to define everything from self-managing teams to communities of practice. However, even though a definitive formulation has not yet gained unanimity, recently, a confluence of ideas has emerged in the literature on the attributes necessary for PLC development (In Praxis Group Inc. 2006 , p. 11). Table 1 is a typology of dimensions some scholars describe as critical by PLCs.

Table 1. Typology of PLC Dimensions

\begin{tabular}{l|l} 
Hord (2004, p. 7) & $\begin{array}{l}\text { (1) supportive and shared leadership, (2) shared values and } \\
\text { vision, (3) collective learning and application, (4) supportive } \\
\text { conditions and (5) shared practice }\end{array}$ \\
\hline Stoll et al. (2006, p. 4) & $\begin{array}{l}\text { (1) shared values and vision, (2) collective responsibility, } \\
\text { (3) reflective professional enquiry, (4) collaboration, (5) group } \\
\text { as well as individual learning, (6) mutual trust, respect and } \\
\text { support, (7) inclusive school wide membership, (8) networks } \\
\text { and partnerships beyond the school }\end{array}$ \\
\hline Bolam et al. (2005, p. 145) & $\begin{array}{l}\text { (1) reflective dialogue, (2) de-privatisation of practice, } \\
\text { (3) professional growth, (4) mutual support and mutual } \\
\text { obligation }\end{array}$ \\
\hline Feger et al. (2008, p. 3) & $\begin{array}{l}\text { (a) shared mission, vision and values, (b) collective } \\
\text { inquiry, (c) collaborative teams, (d) action orientation and } \\
\text { experimentation, (e) continuous improvement and (f) results } \\
\text { orientation. }\end{array}$ \\
\hline $\begin{array}{l}\text { DuFour and Eaker (1998, } \\
\text { pp. 25-29) }\end{array}$
\end{tabular}

The PLC concept is soundly built on educational principles. Nonetheless, it needs to be put in the context of the country's educational system, the school's culture and history, as well as applied on a more humane level for the benefit of all stakeholders. Consequently, the research review has sought to provide a conceptual underpinning on the basis of which an investigation can be constructed. The dimensions by Hord (2004) have been chosen as the base concepts to be implemented during the research process which is described in the methodology section later on.

\section{The school context}

St Peter and St Paul school (SPP) is a new Catholic Church primary school, which opened its doors to its first students in September 
2011. At the initial stages of this research, the school admitted only two grades, namely grade 1 (5-6 year olds) and grade 4 (8-9 year olds), totalling a school population of 150 students. During this phase, 30 staff members worked in the school's primary section comprising senior management, teachers, learning support assistants and support staff. In its second operative scholastic year, during which the research was undertaken, the primary school's population doubled to 300 students. This was made up of 150 new students in grades 1 and 4 , as well as the previous year's students who were promoted to grade 2 and grade 5 respectively. Consequently, the school also experienced the addition of new teaching, administrative and support staff.

SPP school is an extension to the extant secondary school. An external audit of the secondary section had been identified as having a 'positive school culture founded on Catholic communitarian values'. The leaders' vision was to have a whole-school approach to development and that a positive culture would embrace both sections. In order to strengthen this unitary vision, the school organisation was established with one head acting as a principal with a deputy head for each section. It was envisaged that the new primary school would serve to strengthen the secondary section with innovative approaches.

The initiative to extend the school was as a result of one of the reforms in Maltese education (Cutajar, 2007), which established the importance of continuity from ages 5 to 16, and from the school's leadership objective of addressing learning difficulties at the earliest. In this context of reform and innovation, the school was shaping its organisational structures and consolidating its principles and policies. It was within this context that the principles behind PLCs have been deemed central to this research, and thus positioned as the main aim of the study.

It was a particularly exciting time as the culture of the researched school was in what can be described as the 'making process' where the aim was to put the school on track towards sound professional and educational principles that work to optimise learning. Since, SPP was in its initial stages of setting and shaping its culture and organisational structures, this research aimed at guiding the school through an action research project to pilot the effective principles portrayed in the PLC research field. 
The research took place in a context that has seen the development of a vision through the concerted efforts of many educators. A number of professionals were involved in various structured and scheduled discussions that focused on issues such as formulating curricular ideas, pedagogies of learning, staffing requirements and identifying the logistical needs for the new school. Starting a year after the school opened its doors to the first cohort of students, this study aimed to carry out a review of the developments that have taken place till then, and to identify potential ways of nurturing those principles that will help the school develop into a PLC.

SPP, being a Catholic Church school, falls under the country's Church schools' directorate which works in collaboration with the country's education authorities. SPP enjoys a great degree of autonomy on how to run the school compared to schools run by the State. However, it was still bound by the country's Education Act (1988) and the Church-State agreement of 1991 (Agreement on Church Schools, online). Whilst accepting and respecting these binding documents, the school was free to establish its own mission statement, vision and educational policies.

\section{The research methodology}

This research aimed to explore the extent to which PLC principles could be embedded effectively in the culture of SPP. It adopted an action research approach as it aimed at changing 'practitioners' practices', their 'understandings of their practices', and the "conditions in which they practise" (Kemmis, 2007, p. 1). The following research questions guided the investigation:

1. What are the existing characteristics of a PLC as identified in the literature and as applied to SPP school?

2. What is the readiness level of staff at SPP in relation to implementing the principles behind the PLC?

3. Which areas need to be addressed to enhance the school's internal capacity to become a PLC?

4. What marked developments take place within the action research period?

5. What are the leadership implications for the required changes? 
The research motivations flow from two previous studies at this school, one on the school culture (Farrugia, 2011), and the other on the effect of collaboration on newly qualified teachers (Farrugia, 2012). Both studies converge on the benefits of a school wide collaborative culture. The concept of PLC emerged from the literature as that which encompasses a comprehensive model of collaborative practices in schools. A number of dimensions emerged from research that define the functioning of a school on the PLC model. For the purpose of this study the dimensions presented by Hord (2004) were chosen (see Table 1). The rationale behind this choice was based upon the comprehensiveness of the concepts and also the alignment with the audit tool chosen.

Since the study was intended to improve the school's practice, a critical theory and praxis framework were considered as the epistemological structures fitting to reach the aims, thus following the non-positivist/ interpretative paradigm of reflective rationality (ZuberSkerritt, 2001, p. 2). Moreover, action research is seen as an educative process which fits perfectly with PLC dimensions thus stimulating a beneficial practice of collaboration between participants through the research practice itself (Chioncel et al., 2003, p. 498). Critical action research also collectively treats practitioners as being simultaneous theorists and researchers (Kemmis, 2007, p. 7), as symmetrical communicators implying that everyone has something to contribute (Zuber-Skerritt 2001, p. 11). This also fits in the praxis paradigm "as the interdependence and integration - not separation - of theory and practice, research and development, thought and action" (ibid., 15).

Participants develop both a self-critical attitude and a collective endeavour such that "critique is never taken as a personal attack (destructive), but accepted as a necessary condition for organisational change, innovation or recreation (constructive)" (ibid., 12). As phenomenologists believe, the participants "explore together their patterns of sayings, doings and relating as socially-constructed formations" which reasonably have to pass the sustainability rationale (Kemmis, 2007, p. 8).

However, emancipatory action research is often criticised that it has a social agenda and often resolves to create a status quo (Cohen et al., 2007, p. 304). Though conscious of the latter, this difficulty was considered minimal due to the nature of the research itself which had 
the aim of starting PLC practices which in principle generate a culture of self-reflection and self-criticism (Protheroe, 2004).

In addition, a pragmatic approach was seen appropriate to address the underlying research questions effectively. Utilising a quantitative (positivist) paradigm (PLCA-R questionnaire; PLCDR) in conjunction to the qualitative (non-positivist) paradigm (field notes, focus groups) discussed above, the commonly ascribed traditional dichotomy was therefore ignored to address the research aims (Onwuegbuzie \& Leech, 2005, p. 385).

An action research approach was central to this study. Zuber-Skerritt (2001, p. 2) defines action research as a "cyclical iterative process of action and reflection on and in action." Reflection constructs the concepts and generalisations extracted from the action consequences themselves. These concepts will have to be confirmed or not through investigating new situations.

Table 2. Synthesised action research model from literature

\begin{tabular}{|c|c|c|}
\hline & Preparation & $\begin{array}{l}\text { Define the inquiry } \\
\text { Review related Literature } \\
\text { Describe the educational situation }\end{array}$ \\
\hline \multirow[t]{2}{*}{ PLANNING } & Audit Phase & $\begin{array}{l}\text { Review of current practice } \\
\text { Collect evaluative data and analyse it } \\
\text { Review the data and look for contradictions } \\
\text { Identify an aspect to improve }\end{array}$ \\
\hline & Planning & $\begin{array}{l}\text { Plan a way forward } \\
\text { Introduce change through an action }\end{array}$ \\
\hline ACTING OBSERVING & Observing & Monitor the change \\
\hline ACTING & Modifying & $\begin{array}{l}\text { Modify the plan in the light of findings and } \\
\text { continue with 'action' }\end{array}$ \\
\hline \multirow[t]{2}{*}{ REFLECTING } & Reflecting & $\begin{array}{l}\text { Analyse evaluative data about the change } \\
\text { and modified action } \\
\text { Review the change and decide what next }\end{array}$ \\
\hline & Communicating and Validating & Share and communicate the results \\
\hline
\end{tabular}

Action research includes active learning, searching, problem solving, and systematic inquiry, which is rigorous, scrutinisable, verifiable, and always made public (ibid., p. 2). It results in better evaluation, improvement and decision making which subsequently will lead to better practice. Moreover, Cohen, Manion and Morrison (2007, p. 297) 
state that action research can be used as a school-wide improvement which perfectly fits the intents of this research.

Bassey (1998, p. 94-95), McNiff et al. (1996, p. 47) and Mertler (2006, p. 22) outline an action research cycle summarised in eight or nine steps. These are a practical expansion of the cyclical or spiral traditional models found in literature of action research, which are structured on planning, acting, observing and reflecting (McNiff et al., 1996, p. 22). Table 2 is a synthesis of the steps defined by Bassey (1998), McNiff et al., (1996) and Mertler (2006).

\section{The research design}

The investigation was planned on the model outlined above in Table 2 (see also Figure 1). During the planning phase, the review of literature was critically drawn to shed light on PLC and research in the field. This helped to put the subject in a wider perspective and give insights on which basis the investigation could be built.

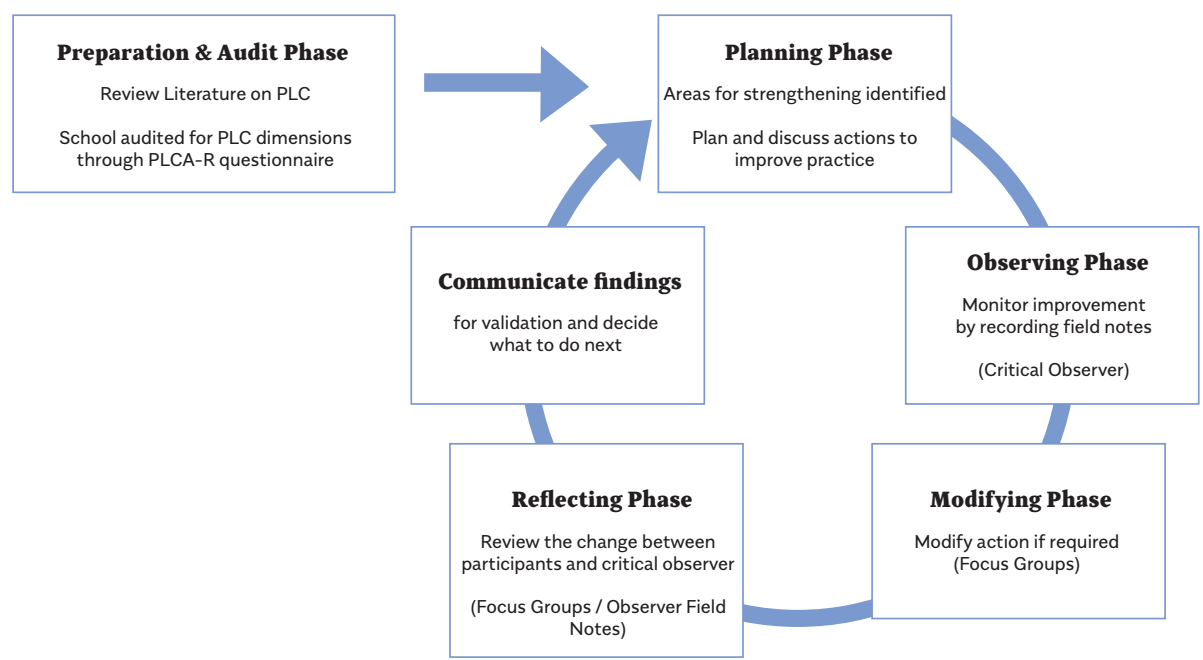

Figure 1. Action research cycle for SPP to progress as a PLC: Research design outline

During the audit phase, the PLCA-R questionnaire (Huffman \& Hipp, 2003) was chosen as an auditing tool and placed on the school 
e-learning platform (MOODLE) with a minor modification to the original PLCA-R to probe for readiness. The PLCA- $R$ is a four level Likert-Scale type questionnaire filed in sections, investigating PLC dimensions. At the end of each section, an open type question prompts for any comment by respondents. This open-ended question was slightly modified for this research by specifically asking the respondents for their view on that particular dimension. Consequently, from the respondents' points of view one would be able to sense the aptitude towards PLC and eventually conclude the collective readiness of the whole school.

The MOODLE facility was seen as a good medium as it is easy to construct, fast to deliver, provides anonymity and computes results with every entry giving the facility to monitor entries. After ensuring all ethical research procedures were respected an informative email explaining the aim of the whole research and the questionnaire were sent to all the staff in the primary school.

Following an email reminder, 16 participants out of 22 responded to the questionnaire (Response Rate $=72 \%$ ), thus providing the research with a degree of representativeness and increasing reliability by minimizing researchers' bias Golafshani (2003) . Consequently, the data gathered was analysed to identify the areas needing adjustment.

At the end of this phase, the areas that needed strengthening were identified and paired with possible interventions for improvement. The areas were presented to the participants, and an action was collectively decided. Having the actions implemented, and operating, monitoring and modification led to the evaluation phase by means of focus groups.

Four focus groups were conducted with four different grade level teachers. The observing phase involved data gathered from focus groups and the use of field notes recorded by a participant critical observer. This cycle was implemented for a number of areas needing change.

The data gathered from the focus groups was transcribed, sorted and analysed to extract perceptions on the changes done, and if they had improved school practices. The findings were communicated to validate the research and eventually start the process again to keep improving in the area studied. Figure 1 outlines the whole process. 
Throughout the preparation phase of this research, twenty-two members of the teaching staff were invited to audit the current state of PLC at the school. From the planning phase onwards, the school expanded with new student entrants and fourteen newly recruited teaching staff, the latter being also invited to join in this research. The participants included members of management, teaching and support staff. These are categorised according to McNiff and Whitehead (2009, p. 61) as research participants. They also served as critical friends and validation group (ibid., 61).

The inclusion coordinator (INCO) and the school external consultant were invited to act as observers using the PLC development rubric as a guide. Their choice is motivated from their relation to the school. The nature of work of the INCO, which is flexible and spread across the whole school, puts her in a strategic position to observe developments. Meanwhile, the external consultant, would help to identify changes and triangulate the data.

Action research involves gathering a sizeable amount of data while the research unfolds. Thus, data needed careful sorting and categorising. Consequently, the general criteria to regulate data is that only data conspicuously relevant to the research questions was used (McNiff \& Whitehead, 2009, p. 62). Meanings were then extracted from data gathered through the chosen design tools. Data was analysed through a reflective and dialectic critique (ibid., p. 123). This implied awareness of personal values as positioned and relative to the context of the research when analysing the data. Moreover, the aspects studied were viewed as inter-reliant in that together they compose the phenomenon, but separately they are diverse and thus theoretically in conflict (Waters-Adams, 2006, online). Consequently, the extracted data provided some valid recommendations in the form of leadership intentions to foster continued school improvement to keep the school improving.

\section{Discussion of findings}

Probing on the readiness level of the school and adopting Morrissey's (2000, p. 29) two indicators of PLC readiness, that is a) the overall climate of acceptance, growth, and learning among teachers, and b) the openness and availability of the principal, one might conclude that the school readiness level was positively oriented. Table 3 presents some 


\section{opinions of respondents on the five dimensions of PLC, thus attempting to present the collective attitude. The representative comments were chosen on the criteria of frequency of concepts expressed, collective representation and the comprehensiveness of the content in relation to the PLC dimension chosen.}

Table 3. Opinions of SPP staff on PLC Dimensions

PLC DIMENSION

COMMENTS BY SPP RESPONDENTS

$\begin{array}{ll}\text { SHARED AND SUPPORTIVE } & \text { I do believe that the school is not only of the headmaster or SLT, } \\ \text { LEADERSHIP } & \text { but it is of the members of staff, students and parents. However, to } \\ \text { ensure that shared and supportive leadership is being implemented, } & \text { more communication meetings have to be held so one can share his } \\ \text { intentions, share ideas and resources such as good practices so that } \\ \text { the school community will own the leadership itself. }\end{array}$

SHARED VALUES AND VISION

I personally think that if schools and working staff build together a collective educational vision which is clear, concise and linked with teaching and learning, this will result in in-depth learning. Such shared values and vision are the bases of a true community. They also help to focus attention on what is important, motivates staff and students, and increases the sense of shared responsibility for student learning.

\section{COLLECTIVE LEARNING} AND APPLICATION

SHARED PERSONAL PRACTICE

Collective learning is an asset in my opinion, as when one works in a group, one learns through others' input, concerns and visions. For example, sharing a learning experience with parents gives one an opportunity to get to know how parents think about certain areas, whereas sharing a learning experience with colleagues gives one a totally different experience as one shares with others who have the same pedagogical formation and aptitudes.

I believe it has a lot to benefit from as one learns from the other and each individual's learning, experience and knowledge grows faster. Obviously the children will ultimately benefit from this as well. It is always wise and beneficial to be open and be ready to learn from others. All of us have a lot to contribute to the diverse aspects of the teaching and learning process.

\section{SUPPORTIVE CONDITIONS - STRUCTURES}

\section{SUPPORTIVE CONDITIONS -} RELATIONSHIPS

These are very helpful. All the points mentioned above (in the questionnaire) ease the job and make it more pleasurable to work in an environment where the teacher will find ongoing help and professional support and care. Resources together with a welcoming environment are important to make the lesson more successful.

They are vitally important as the school is a community, a second home where we all come to every single day. Thus it is extremely important that each member feels a sense of belonging and supported as this will in turn strengthen his/her performance at work. 
Despite some hesitation, there was overall agreement by staff that PLC dimensions were desirable, and that their implementation would improve student learning.

Following a professional discussion with the headmaster, the concept of PLC was welcomed with enthusiasm and support, where the head expressed motivation to support this challenge, visioning that this was a good way forward for the school.

\section{Findings from the audit phase}

The responses to the questionnaire presented a number of compelling factors about the school's culture. Considering that it was the school's first year in operation, a number of essential processes were already in place and developing. There were areas, though, that needed attention and support for improving the teaching and learning experience. In answering the third research question, the main identified areas to be addressed were the following:

1. Promote and nurture more leadership among staff members.

2. Promote collaborative analysis of multiple sources of data to assess the effectiveness of instructional practices and share student work to guide overall school improvement.

3. Improve supportive conditions mainly structural, i.e. organise the timetable to increase collaborative time.

4. Improve vertical communication amongst staff.

5. Create opportunities for staff members to observe peers and provide feedback and encouragement related to instructional practices.

6. Create opportunities for coaching and mentoring.

7. Allocate funds for a professional development programme.

These conclusions led to the planning phase where possible strategies to improve these areas were discussed and implemented (see Table 4 for the structured plan). Having the planning concluded, the implementation, observing and modifying phase followed. 
Table 4. Changes devised to improve PLC at SPP

\begin{tabular}{|c|c|c|}
\hline DIMENSION DEVELOPED & $\begin{array}{l}\text { SUPPORTIVE CHANGES OF HUMAN } \\
\text { CAPACITY/ COLLEGIAL RELATIONSHIPS }\end{array}$ & STRUCTURAL CHANGES \\
\hline $\begin{array}{l}\text { 1. Promote and nurture } \\
\text { more leadership among } \\
\text { staff members }\end{array}$ & $\begin{array}{l}\text { Change in headship style with } \\
\text { a more collaborative approach } \\
\text { SLTs meet every day to discuss } \\
\text { daily and curricular issues and } \\
\text { given room for autonomy } \\
\text { Teachers were participative } \\
\text { on the school improvement plan } \\
\text { A positive student-teacher-head } \\
\text { relationship underpinned } \\
\text { by trust } \\
\text { Encourage and praise initiatives }\end{array}$ & $\begin{array}{l}\text { Time allocated for discussions } \\
\text { Quality time dedicated } \\
\text { to communicate on a personal } \\
\text { level }\end{array}$ \\
\hline $\begin{array}{l}\text { 2. Promote collaborative } \\
\text { analysis of multiple } \\
\text { sources of data to assess } \\
\text { the effectiveness of } \\
\text { instructional practices } \\
\text { and share student work } \\
\text { to guide overall school } \\
\text { improvement }\end{array}$ & $\begin{array}{l}\text { Mentor support to interpret data } \\
\text { IT support for users }\end{array}$ & $\begin{array}{l}\text { A weekly fixed slot to discuss } \\
\text { curricular issues to align with } \\
\text { students' needs } \\
\text { Teachers were given flexibility } \\
\text { to adopt a student profile to } \\
\text { identify needs } \\
\text { Facilitate the School } \\
\text { Management Information } \\
\text { System }\end{array}$ \\
\hline $\begin{array}{l}\text { 3. Improve supportive } \\
\text { conditions mainly } \\
\text { structural i.e. organise } \\
\text { the time-table to increase } \\
\text { collaborative time }\end{array}$ & $\begin{array}{l}\text { SLT present for support } \\
\text { in curriculum meetings }\end{array}$ & $\begin{array}{l}\text { Two hours per week allotted } \\
\text { for curriculum meetings and } \\
\text { planning where grade level } \\
\text { teachers can meet together } \\
\text { Some slots permitted vertical } \\
\text { collaboration }\end{array}$ \\
\hline $\begin{array}{l}\text { 4. Improve communication } \\
\text { amongst staff }\end{array}$ & $\begin{array}{l}\text { SLT present regularly in } \\
\text { corridors and open spaces }\end{array}$ & $\begin{array}{l}\text { Communication encouraged } \\
\text { during meetings and through } \\
\text { emails } \\
\text { SLT sends weekly forecast and } \\
\text { decisions concluded the week } \\
\text { before } \\
\text { Classrooms are in proximity } \\
\text { of same grade } \\
\text { Network storage of schemes } \\
\text { of work are accessible to all } \\
\text { teachers }\end{array}$ \\
\hline
\end{tabular}




\begin{tabular}{l|l|l}
\hline $\begin{array}{l}\text { 5. Create opportunities } \\
\text { for staff members } \\
\text { to observe peers and } \\
\text { provide feedback and } \\
\text { encouragement related to } \\
\text { instructional practices. }\end{array}$ & $\begin{array}{l}\text { Mentor offered observation on } \\
\text { voluntary basis and encourage } \\
\text { good practice. }\end{array}$ & $\begin{array}{l}\text { Each grade teacher has a daily } \\
\text { lesson free from the class } \\
\text { to have the availability to visit } \\
\text { or meet peers for observation } \\
\text { and planning. } \\
\text { Opportunities are created to } \\
\text { share good practices during } \\
\text { professional development } \\
\text { programmes. }\end{array}$ \\
$\begin{array}{l}\text { 6. Create opportunities for } \\
\text { coaching and mentoring. }\end{array}$ & $\begin{array}{l}\text { Staff was given the opportunity } \\
\text { to avail of an external mentor } \\
\text { following a CPD training on } \\
\text { differentiated techniques. }\end{array}$ & $\begin{array}{l}\text { Space and time was facilitated } \\
\text { when staff asked for the } \\
\text { mentor's support. }\end{array}$ \\
\hline $\begin{array}{l}\text { 7. Allocate funds to } \\
\text { create a programme for } \\
\text { professional development. }\end{array}$ & $\begin{array}{l}\text { The school engaged in } \\
\text { a European funded programme } \\
\text { that offers support in continuous } \\
\text { professional development and } \\
\text { mentorship. } \\
\text { Teachers invited to share } \\
\text { good practices in professional } \\
\text { development programmes. }\end{array}$ & $\begin{array}{l}\text { Planned dates during the } \\
\text { scholastic year for professional } \\
\text { development. }\end{array}$ \\
\hline
\end{tabular}

\section{Observations during the implementation phase}

This phase helped to identify six main issues that may not be new to anyone engaged in the area but help to throw light on the dynamic nature in which such endeavours take place. It also helps us to appreciate the uniqueness of a PLC. As Tillema and van der Westhuizen (2006) argue, PLCs can be structured in uniquely different ways and just as this particular school is evolving in its own ways every PLC needs to be observed as unique as the individuals making up that community (Attard, 2009, p. 247).

\section{A PLC takes times to develop}

This research supported and indeed justified, even more in the context of a new school, what Hargreaves advises that "Strong and sustainable PLCs cannot be rushed or forced. They can only be facilitated and fed. Professional learning communities take time. Like virtue or community in general, they cannot be mandated and legislated by imposed and over confident design. They can only be built and developed through strengthened relationships" (2007, p. 188).

Whilst starting on a strong footing and with the right approaches was critical, one has to acknowledge that there was a lot to be established at 
this initial phase. The number of new teachers and support staff to be inducted in the school's culture was in itself a challenge. The 'ephemeral' effect of the school culture (Deal \& Peterson, 1998, p. 28) in this context was magnified and makes the PLC undertaking more challenging as it was 'constructed and reconstructed through the collective articulation of beliefs' (Bates, 1992, as cited in Bates 2006, p. 158).

\section{Integrated professional culture and the PLC}

This research has unveiled an interesting dimension to inform educational research. In the first year, a number of recruited veteran classroom teachers resisted the collaborative culture projected from the start by the school leaders. A high veteran to novice ratio had originally been aimed at achieving some knowledge base as a starting school (Stoll \& Seashore Louis, 2007b, p. 4). Unfortunately, it did not work as envisioned. Before the second scholastic year, the teachers that offered resistance left and made room for new novice teachers.

The result was that the novice teachers participated 'from the start, building and defining a school's professional culture' (Kardos et al., 2001, p. 256). Moreover, the school, in this phase of great demand, benefitted from what Susan M. Kardos and Susan Moore Johnson (2007, p. 2085) define as the 'idealism and energy' that characterises noviceoriented professional cultures. This proved to be more productive and easier to align with the school's values and vision of a collaborative culture. Moreover, all the new recruits and the rest of the previous year's teachers created an integrated professional culture (ibid., p. 2088) where novices interacted at par with veterans, the latter recognising their needs as beginners. Consequently, a shared responsibility for the school and its students was developed among teachers, recognised as a key aspect of a PLC.

These incidents, in this particular context, did not support the theories put forward by Talbert (2010, p. 558) who purported that teacher turn over 'undermines social cohesion' and that 'schools with high proportion of beginning teachers ... are handicapped in their knowledge resource' thus hindering PLC progression. On the contrary, at SPP the energy and motivation of new teachers, together with support from the SLTs and experienced teachers, eased these drawbacks and were turned into opportunities. Facilitation and support was continuous to avoid what Hargreaves (2007, p. 183) warns against as the risk of 
"driving teachers to distraction - away from the passion of teaching and learning in classrooms and enriched relationships with children....."

\section{Starting from the practitioners knowledge}

Practitioners' knowledge was always the starting point for every decision taken to generate change. This made every stakeholder feel confident and esteemed and added greater professional efficacy and motivation. Utilising the school's internal capacity to build capacity (Fullan, 2003, p. 7) at SPP not only gave more confidence and efficiency but added ownership leading to a deeper sense of shared leadership. Two strategies were employed to tackle decisions. The Teaching Learning Cycle (Cowan, 2010, p. 58) was introduced for the weekly curriculum meeting which involved the study of the problem, selecting a strategy, planning the way forward, the implementation, the analysis, and finally a decision on the adjustments that were deemed necessary. This strategy placed the teachers and support staff as co-contributors in the action research process, hence giving them more leadership in curriculum decisions. Subsequently, the mentor adopted the GROW model (Whitmore, 2002, p. 56) to coach and mentor teachers in tackling problems in instruction. Both strategies were aimed at starting from what practitioners know and progressing to action research (Fullan, 2002 , p. 18), thus creating a supporting structure of regeneration through the school's internal capacity (Morrissey, 2000, p. 10).

\section{PLC and the external facilitator}

One of the common strategies acclaimed by administrators as making a difference in their schools is the identification and hiring of 'skilled teacher educators and facilitators outside the system to support PLC improvement efforts' (Talbert, 2010, p. 564). This research validates this strategy as the external mentor appointed at SPP was well accepted and perceived as less threatening due to the fact that he was from outside the school community and also a foreigner. Another important factor that helped the mentoring process was that the suggestions forwarded by the mentor and the approach adopted were very practical and relevant (Roehrig et al., 2008, p. 696); contrasting, according to the participants, with theories taught at university level. 


\section{The leaders' emotional intelligence and the PLC}

Fullan $(2002$, p. 18) states that in complex times emotional intelligence needs to stand out. In the context of SPP where, due to the growth of the school, change was a constant, working on relationships was imperative. Although, distributed leadership was regarded as an important aspect in a PLC and very much desired and embraced by staff at SPP, they still felt the emotional need of a leader from whom to get direction and support when needed. Leaders at SPP worked relentlessly to create positive relationships amongst staff by mastering and refining emotional competencies needed to improve workplace performance and personal relationships (Goleman, 1998). They were sensitive to staff emotional states and at times were inspiring in a number of situations. This disposition from the part of the SLT helped to foster trust and a greater sense of community among staff, facilitating growth as a PLC. Genuine collaboration is only possible if there is trust (Gideon, 2002) and echoing Calderwood's (2000) findings, participants in this study appreciated the value of trust as expressed by the SLT.

\section{Communicating the PLC model}

The PLC model was never mandated but only verbally communicated, explained and modelled as Talbert (2010, p. 560) advised. This strategy made participants feel comfortable and free to pace their efforts in line with the PLC principles without feeling unduly pressured. However, a finding worth noting is that one should never take anything for granted or assume that people have understood you. Certain benefits needed to be regularly communicated and encouraged. It transpired from this research that although certain supportive conditions for collaboration were explained and embedded in the school's organisational structure, the majority of teachers failed to benefit from them.

In addition, communicating success is motivating and leaves a positive impact. During the research period SPP was awarded a Bronzelevel CPD mark established by the hired training company sponsored by the EU programme. This and other students' achievements were consistently communicated in recognition of the effort and work done by the staff (Talbert, 2010, p. 567).

The above conclusions surfaced after approximately a year from the start of the research and at the end of a first research cycle. St Peter and St Paul's Primary school was in the implementation stage of PLC 
(see Figure 2). The latter was established through the participant critical observers' notes using systemic observation through the professional learning community development rubric (PLCDR) deviced by Hipp and Huffman (2010). From the beginning a number of dimensions that were supported for improvement have evidenced progress. However, after the research analysis there were a number of areas which emerged as needing a more systematic input such as the use of student's data, communication across levels and shared personal practice. At the same time a number of recommendations have emerged. Whilst the intention is not to be seen as a plan that works for every school they may be of value to school leaders who are interested in introducing or considering PLC principles and practices.

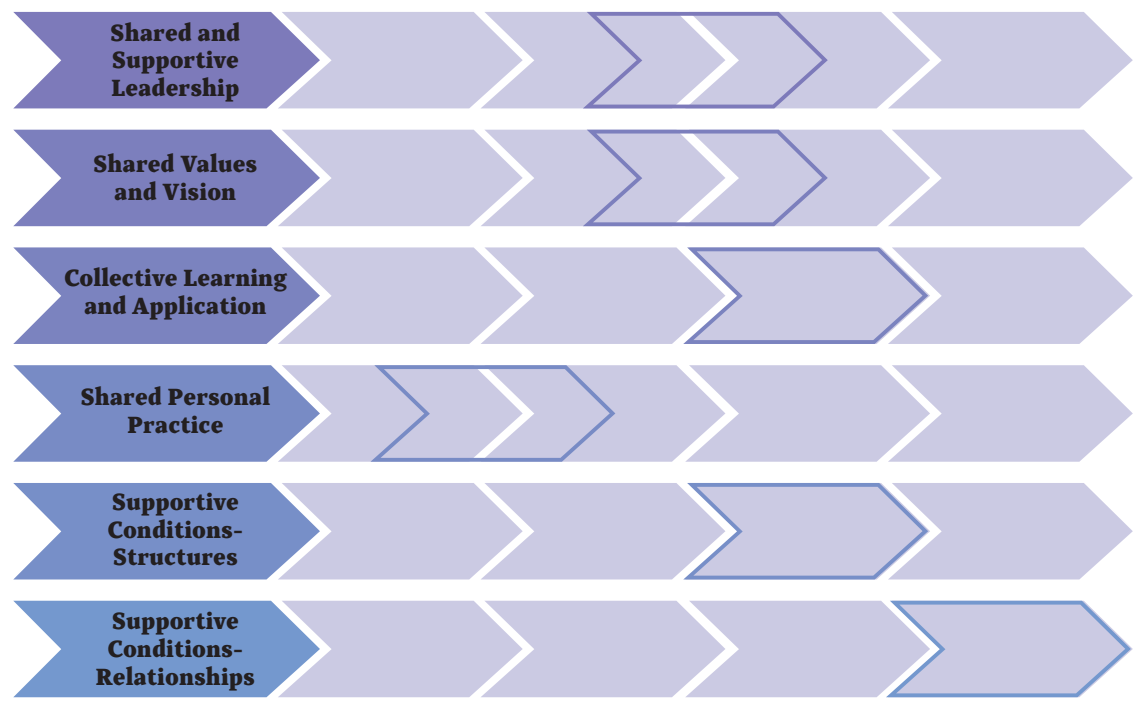

Figure 2: Graphical representation of PLC Progress Continuum at SPP

\section{Conclusions and implications for leadership}

The context of this starting school was a combination of building and changing a school culture. Building the culture of a starting school involves a culture change needed to harmonise the vision of the school with that of new staff that comes with preconceived beliefs, ideas and practices. In this context, a culture of collaboration was designated 
as the most comprehensive to achieve the desired aims. Research evidence shows that a culture of collaboration generates positive outcomes in achievements and is critical to establish a PLC (DuFour 2004 , p. 1). Consequently, the following six recommendations emerge from this study intended to lay foundations for a PLC. Leaders benefit:

$\rightarrow$ from acknowledging the importance of emotional intelligence and using it with their staff;

$\rightarrow$ from diligently modelling and communicating PLC and avoid mandating (Talbert, 2010, p. 567) and the risk to "turn into addon teams that are driven by data in cultures of fear that demand instant results" (Hargreaves, 2007, p. 183);

$\rightarrow$ from perseverance as PLCs need time to develop (Kruse \& Seashore Louis, 2007, p. 115) as "the more patient, less deliberate modes are particularly suited to making sense of situations that are intricate, shadowy or ill defined" (Claxton, 1997, p. 3 as cited in Fullan, 2001, p. 122);

$\rightarrow$ from pacing and prioritising changes as one "cannot press on relentlessly for more tested achievement by burning our teachers and leaders out" (Hargreaves, 2007, p. 191), since PLCs need time and continuous adjustments;

$\rightarrow$ by starting from the practitioners' knowledge (Earl \& Hanney, 2011) as this imparts confidence, efficacy and collective creativity (Hord, 1997, p. 10): "the collective ability of people, in an organisation, to learn their way out of trouble, and forward into the future" (Hargreaves, 2007, p. 185);

$\rightarrow$ if they engage an external facilitator as a support and change agent (Hill \& Crevola, 2003, p. 398) where "with strong interpersonal, organisational and communication skills, [s/he] is the linchpin that holds the implementation together" (Cooper, 1998, p. 12);

$\rightarrow$ when recruiting new staff, by balancing judgement between professional responsibility and maturity (Hargreaves, 2003, p. 163) rather than level of knowledge base, and select individuals who can "make connections between the priorities of the school and their individual personal, professional and collective identity and commitment" (Day et al., 2005, p. 575). 


\section{Concluding remarks}

The praxis paradigm adopted by this research where "theory and practice, research and development, thought and action" (ZuberSkerritt, 2001, p. 15) were associated to develop a culture of PLC, definitely provided interesting results. The work has progressed on two critical fronts - first in starting a PLC, and secondly on how that impacts on the school leadership. SPP culture emerged as showing evidence of implementing a number of PLC dimensions that create a positive learning environment for teaching staff and that during this short research period the SLT learned a number of important lessons that strengthened its efficacy. The next step to attempt to validate that PLC foundations are educationally comprehensive would be to investigate if these dimensions subsequently result in improved learning and achievement for all stakeholders especially the students. This would involve a whole new set of research challenges. 


\section{References}

$\rightarrow$ ACTEQ (2003). Towards a learning profession: The teacher competencies framework and the continuing professional development of teachers. Hong Kong. Accessed on April 23, 2012.Available at: http://www.acteq.hk/media/ ACTEQ-\%20Eng.pdf.

$\rightarrow$ Astuto, T. A., Clark, D. L., Read, A.-M., McGree, K. \& de Koven L. F. (1994). Roots of reform: Challenging the assumptions that control education reform. Accessed on April 13, 2013. Available at: http://www.questia.com/PM.qst?a=o\&d=98415814.

$\rightarrow$ Attard, K. (2009). Promoting ongoing learning within learning communities. In Ch. Bezzina (Ed.), Educational leadership: Nurturing meaning in a context of change (pp. 231-249). Malta: Printlt.

$\rightarrow$ Barber, M. \& Mourshed, M. (2009). Shaping the future: How good education systems can become great in the decade ahead. Report on the International Education Roundtable. Singapore: McKinsey \& Company.

$\rightarrow$ Bates, R. (1992). Leadership and school culture. Seville, Spain: Interuniversity Congress of the Organization of Teaching Faculty of Philosophy and Science of Education.

$\rightarrow$ Bassey, M. (1998). Action research for improving educational practice. In R. Halsall (Ed.), Teacher research and school improvement: Opening doors from the inside (pp. 93-108). Buckingham: Open University Press.

$\rightarrow$ Bezzina C. (2006). The road less travelled: Professional communities in secondary schools. Theory into Practice, 45(2), 159-167.

$\rightarrow$ Bezzina, C. (2008). Towards a learning community: The journey of a Maltese Catholic church school. Management in Education, 22(3), 22-27.

$\rightarrow$ Bezzina, C. (2012). The SPP introductory report. A report done by an external consultant to SPP school. Malta.

$\rightarrow$ Bezzina, C. \& Testa, S. (2005). Establishing schools as professional learning communities: Perspectives from Malta. European Journal of Teacher Education, 28 (2), 141-150. 
$\rightarrow$ Bolam, R., McMahon, A., Stoll, L., Sally, T., Wallace, M., Greenwood, A., Hawkey, K., Ingram, M., Atkinson, A. \& Smith, M. (2005). Creating and sustaining effective professional learning communities. Research Report 637. London: DfES and University of Bristol.

$\rightarrow$ Calderwood, P. (2000). Learning community: Finding common ground in difference. London: Teachers' College Press.

$\rightarrow$ Claxton, G. (1997). Hare brained and tortoise mind. London: Fourth Estate.

$\rightarrow$ Chioncel, N., Van Der Vee, E., Ruud, G.W., Wildemeersch, D. \& Jarvis, P. (2003). The validity and reliability of focus-groups as a research method in adult education. International Journal of Lifelong Education, 22 (5), 495-517.

$\rightarrow$ Cohen L., Manion, L. \& Morrison, K. (2007). Research methods in education. 6th ed. London: Routledge.

$\rightarrow$ Cooper, R. (1998). Socio-cultural and within-school factors that affect the quality of implementation of school-wide programs. Report No 28. U. S. Department of Education: Center for Research on the Education of Students Placed at Risk. Accessed on April 11, 2013. Available at: http://www.csos.jhu. edu/CRESPAR/techReports/Report28.pdf. [

$\rightarrow$ Cormier, R. \& Olivier, D. F. (2009). Professional learning communities: Characteristics, principals, and teachers. Paper presented at the annual meeting of the Louisiana Education Research Association, Lafayette, Louisiana. Accessed on April 15, 2012. Available at: http://ullresearch.pbworks.com/f/ Cormier_ULL_PLC_Characteristics_Principals_Teachers.pdf.

$\rightarrow$ Cowan, D. F. (2010). The professional teaching and learning cycle: A strategy for creating Professional Learning Communities. In K. K. Hipp \& J. B. Huffman (Eds.), Demystifying professional learning communities: School leadership at its best (pp. 57-68). United Kingdom: The Rowan \& Littlefield Education.

$\rightarrow$ Cutajar, M. (2007). Educational reform in the Maltese Islands. Journal of Maltese Educational Research, 5(1), 3-21.

$\rightarrow$ Day, C., Elliot, B. \& Kington, A. (2005). Reform, standards and teacher identity: Challenges of sustaining commitment. Teaching and Teacher Education, 21 (5), 563-577.

$\rightarrow$ Deal, T. E. \& Peterson, K. D. (1998). How leaders influence the culture of schools. Educational Leadership, 56 (1), 28-30.

$\rightarrow$ Denscombe, M. (2007). The good research guide for small-scale social research projects. 3rded. England: McGraw-Hill.

$\rightarrow$ DiPaola, M. F. (2002). Conflict and change: Daily challenges for school leaders. In N. Bennett, M. Crawford \& M. Cartwright (Eds.), Effective educational leadership (pp. 143-157). London: Sage. 
$\rightarrow$ DuFour, R. (2004). What is a 'Professional learning community'? Educational Leadership, 61(8),1-6.

$\rightarrow$ DuFour, R. \& Eaker, R. (1998). Professional learning communities at work: Best practices for enhancing student achievement. Bloomington, IN: Solution Tree.

$\rightarrow$ Earl, L. \& Hannay, L. (2011). Educators as knowledge leaders. In J. Robertson \& H. Timperley (Eds.), Leadership and learning (pp. 186-201). London: Sage.

$\rightarrow$ eVALUEd (2006). Focus groups http://www.evalued.bcu.ac.uk/tutorial/4b.htm. Accessed on June 7, 2011.

$\rightarrow$ Farrugia, M. A. (2011). St. John Baptist school culture: In investigation of the leadership's role in transfusing a positive culture to a new church primary school. MSc in Educational Leadership assignment: University of Leicester.

$\rightarrow$ Farrugia, M. A. (2012). The significance of collaboration for Newly Qualified Teachers: A case study at St. Peter and St. Paul Primary Schools. MSc in Educational Leadership assignment: University of Leicester.

$\rightarrow$ Feger, S., Arruda, E., Pringle, R. \& Briggs, D. (2008). Professional learning communities: Key themes from the literature. The Education Alliance: Brown University, Providence.

$\rightarrow$ Fullan, M. (1998). Leadership for the 21st century: Breaking the bonds of dependency. Educational Leadership, 55, 6-11.

$\rightarrow$ Fullan, M. (2001). Leading in a culture of change. San Francisco: Jossey-Bass.

$\rightarrow$ Fullan, M. (2002). The change. Educational Leadership, 59(8), 16-20.

$\rightarrow$ Fullan, M. (2003). The moral imperative of school leadership. Thousands Oaks, CA: Corwin Press.

$\rightarrow$ Gideon, B. (2002). Structuring schools for teacher collaboration. Education Digest, 68(2), 30-34.

$\rightarrow$ Goleman, D. (1998). Working with emotional intelligence. New York: Bantam.

$\rightarrow$ Golafshani, N. (2003). Understanding reliability and validity in qualitative research. The Qualitative Report, 8 (4), 597-606.

$\rightarrow$ Hargreaves, A. (2003). Teaching in the knowledge society. Buckingham: Open University Press.

$\rightarrow$ Hargreaves, A. (2007). Sustainable professional learning communities. In L. Stoll \& L. K. Seashore (Eds.), Professional learning communities: Divergence, depth and dilemmas (pp. 181-195). Maidenhead Berkshire, England: Open University Press.

$\rightarrow$ Hargreaves, A. (2008). Leading professional learning communities: Moral choices amid murky realities. In A. M. Blankstein, P. D. Houston \& R. W. Cole (Eds.), Sustaining professional learning communities (pp.175-197). Thousand Oaks, CA: Corwin Press.

$\rightarrow$ Hipp, K. K. \& Huffman, J. B. (Eds.) (2010). Demystifying professional learning communities: School leadership at its best. Lanham, MD: Rowman \& Littlefield Education. 
$\rightarrow$ Hill, P. \& Crevola, C. (2003). Organizational learning. In D. Brent \& B. West (Eds.), Handbook of educational leadership and management (pp. 394-403). London: Pearson.

$\rightarrow$ Hopkins, D. \& Jackson, D. (2003). Building the capacity for leading and learning. In A. Harris, C. Day, D. Hopkins, M. Hadfield, A. Hargreaves \& C. Chapman (Eds.), Effective leadership for school improvement (pp. 84-104). London: RoutledgeFalmer.

$\rightarrow$ Hord, S. M. (1997). Professional learning communities: Communities of continuous inquiry and improvement. Austin, Texas: Southwest Educational Development Laboratory.

$\rightarrow$ Hord, S.M. (Ed.) (2004). Learning together, leading together: Changing schools through professional learning communities. New York: Teachers College Press.

$\rightarrow$ Huffman, J. B. \& Hipp, K. K. (2003). Reculturing schools as professional learning communities. Lanham, MD: Scarecrow Education.

$\rightarrow$ InPraxis Group Inc. (2006). Professional learning communities: An exploration, report for the school improvement branch. Basic Learning, Alberta Education. Accessed on March 15, 2012. Available at: http://www.assembly.ab.ca/lao/ library/egovdocs/2006/aled/158824.pdf.

$\rightarrow$ Kardos, S. M. \& Moore, J. S. (2007). On their own and presumed expert: New teachers' experience with their colleagues. Teachers College Record, 109 (9), 2083-2106.

$\rightarrow$ Kardos, S. M., Moore, J. S., Peske, H., G., Kauffman, D. \& Liu, E. (2001). Counting on colleagues: New teachers encounter the professional cultures of their schools. Educational Administration Quarterly, 37(2), 250-290.

$\rightarrow$ Kemmis, S. (2007). Action research as a practice-changing-practice. Opening address for the Spanish Collaborative Action Research Network (CARN) Conference, University of Valladolid. http://www.infor.uva.es/ amartine/ MASUP/Kemmis_2007.pdf [Accessed June 15 2012].

$\rightarrow$ Laws of Malta (2006). An act to amend the Education Act. Cap.327. Valletta: Department of Information.

$\rightarrow$ MacGilchrist, B., Jane, R. \& Myers, K. (2004). The intelligent school: London: Sage.

$\rightarrow$ Malta Diocese (2013). Agreement on church schools. The Holy See and The Republic of Malta. Accessed on April 13. Avialable at: http://maltadiocese.org/ files/2009/09/agreement-on-church-schools.pdf.

$\rightarrow$ McLaughlin, M, W. \& Talbert, J. E. (2006). Building school-based teacher learning communities: Professional strategies to improve student achievement. New York: Teachers College Press.

$\rightarrow$ McNiff, J., Lomax, P. \& Whitehead, J. (1996). You and your action research project. London: Routledge. 
$\rightarrow$ McNiff, J. \& Whitehead, J. (2009). Doing and writing action research. London: Sage.

$\rightarrow$ Menter, I., McMahon, M., Forde, Ch., Hall, J., McPhee, A., Patrick, F. \& Devlin, A. M. (2006). Teacher working time research: Final report to the Scottish Negotiating Committee for Teachers. Faculty of Education, Glasgow University. Accessed on April 3, 2013. Available at: http://eatwellscotland.org/Resource/ Doc/920/0113661.pdf.

$\rightarrow$ Mertler, C. A. (2006). Action research: Teachers as researchers in the classroom. London: Sage.

$\rightarrow$ Morrissey, M. (2000). Professional learning communities: An ongoing exploration. Austin, TX: Southwest Educational Development Laboratory. SAccessed on May 19, 2010. Available at: http://www.sedl.org/pubs/change45/plc-ongoing.pdf.

$\rightarrow$ OECD (2008). Ten steps to equity in education. OECD observer: Policy brief, January: 1-8. Accessed on February 12, 2013. Available at: http://www.oecd. org/education/preschoolandschool/39989494.pdf .

$\rightarrow$ Olivier, D. F. \& Hipp, K. K. (2010). Assessing and analysing schools as professional learning communities." In K.K. Hipp \& J. B. Huffman (Eds.), Demystifying professional learning communities: School leadership at its best (pp. 29-41). United Kingdom: The Rowan \& Littlefield Education.

$\rightarrow$ Olivier, D. F., Antione, S., Cormier, R., Lewis, V., Minckler, C. \& Stadalis, M. (2009). Assessing schools as professional learning communities symposium. Paper presented at the Annual Meeting of the Louisiana Education Research Association. Lafayette: University of Louisiana.

$\rightarrow$ Onwuegbuzie, A. J. \& Leech, N. L. (2005). On becoming a pragmatic researcher: The importance of combining quantitative and qualitative research methodologies. International Journal of Social Research Methodology, 8(5), 375-387.

$\rightarrow$ Protheroe, N. (2004). Professional learning communities. Principal-Arlington, 83 (5), 39-42.

$\rightarrow$ Robinson, V. M. \& Timperley, H. S. (2007). The leadership of the improvement teaching and learning: Lessons from initiatives with positive outcomes for students. Australian Journal of Education, 51(3), 247-262.

$\rightarrow$ Roehrig, A. D., Bohn, C. M., Turner, J. E. \& Pressley, M. (2008). Mentoring beginning primary teachers for exemplary teaching practices. Teaching and Teacher Education, 24(3), 684-702.

$\rightarrow$ Sahlberg, P. \& Boce, E. (2010). Are teachers teaching for a knowledge society? Teachers and Teaching: Theory and Practice, 16 (1), 31-48. 
$\rightarrow$ Salafia, T. (2003). Moving towards a learning organisation? A study at a local secondary school. Unpublished M.Ed. (Leadership) Dissertation. Malta: University of Malta.

$\rightarrow$ Schmoker, M. J. (2006). Results now: How can we achieve unprecedented improvements in teaching and learning. Alexandria, VA: ASCD.

$\rightarrow$ Senge, P. (1990). The fifth discipline: The art and science of the learning organisation. New York: Currency Doubleday.

$\rightarrow$ Senge, P. (2006). The fifth discipline: The art and practice of the learning organisation. London: Random House.

$\rightarrow$ Sergiovanni, T. J. (1994). Building community in schools. San Francisco: Jossey-Bass.

$\rightarrow$ Stoll, L. \& Seashore Louis, K. (2007a.) Professional learning communities: Divergence, depth and dilemmas. London: Open University Press.

$\rightarrow$ Stoll, L. \& Seashore Louis. K. (2007b). Professional learning communities: Elaborating new approaches. In L. Stoll \& K. Seashore Louis (Eds.), Professional learning communities: Divergence, depth and dilemmas (pp. 1-13). London: Open University Press.

$\rightarrow$ Stoll, L., Bolam, R., McMahon, A., Wallace, M. \& Thomas, S. (2006). Professional learning communities: A review of the literature. Journal of Educational Change 7(4), 221-258.

$\rightarrow$ Stoll, L., Bolam, R., McMahon, A., Thomas, S., Wallace, M., Greenwood, A. \& Hawkey, K. (2006). Professional learning communities: Source materials for school leaders and other leaders of professional learning. User guide getting started and thinking about your journey. Accessed on May 4, 2012. Available at: http://www.lcll.org.uk/professional-learning-communities.html.

$\rightarrow$ Talbert, J. E. (2010). Professional learning communities at the crossroads: How systems hinder or engender change. In A. Lieberman (Ed.), Second international handbook of educational change (pp. 555-571). Dordrecht, The Netherlands: Springer.

$\rightarrow$ Tillema, H. \& van der Westhuizen, J. (2006). Knowledge construction in collaborative enquiry among teachers. Distance Education, 25(1), 51-67.

$\rightarrow$ Waters-Adams, S. (2012). Action research in education. Faculty of Education, University of Plymouth, URL: http://www.edu.plymouth.ac.uk/resined/ actionresearch/arhome.htm 2006. [Accessed June 28, 2012].

$\rightarrow$ Zuber-Skerritt, O. (2001). Action learning and action research: Paradigm, praxis and programs. In S Sankara, B. Dick \& R. Passfield (Eds.), Effective change management through action research and action learning: Concepts, perspectives, processes and applications (pp. 1-20). Lismore, Australia: Southern Cross University Press. 


\section{Biographical notes:}

Christopher Bezzina FCCEAM is Professor of educational leadership at the Faculty of Education, University of Malta. He is currently Deputy Dean and Head of the Department of Leadership for Learning \& Innovation, a member of the Department of Education at Uppsala University, Sweden, and visiting professor at the University of Bologna, Italy. He does consultancy work both locally and abroad. Christopher has published in the areas of professional development and leadership in various peer-reviewed journals, including a number of books. He is involved in various European and international educational institutions, and serves on a number of editorial boards. Christopher is Vice President of the Commonwealth Council for Educational Administration and Management.

Mark Farrugia is a deputy head at a Maltese Church school and a visiting lecturer at the University of Malta specializing in reflective practices. After his bachelor's degree in Physical Education and Early and Middle Years he furthered his studies in leadership and administration with Leicester University. During this period his main areas of reaearch focused on culture, collaboration and professional learning communities. Mark has used these interests to be part of a team of educators to start a new primary school as an extension of an established secondary school. Mark is curently undergoing his doctoral studies with University College London. His research aims at exploring what happens when professional learning and development is entrusted to teachers themselves. 



\title{
Teachers in communities of practice: perspectives and experiences from three doctoral research studies
}

\author{
James Calleja \\ University of Malta \\ Doreen Mizzi \\ Secretariat for Catholic Education, Malta \\ Ivan Riolo \\ University of Malta
}

\section{Abstract}

This chapter delves into the notion of community of practice (CoP) from the perspective undertaken by three doctoral research studies focusing on the continuing professional development (CPD) of mathematics, science and physical education secondary school teachers in Malta. Within a local context in which teacher development through participation in CoP is still in its infancy, we discuss how our understandings and experiences of CoP inform our designs. All three CPD programmes are designed to assist teachers in developing and deepening understandings of both pedagogy and content. Yet, while for the mathematics and science programmes CoP was designed within CPD, for physical education CoP became an emergent component. This chapter will focus on four design features for creating and cultivating communities of practice - the learning environment, reflective practices, the negotiation of meanings and long-term engagement. These features are analysed from data related to accounts of practice from the perspectives and experiences of teacher-participants and the three researchers within their CoP. For the three CPD programmes, the CoP component offered space for teachers to gain more ownership, encouraging reviewing and 
constructing new knowledge and, along the process engage in deeper reflection on practice. These experiences highlight the need to move from isolated learning practices towards more collegial approaches.

\section{Keywords:}

communities of practice

teachers' continuing professional development

CPD programmes

collegial approaches to practice 


\section{Introduction}

Community of practice (CoP), a term coined by Lave and Wenger (1991) in studying how practice in a community enables the apprentice to move from peripheral to full participation, has been used widely in research into teacher professional learning (Coburn \& Stein, 2006; McLaughlin \& Talbert, 2001; Shabani, 2012). The notion of CoP is one domain that has characterised our daily practice as teachers, teacher educators and novice researchers, and the way we conceive teacher learning and the development of practice. In this chapter, we will focus on how CoP was a key feature in three separate CPD programme designs for secondary school teachers of mathematics, science and physical education. While CPD for mathematics was designed to support the use of inquiry-based learning (IBL), the science programme was intended to enhance both the content and pedagogical content knowledge of non-specialist chemistry teachers, and the physical education one aimed to inform and qualify a group of teachers on an innovative value laden model teaching personal and social responsibility (TPSR) prior to its implementation.

Our interest in communities of practice arises from our work, initially as teachers but also as teacher educators. Within our profession, we meet teachers on a regular basis and collaborate with them on different initiatives. Stemming from this work is our understanding that Maltese teachers need and value experiences as participants in communities of practice (see Attard Tonna, Murphy, \& de Paor, 2017 in Chapter 12 of this same book) in which they are afforded agency to experiment in reforming practices and strategies, with the support of colleagues (Attard, 2012; Putman \& Borko, 2000; Stein, Smith, \& Silver, 1999). We believe that community is a necessary feature in bringing about change, and that learning about teaching is fundamentally social (Spillane, 1999). With hindsight, these insights inspired and informed the design of our three CPD programmes.

The Faculty of Education doctoral committee within the University of Malta organises seminars for PhD students. Back in 2014 we started attending these seminars, and this is where we got to know each other better and more about the research work that we were conducting. These meetings, generally held once every two months, include PhD students' presentations of research work-in-progress and seminars led by visiting Professors from foreign universities. These doctoral 
seminars created a CoP for PhD students. As novice researchers, we shared common interests, concerns and a passion about research. This brought the three of us closer together and developed what Barab, Makinster, and Scheckler (2004, p. 5) define "a persistent, sustained social network of individuals who share and develop an overlapping knowledge base, set of beliefs, values, history and experiences focused on a common practice and/or mutual enterprise." Indeed, practice within the doctoral community enabled the emergence of our CoP the one that motivated us to disseminate our experiences, present our work at the TEPE 2016 conference and eventually write this chapter. It seemed that the CoP created by the doctoral committee, which we refer to here as a designed community - because it was intended to bring novice researchers together - enabled the emergence of a new community whose practice converged towards CPD design and the study of teacher professional development and learning. We refer to this CoP as an emergent community because it developed as a result of our interactions within the larger doctoral research community that we formed part of (Barab, Barnett \& Squire, 2002). Within the mathematics and science CPD designs, CoP was a designed component of the two programmes. The CoP component was conceived as offering teachers ongoing collaborative learning experiences within their CPD journey. Since teacher meetings were to be held within school hours, these time-slots were scheduled beforehand in collaboration with heads of school and the teacher-participants. For the physical education CPD, however, the CoP component emerged from the participants' practice and involvement during group meetings originally planned as a data gathering setting.

Our philosophies in teacher professional development draw on socio-constructivist and sociocultural theories of learning (see Vygotsky, 1978) and are driven by the belief that social processes shape teacher learning. Research into CPD gives considerable attention to the impact that community plays within teachers' learning to teach and implement innovative practices (Barab et al., 2002). In particular, CPD taking the form of teacher learning community (Little, 1993; Watson, 2014) is considered appropriate to initiate, support and sustain teacher change. This social aspect of teacher learning highlights that teachers learn more effectively when they collaborate with others rather than when working in isolation (Levine \& Marcus, 2010). CPD programmes may 
have a greater impact towards teacher learning, improved practices and changes in beliefs, when collaborative structures are central to the design.

All three CPD programmes were intended to support teachers in successfully implementing new practices and in refining them. We believe that for this to happen, teachers should be afforded opportunities to participate actively in communities of practice in which they could share and discuss new teaching strategies while, at the same time, profit from support provided by their peers as they implement those strategies in their classrooms (Cochran-Smith \& Lytle, 1999). In the CoP perspective, learning is conceptualised as occurring within collaborative interactions among teachers as they attempt to develop and improve practice (Stein et al., 1999). Central to the design of CPD with a CoP orientation is that considerable time is offered to teachers over long periods (Guskey, 2002) so that they may engage in reflective practices (Attard, 2012) by sharing and negotiating meanings (Shabani, 2012) about their classroom practices. This is more likely to happen if a safe and nonthreatening environment is nurtured in order for teachers to build trust and rapport (Fullan, 1993). In this chapter, we will discuss these four CoP features - the learning environment, reflective practices, the negotiation of meanings and long-term engagement - as embedded within our CPD designs from the perspectives of both the teacher-as-participant and the researcher-as-participant. Since the CoP component within CPD for mathematics and science teachers was designed, we discuss CoP features from the teacher-as-participant viewpoint using data gathered from a focus group held with each group of teachers. On the other hand, because of the emergent nature of CoP within the physical education CPD and the fact that the TPSR model was new to both the researcher and his participants, we focus our discussion from a researcher-as-participant perspective. We also bring this analysis together with insights drawn from deliberations in our own CoP while planning to present our research work leading to the TEPE 2016 conference.

\section{Research contexts}

Teacher professional development in Malta runs on a three-phase model: The University of Malta via the Faculty of Education, which is responsible for the preparation of prospective teachers; the Ministry for Education and Employment (MEDE) which, through the Institute for Education, 
caters for professional development through the provision of INSET (In-Service Education Training) courses; and the University of Malta and other institutions which offer postgraduate courses for educators. During the scholastic year, CPD opportunities for teachers usually occur at school or college level. Moreover, teachers may be asked to attend INSET training either in July and in September, and this consists of three half-day sessions held outside the scholastic year. Teachers, in the state sector, are obliged to attend a total of 30 hours of CPD each year should they be called for the INSET training course component. This training time is equivalent to approximately 7.3 days - well below the TALIS (Teaching and Learning International Survey) average of 15.3 days (OECD, 2009). CPD duration and format are established by the MEDE through a collective agreement signed with the Malta Union of Teachers (Malta Union of Teachers, 2010), and changes to it may only be possible following new negotiations. This agreement only governs the state sector. However, a similar agreement guides church schools with professional development being less structured and, similar to other non-state schools, falls under the school's administrative responsibility.

Bezzina and Camilleri (2001) recommended instilling a culture of collaboration seen as a lifelong process which should link to collegial reflective practice and the engagement of professionals through discussion. They insisted about the need to establish a professional development culture sustained through practice. Some years later, Bezzina (2006) again urged for a move towards nurturing collegiality between educators through professional learning communities. This entails a major change from the common practices of INSET academic courses. Professional learning communities may serve as a means to address the immediate needs of teachers arising within their school environments. Still, this requires educators to shift from being passive participants to becoming actively engaged with a voice in the development of whole school policies and planning. More recently, this shift is reflected by the National Curriculum Framework (Ministry of Education and Employment, 2012) promoting school as learning communities.

It is only lately that a limited number of initiatives have provided collaborative hands-on and on-going approaches to CPD - for example: focused training for teachers teaching the core competences learning programmes in mathematics, Maltese and English; the Promoting Inquiry in Mathematics and Science across Europe (PRIMAS) project 
and a number of local studies using a CoP approach to teacher learning. This shift, which weds CPD and CoP, frames our designs and a concern for quality education that is explored in practice within our studies. Framing CoP within CPD, adopted diversely within our research, provides evidence on the application of innovative teacher professional development.

\section{Design structure of CoP within CPD}

At the time of the research, the first two authors were heads of department in two secondary schools one for mathematics and the other for chemistry. The third author was a University lecturer in physical education. Within our roles, we met teachers and worked with them on a day-to-day basis. We gained much experience related to what works for teachers in the local context. Our experience informed by research literature was key to our CPD design structure. Because of practical and logistical issues, we operated the provisions of CPD around the local model of INSET training. Yet, because we value knowledge, teaching and learning as being socially created and culturally constructed (Vygotsky, 1978) over time, we applied a 'sociocultural model' of CPD (Putman \& Borko, 2000).

Evidently, to be successful, CPD must be undertaken as a process, rather than an event (Loucks-Horsley, Stiles, Mundry, Love, \& Hewson, 2010). Hence, we extended the INSET summer workshops to include an ongoing year-long CoP component (see Figure 1). Putman and Borko (2000, p. 7$)$ argue that:

"One promising model for the use of multiple contexts combines summer workshops that introduce theoretical and research-based ideas with ongoing support during the year as teachers attempt to integrate these ideas into their instructional programs."

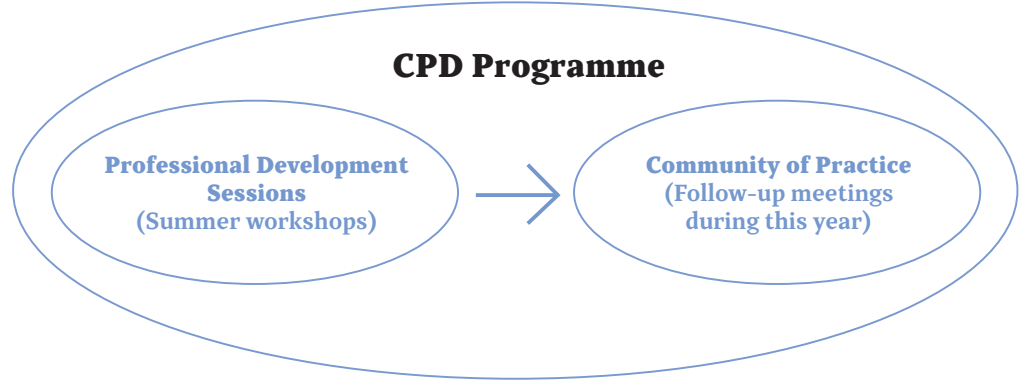

Figure 1: Design structure of the three CPD programmes 
This design combines learning-off-job in summer workshops with learning-on-job in follow-up meetings. Summer workshops provided teachers with intensive learning experiences, while follow-up meetings held during the scholastic year were aimed at supporting teachers "to practice-teach and reflect on their teaching" (Lotter, Yow, \& Peters, 2014, p. 3). In our CPD design, the follow-up meetings were intended to offer teachers the space to share strategies and address issues of practice. All three studies followed a one-year CPD programme (see Table 1).

Table 1. Design structure of CoP within CPD

\begin{tabular}{|c|c|c|}
\hline SUBJECT & SUMMER WORKSHOPS COMPONENT & FOLLOW-UP COMPONENT \\
\hline MATHEMATICS & $\begin{array}{l}4 \text { half-days in July and September } \\
2015 \text { led by teachers of } \\
\text { mathematics with experience in } \\
\text { IBL and CPD } \\
\text { For teachers interested in learning } \\
\text { to teach mathematics through } \\
\text { inquiry }\end{array}$ & 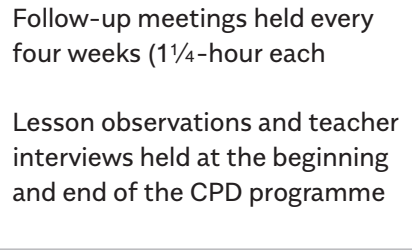 \\
\hline SCIENCE & $\begin{array}{l}3 \text { half-days in July } 2014 \text { led by } \\
\text { Chemistry specialist teachers and } \\
\text { the researcher } \\
\text { For science teachers who are non- } \\
\text { chemistry specialists }\end{array}$ & $\begin{array}{l}3 \text { one-day sessions - one per term } \\
\text { ( } 5 \text { hours each) with an additional } \\
\text { meeting used as a final evaluation } \\
\text { Lesson observations and teacher } \\
\text { interviews throughout the year }\end{array}$ \\
\hline PHYSICAL EDUCATION & $\begin{array}{l}3 \text { half-days in July } 2013 \text { led by } \\
\text { a TPSR expert, followed by } 4 \\
\text { group meetings in preparation for } \\
\text { implementation } \\
\text { For selected teachers interested } \\
\text { in using the TPSR model }\end{array}$ & $\begin{array}{l}\text { TPSR monthly group meetings } \\
\text { ( } 2 \text { hours each) } \\
\text { Lesson observations and teacher } \\
\text { interviews throughout the } \\
\text { implementation year }\end{array}$ \\
\hline
\end{tabular}

\section{The three CPD programmes}

Inquiry-based learning is becoming more relevant in the Maltese educational system, and in mathematics and science education in particular (Ministry of Education, 2012). In addressing this, teachers become key in developing learners' competences and in enabling them to nurture an inquiry stance to learning. Learning to teach mathematics through inquiry (LTMI) is a CPD programme designed as a set of experiences where teachers have opportunities, over a oneyear period, to experience, integrate, reflect upon and develop their inquiry teaching practices. During mathematical inquiry, students 
assume a central active role - wrestling with ideas, asking questions, exploring and explaining meanings - supported by the teacher as a facilitator. LTMI, offered as a voluntary course, was designed as an intervention programme to provide inquiry-based learning (IBL) experiences for teachers first through summer workshops, and then by participating in follow-up meetings held during the scholastic year. The summer workshops focused on four IBL features: mathematical tasks, collaborative learning, purposeful questioning and, student agency and responsibility (see Calleja, 2016). The follow-up meetings, which lasted 75 minutes, were held during school hours at the school in which the researcher was teaching at the time. Teachers and teacher educators with experience in inquiry practices facilitated the workshops and follow-up meetings, with the researcher acting as a non-participant observer - collecting feedback to improve the programme in the piloting phase, and gathering field notes and other data to study the process of teacher learning during the main phase. For the piloting phase, held during the scholastic year 2014-2015, five teachers took the programme while another 12 enrolled for the main study held the following year.

In Malta, integrated science is part of the core curriculum at early secondary level (ages 11 to 13) and includes topics from physics, chemistry and biology. At upper secondary level (ages 14 to 16) students study one compulsory science subject, generally physics, but can opt to study the other two. Depending on the school population, science teachers may be asked to teach their specialised science subject at upper secondary level or else a combination of integrated science and their specialised science subject. To date, one can become a science teacher by specialising in only one of the three science subjects, at undergraduate level. Hence, when teaching integrated science, teachers will be teaching at least two subjects outside their area of science specialisation. In the case of physics teachers, for example, these may have never studied chemistry or biology at secondary level since physics was their compulsory science. Teaching the chemistry topics within the science curriculum becomes a major challenge for them as would not have studied these at degree or advanced level. A CPD programme was designed to support teachers teaching their non-specialist area both in content and pedagogy. This programme was specifically designed for science teachers who are non-chemistry specialists and who would 
need to approach the teaching of chemistry-based science topics in the integrated science curriculum. Eight teachers from different schools participated in the CPD programme on a voluntary basis. The programme, held during the scholastic year 2014-2015, was based on three-day interactive summer workshops followed up by three one-day sessions (5-hours each) spread over three terms. These sessions allowed participants to explore their fears and challenges, but also to work together to develop skills and resources that helped them improve their confidence in teaching chemistry-related topics.

The CPD programme for physical education teachers centred round implementing the TPSR model (see Hellison, 2003) - a valueladen model which targets teaching responsibility using a physically active medium. Since teachers needed a sound knowledge base to implement this model, a foreign expert in the field of TPSR was invited to deliver a module to teachers, preparing them for the implementation year. Initiated in July 2013, the TPSR training module started off with a 3-hour taster seminar which brought together PE teachers as well as a number of professionals within the fields of personal and social development, special education and heads of schools. Following that, seven educators (including the researcher) participated in a 14-hour intensive teacher training module. Four teachers voluntarily agreed to pursue with meetings, during the scholastic year 2013-2014, as they implemented the model in their respective schools. These monthly 2-hour meetings took place after school hours. The purpose of these meetings was two-fold: a place and time where teachers openly discussed, shared and talked about their implementation experiences, as well as an ongoing personal and social responsibility teacher training.

For all the three CPD programmes, a minimally structured setting was organised which allowed teachers to draw on their subjective experiences that they felt were important and relevant. Initially, to help kick start discussion, teachers were supported to explore classroom practices including lesson planning, challenges, student engagement and critical incidents. Teachers were encouraged to pick on moments and experiences and discuss these within the group. All meetings were held in an informal setting over coffee and some refreshments. Meetings were audio-recorded and later transcribed. 


\section{Presenting four features in designing CoP}

Both the 'summer workshops' and the 'follow-up' components of providing CPD were common within our programme designs. Yet, CoP within the follow-up component of the three studies was applied differently. For teachers of mathematics and science the CoP component was designed - it was conceived as a means for teachers' on-going collaborative learning within the CPD design. For physical education CoP was emergent. CoP emerged from a data collection setting with teachers, and developed from their need and request to meet, and form a support group (see Table 2).

Table 2. Designed and emergent CoP

\begin{tabular}{|c|c|c|}
\hline \multicolumn{2}{|c|}{ DESIGNED COP } & EMERGENT COP \\
\hline MATHS TEACHERS & SCIENCE TEACHERS & PE TEACHERS \\
\hline $\begin{array}{l}\text { Environment: } \\
\text { Reflective Practice: } \\
\text { Theory of Learning: } \\
\text { Time-frame: }\end{array}$ & \multicolumn{2}{|c|}{$\begin{array}{l}\text { Non-threatening and safe, building trust and rapport } \\
\text { Sharing, discussing and reflecting on classroom practices } \\
\text { Learn by communicating and negotiating meanings } \\
\text { Long term engagement, on-going CPD opportunities }\end{array}$} \\
\hline \multicolumn{2}{|c|}{$\begin{array}{l}\text { Activities modelling an inquiry approach } \\
\text { Gradually removing scaffolding for teachers to eventually take } \\
\text { a more active role in setting agendas and running meetings }\end{array}$} & $\begin{array}{l}\text { Data collection target } \\
\text { Unstructured sessions } \\
\text { Flashcards with themes }\end{array}$ \\
\hline $\begin{array}{l}\text { Using a conflict discussion } \\
\text { approach }\end{array}$ & $\begin{array}{l}\text { Collaborative design involving } \\
\text { lesson and topic plans }\end{array}$ & $\begin{array}{l}\text { leading to open discussion } \\
\text { Teacher-led discussions }\end{array}$ \\
\hline
\end{tabular}

In designing for, creating and cultivating CoP, our ideas converged to focus on four key aspects: the learning environment, reflective practices, the negotiation of meanings and long-term engagement. A common aspect to our design was the need for teachers to take active roles in designing, implementing and reflecting on their classroom practices. Additionally, the CPD programmes were intended to shape the way teachers develop their identities as teachers of mathematics, science and physical education. Wenger $(1998$, p. 5) describes identity as "a way of talking about how learning changes who we are." Our primary role as designers was to set up and ensure that teachers could operate within a non-threatening, supportive and safe environment (Fullan, 1993). Teachers kept a reflective journal and had opportunities to share critical incidents during the meetings. This, we felt, was vital for teachers to share, discuss and reflect upon their practices. However, 
creating and cultivating such an environment needed time and long term engagement.

Probably an overlooked aspect of professional development is sustaining learning over time (Guskey, 2002). Research shows that teacher practices are more likely to be transformed by CPD that is sustained, coherent and intense (Garet, Porter, Desimone, Birman \& Yoon, 2001; Supovitz, Mayer \& Kahle, 2000). In order for teachers to change and improve their practices they must engage into a personally transformative experience that can only occur over time. Aligned to this research-based knowledge, our CPD designs provided sustained ongoing engagement over a one-year period.

Moreover, effective CPD is generally seen as being practice-based, and involves the negotiation of meanings, collaboration, and reflective practice (Loucks-Horsley et al., 2010; Mewborn, 2003). Within the CPD experiences offered, we highlighted teachers' own active engagement in critically reflecting upon (see Attard, 2012) and analysing teaching and learning through inquiry and teacher-led discussion. We also made sure that learning experiences provided a coherent framework that aligned CPD with teachers' goals, their experiences and professional context, but also focusing on deepening teachers' content and pedagogical knowledge.

\section{Methodology}

We believe that knowledge lies within the communities that create it, and hence draw on a CoP perspective as a methodology for understanding teacher professional development within collaborative settings. We are interested in social interactions to understand how participants in communities of practice (Wenger, 1998) experience the four CoP features we described in the previous section. An accounts of practice methodology was employed for data analysis, adapted from Simon and Tzur (1999). In this approach, we overtly recognise and value viewpoints of both participants and researchers in the analysis of phenomena. We attempt to explore perspectives into the accounts of practice from the teachers-as-participants and the researcher-asparticipant and look into these through discussions within our own CoP.

Our accounts of practice were gathered within settings in which teachers were co-constructing their learning. As researchers, we were the main data-gathering instrument (Lincoln \& Guba, 1985). Our 
researcher-as-instrument approach (Patton, 2002), hence, required spending time with participants to capture, as precisely as possible, the views, experience and claims they were making. While understanding that reality is socially constructed (Putman \& Borko, 2000; Spillane, 1999) and impossible to capture objectively (Denzin \& Lincoln, 1998), the mathematics and science researchers assumed a position where they 'distanced' themselves from teacher activity while collecting data. In both cases the researchers were themselves designers of the CPD programmes. Hence, detachment from teacher activity was an arduous task with challenges to face and overcome - for example, reminding teachers that, as researchers, we were not facilitators of learning; and avoiding direct interventions, taking a step back and allowing teachers to struggle by bouncing questions back to teachers when they sought approval or attempted to involve us in their discussions. This was, however, not the case for physical education where the researcher was a participant. The researcher-as-participant role involved active engagement in the learning activities since TPSR learning was innovative for both teachers and researcher. This 'innovative to all' learning context, generated an environment in which researcher and participants were equals in terms of their knowledge of implementing TPSR. Although, the researcher acted as a facilitator to teacher activity, the coconstructivist nature of the learning environment supported active collaborative engagement and immersion by those involved. However, such immersion presented challenges for the researcher in, for example; taking detailed field notes, limiting much of the data collection to audio recording and immediate transcription. While for mathematics and science the researchers collected data as 'non-participant observers', the physical education researcher was an active participant. Although we all set out to use an inductive coding method in analysing the data, we valued our subjective positions as well. Our subjective judgments were indeed essential in making sense of the data, at a stage when moving from providing descriptions towards interpretations (Lincoln \& Guba, 1985). In the case of physical education, within a constructivist grounded analytical approach (Charmaz, 2000) used, the subjective judgements were essential in constructing meanings - not individual ones but meanings co-constructed with the participants.

We use three data sources: two focus group discussions held with mathematics and science teachers at the end of the CPD programmes; 
reflections of the researcher-as-participant in the TPSR meetings; and a final presentation that we prepared for the TEPE 2016 conference presentation based on our own ongoing conversations. The focus groups highlight the teachers-as-participants' perspective of communities of practice while the reflections from the TPSR meetings take a researcheras-participant perspective. We see these two 'distinct' viewpoints as complementary in giving a more holistic picture of the experiences of participants within designed and emergent communities of practice. Moreover, our ongoing deliberations of teachers' accounts of practice help us to explore these experiences and viewpoints more deeply.

\section{Data sources}

Focus groups are generally used for an in-depth discussion from personal experiences, on a specific research theme by exploring the attitudes, perceptions, feelings and ideas of participants about a specific topic (Krueger \& Casey, 2015; Morgan \& Spanish, 1984). For mathematics and science teachers a focus group discussion was used to collect the shared understanding of a CoP as well as the views of individuals within the community (Bloor, Frankland, Thomas, \& Robson, 2001), yielding data about the meanings that lie behind teachers' CoP experiences. Each focus group was held at the end of each CPD programme, and in both cases, the researcher designed an interview guide made up of questions and/or prompts to open the conversation and to promote further interaction between members (Krueger \& Casey, 2015). As a result of the group interaction, data from the focus groups was socially constructed as participants provided insights and experiences related to their participation in a CoP. In both studies, the focus group discussion was facilitated by the researcher and lasted for around 75 minutes. The discussion was audio-recorded and later transcribed verbatim using pseudonyms.

Reflections from TPRS meetings were framed within the researcher's personal and collective experiences of CoP. These reflections, pertaining to the implementation as well as the dynamic interactive experiences, were initially recorded as written field notes. The written field notes, supported by personal experiences as a participant in the CoP, formed the researcher-as-participant reflections. All TPSR meetings were audio recorded and transcribed immediately after 
each meeting since continuous interaction with data was essential in understanding teacher the developmental implementation of TPSR.

As novice researchers, we negotiated meanings (Wenger, 1998) in an attempt to make sense of data emerging from teachers' CoP experiences within the three CPD programmes. Meetings to discuss our research data provided a context for sustained professional conversations around the CoP domain and practice issues (see Wenger, McDermott \& Snyder, 2002). This negotiation eventually led us to present our work at the TEPE conference in 2016. By adopting a CoP perspective on our development, we shift attention away from analysing the practices of each one of us as individual researchers and instead focus on analysing the collaborative interactions that occurred amongst us. We thus use the TEPE presentation notes as a data source illustrating our ongoing deliberations about research and practice into teacher engagement within communities of practice. We explore experiences, reflections, insights and challenges that emerged from our immersion in the CPD programmes with teachers, and the collaborative discussions that emerged during our own CoP meetings.

\section{CoP perspectives and experiences}

Rather than presenting data related to features of CoP from each CPD study separately, in line with a socio-constructivist perspective, we choose to combine our CoP experiences and look into emergent commonalities. We thus start by presenting data related to the learning environment, reflective practices, the negotiation of meanings and longterm engagement drawn from within the three CPD programmes. We also use examples of accounts of practice from each CPD programme to capture the interrelated aspects of teachers' practice, and attempt to explain these within a CoP from both the teachers' and the researchers' perspectives.

The CoP environment created emerged as a distinctive feature within all the three programmes, particularly in fostering a climate of respect and positive working relationships (Borko, Koehler \& Jacobs, 2014). In creating teachers' learning environments, we acted in a mindful way (see Groschner, Seidel, Pehmer, \& Kiemer, 2014) to foster collaboration. Those facilitating the meetings were careful in creating an environment that was welcoming and safe for teachers to make contributions and share experiences. They sought to build 
trust and rapport by reassuring participants that contributions were neither right nor wrong. Instead, teacher contributions were valued as opportunities for discussion, exploration and learning. Teachers also met in comfortable environments. For example, in the physical education CPD, teachers met in a kitchenette at the University of Malta and discussions were held over coffee and refreshments. Informality within the setting was an effective means towards sustaining a friendly and collaborative atmosphere. Yet, getting teachers to talk was a challenge we all shared. Teachers were initially hesitant to share ideas and communicate their limitations. This, we feel, was due to a number of reasons: (1) participants did not know each other well, hence they needed time to get to know each other; (2) this was a new setting and possibly a new way of learning about teaching for most of them; and

(3) participants felt they lacked experience and hence expertise about the topic - be it teaching through inquiry, chemistry-related topics or implementing TPSR. Getting to know colleagues, both personally and professionally, was an important first step for teachers (Meirink, Meijer \& Verloop, 2007; Putman \& Borko, 2000). This was carried out by adopting a developmental approach to setting agenda and collaboration (Stein et al., 1999). Initially, group discussions were guided and scaffolding was provided, until teachers gained confidence. Eventually, they started to feel that they could trust each other, "sharing both the positives and the negatives." Teachers stated that they felt open not only to speak of their strengths but also to share their fears and concerns. They felt an increased "sense of trust and appreciation between members" of the community, and the environment created within the CoP "helped everyone to become more open."

For teachers of mathematics, for example, the learning environment provided "the opportunity to demonstrate" their work and practices. The environment eventually allowed agency and freedom for teachers to make as many contributions as they liked. For Colin, the environment offered a sense of freedom to liberate personal tensions. As he revealed, "having been able to expose my practices here has helped me to free myself from the tensions of sharing my views and practices about teaching because I am always fearful of being judged." The environment for Chris, another mathematics teacher, afforded a different kind of freedom. As he put it, "if there was a time when I could not do as much, there was nothing wrong with that. In this environment, I was free... 
free from the control of having things imposed on me." Colin spoke about the influence that the CoP environment had on freeing his "fear of judgement" while Chris about the "control" that teachers seem to be under in their daily professional work. Chris contested the fact that teachers are not trusted by their superiors. According to Chris and others in the group, it seems that, for school administrations, it is not enough for teachers to teach 'good' lessons. Teachers are overwhelmed with preparation workload related to keeping and presenting schemes of work, detailed lesson plans and up-to-date assessment records. While these responsibilities are important, they appear to be taking most of the teachers' time; time that they could dedicate towards planning more reform-oriented lessons. But, more importantly, such an obligation is seen as a sign of lack of trust. Schools already have 'control' on what teachers should teach (through examination syllabi) and 'judge' teachers' work (through internal and external reviews). Teachers, however, although having some say on the way they teach, appear to be asking for increased 'freedom' to embark on innovative practices without the need of a 'watchdog'. What they seem to be saying is that they need to be trusted so that they could reform their practice at their own pace, and possibly without the "fear of judgement."

The notion of the reflective practitioner and making reflective practice public (Attard, 2012) were rigorously celebrated within these CoP settings. Teachers had opportunities to reflect in different ways - within the CoP meetings, through journal writing, and informal conversations with colleagues at school. A genuine and meaningful engagement in reflective practice became evident in the way teachers commented about this practice: "a journey of self-reflection and brainstorming of pedagogical ideas through discussing with other teachers experiencing the same thing," as well as in the way teachers appreciated the impact of reflective practice on their ongoing personal development: "initially I thought I just had to learn about teaching through IBL, yet I started to find out that our deep reflective practice led to other minor challenges that became evident during our meetings."

The learning environment and increased collegiality allowed for a deeper engagement in reflective practice (Vulliamy \& Webb, 1992). As one science teacher said: "you will reflect when you are on your own but you will not go into such depth. But when you are discussing with another person or a group I think you will reflect in more depth." 
Making reflections public went beyond the narration of actions and methods across practice. Through reflective dialogue, teachers explored the multi-relational aspects of arising issues and their fit within educational settings. For example, discussion around TPSR implementation moved from simple narration of events to a higher critical and reflective practice. Teachers sought an understanding and explanation of actions related to students' behaviours which eventually led the group to reflect and discuss concepts of enculturation and its effect on education. Furthermore, reflecting on implementation experiences, teachers questioned the ways subjective differences in the philosophical make-up of the teacher impinge on quality education. Discussion around the role of the teacher and content knowledge, in physical education, led to reflection on curricular compartmentalisation and the essential qualities of the teacher. The interactive environment, shared interests and perhaps similar ontological commitments of the teachers accentuated this depth in reflective practice. Similar to the findings of Slavit and Nelson (2010), teachers' collective engagement in reflective practice were going deeper and, as a result, perpetuated a more critical stance to their views about teaching and education.

Ongoing opportunities of sharing practice-based experiences were another prominent aspect that teachers mentioned. It appears that teachers looked forward to and be part of their CoP because they did not spend hours listening to a speaker but shared experiences, worked together and designed useful and relevant materials that they could apply to their particular classroom setting. Meetings promoted active involvement where teachers constructed their knowledge about teaching by negotiating meanings. A teacher's account of his experience captures the importance of active learning and the common traits that emerged within the CoP he participated in: "we got our hands dirty, we found challenges and difficulties, we understood that the challenges we encountered were common to all." Not only did teachers value such active sharing and discussion, but they expressed how much they learnt from such opportunities. Teachers valued the comments and the feedback received from their colleagues working in different school contexts. The year-long CPD programme provided time and opportunities for teachers to "share concerns and problems," to discuss and reflect whilst they were teaching mathematics, chemistry topics or implementing the TPSR model. Discussions and support found within the CoP instigated teachers 
to try out and experiment with new methods in their own classrooms, thus venturing out from their own comfort zones. Feedback given on the lesson plans and activities they shared was important, particularly since the ongoing negotiation of their different perspectives was an essential process in their development of professional practice.

The benefits of being part of a community were recognised by teachers. One teacher commented that "you learn more through sharing of experiences; teaching happens more effectively in a learning community because you are not alone." This may be indicative, we believe, of the contrasting situations that teachers, by and large, experienced between working in isolation (possibly at their respective schools) versus working as a community (within the CPD). Experiences shared within the CoP contrasted with school life, and qualities of collegiality emergent from the CoP mirrored educational needs in local schooling. For example, collegiality and working together were strongly supported within the CoP yet heavily criticised and, at times, found lacking across local schooling. The educational potential and strength of informal learning, as an educational process experienced within the same CoP, contradicts the 'modus operandi' within Maltese schools. Teachers were critical towards the pre-set educational targets that students are expected to attain through prescriptive curricula, and the devaluing of informal education in comparison to traditional academic subjects. Collegiality within the CoP was not valued simply because it offered opportunities for the sharing of experiences. Teachers listened to and provided their own reflections on each other's experiences whilst appreciating the diverse working contexts framing their respective work places.

Our studies show that engagement in communities of practice shaped teachers' identities, that is, their self-perception of their own role, their agency and relationship with others (Wenger, 1998). Participation in a CoP has brought about teacher learning with changing participation in social practices. Identities, in the sense suggested by Wenger (1998), are not static entities, but are created and recreated through a process of accommodation (Peressini, Borko, Romagnano, Knuth \& Willis, 2004). Through participation in communities of practice, teachers become enculturated into new ways of being and acting. This ongoing engagement was illuminative for Chris, for example, in the way he transformed his understanding of learning: 
"I have come to understand that we do not learn in a systematic way but learn by discovering small pieces and then seeing how these fit together... I feel we learn things this way, not only mathematics but also life skills. For example, we learn by trial and error ... today I may not be successful but I might be successful tomorrow, what I know today for a fact might turn out to be false the next day and what I do not know now I might discover something about it later on in life."

This notion of learning - that learning takes place over time - is evolutionary and ever changing. It seems that Chris developed this as a result of both his engagement with enacting inquiry practices in his classroom and the ongoing interactions and negotiation of meanings he has had with colleagues within the CoP.

\section{Conclusions and recommendations}

Our analysis focused on four features of CoP looking into how these shaped teachers' personal and professional development. Within both the designed and emergent communities of practice in our CPD programmes, we found commonalities related to the social aspect of teacher learning. We reported teachers' accounts of practice through which they demonstrated new ways of being, a sense of freedom, deep collaborative reflective practice and negotiation of meanings that went beyond sharing teaching ideas. Teachers shared aspects and engaged in practices that were unusual for them. They shared personal challenges, limitations and dilemmas about reforming their practices. But they also contributed to support one another in constructing an understanding of practice.

Teachers' agency, deep engagement and understanding of practice brought forward issues of 'belonging to a community' and 'becoming a community', highlighted by Potari, Sakonidis, Chatzigoula, and Manaridis (2010) in their study of a community of practice made up of teachers and educators/researchers. These, we believe, shaped teachers' identities of apprentices moving from peripheral to full participation within their CoP. Members had a joint enterprise and shared goals, that eventually developed into a shared repertoire of understandings (Wenger, 1998).

Yet, this new identity created conflicts between the CoP within the CPD and the contexts of their schools - their 'real' world of practice. One teacher expressed 'freedom' within CoP that his institution was 
holding back from him. He seemed to view his school as a 'controlling body' that limited him from progressing because he wished to do this at his own pace. Others echoed a similar viewpoint of being judged and, hence, constrained from acting liberally, and autonomously. Teachers seemed to develop their identity within a learning environment that encouraged and supported teachers' collaborative reflective practice. While teachers viewed individual reflections as important, they experienced the benefits of making them public (Attard, 2012), that eventually nurtured a critical stance towards practice. Teachers became aware of inconsistencies between the existent CoP within the CPD programmes offered, and the 'inexistent' CoP within their place of work. We use the word 'inexistent' to express teachers accounts of what productive communities of practice are built upon.

We end this chapter by presenting recommendations informed by the experiences and perspectives emanating from teachers, but also emerging from our dual roles as researchers-designers working within a CoP. However, before moving on to present our recommendations, we briefly discuss a number of boundaries within our studies. Primarily, teachers in our CPD programmes participated voluntarily - they identified a personal need and willingness to develop their practices when joining the CPD programmes offered to them. Results, we contend, are likely to be different had teachers been 'made to attend' such CPD programmes. Secondly, the data emerging from the three programmes is limited to the participation of a few teachers in each programme -12 for mathematics, eight for science and seven for physical education which are definitely not representative samples of the whole population of mathematics, science and physical education teachers in Malta. In all cases, teachers attending CPD came from different schools. For teachers, then, engaging in CoP and working with new teachers from different school settings was perhaps a more challenging CPD experience since they did not know the other participants. This leads us to a third limit that all three programmes and research studies spanned over a scholastic year. Hence, the data reported here is 'limited' to a particular period. We cannot argue that the practices teachers engaged in during their CoP continued to develop further, weakened or ended following their engagement with CPD. This taps onto the limit of continuation - a fourth and final consideration. Given the sense of community that developed within all three programmes, 
we also do not exclude the possibility of networks being created but we hypothesise potential difficulty for teachers to meet face-to-face. We cannot, hence, extend our claims about aspects, experiences and developments beyond teachers' CPD experiences within the three programmes presented here. While the boundaries within our three CPD programmes may be seen as limitations, we strongly believe that the findings emerging from our studies, reported here, become strengths for those intending to design CPD interventions. Moreover, these boundaries furnish particularities and commonalities of the implementation of three CPD programmes designed for a specific context (Malta), a professional development context that is likely to resonate with others elsewhere, and upon which we based our forthcoming recommendations.

\section{Cultivating a CoP culture for teacher professional learning}

When teachers are trusted as active agents, CoP experiences become empowering for them - they may transform teachers' ways of being and acting to facilitate their professional development. We thus suggest that teachers need to become enculturated in this kind of learning setting that values and celebrates teachers' practice-based knowledge. We also propose that schools should become communities of practice by design. The school as a designed $\mathrm{CoP}$ is based on nurturing a collegial environment where members have a voice, feel safe to share insights about practice, and are respected and trusted as professionals. A school with CoP culture may support the development of other emergent communities within, and these may eventually strengthen the overall collegial culture. A CoP culture should start in the initial teacher training programmes so that it eventually perpetuates in schools. CoP practices need to become part of teacher preparation programmes, not as a concept explored solely theoretically but applied and lived within practice.

\section{Scheduling time for teacher collaboration}

Teachers should be given time and space to share, discuss and reflect about reforming their practices. This may be possible if it is well structured and designed within teachers' daily work. Teachers, in our studies, value the benefits of collaboration. However, they require an ongoing and long-term engagement with colleagues. A common difficulty that Maltese teachers encounter in their attempts to 
collaborate with others is related to the issue of 'when to meet'. We argue that selected time-slots in timetables would ensure that teachers have time purposefully set for collaboration. Drawing on empirical evidence, we believe that scheduling time for collaboration would enable groups of teachers with a shared interest and similar philosophical dispositions to come together and engage in meaningful CoP.

\section{Supporting teachers to learn at their own pace}

Teachers learn and develop their practice just as students do - they value support as much as agency. They thrive when they work within environments that celebrate mistakes and that respect them as individuals that learn at their own pace. We argue that teachers may embark more actively and productively on more challenging practices when supported by leaders acting as critical friends and facilitators of the learning process.

\section{Preparing CPD facilitators who are receptive to the process of teacher learning}

Teachers may initially be uncomfortable sharing their practices. Facilitators are responsible for creating an environment in which teachers feel safe and eventually become confident in negotiating meanings about practice. The facilitator's role, we argue, is critical in guiding discussion and inviting teachers to question one another in a supportive environment. We feel that communities of practice may flourish if facilitated by knowledgeable teacher leaders. We also argue that the roles and responsibilities of CPD facilitators still need to be clearly defined, studied and regarded highly. Hence, programmes to prepare CPD leaders need to be developed and implemented.

Within context such as Malta, where teaching is still prevalently a lonely profession carried out by teachers working in isolation, taking on board these recommendations is essential to start putting into practice notions of collegiality and community put forward by Bezzina and Camilleri (2001) and Bezzina (2006). We add that schools can support teachers in communities of practice by design. CoP opportunities within CPD should be embedded in teachers' daily practice. Time allocated for teachers to meet on a regular basis framed within a trust-building environment may be key towards initiating, cultivating and sustaining the culture of communities of practice in and across schools. 


\section{References}

$\rightarrow$ Attard, K. (2012). Public reflection within learning communities: an incessant type of professional development. European Journal of Teacher Education, 35(2), 199-211.

$\rightarrow$ Attard Tonna, M., Murphy, T. \& de Paor, C. (2017). Teacher CPD Needs: Perspectives from teachers in Malta and the Republic of Ireland. In M. Attard Tonna \& J. Madalińska-Michalak (Eds.), Teacher Education - International Perspectives and Inspirations. Warsaw: Foundation for the Development of the Education System.

$\rightarrow$ Barab, S. A., Barnett, M. \& Squire, K. (2002). Developing an empirical account of a community of practice: Characterizing the essential tensions. The Journal of the Learning Sciences, 11(4), 489-542.

$\rightarrow$ Barab, S. A., Makinster, J. \& Scheckler, R. (2004). Characterizing system dualities: Building online community. In S. A. Barab, R. Kling \& J. Gray (Eds.), Designing for virtual communities in the service of learning (pp. 53-90). Cambridge, MA: Cambridge University Press.

$\rightarrow$ Bezzina, C. (2006). "The road less traveled": Professional communities in secondary schools. Theory and Practice, 45(2), 159-167.

$\rightarrow$ Bezzina, C. \& Camilleri, A. (2001). The professional development of teachers in Malta. European Journal of Teacher Education, 24(2), 158-170.

$\rightarrow$ Bloor, M., Frankland, J., Thomas, M. \& Robson, K. (2001). Focus groups in social research. Thousand Oaks: SAGE Publications.

$\rightarrow$ Borko, H., Koehler, K. \& Jacobs, J. (2014). Examining novice teacher leaders' facilitation of mathematics professional development. Journal of Mathematical Behavior, 33, 149-167.

$\rightarrow$ Calleja, J. (2016). Teaching Mathematics through inquiry: A continuing professional development programme design. Educational Designer, 3(9). Retrieved from http://www.educationaldesigner.org/ed/volume3/issue9/ article30/ 
$\rightarrow$ Charmaz, K. (2000). Grounded theory: Objectivist and constructivist methods. In N. K. Denzin \& Y. S. Lincoln (Eds.), Handbook of qualitative research (pp. 509-535). Thousand Oaks, CA: Sage.

$\rightarrow$ Coburn, C. E. \& Stein, M. K. (2006). Communities of practice theory and the role of teacher professional community in policy implementation. In M. I. Honig (Ed.), New directions in education policy implementation: Confronting Complexity (pp. 25-46). Albany, USA: State University of New York Press.

$\rightarrow$ Denzin, N. K. \& Lincoln, Y. S. (1998). The landscape of qualitative research: Theory and issues. Thousand Oaks, CA: Sage Publications.

$\rightarrow$ Fullan, M. G. (1993). Why teachers must become change agents. Educational Leadership, 50(6), 12-17.

$\rightarrow$ Garet, M., Porter, A., Desimone, L., Birman, B. \& Yoon, K. (2001). What makes professional development effective? Results from a national sample of teachers. American Educational Research Journal, 38(4), 915-945.

$\rightarrow$ Groschner, A., Seidel, T., Pehmer, A. \& Kiemer, K. (2014). Facilitating collaborative teacher learning: the role of "mindfulness" in video-based teacher professional development programs. Gruppendyn Organisationsberat, 45, 273-290.

$\rightarrow$ Guskey, T. R. (2002). Professional development and teacher change. Teachers and Teaching: Theory and Practice, 8(3/4), 381-391.

$\rightarrow$ Hellison, D. (2003). Teaching responsibility through physical activity (2nd ed.). Champaign, IL: Human Kinetics.

$\rightarrow$ Krueger, R. A. \& Casey, M. A. (2015). Focus groups: A practical guide for applied research (5th ed.). USA: SAGE Publications.

$\rightarrow$ Lave, J. \& Wenger, E. (1991). Situated learning: Legitimate peripheral participation. Cambridge, UK: Cambridge University Press.

$\rightarrow$ Lincoln, Y. S., \& Guba, E. G. (1985). Naturalisitic inquiry. Newbury Park, CA: Sage.

$\rightarrow$ Little, J. W. (1993). Teachers' professional development in a climate of educational reform. Educational Evaluation and Policy Analysis, 15, 129-151.

$\rightarrow$ Lotter, C., Yow, J. A. \& Peters, T. T. (2014). Building a community of practice around inquiry instruction through a professional development program. International Journal of Science and Mathematics Education, 12, 1-23.

$\rightarrow$ Loucks-Horsley, S., Stiles, K., Mundry, S., Love, N. \& Hewson, P. (2010). Designing professional development for teachers of Science and Mathematics (3rd ed.). Thousand Oaks, CA: Corwin.

$\rightarrow$ Malta Union of Teachers. (2010). Agreement between the Government of Malta and the Malta Union of Teachers. MUT. Malta.

$\rightarrow$ McLaughlin, M. W. \& Talbert, J. E. (2001). Professional communities and the work of high school teaching. Chicago: University of Chicago Press. 
$\rightarrow$ Meirink, J. A., Meijer, P. C. \& Verloop, N. (2007). A closer look at teachers' individual learning in collaborative settings. Teachers and Teaching: Theory and Practice, 13(2), 145-164.

$\rightarrow$ Mewborn, D. (2003). Teaching, teachers' knowledge, and their professional development. In J. Kilpatrick, W. G. Martin, \& D. Schifter (Eds.), A research companion to principles and standards for school Mathematics (pp. 45-52). Reston, VA: National Council of Teachers of Mathematics.

$\rightarrow$ Ministry of Education (2012). Handbook for the teaching of Mathematics. Malta: Curriculum Management and eLearning Department.

$\rightarrow$ Ministry of Education and Employment (2012). A National Curriculum Framework for All. Malta: Salesian Press.

$\rightarrow$ Morgan, D. L. \& Spanish, M. T. (1984). Focus groups: A new tool for qualitative research. Qualitative Sociology, 7(3), 253-270.

$\rightarrow$ OECD (2009). Creating effective teaching and learning environments: First results from TALIS. Paris: OECD.

$\rightarrow$ Patton, M. Q. (2002). Qualitative research and evaluation (3rd ed.). Thousand Oaks, CA: Sage.

$\rightarrow$ Peressini, D., Borko, H., Romagnano, L., Knuth, E. \& Willis, C. (2004). A conceptual framework for learning to teach secondary mathematics: A situative perspective. Educational Studies in Mathematics, 56, 67-96.

$\rightarrow$ Potari, D., Sakonidis, H., Chatzigoula, R. \& Manaridis, A. (2010). Teachers' and researchers' collaboration in analysing mathematics teaching: a context for professional reflection and development. Journal of Mathematics Teacher Education, 13, 473-485.

$\rightarrow$ Putman, R. T. \& Borko, H. (2000). What do new views of knowledge and thinking have to say about research on teacher learning? Educational Researcher, 29(1), 4-15.

$\rightarrow$ Shabani, K. (2012). Teacher's professional development from Vygotskian optique. Advances in Language and Literacy Studies, 3(2), 101-120.

$\rightarrow$ Simon, M. A. \& Tzur, R. (1999). Explicating the teacher's perspective from the researchers' perspectives: Generating accounts of mathematics teachers' practice. Journal for Research in Mathematics Education, 30(3), 252-264.

$\rightarrow$ Slavit, D. \& Nelson, T. H. (2010). Collaborative teacher inquiry as a tool for building theory on the development and use of rich mathematical tasks. Journal of Mathematics Teacher Education, 13(3), 201-221.

$\rightarrow$ Spillane, J. P. (1999). External reform initiatives and teachers' efforts to reconstruct their practice: The mediating role of teachers' zones of enactment. Journal of Curriculum Studies, 31(2), 143-175. 
$\rightarrow$ Stein, M. K., Smith, M. S. \& Silver, E. A. (1999). The development of professional developers: Learning to assist teachers in new settings in new ways. Harvard Educational Review, 69(3), 237-269.

$\rightarrow$ Supovitz, J. A., Mayer, D. P. \& Kahle, J. B. (2000). Promoting inquiry-based instructional practice: The longitudinal impact of professional development in the context of systemic reform. Education Policy, 14(3), 331-356.

$\rightarrow$ Vulliamy, G. \& Webb, R. (1992). The influence of teacher research: Process or product? Educational Review, 44(1), 41-58.

$\rightarrow$ Vygotsky, L. (1978). Mind in society. Cambridge, MA: Harvard University Press.

$\rightarrow$ Watson, C. (2014). Effective professional learning communities? The possibilities for teachers as agents of change in schools. British Educational Research Journal, 40(1), 18-29.

$\rightarrow$ Wenger, E. (1998). Communities of practice: Learning, meaning and identity. Cambridge, MA: Cambridge University Press. 


\section{Biographical notes:}

James Calleja is an assistant lecturer within the Faculty of Education at the University of Malta. He taught mathematics in secondary schools for 23 years and was a head of department for mathematics for six years. James is currently doing his doctoral research with the University of Nottingham (UK) where he is studying teacher learning in enacting inquiry-based pedagogies in the mathematics classroom. His main research interests are the design and implementation of continuing professional development programmes for teachers, mathematics education, inquiry-based learning, and teacher development and learning. James has presented his work, particularly related to the design of professional development materials, in a number of conferences abroad.

Doreen Mizzi is a Head of Department for Chemistry in church schools within the Secretariat for Catholic Education. She also teaches Chemistry in a secondary school. Doreen is a doctoral student at the University of Malta. Her work focuses on finding CPD practices that support science teachers teaching a subject outside their science specialism. Her research interests include science education, curriculum development, professional development and teacher learning.

Ivan Riolo is an assistant lecturer within the Institute for Physical Education and Sport at the University of Malta. He is presently concluding his doctoral research at the School of Sport Exercise and Health Sciences at Loughborough University. His area of research lies within the field of social sciences. His main research interest are value laden physical education, physical education and sport pedagogy, collaborative and cooperative learning. 


\title{
Implementing inquiry science in the early years: \\ teachers' achievements and challenges
}

\author{
Suzanne Gatt \\ University of Malta \\ Claire Buttigieg \\ Directorate of Education Services, Malta \\ Government of Malta
}

\section{Abstract}

Europe considers inquiry-based learning as one of the most effective pedagogies to teach science at primary level. Inquiry is particular as it views learners as actively engaged: emotionally, cognitively and socially as they carry out investigations to answer questions which they set. Primary schools wanting to reform the way that science is taught often need to experience a paradigm shift in their view of how science is taught: from a transmission approach where children sit, hear and learn, to one where children are engaged in asking questions, designing investigations and gathering data to formulate answers. This shift is not easy to achieve as it requires a change in teaching practices as well as in the use of space and resources within the school. This chapter presents two case studies of primary schools committed to inquiry-based learning in science and the challenges and demands that they face in terms of physical and human resources. The case studies presented in this chapter highlight the importance of teacher commitment and capacity as well as the need for physical resources such as scientific equipment or everyday things. Recommendations for schools wanting 
to implement inquiry-based learning, mainly in terms of investment in professional development are proposed.

Keywords:

Inquiry science

primary, challenges

resources 


\section{Introduction}

Young children naturally experiment with their environment (Gopkin, 2010) as they wonder about how the world around them works (Chiarotto, 2011). This natural curiosity needs to be continually fostered as children grow and develop. However, developing this natural curiosity to the structured way of formulating questions in science, is a skill that children need to learn. Through science, children can be encouraged to continue to ask questions, think out possible explanations, conduct investigations, collect data and draw conclusions. With experience in science, children develop their scientific knowledge, skills and attitudes (Worth, 2010).

Inquiry is an emergent pedagogy used in science teaching also in the early years. Inquiry focuses on the questions and ideas that children pose. One approach to introduce inquiry is through stories, where children are encouraged to think and be imaginative (Fisher, 2006), get inspired and to ask questions about phenomena that puzzle them. Stories help children be actively engaged with specific contexts, and through inquiry try to solve problems that really matter to them.

The teacher plays a very important role in inquiry-based learning. Children need a role model to foster a 'culture of inquisitiveness' in the classroom (Chin, 2002). Teachers promote inquiry as they are expert at asking questions, designing investigations, gathering information through observations, reflecting and drawing conclusions from evidence. Teachers thus have to take on new responsibilities: that of acting as an expert model of an inquirer. Teachers need to be good inquirers themselves first before teaching through inquiry. This chapter discusses the challenges faced by three teachers who trialled inquiry activities with children in the early years. It sheds some insights into the difficulties which teachers face and possible ways of supporting teachers to overcome them.

\section{Aim of study}

This chapter tackles the challenges that teachers experience in changing their pedagogy in science to one of inquiry, using storytelling and investigations which enable children to find potential answers to the questions set.

The stories introduced contexts, leading to inquiry-based learning activities. The stories encouraged the children to question, explore and provide explanations for the scientific concepts elaborated in the story. 
The aim of the study was to identify the key challenges that teachers faced; how they reacted when using stories to present the problem; and in implementing inquiry activities which required them to act as role models of inquirers. The research question set thus was: 'What are the main challenges that teachers experience in teaching inquiry in science to early years children when introducing inquiry-based learning through storytelling?'

\section{Theoretical framework}

Innovative pedagogical approaches based on the constructivist approach place children at the centre of the learning process. Children learn by making connections between prior knowledge and present experiences (Blanchett, Powis \& Webb, 2012). Children take centre stage (Bauersfeld, 1995) as active learners. The teacher plays the role of a facilitator for the construction of knowledge, focusing on the learner rather than the content (Gamoran at al., 2000).

Inquiry-based learning is one example of constructivist learning. It is a research-based strategy, where children explore content and question surrounding scientific concepts. They test their ideas through investigations (Ansberry \& Morgan, 2012), gathering evidence, formulating explanations, evaluating hypothesis and communicating explanations produced (The National Research Council, 2000). Inquiry gives children control of their own learning as they ask questions that are meaningful to them. They have the opportunity to experience phenomena directly and to draw their own conclusions from their observations (de Vries at al., 2011).

Inquiry requires creative teaching methods that encourage children to think critically, develop their inquiry skills and carry out investigations to experience their environment in a direct way. Creative approaches may include role-play, stories, cross-curricular teaching and real openended investigation. These approaches stimulate children's interest and enthusiasm (Murphy, Beggs, Russell \& Melton, 2005), promoting a positive attitude towards science and a willingness to continue studying it in the future (Klein, 2006). Through inquiry, children become observant, inquisitive and reflective persons (Edmonds \& Herr, 2003). Through investigation and hands-on activities they also consolidate their learning as they apply the knowledge learned to new situations (Ansberry \& Morgan, 2012). 
Science and literacy can be simultaneously presented in a meaningful way. Texts can promote inquiry learning (Atkinson, Matusevich \& Huber, 2009). Stories can address children's interests and questions whilst also building their vocabulary. Literacy is central to doing science (Yore, 2004). Story books present connections between the classroom and real life situations (NCF, 2012). Science is no longer abstract as children encounter situations from everyday life, not only taking place in a laboratory, classroom or textbooks. Story books are also userfriendly as they use familiar language. When science is presented in everyday language, children are more comfortable to discuss and explore (Akerson, 2001) their scientific ideas, and hence are more likely to learn (Ciechanowski, 2009).

Story books with a scientific theme can be used to teach science concepts through literature or present an inquiry question where children analyse, synthesise and critically evaluate ideas (Chamberlain \& Corby Crane, 2008). Children can inquire through opportunities to predict the outcomes of stories, promoting creativity and thinking skills (Clarke, 2007). Activities can be organised during, before and after shared reading. At the pre-reading stage, children can predict what the story is about and what will happen by looking at the cover page. The teacher can ask questions to stimulate creative thinking. The teacher can invite the children to predict the title and content from the cover pictures (Parkes, 2000). In science lessons, stories can also be used to let the children predict outcomes related to science and share their thoughts on scientific concepts before they try them out (Daehler, Shinohara \& Folsom, 2011). During the reading session, the teacher first reads, as children listen and follow, and enjoy the story. The teacher can encourage the children to join in whenever possible. Children begin to see patterns in the structure of the words and the story (Gilman, 2008). At the post reading stage the teacher presents the challenge (Pianta \& La Paro, 2003) as a follow up to the story.

Inquiry-based learning poses new challenges to teachers as their role changes from that of a transmitter of knowledge to a facilitator of learning. The teacher also needs to act as a role model of an inquirer, supporting children in the process of exploring knowledge and testing their ideas. Instead of providing the children with answers to their questions, the teacher needs to help children to propose investigations which provide observations from which answers can be deduced, 
guiding them and being a model of an inquiring learner (Martin, 2011). The teacher facilitates negotiation of ideas rather than tell, as students reflect on their observations and formulate classroom knowledge (Gatt \& Theuma, 2012).

Children need the teacher's guidance on how to pose questions, especially at primary level and without practice at posing inquiry questions. The teacher, as an inquirer creates appropriate situations that encourage children to ask meaningful questions (Chin, 2002). These questions can be open-ended and problem-solving tasks and serve to stimulate children to wonder and be curious about the world around them, even if the teacher might not always know all the answers. Inquiry does not only pose the challenge to change one's way to organising learning in the classroom, but also to change the role that they take in the classroom.

\section{Methodology}

The research was carried out as a case study involving three teachers trialling out inquiry activities with students in their second year of primary education aged 6-7 years. A qualitative approach was adopted through non-participant observation of the lessons and postactivity interviews with the teachers and the children. The data thus provided information about the implementation of the activities from different perspectives.

\section{Design of the inquiry activities}

The topics were first identified and inquiry activities then developed. The inquiry activities satisfied specific criteria which ensured that they were: authentic and relevant to the children's everyday life and interests; appropriate for children's age; involved investigations related to a question; and allowed stories to be developed.

The topics chosen were: melting ice; materials and porosity; and shadows. The stories introduced the context to the children (Haven, 2007) and presented the inquiry problem. The stories included two main characters: a boy named 'Jim' and a girl named 'Jade'. The stories presented Jim and Jade in situations familiar to the children such as the classroom, their home, school playground and garden. Jim and Jade needed to make the ice melt faster. They also had to decide how to 
make an umbrella, as well as create shadows. The inquiry quests set in the stories were:

$\rightarrow$ How are we going to make an umbrella that keeps us dry?

$\rightarrow$ How are we going to make a big shadow of a dinosaur?

$\rightarrow$ How are we going to melt ice in the fastest way possible?

The stories were kept short and did not exceed ten pages. Attention was given to the number of words per page and the size of the print. Each page had colourful pictures to attract the young readers' attention. The big book used was also interactive as children could touch the pictures, open them to see what was inside or under the flap, move them to put them somewhere else in the story book and feel their texture.

The book was designed to recreate the investigation mentioned in the story. In the story: 'Jim, Jade and the dinosaur', the pictures of the dinosaur shadow, the toy dinosaur and the torch could be removed from the book and used by the children to produce the shadow of the dinosaur. The children thus conducted the experiment through using parts of the storybook itself.

Each activity was based on a similar pedagogical framework. The teacher first read the story using the big book. Each story presented the children with a question and a problem that the main characters had to solve. The teacher then elicited the children's prior knowledge about the topics and encouraged them to think of possible solutions and ways to test them. The teacher at this point used her inquiry skills to help the children develop their own questions and to inquire about them. The children then carried out the investigation in groups. Towards the end of the activity, the children referred back to the book and discussed their answers to the question proposed by Jade and Jim.

\section{Data Collection}

The study was conducted in a private school in Malta. Due to the children's proficiency in English, the stories and lessons were read and delivered in English. Three Year 2 (second year of primary school) classes of six to seven year old children participated. This age was chosen as children are still very inquisitive and not yet influenced into accepted forms of learning by the structure of the educational system (Conrad \& Serlin, 2011). In addition, children are still getting to know their world and asking questions about their surroundings. 
Ethics clearance to conduct the study was obtained from the Faculty Ethics Research Committee. This ensured that all required permissions from the school, consent from the teachers participating and the guardians of the children interviewed were obtained. The school was then visited to make the necessary preparations. The head of school wanted all the year two classes to have the same scientific experience, with each class participating in one of the lessons. Three class teachers and 76 pupils took part. In each case, the class teacher was to deliver the lesson. A two-hour session to present and go over the inquiry activities to the teachers inquiry and the framework of the activities was organised. The teachers then delivered the activities. The teachers were all female graduates but none of them were science specialists. During the delivery of the lesson, they were free to decide on the best approach and classroom routines to choose. They could decide how to read the story, what questions to ask during the story, how to divide the class into groups, the level of support to give etc. What was highly recommended was that they should act as much as possible as inquirers and encourage the children to also be inquirers. Thus it was important that the teachers did not offer solutions but allowed the children to come up with their own suggestions.

\section{The research tools}

The data for the study was collected from four main sources. These included: the notes taken during the observation of the lessons; the worksheets worked out by the children during the activities; the interviews with the three teachers; and the interviews with 18 children following the inquiry lessons.

The observations gathered data about what actually happened during the activities, focusing on: the impact of the story on the children and how much they engaged them, the way that the teacher presented the problem and allowed the children to explore and test their ideas, how much the teacher actually acted as an inquirer herself and how open-ended was the activity. The observations also considered the children's interaction during the activities: with the story and the book, with the inquiry questions set, with their peers as well as the degree to which they were influenced, if at all, by the teacher as a role model.

The teachers' interviews were semi-structured. The teachers were asked to provide their opinion about the story and the use of the big 
book to introduce the inquiry activity. They were also invited to reflect on their role as models of inquirers and to share the main challenges that they experienced in try to inquire with the children rather than direct the children with their inquiry. They were also asked to comment on the impact of their modelling on the children. The children, on the other hand, were asked if they enjoyed the story, what they learned as well as what they liked or disliked about the lesson. The children were also invited to share what they had learned and in what ways the teacher helped them. The children were interviewed in pairs so that they felt more comfortable to talk.

\section{Results}

The data collected was analysed from two main perspectives: the effectiveness of the activities to promote learning science through inquiry, and the challenges experienced by the teachers to implement inquiry-based learning as they act as role models of inquirers.

\section{Effectiveness of the activities}

The effectiveness of each activity was evaluated according to the learning that took place, how much the children enjoyed the activities, and how much the children were involved in the inquiry process.

All the children stated that they had learned some new science. In the activity on melting ice, most children did not know that salt makes ice melt faster. In the activity related to the umbrella as one child said she "... learned that plastic did not tear and I didn't know this" and that "paper tears, plastic does not tear and water goes through cloth." One child, however, stated that she found the lesson easy as she knew the answer right away as "it's obvious plastic [is the right choice for the umbrella] because cloth has little holes and paper is very thin." However, she still liked doing the experiment as she could see that "plastic really works."

Many of the children could explain in their own words what they had learned. Many were also able to give a correct brief description of the scientific process and the results of the experiment. However, some misconceptions could still be identified, mainly about light and shadows. Some children were mixed up when explaining how they created a big shadow. Despite this difficulty, the answers given in the worksheet was correct by all the groups. 
All the children said that they enjoyed the lesson and a large number found the stories and activities to be "fun" because they were active participants. One girl pointed out how "it was fun because you got to draw and colour and do things with water." Another boy enjoyed experimenting with the cups, material and the water, stating that "it was fun doing the activity, putting them [cups] in and checking what will happen." Some children did give suggestions for improving the stories in order to suit more their liking. One girl suggested using a bunny instead of a dinosaur as bunnies are "less scary because they are sweet." The children demonstrated engagement with the story and suggested changes to the book. One child suggested adding another page to the book, ending the story with a picture of the mother character saying "I wasn't scared of the dinosaur." Another child said that she did not want Jade to lose her umbrella and wanted to know what happened to the umbrella. She said that this could have been included in the book and gave examples of what might have happened to it, mentioning examples like, it could have been stolen or the wind blew it away. These comments show that the children did follow and understand the stories and the related science activities.

All the teachers agreed that the children were involved in science inquiry during the activities. However, the teachers focused on different aspects of the inquiry process. One teacher commented on the children being active participants in the lesson, as they "were interested in asking questions, finding out things for themselves and trying out things to see if they can do this and they can do that and they were more absorbed in doing the experiment." The second teacher liked giving the children the chance to experiment themselves and was not about not giving the answer straight away: "science is fun when you let them try out and experiment. If you tell them straight away there is nothing for them to explore." She added that they were all engaged in inquiry as in the shadows experiment they were "try[ing] different positions, move[ing] back and forward." The third teacher also commented on the experimenting aspect, saying that "inquiry helped them (the children) to find out what they did not know." She also added that the children could guess the outcomes of inquiry. When some children "guessed wrongly" they had the chance to test their ideas and change their predictions when the results obtained showed otherwise. 
All the three teachers liked the stories and the resource book. They all agreed that the way in which the stories were presented engaged the children and all of them would use them again in their lessons. The context used was relevant to $6 / 7$ year olds. The illustrations were considered as very good since they were colourful. One teacher, however, stated that she preferred more colour and texture in the illustrations as these attract the children's attention. A feature of the book that two teachers did not like was the way that the book was bound together, stating that it needed to be more, "flexible because it is a bit confusing when turning the pages ...which way it's going."

The children stated that they did not have any difficulty to understand the story and the main concept in the book. One boy said that, "it was easy to understand the story because it was fun and nice." The length of the story also helped them to comprehend it better, "I understood it because it was short" (girl). The children also enjoyed very much the interactive features of the big book: "there were lots of parts you could do, you could listen and you could do things.' One boy also mentioned that he liked the book "because you could stick the umbrella of your choice." The book thus helped the children connect their learning experiences with the story in the book. As one boy stated: "I learned science better because first you could read it and then you could try it (the experiment) out."

\section{The teachers challenges as role models of an inquirer}

The teachers were observed to make an effort to take the role of inquirers. They managed to facilitate the children's learning without intervening to different degrees. They were careful as much as possible not tell the children how they could test their ideas. The teachers tried to use questioning techniques to lead the children to find their own solutions. However, the questions set were at times content laden and indirectly indicated the 'correct answer' or an aspect which the teacher wanted the children to learn.

In one of the lessons, the teacher invited the children to think of reasons and provide ways how they would like to conduct the experiment to test which was the best material to make an umbrella. The teacher provided space so that the children could put forward their ideas, but still at one point tended to direct the children's thinking by indicating indirectly the expected answer: 
$\mathrm{T}$ : What are we going to do with the container and the water?

C: Put the water in the container.

T: What will you find out like that?

Children think and give another suggestion.

C: Water on top of material.

T: That's better.

Here the teacher influenced the children's work and indicated that they were on the expected right track, thus assessing their contributions rather than scaffolding the inquiry process.

In the second case, the teacher only succeeded to take on the role of an inquirer to a degree as the children tried to answer the questions of the story: "What do you think Jim and Jade did wrong? Can you help them make a big shadow of their toy dinosaur?" The teacher created a dialogue with the children, and was careful to refrain from stating her opinion, or to judge the children's answers. However, through her comments about darkness, she still indirectly led the children to the expected answer as the excerpt below shows.

Teacher: How are they going to make a big dinosaur?

Child 1: With light.

Child 2: With a shadow, the further the light the bigger it gets.

Teacher: What do you think they did wrong so?

Child 2: Too much light.

Teacher: So you need darkness?

Whole Class: Yes.

The third teacher encouraged the children to think of ways on how to conduct the experiment and thus answer the question set in the story: "Which is the fastest way to melt ice?" This teacher was observed to let the children discuss the most and to provide most space where they could propose several solutions on how to tackle the problem posed. She encouraged the children to think and come up with ideas on how to melt ice. It was impressive to see that when children were given the opportunity to contribute to the thinking process, they participated very enthusiastically. When the teacher asked the children to think of ways to melt the ice faster, the children put forward numerous options: candle; marshmallow stick; an oven hob; a fire place; hot water; matches; fire from rubbing sticks; and fire from burning books. 
Although the teachers made efforts to help the children become better inquirers, it was evident that the teachers experienced difficulty in acting as inquirers throughout. As an inquirer, the teacher's job goes beyond simply asking questions to try to make sense of the data to answer a scientifically based question. Inquiry-based learning involves negotiating ideas, and the teacher shifts authority from her to the students (ibid.) The teachers still tended to hold on to their own ideas of what is right or wrong and still felt the need to assess the children's ideas by classifying them as right or wrong. This was observed across the three lessons by the three teachers and also acknowledged by the teachers in the interviews. One teacher commented that the children 'answered well', demonstrating that she still felt the need to ensure that the children needed to reach the right answer and that it was important to learn facts rather than inquiry skills.

The teachers were also not very sure of what their role as inquirers was. During the lessons, the teachers were observed to be sometimes hesitant to respond to the children and to help them with their experiment since they wanted them to learn through the inquiry. This created an imbalance between child-initiated activity and teacher's guidance. One teacher said that she felt she couldn't act as a role model when she let the children explore on their own. She believed that she could only help the children when the activity became more guided. In her own words: "I couldn't really act as a role model because the children were let to explore how to make shadows on their own. It was only at the end when it was more guided that I could act as a role model and help them portray a shadow on the screen."

She stated that through guided activity, she was able to ask them the appropriate questions to help them come up with a result. These comments show that the teachers either do not clearly understand what it means to be a good role model for inquiry science or else they did not feel comfortable to act as role models in a non-controlled environment.

One teacher thought that being a role model of an inquirer required that the children engage in discussions with her rather than amongst themselves. This teacher in fact was concerned that she somehow did not manage to show the children the need to debate and discuss ideas as part of the inquiry process. The teacher described the level of inquiry to be ' 50,50 ' as the children did not ask her many questions. She said that the children: "... were more interested in doing hands on, 
than they were more debating, and asking amongst themselves rather than asking me. They just thought about it themselves, the activity did not provide for them to interact with me [the teacher] a lot."

The teacher felt that she was not involved in the inquiry as she had expected and consequently did not feel that she was being a good role model.

Teachers felt uncertain and feared losing control when the children worked in groups. An inquiry base approach requires children to move around, experiment and discuss. From the observations it was evident that although all the teachers said that the children had already worked in groups, they were not fully comfortable with this type of class setting. Two of the teachers chose to keep control by not allowing the children to be fully independent during the experiment. Instead, they dictated step by step what had to be done and did not let any group go faster than the other groups. As a result, some of the aspects of inquiry were lost.

One of the three teachers let each group experiment freely. The children were allowed to move out of their places, go to different areas of the classroom and talk to each other. However the teacher felt uncomfortable as the class environment became rowdy and noisy. She did stop the activity at one point and ordered everyone to sit down and lower their voices in order for the activity to continue. Her comments during the interview about this episode was that she did not like leaving the children to experiment on their own since not all the children had the chance to try "all the different (shadow) positions." When asked how she would have done it differently, she said that: "I would have first let them experiment to try out different things, first let them on their own and them guide them because some were not very sure so that everyone would have achieved the same results."

The teachers struggled most with giving children freedom to inquire on their own. They were still reluctant to shift from one who guides towards scientific content to one who is a role model of an inquirer.

\section{Discussion}

Although inquiry-based learning and teaching is possible in the science classroom, teachers still face challenges with the pedagogical demands that it brings as they get used to the new practice. Traditionally, the teacher is seen as the knowledge giver, the scriptwriter who has full 
authority in the classroom (Yan, 2012). When the teachers traditional role changes, teachers tends to feel uncomfortable since they are out of their element (Scott, 2015). Although there was a positive response to inquiry learning, the educators did struggle at times to act as inquirers in the learning process. What was observed were teachers either controlling the inquiry process to a degree where student input was still controlled. In the most open-ended approach observed, the teacher appeared to relinquished control on lesson development, but on the other hand, still provided guidance support to the children within an informal setting. The teachers adopted different types of communication, reflected forms of dialogic learning to different degrees. Dialogic learning helps teachers find that fine balance between not telling students and the level of guidance that they can provide children with during inquiry teaching (Lehesvuori et al., 2011). Dialogic teaching focuses on the social aspect of inquirybased teaching (Alexander, 2004). Teacher and pupils jointly participate together in the learning process as a group or as a class. Teacher and children listen to each other, share ideas and consider alternative views, without fear of being incorrect. The teacher and children develop their ideas, jointly constructing knowledge; the teacher paying attention to the educational goals (Lehesvuori et al., 2011).

The study highlights the tension that teachers experience between stimulating inquiry by encouraging the children to ask questions, and learning scientific content by making sure that children reach the correct conclusions in their investigations. This highlights the importance of revisiting the main aims of science education at primary level and whether it aims to promote an inquiry mindset or an understanding of science content or a combination of both. This uncertainty in the main aim of doing science is reflected in the teachers' reactions in this study. This tension is not surprising as teachers need to understand the pedagogical purpose of using the inquiry approach apart from making science fun (Walan \& Mc Ewen, 2016). The importance of developing inquiry skills has a degree of importance over the covering of specific content, even if inquiry does contribute to learning with understanding (Harlen, 2014).

The study also showed that inquiry-based teaching needs time and training of teacher in order to behave inquiry-based learning implemented well in the classroom. The teacher needs first to be a learner in the inquiry process, and understand the nature of inquiry 
as part of professional development (Artigue, 2017). Bianchi (2017) presents the Trajectory of Professional Development (TOPD) which highlights how teachers develop though the stages of development through: teacher participation in continuous professional development; to teacher collaboration in planning and teaching; co-creation of science resources as teachers work together; and eventually experienced teachers connecting with less experienced teachers to support them in their professional development. Teachers need to gain confidence in science, in teaching science as well as learn how to work with other fellow teachers to co-create and to network with other primary teachers.

Teachers also need to find time to reflect on their practice in order to improve (Mergler \& Spooner-Lane, 2012). Since inquiry teaching requires the teacher to take on a different role and get accustomed to different practices, time for reflection is vital. Their view on their conception of learning might also need to change and this takes time. Teachers need to be offered the opportunity to share good practices and ideas together in order to help each other improve. This process can be achieved through creating a network between teachers and schools (European Communities, 2007). Being part of a network helps teachers to improve the quality of their teachings and offers them the motivation that they need (Gatt \& Costa, 2009).

\section{Conclusion}

This study has shown that expecting teachers to teach through inquiry presents a hard challenge which needs convincing, understanding, and perseverance by teachers. However, what is crucial is that teachers need to first become inquirers themselves. Investing in the personal growth of teachers first as inquirers thus will predetermine to a great degree how much teachers will manage to implement proper inquiry in early years classes. Teachers are thus the key players implementing European policy, mainly the ROCARD report (European Communities, 2007) which identified the inquiry-based approach as the way forward to improve learning in science across Europe. The experiences of teachers in this case study thus provide some insights on how to support teachers which are relevant at both European and global level. 


\section{References}

$\rightarrow$ Akerson, V. L. (2001). Teaching science when your principal says 'Teach language arts'. Science and Children 38(7), 42-47.

$\rightarrow$ Alexander, R. (2004). Towards dialogic teaching: Rethinking classroom talk. York: Dialogos.

$\rightarrow$ Ansberry, K. \& Morgan, E. (2012). Picture-perfect science lessons: Using children's books to guide inquiry 3-6. Second edition. Arlingon: National Science Teachers Association.

$\rightarrow$ Atkinson, T. S., Matusevich, M. N. \& Huber, L. (2009). Making science trade book choices for elementary classrooms. The Reading Teacher, 62(6), 484-497.

$\rightarrow$ Artigue, M. (2017). The Fibonacci project. Scientific background. The Fibonacci Project, accessed January 19th 2017. http://www.fibonacciproject.eu/

$\rightarrow$ Bauersfeld, H. (1995). The Structuring of the structures: Development and function of mathematizing as a social practice. In L. Steffe \& J. Gale (Eds.), Constructivism in education (pp. 137-158). Hillsdale, NJ: Lawrence Erlbaum Associates.

$\rightarrow$ Bianchi, L. (2017). A trajectory for the development of teacher leadership in science education. Journal of Emergent Science, 12, 72-82.

$\rightarrow$ Blanchett, H., Powis, C. \& Webb, J. (2012). Guide to teaching information literacy: 101 practical tips. London: Facet Publishing.

$\rightarrow$ Chiarotto, L. (2011). Natural curiosity: Building children's understanding of the world through environmental inquiry. The Laboratory School at The Dr. Eric Jackman Institute of Child Study, University of Toronto.

$\rightarrow$ Chamberlain, K., Corby Crane, C. (2008). Reading, writing, and inquiry in the science classroom: Grades 6-12: Strategies to improve content learning. California: Corwin Press.

$\rightarrow$ Chin, C. (2002). Student-generated questions: Encouraging inquisitive minds in learning science. Teaching and Learning, 23 (1), 59-67. 
$\rightarrow$ Ciechanowski, K. M. (2009). 'A squirrel came and pushed Earth': Popular cultural and scientific ways of thinking for ELLs. The Reading Teacher, 62(7), 558-568.

$\rightarrow$ Clarke, J. (2007). Sustaining shared thinking: Supporting thinking skills in young learners. Leicestershire: Featherstone Education Ltd.

$\rightarrow$ Conrad, C. F. \& Serlin, R. (2011). The SAGE handbook for research in education: Pursuing ideas as the keystone of exemplary inquiry (Second edition). Thousand Oaks, CA: Sage.

$\rightarrow$ Daehler, K. R, Shinohara, M. \& Folsom, J. (2011). Making sense of science: Force \& motion for teachers of grades 6-8. San Francisco, CA: WestEd.

$\rightarrow$ de Vries, M. J, van Keulen, H., Peters, S., \& van der Molen, J. (2011). Professional development for primary teachers in science and technology: The Dutch VTBPro Project in an international perspective. International Technology Education Studies, 9, 2011.

$\rightarrow$ Edmonds, A. \& Herr, P. (2003). Inquiry-based learning using everyday objects. Charlottesville: University of Virginia.

$\rightarrow$ European Communities (2007). Science education now: A new pedagogy for the future of Europe, Brussels: Directorate-General for Research Science, Economy and Society, High Level Group on Science Education.

$\rightarrow$ Fisher, R. (2006). Talking to think: Why children need philosophical discussion. In D. Jones \& P. Hodson (Eds.), Unlocking speaking and listening (pp. 94-107). London: David Fulton.

$\rightarrow$ Gamoran, A., Secada, W.G. \& Marrett, C. B (2000). The organizational context of teaching and learning: changing theoretical perspectives. In M.T. Hallinan (Ed.), Handbook of sociology of education (pp. 37-63). New York: Springer.

$\rightarrow$ Gatt, S. \& Costa, M. F. (2009). Networking school teachers to promote better practice in the teaching of science across Europe. European Journal of Education Research, Development and Policy, 44 (4), 493-506.

$\rightarrow$ Gatt, S. \& Theuma, G. (2012). Inquiry-based learning in the early years through storytelling. The Journal of Emergent Science, 4, 19-24.

$\rightarrow$ Gilman, P. (2008). Something from nothing: Scholastic big book teaching guide. Toronto Canada: Scholastic Canada Ltd.

$\rightarrow$ Gopnik, A. (2010). How babies think. Scientific American, 303(1), 76-81.

$\rightarrow$ Harlen, W. (2014). Helping children's development of inquiry skills. Inquiry in Primary Science Education (IPSE), 1, 5-19.

$\rightarrow$ Haven, K. (2007). Story proof: The science behind the startling power of story. Westport CT: Greenwood Publishing Group.

$\rightarrow$ Klein, M. B. (2006). New teaching and teacher issues. New York: Nova Science Publishers. 
$\rightarrow$ Lehesvuori, S., Ratinen, I., Kuhomäki, O., Lappia, J. \& Viiri, J. (2011). Enriching primary student teachers' conceptions about science teaching: Towards dialogic inquiry based teaching. NorDiNa- Nordic Studies in Science Education 7(2), 140-159.

$\rightarrow$ Martin, D. J. (2011). Elementary science methods: A constructivist approach. Wadsworth: Cengage Learning.

$\rightarrow$ Mergler, A. \& Spooner-Lane, R. (2012). What pre-service teachers need to know to be effective at values-based education. Australian Journal of Teacher Education, 37(8), 66-81

$\rightarrow$ Murphy, C., Beggs, J., Russell, H. \& Melton, L. (2005). Primary horizons: Starting out in Science. London: Welcome Trust.

$\rightarrow$ Parkes, B. (2000). Read it again! Portland: Stenhouse Publishers.

$\rightarrow$ Pianta, R. \& La Paro, K. (2003). Improving early school success. Educational Leadership 60(7), 24-29.

$\rightarrow$ Scott, C. L. (2015). The futures of learning 3: What kind of pedagogies for the 21st century? UNESCO: Education Research and Foresight Working Papers. Paris: UNESCO.

$\rightarrow$ Walan, S. \& Mc Ewen, B. (2017). Primary teachers' reflections on inquiry - and context -based science education. Research in Science Education, 47 (2), 407-426.

$\rightarrow$ Yan, S. (2012). Teachers' roles in autonomous learning. Journal of Sociological Research, 3(2), 557-562.

$\rightarrow$ Yore, L.D. (2004). Why do future scientists need to study the language arts? In W. E. Saul (Ed.), Crossing borders in literacy and science instruction: Perspectives on theory and practice (pp. 71-94). Newark, DE: International Reading Association. 


\section{Biographical notes:}

Suzanne Gatt is Associate Professor, Head of Department of Early Childhood and Primary Education at the Faculty of Education, is a teacher trainer and science educator with an interest also in European integration of education and training at pre-school, primary, secondary, vocational and Higher Education. Prof. Gatt has conducted research and published internationally on: children's ideas on plants and animals, constructivism, education reform at European level, career guidance, employment, community involvement, quality assurance, and apprenticeships among other areas. She has coordinated the European Funded FP7 project Pri-Sci-Net which promoted inquiry-based learning in primary science (www.priscinetwork.wordpress.com). She is content co-editor of the Journal of Emergent Science of the Association for Science Education.

Claire Buttigieg graduated as a primary teacher from the Faculty of Education, University of Malta in 2013 and is now working as a primary school teacher. Between 2013 and 2015 she taught at San Gorg Preca Marsa Primary, following which she went to teach for a year to teach in Italy from October 2015-2016. She is this year teaching in St. Thomas More Fgura Primary B. The research discussed in the chapter is based on her dissertation research which was part of her Bachelor of Education (primary education) studies at the University of Malta. Her dissertation focused on inquiry-based learning in the early years introduced through stories. 


\section{Moving to multi-cultural classrooms: lessons from the Celtic Tiger}

Anita Gracie

Stranmillis University College

\section{Abstract}

This chapter explores the fact that strikingly similar economic and socio-political factors attracted significant numbers of asylum seekers and economic migrants to Ireland North and South almost a decade apart and radically altered the ethnic profile of the school population. It outlines the current situation where student teachers in Northern Ireland, who have themselves been educated in relatively homogeneous classrooms, in terms of language, ethnicity and religious identity, are now teaching in multi-ethnic, multi-faith and often multi-lingual classrooms. The chapter makes use of a rights-based framework developed by the author for a study in the Republic of Ireland during what became known as the 'Celtic Tiger Years', a period of strong economic growth, to assess the current provision for newcomer pupils in Northern Ireland. In this chapter the author examines the potential for teacher education in Northern Ireland to bridge the gaps identified between entitlement and provision for the newcomer student by preparing student teachers more fully for the reality of teaching in a truly multi-cultural society. The hope is that when sufficiently prepared, student teachers should embrace the richness of the experience of diversity in the classroom 
and the potential for the creation of a positive, respectful and equitable multi-cultural school community.

\section{Keywords:}

teacher education

Northern Ireland, education rights

Celtic Tiger

diversity

rights-based research

multi-cultural classrooms 


\section{Introduction}

At the heart of what we do at Stranmillis University College is preparing student teachers for the future reality of schools in Northern Ireland. That future reality is that the classrooms in which they spend their teaching career, whether in Northern Ireland, elsewhere in the United Kingdom or almost anywhere in the developed world, will be multicultural. The physical reality of globalisation has already begun to take effect with significant numbers of newcomer children coming to live in countries across Europe either as refugees or asylum-seekers, or with their families who have come in search of work and better opportunities. The term 'newcomer' is used in this study in preference to 'migrant' or 'ethnic minority child' as it is the term used by the Inclusion and Diversity Service Northern Ireland to refer to "a pupil who has enrolled in the school but who does not have satisfactory language skills to participate fully in the school curriculum" (IDS, no date).

Another of our priorities at Stranmillis is to use research to inform practice in all areas of our teacher education and to this end this chapter builds on my own doctoral research (completed in 2011) studying newcomer students in secondary schools in the Republic of Ireland. The current chapter demonstrates that there is sufficient similarity of context and culture to provide a rationale for using the findings of the study to inform practice with regard to multicultural classrooms in the UK and elsewhere.

\section{Context of the Celtic Tiger Study}

The original research on which this chapter is based was instigated during what became known as the 'Celtic Tiger' period (1995-2005) when, after long decades of depression and stagnation, Ireland's economy entered a period of prosperity and growth. Suddenly instead of exporting young people to work in countries all around the globe, Ireland briefly became a destination of choice for job-seekers, economic migrants and asylum-seekers from new member states of the European Union (A10 countries) and from the developing world. As a result Ireland is now more ethnically diverse than ever and it will continue to be so for the foreseeable future (Darmody et al., 2010; Murray \& Urban, 2013). Schools very quickly became multicultural environments and took on the vital role of preparing students, both national and newcomer, for life in the newly-multicultural Ireland (RIA, 2011; NCCA, 2006; Devine, 
2011, Coolahan et al., 2012). This role was not without its difficulties however, as schools are often the arena in which tensions and conflicts between different values, cultures and beliefs are played out in a global society where issues of faith and ethnicity are becoming more pertinent (Lundy, 2005; Cullen, 1996). These tensions had been largely absent from education policy discourses in Ireland due to a highly segregated system of educational provision and the very small size, until recent years, of the non-Christian ethnic minority (Lentin, 2001; Lynch \& Lodge, 2004).

Almost overnight schools which had been relatively mono-cultural for generations suddenly had pupils of differing ethnicities, faithbackgrounds and languages. This study set out to examine how schools were managing this change and how well newcomer students' needs and entitlements were being met by the Irish education system. A human rights-based perspective was used to examine whether the education law, policy and practice in schools at that time was fit for purpose, and international human rights standards were used to benchmark provision for children recently arrived into the school system (this process is more fully described below).

\section{Relevance to Northern Ireland's current context}

The similarities between the Irish context during the 'Celtic Tiger' era and the current situation in Northern Ireland in terms of demographic change could not be more striking. For decades following the post-war decline of heavy industry, Northern Ireland suffered the same economic downturn as other parts of the United Kingdom such as Glasgow and the North of England where ship-building and other manufacturing jobs could no longer be relied upon for employment and young people often emigrated in search of jobs in London or further afield. Added to the poor economic conditions, Northern Ireland's "Troubles" - the oftenviolent conflict between the unionist and nationalist communities

- contributed to many young people over recent decades choosing to study and then to work abroad to escape from the tension and conflict at home (Gudgin, 1999). This decline was only reversed after the ceasefire on behalf of the paramilitary groups (1995) and the 'Good Friday' Power-Sharing agreement (1998) which brought relative peace and the beginning of progress towards prosperity for the province. 
Northern Ireland is now described as "a society emerging from conflict" (Hamber \& Kelly, 2005) and although there are still worrying numbers of young people leaving the province after completing secondary school (Weir, 2014) the population is once again starting to increase. Just like other parts of the UK, economic migrants and refugees are coming to Northern Ireland and finding jobs in both the industrial and service sectors of an economy which, like the population, has returned to modest growth. The proportion of Northern Ireland residents who were born outside the UK and the Republic of Ireland increased from $1.6 \%$ in 2001 to $4.5 \%$ in 2011 and are not an ethnically homogenous group but rather come from a wide variety of different backgrounds (NISRA, 2016). This has resulted in increased numbers of newcomer and ethnic minority children in classrooms and a need for teachers to work within multicultural and often multi-lingual environments. In a report carried out for the children's charity Barnardo's, Kernaghan $(2015$, p.14) states that newcomer pupils now account for $3.2 \%$ of the total school population and $4.3 \%$ of the primary school population. While Polish is the most widely spoken main language among newcomer pupils, it only accounts for $35 \%$ of the languages spoken in Northern Ireland other than English and Irish. The other 65\% is made up of a very wide variety of languages spoken by only small numbers of the school population. This situation is as unfamiliar to many teachers in Northern Ireland today as it was to their colleagues in the Republic of Ireland at the beginning of the Celtic Tiger period and we hope to use some of the examples of best practice observed in our original study to instruct student teachers embarking on a future career within a multi-cultural reality. The guidelines and recommendations for teachers which are laid out below can easily be adapted by other countries which are moving from mono to multi-cultural classrooms as is the case in so many countries in Western Europe in the 21st century.

Just as in the Irish Republic, the migrant population has not been evenly spread throughout Northern Ireland with the vast majority of newcomers living in or on the outskirts of the cities of Dublin and Belfast where rental properties are available and more affordable, and employment opportunities more plentiful. Clusters of migrant families can also be found around the towns of Craigavon and Dungannon where local factories provide employment. Schools in these areas can have quite high concentrations of newcomer pupils including one school in 
Belfast whose current school population is over $60 \%$ newcomer and where more than 15 languages are spoken as a main language by the pupils. Some, mostly rural primary schools both in the Republic and in Northern Ireland have been left largely untouched by the changes in the population or may have only one or two ethnic minority pupils but that is not to say that teachers in those schools do not need to prepare their pupils for a multi-cultural future. Globalisation has come to almost every corner of the European continent and even when it is not (yet) reflected in the ethnic make-up of their local community, primary school children are already inhabitants of the global village by the time they start school due to their use of and exposure to international digital media (Holloway et al., 2013).

Another similarity between the two jurisdictions on the island of Ireland is that the vast majority of schools are religiously segregated and reflect the ethos of one or other of the main Christian denominations. In the Republic of Ireland at the time of the original research, $98 \%$ of schools were under the trusteeship of the Catholic Church. In Northern Ireland, the largest grouping of schools is within the Controlled Schools sector which mainly serves the Protestant population but is open to pupils of any faith background, followed by the Maintained Schools which mainly serve the Catholic population and which have a strongly Catholic ethos: "Based on a partnership between the home, school and parish community and bearing in mind our obligation for the global common good of humanity, Catholic schools deliver high quality education in an environment which encourages children and young people not just to learn but to embark on a journey and a way of life in which Catholic belief is put into practice" (CCMS, 2016, p.4).

While pupils of all religions and none are accepted into schools of either sector, Integrated Schools, which are deliberately multidenominational, are only available in certain areas and currently cater for just under $7 \%$ of the Northern Ireland school population. Integrated schools, while not under the trusteeship of any particular church are "essentially Christian in character" (Macaulay, 2009, p.9).

\section{Methodology - A human rights approach}

A human-rights based approach was chosen for this study originally for a number of reasons. Firstly, the subjects of the research (newcomer students and their parents) were rights holders under the various 
international human rights standards, but also in belonging to certain categories of social groupings they were entitled to additional protection and provision by specific rights conventions and declarations. Namely, they are predominantly children so they are rights-holders under the UN Convention on the Rights of the Child (CRC hereafter), they form part of an ethnic minority within the Irish or Northern Irish population so they are covered by Convention on the Elimination of Racial Discrimination (CERD hereafter) and many are members of a religious minority in their adopted state whose rights are protected by the Declaration on the Elimination of All Forms of Intolerance and of Discrimination Based on Religion or Belief. A human rights approach also seeks to improve the life of, or eliminate inequality for the subjects of the research (Lundy \& McEvoy, 2012) and it is clear that the experience of newcomer students in schools is impacted directly and daily by whether and how well their rights to equality of education, to respect for their religion and culture and to protection from racial bullying and harassment are respected.

International human rights standards were used as a benchmark for the provision for the educational rights of the newcomer child by schools which are the agents of the state in their duty towards these children under international law. They are useful in that they are global standards to which the vast majority of countries of the world have signed up, and they have reporting mechanisms whereby states can be called to account if they fail to live up to the standards of provision expected (Freeman, 2010). Secondly, the very fact of recognising newcomer children as rights holders and therefore entitled to provision confers a dignity which benevolent or charitable provision does not. It also makes them autonomous agents in the vindication of their rights rather than passive beneficiaries of state obligations (Lundy, 2007; Donnelly, 2003). It is an approach and a language which should be used more often in policy dialogue especially around migrants and refugees to counter negative stereotyping which is so prevalent in print and digital media. Respect for human rights confers dignity not only on the rights holder but also on society as a whole by recognising the inherent value of each individual (Hale, 2009).

To this end a framework was designed which served to condense and clarify the primary provisions of the international human rights standards against which the experiences of the newcomer students could be assessed. The headings from the human rights framework 
were then used as the basis for more specific research questions which the study would seek to examine from the perspective of the newcomer students and their teachers who took part. These included whether newcomer students enjoyed equality of respect for their religious and cultural background in school, whether their linguistic rights to instruction in English and their heritage language were being provided for and, finally, whether they were sufficiently protected from racial prejudice and bullying.

\section{Data collection within the human rights approach}

The Celtic Tiger study sought the views of newly arrived international students in keeping with a child-centred approach, as advocated by Lundy and McEvoy (2012) among others, and the data was further enriched by individual and focus-group interviews with students, teachers and school principals from three case-study schools. These schools were chosen as, although not geographically representative of the whole country, they had varying proportions of newcomer students enrolled and also represented different school types within the nonfee-paying sector of second level schools. A profile of each of the case study schools can be found in Table 1 below:

Table 1: Profile of the case study school

\begin{tabular}{l|l|l|l|l|l}
\multicolumn{1}{c|}{ SCHOOL NAME } & \multicolumn{1}{|c|}{ SCHOOL TYPE \& LOCATION } & GENDER & TOTAL & NC & \% \\
\hline $\begin{array}{l}\text { Seaview } \\
\text { Community } \\
\text { School }\end{array}$ & $\begin{array}{l}\text { Community School } \\
\text { Suburban } \\
\text { Outskirts of Dublin }\end{array}$ & Mixed & 1,200 & 30 & 2.5 \\
\hline $\begin{array}{l}\text { St. Mary's } \\
\text { Secondary } \\
\text { School }\end{array}$ & $\begin{array}{l}\text { Catholic Secondary } \\
\text { SchoolTown Centre } \\
\text { Mid-sized Commuter Town }\end{array}$ & Girls & 550 & 29 & $5.4 \%$ \\
\hline $\begin{array}{l}\text { Parnell Secondary } \\
\text { School }\end{array}$ & $\begin{array}{l}\text { Catholic Secondary School } \\
\text { (Economically Deprived) } \\
\text { City Centre }\end{array}$ & Boys & 360 & 198 & $55 \%$
\end{tabular}

In order to provide sufficiently rich data, several visits were made to the case study schools and notes made on the atmosphere and ambience of the school, their school policies were examined for ethos and emphasis and audited against human rights standards and this was added to the data from the questionnaire and interviews. In total 100 newcomer students in three case study schools filled in a questionnaire 
which had been designed in consultation with a pilot group of newcomer students to ensure the questions and language used were accessible and relevant to their peers. At a later stage, individual semi-structured interviews were carried out with nine newcomer students and four teachers and then with a focus-group of four teachers. Finally, this research was in itself in keeping with human-rights best-practice as it consulted those directly affected by the policy implications it was trying to assess; thereby acknowledging their status as stakeholders in their own educational provision. Rights-based research "gives children a voice in issues which concern them" (CRC, Art.12).

\section{Relevant findings for teacher education}

In the original study, the findings were presented under three broad headings of rights to, in and through education although the emphasis in this chapter will be on those rights which pertain most particularly to teacher education and practice, namely rights in education and this is where significant similarity between the two jurisdictions can be seen. These rights can be further categorised as linguistic rights, religious and cultural rights and freedom from racial harassment and bullying and is the area where good, informed teacher practice can have significant positive impact.

\section{Linguistic rights}

The main and most immediate difficulty for newcomer students arriving in Ireland or the UK is not having the English language skills necessary to access the curriculum. This may be exacerbated in the case of refugee or asylum-seeking children by little or interrupted previous schooling in their country of origin followed in many cases by weeks, months or years of migration before they reached these shores. The Celtic Tiger study found that the older the child is when entering the school system, the harder it is for them to access the curriculum. In the Foundation Stage in Northern Ireland a 'play-based curriculum' has been introduced where much of the children's learning comes from activities and experiential learning and language and socialisation are being learned through play by all the children at roughly the same time. Obviously older children have to cope with more advanced vocabulary in the classroom and their peers may have had several years more schooling than they have. 
Another big challenge as regards language with newcomer children highlighted in the original study and which remains a concern for teachers in Northern Ireland, is that language difficulties may mask either special educational needs or, in contrast, very high academic ability in newcomer pupils who can get frustrated if work is either too easy or too difficult for them. Newcomer students in many countries often find themselves placed in lower-ability classes based on their level of English rather than their ability in that subject. There they share a class with the weakest and often least-motivated students. This may be in sharp contrast with the highly motivated newcomer who often has to struggle to be moved into a higher stream as his/her language skills improve. In the primary classroom, different abilities are managed by differentiation but catering for so many levels within the one classroom is hugely demanding for teachers who report a lack of age-appropriate materials for older newcomer pupils in Key Stage 2 which adds to pupils' frustration and may lead to bad behaviour as pupils 'act out' their frustration (Kernaghan, 2015, p.8).

In both jurisdictions the main focus of support for newcomer pupils was on the development of English language skills rather than helping children to continue learning their own native language. This is despite the fact that international human rights conventions ask states to provide for the teaching of both the host language and the heritage language of the newcomer child (CRC, Art. $29 \& 30, C D E$, Art. 3 \& 5, DRNEL, Art.4(3)). International studies have for many decades acknowledged the importance of a child's first language for the learning of second and subsequent languages (Cummins, 1986 and 2001; Ruiz, 1984), and McDaid (2011) points out the personal and cultural benefits for the student whose heritage language is acknowledged and respected by the school. Very few bilingual resources are available in primary schools in Northern Ireland and this reflects a prevailing view that, as a teacher in the original study pointed out, "language is the key to integration. Get the language and then they will integrate and make friends." There are concerns however, that this attitude reflects UK government policy around security and integration of their growing migrant population in the same way as the requirement for schools in England (though not yet in Northern Ireland) to teach 'British Values' in schools and for adults to be required to take English language lessons if 
they want to remain in the UK (Tom Peck, 2017), rather than 'the best interests of the child' (CRC, Art.3).

\section{Respect for religious and cultural heritage}

The RE Curriculum in the Republic of Ireland was being drawn up at the same time as the country was becoming multi-cultural and therefore reflects principles which would later be incorporated into the government's Guidelines for Inter-Cultural Education (2006): "Religious education should ensure that students are exposed to a broad range of religious traditions and to the non-religious interpretation of life. It has a particular role to play in the curriculum in the promotion of tolerance and mutual understanding. It seeks to develop in students the skills needed to engage in meaningful dialogue with those of other or of no religious traditions" (DES, 2003, p. 3).

In the Celtic Tiger study we found that having students in the class from other faiths really helped make RE lessons more interesting and enjoyable for the Irish students and many were stimulated to learn more about their own faith so that they could answer the challenges posed by some of their well-informed Muslim classmates. In Northern Ireland the RE Core Syllabus was drawn up by the four main Christian denominations in Northern Ireland and consists of mainly Bible-based teaching about the Christian faith. While teachers are encouraged to "go beyond the Core Syllabus" (DENI, 2007) and many do teach about other religions, others lack the confidence or knowledge of how to teach these effectively (Richardson, 2014). The legislation in each jurisdiction complies with international human rights standards by offering parents the right to withdraw their children from religious education but many studies (Mawhinney et al., 2010) have concluded that this option makes onerous demands on schools to supervise and provide alternative teaching for children who are withdrawn from class during RE and it also isolates the child from his or her classmates for a period and may contribute to what Devine (2006) has described as 'othering' or accentuating the child's 'difference' from their peers.

The Celtic Tiger study also showed that although school policies and government guidelines followed international human rights requirements for states 'to encourage knowledge of the history, traditions, language and culture of the minorities existing within their territory' (UN, 1992, Art.4), the experience of newcomers in the 
classroom was quite different. The majority of the students when questioned about whether they had ever learned about their home country in class, answered negatively and a few commented on the disparity between how much they had to learn about Irish culture and how little attention was given to other cultures: "I am not happy about that because I always feel left out. All I hear about is Irish, Irish, Irish country." What annoyed newcomer students most however, was when an inaccurate or unduly negative portrayal of their country was taught in class often focusing on poverty or social unrest and ignoring the positive aspects of that society or country. To counter this, schools often hold special international days or celebrations and while such events are an opportunity to showcase the music, dress, dances, food and culture of other cultures, Devine $(2011$, p. 79$)$ points out that they can also have the unintended consequence of further marginalising minority students by "highlighting the difference and 'otherness' of minority students, especially when the majority culture is not similarly put on display."

\section{Protection from bullying and racial harassment}

The clustering of newcomer pupils in schools located in areas of economic disadvantage was also common to the two jurisdictions especially in the cities of Dublin and Belfast where schools were already coping with proportionally more students with socio-economic as well as educational and behavioural needs. One downside of this was that it was in the more deprived areas that newcomer families faced the most hostility and racism (Amnesty, 2001). It was in the case study school located in the centre of Dublin, a school which was designated 'disadvantaged', we heard most reports of bullying and racial harassment of newcomer students in the original study. Schools have a duty to protect students from bullying and racial abuse under Article 19 (freedom from abuse) and Article 2 (freedom from discrimination) of the CRC and under CERD which defends, "the right to security of person and protection by the State against violence or bodily harm" (Article 5(b)). The study also suggested that schools which are not afraid to address racism directly and to challenge explicitly the idea that it is acceptable to be-little or exclude someone because of their race may be more successful in combating racist bullying (Kilkelly, 2007; Fanning et al., 2011; Devine \& Kelly, 2006). Primary schools in Northern 
Ireland are not immune from incidents of bullying which can range from violence to racist name-calling and exclusion (Biggart, O'Hare and Connolly, 2013) and racist attitudes have been observed in children in Northern Ireland as young as six years of age (Connolly, Kelly and Smith, 2009).

\section{Rights through education}

In a later section of the Celtic Tiger study, we looked at whether is the education system was supplying the rights of a newcomer child to "benefit equally from education" (UDHR, ICESCR, CRC, CDE). The original study was with newcomer students in secondary schools and we looked at whether their time in education had given them what they needed in order to continue on to higher education. While were not able to assess their individual academic achievement, statistics have consistently shown that "Equality of presence in the classroom (was) not securing equality of participation or achievement" (Lyons, 2010, p.289) and numbers of ethnic minority students in university and third-level education remain below of majority-ethnic students in the UK and Ireland. This may have many factors but one of these is undoubtedly the fact that the academic ability of newcomer and ethnic minority children is often taken to be the same as their ability to speak and write the English language (Gilborn, D., 2010). The earlier that academic selection takes place in the educational system, or the closer to selection the child has arrived in the school, the more disadvantaged by this judgement they will be. In Northern Ireland academic selection takes place in the autumn term of the final year of primary school to decide which children will get a place in a grammar school for their secondary education. If a newcomer child is not judged to have the necessary language skill to succeed in that exam they will not be entered for it and are unlikely to enter grammar school education in the future, even if their language skills improve (Equality Commission, 2014, p.15).

\section{Recommendations for teacher education for multicultural classrooms}

This chapter concludes that a framework based on international human rights standards would be a useful benchmarking tool to assess education policy and practice in any country which has signed 
up to those conventions or declarations (almost every country in the world, in most cases). The following are 10 recommendations based on international human rights standards and drawn from the original study of newcomer students coming into the Irish education system during the Celtic Tiger years which can be used to prepare student teachers for the future reality of teaching in multicultural classrooms:

1. Initial teacher education should incorporate compulsory training in English as an Additional Language (EAL) for all students and not just for those hoping to work in language support so that pupils can be taught alongside their peers in the classroom and not have to be withdrawn for special help with the English language. Many of the techniques used by EAL teachers can also be helpful for nativeborn pupils with weaker language and literacy or communication skills and should be learned by teachers of any subject during their initial teacher education.

2. More use should be made of heritage languages in the classroom and ITE courses should allow language students to maintain their fluency in any languages they may have learned at school, or to take up a new language, by offering languages classes alongside their education studies.

3. More bilingual and multilingual resources should be provided in schools and teachers should be educated about the many educational benefits as well as the human rights duties of developing both the host and the heritage languages of their newcomer pupils.

4. The value of working with newcomer parents as classroom assistants cannot be overstated. They can help not only with minority languages, but may also provide a bridge between the two cultures and be a resource to many teachers in the school when teaching about the newcomer students' heritage country, religion and culture. Student teachers should be taught about the many benefits of working with ethnic minority adults in the classroom. One of these is the huge benefit for ethnic minority children of seeing members of the teaching staff from their own community as role-models in education.

5. Initial Teacher Education should include learning more flexible methods of assessing pupils' academic levels and learning difficulties which are not based solely on their language ability. 
Also, selection for grammar schools should be more flexible and use multiple methods to assess a newcomer pupil's future potential rather than just one single written exam result.

6. Schools should be a reflection of the whole community and not just the dominant culture and student teachers must be taught to 'look with new eyes' at their classroom to ensure it is as inclusive and welcoming as possible for pupils of any country, religion or ethnicity. Displays, resources, language and classroom routines should all be benchmarked against human rights best-practice to ensure parity of esteem between all cultures.

7. Religious Education should be taught in an open, inclusive and non-confessional manner and include teaching about all faiths and belief systems. This is the approach to RE taught in Stranmillis to all primary teachers and Richardson (2013) suggests that if this approach was fully explained to parents, there would be no need for any child to 'opt-out' of religion classes which would be all the richer for their presence and their contribution.

8. Students from all faith backgrounds should have the opportunity to learn about, to celebrate and to practise their religion within the school. Whether that takes the form of a whole-school assembly or special classroom event or lesson to mark the festival of another religion, it is important that children of minority faiths should feel that their tradition is valued by the school and not just the celebrations of the majority culture which are now deeply embedded in school calendar of events. Many primary schools are already using events such as Chinese New Year to teach about the culture, beliefs and traditions of China and children's experience and world knowledge is being enriched in a very enjoyable way. Initial Teacher Education courses should include compulsory modules examining the faiths and cultures of all the ethnic minorities within the community in which the teacher will be teaching.

9. Student teachers should be taught to recognise the particular facets of racism and racist bullying and be trained in methods of prevention. While schools are often reluctant to use such explicit terms in their school policy documents, they should clearly define racism and racist name-calling as examples of bullying and make clear to parents and children, both native and newcomer that they are not tolerated in the school. Student teachers need to learn 
to address issues of identity, culture, racism and conflict in safe, open and inclusive ways so that children will not see these issues as somehow 'taboo' and something to be 'swept under the carpet'.

10. Finally, learning to teach about human rights should be taught to all student teachers that they are aware of concepts such as equality and entitlement and are empowered to bring these concepts into their classrooms and to teach them to children from their very earliest years. Newcomer children cannot be empowered to seek fulfillment of their rights unless they are aware that they have them and education is an important vehicle for that empowerment. Human rights education prepares all children "for responsible life in a free society, in the spirit of understanding, peace, tolerance, equality of sexes, and friendship among all peoples" (CRC Art.29).

\section{Conclusion}

Initial teacher education should not concentrate on newcomers in terms of deficit - focusing on their needs and on the potential difficulties they may present in the classroom, but instead focus on assessing their potential and working out how best to help them to achieve. Newcomer students bring great richness into school life in so many ways - they can inspire their classmates, enrich and increase knowledge of the world outside Northern Ireland and raise aspirations, especially in deprived areas. Many of the measures put in place in schools which are designed to help newcomers can have huge benefits for the rest of the school population. Finally, students should be aware that under international human rights conventions schools are the instruments of the state's duties to provide for the education rights of newcomer pupils and it is part of a teacher's job to ensure a level playing field is created so that all may flourish equally throughout the education system. 


\section{References}

$\rightarrow$ Batelaan, P. \& Coomans, F. (1999). The intercultural basis for intercultural education including anti-racist and human rights education. 2 nd edn. International Association for Intercultural Education in co-operation with UNESCO: International Bureau of Education and the Council.

$\rightarrow$ BBC History Website (2017). The Good Friday agreement. Available online at: http://www.bbc.co.uk/history/events/good_friday_agreement (last accessed 11/1/17).

$\rightarrow$ Biggart, A., O'Hare, L. \& Connolly, P. (2013). A need to belong?: The prevalence of experiences of belonging and exclusion in school among minority ethnic children living in the "White Hinterlands". Irish Educational Studies, 32 (2), 179-195.

$\rightarrow$ Connolly, P. (1998). Gender identities and young children: Social relations in a multi-ethnic inner city primary school. UK: Routledge.

$\rightarrow$ Connolly, P. \& Keenan, M. (2002). Racist harassment in the white hinterlands: Minority ethnic children and parents experiences of schooling in Northern Ireland. British Journal of Sociology of Education, 23(3), 341-355.

$\rightarrow$ Connolly, P., Kelly, B. \& Smith, A. (2009) Ethnic habitus and young children: A case study of Northern Ireland. European Early Childhood Education Research Journal, 17(2), 217-232.

$\rightarrow$ Coolahan, J., Hussey, C. \& Kilfeather, F. (2012). Report of the forum on patronage and pluralism in the primary sector. Dublin: Authors

$\rightarrow$ Cullen, H. (1996). From migrants to citizens? European Community policy on intercultural education. International and Comparative Law Quarterly 45 (1), 109-129.

$\rightarrow$ Cummins, J. (1991). Interdependence of first and second-language proficiency in bilingual children. In E. Bialystok (Ed.), Language Processing in Bilingual Children (pp. 70-89). Cambridge: Cambridge University Press. 
$\rightarrow$ Cummins, J. (2001). Empowering minority students: A framework for intervention. Harvard Educational Review, 71(4), 649-655.

$\rightarrow$ Darmody, M., Tyrrell, N. \& Song S. (Eds.) (2011). The changing faces of Ireland. Rotterdam: Sense Publishers.

$\rightarrow$ DES (2003). Leaving Certificate Religious Education syllabus. Dublin: Government Publications.

$\rightarrow$ Devine, D. (2011). Immigration and schooling in Ireland: Making a Difference? Manchester: Manchester University Press.

$\rightarrow$ Devine, D. \& Kelly, M. (2006). I just don't want to get picked on by anybody: Dynamics of inclusion and exclusion in a newly multi-ethnic Irish primary school. Children and Society, 20(2), 128-139.

$\rightarrow$ Equality Commission of Northern Ireland (2014). Racial equality policy: Priorities and recommendations, Belfast: ECNI.

$\rightarrow$ Fanning, B., Veale, A. \& O'Connor, D. (2001). Beyond the pale: Asylum-seeking children and social exclusion in Ireland. Dublin: Irish Refugee Council and Combat Poverty Agency.

$\rightarrow$ Freeman, M. (2010). The human rights of children. In C. O'Cinnéide (Ed.), Current Legal Problems (pp. 1-44). Oxford: Oxford University Press.

$\rightarrow$ Gilborn, D. (2010). Reform, racism and the centrality of whiteness: Assessment, ability and the 'new eugenics'. Irish Educational Studies, 29(3), 231-252.

$\rightarrow$ Gudgin, G. (1999). The Northern Ireland labour market. London: The British Academy

$\rightarrow$ Hale, B. (2009). Dignity. Journal of Social Welfare and Family Law, 31(2), $101-$ 108.

$\rightarrow$ Hamber, B. \& Kelly, G. (2005). A place for reconciliation? Conflict and locality in Northern Ireland (Report 18). Belfast: Democratic Dialogue.

$\rightarrow$ Holloway, D., Green, L. \& Livingstone, S. (2013). Zero to eight: Young children and their internet use. LSE, London: EU Kids Online.

$\rightarrow$ Inclusion and Diversity Service (2016). Website: http://www.education-support. org.uk/teachers/ids/ (Last accessed 11/01/2017).

$\rightarrow$ Kernaghan, D. (2015). Feels like home: Exploring the experiences of newcomer students in primary schools in Northern Ireland. Belfast: Barnardo's N.I.

$\rightarrow$ Kilkelly, U. (2007). Barriers to the realisation of children's rights in Ireland. Cork: Office of the Ombudsman for Children and UCC.

$\rightarrow$ Lentin, R. (2001). Responding to the racialisation of Irishness: Disavowed multiculturalism and its discontents. Sociological Research Online, 5 (4). 
$\rightarrow$ Lodge, A. \& Lynch, K. (2001). The diversity deficit: Difficulties in the recognition of difference in Irish schools. Paper presented to the American Education Annual Conference. Seattle, WA: 10-14 April.

$\rightarrow$ Lodge, A. \& Lynch, K. (Eds.) (2004). Diversity at school. Institute of Public Administration, Dublin: The Equality Authority.

$\rightarrow$ Lundy, L. (2005). Family values in the classroom? Reconciling parental wishes and children's rights in state schools. International Journal of Law, Policy and the Family, 19, 346-372.

$\rightarrow$ Lundy, L. \& McEvoy, L. (2012). Childhood, the United Nations Convention on the Rights of the Child and research: What constitutes a 'rights-based' approach? In M. Freeman (Ed.) Law and Childhood Studies. Volume 14 (pp. 75-91). Oxford: Oxford University Press

$\rightarrow$ Lyons, Z. (2010). Articulating a deficit perspective: A survey of the attitudes of post-primary English language support teachers and coordinators. Irish Educational Studies, 29(3), 289-303.

$\rightarrow$ McDaid, R. (2011). GLOS, VOCE, VOICE: Minority language children reflect on the recognition of their first languages in Irish primary schools. In N. Tyrrell, M. Darmody and S. Song (Eds.), The changing faces of Ireland (pp. 17-34). Rotterdam: Sense Publications.

$\rightarrow$ Macaulay, T. (2009). Churches and christian ethos in integrated schools. Belfast: NICIE

$\rightarrow$ Murray, C. \& Urban M. (2012). Diversity and equality in early childhood: An Irish perspective. Dublin: Gill \& Macmillan.

$\rightarrow$ National Council for Curriculum and Assessment (NCCA) (2006). Guidelines on intercultural education for post-primary schools. Dublin: NCCA.

$\rightarrow$ Northern Ireland Statistics and Research Agency (NISRA) (2016). Migration statistics Available online at: http://www.nisra.gov.uk/demography/default.asp17. html (last accessed 12/1/17).

$\rightarrow$ Osler, A. (2009). Testing citizenship and allegiance: Policy, politics and the education of adult migrants in the UK. Education, Citizenship and Social Justice, 4(1), 63-79.

$\rightarrow$ Peck, T. (05/01/17). Immigrants should be made to learn English on arrival to help integration in UK, parliamentary report finds. The Independent online, http:// www.independent.co.uk/news/uk/politics/chuka-umunna-immigrants-shouldbe-made-to-learn-english-on-arrival-in-uk-classes-esol-social-a7509666. html (Last accessed 18/01/17).

$\rightarrow$ Reception and Integration Agency (2011). Annual report. Dublin: Author. 
$\rightarrow$ Richardson, N. (2013). Sharing education: A brief introduction to the possibility of an inclusive approach to Religious Education in Northern Ireland. ( $3^{\text {rd }}$ Edition). Belfast: Stranmillis University College.

$\rightarrow$ Ruiz, R. (1984). Orientations in language planning. The Journal for the National Association for Bilingual Education, 8(2), 15-34.

$\rightarrow$ Weir, C. (2014). Population time bomb: Migration and ageing society to hamper economy. The Belfast Telegraph, Available online at http://www.belfasttelegraph. co.uk/news/northern-ireland/population-time-bomb-migration-and-agingsociety-to-hamper-economy-30388371.html (last accessed 12/1/17) 


\section{Biographical note:}

Having worked as a teacher and completed a doctoral thesis on the human rights of newcomer pupils, Anita is now a Senior Lecturer at Stranmillis University College where she teaches history and religion to undergraduate B.Ed. student teachers. She also contributes to a Continuing Professional Development courses in RE and supervises dissertations in her own subject areas. Her research interests include the pedagogy of Religion in the Primary School and, in particular the development of spirituality and how this is impacted by a student teacher's own religious identity, the challenges and issues surrounding the teaching of History in Northern Ireland and the teaching of contentious issues (religious difference, ethnic diversity, cultural understanding, for example) in the Primary School Classroom. 



\title{
The PACK checklist: A proposed pedagogical tool for multicultural foreign language learning settings
}

\author{
George Cremona
}

University of Malta

\section{Abstract}

This chapter initially presents the findings of a recent study (Cremona, 2015) collecting the views and responses of 11-year old Maltese students of German as a Foreign Language [GFL]. Reacting about these findings, the author takes the initial letter of the four most recurring points (i.e. Perspectives, Attitudes, Changes and Knowledge) and formed the acronym PACK. The chapter focuses on the PACK checklist aimed as a tool through which curricular change may be effected and/or facilitated in similar learning contexts which still need to acknowledge and discuss critically these predominant multicultural trends. The last part of the chapter discusses further possible ways and measures through which curricular change - encompassing diversities and multiculturalism - may be gradually initiated and facilitated. This last part looks at four levels, namely the classroom level, the school (wide) level, the policy-making level and the teacher education level in Malta. The chapter presents also a set of practical initiatives and examples of curricular change which might result as an effect of the use of the PACK checklist and the questions it includes.

\section{Keywords: \\ teacher education \\ foreign language \\ learning \\ diversities and multiculturalism \\ Malta}




\section{Introduction}

Recently published official statistics and daily media reports clearly suggest that multicultural learning backgrounds are constantly being experienced by teachers and students both in Malta and around the globe (Caruana et al., 2013). Seen in this light, this chapter intends to investigate how students react to similar multicultural realities. Initially, I will present the findings of a recent study (Cremona, 2015) collecting the views and responses of 11-year old Maltese students of German as a Foreign Language [GFL]. The results I will present in this chapter will all indicate that the 11-year old Maltese respondents, when answering about diverse multicultural situations, tend to adopt:

1. essentialist and limited perspectives,

2. judgmental attitudes,

3. very conservative non changing views,

4. reduced and non-contextualised knowledge.

Reacting about these findings, I took the initial letter of the four most recurring points (i.e. Perspectives, Attitudes, Changes and Knowledge) and formed the acronym PACK. In this chapter I will present the PACK checklist aimed as a tool through which curricular change may be effected and/or facilitated in similar learning contexts which still need to acknowledge and discuss critically these predominant multicultural trends.

The last part of the chapter will discuss further possible ways and measures through which curricular change - encompassing diversities and multiculturalism - may be gradually initiated and facilitated. This last part will focus on four levels, namely the classroom level, the school (wide) level, the policy-making level and the teacher education level in Malta. I intend to present a set of practical initiatives and examples of curricular change which might result as an effect of the use of the PACK checklist and the questions it includes.

\section{Representations of culture in foreign} language [FL] learning contexts

Foreign language classrooms are sites where representations of culture are continuously used and adopted in practice. Students are presented with representations of culture and identity. These representations are imported in class through texts produced, regulated and selected 
either by the teacher her/himself or by national selecting boards responsible for the design of subject syllabuses. Students end up being the consumers at the receiving end.

Despite the fact that 'the extensive work on intercultural/global competence and the development of the intercultural speaker concept over the last two decades has irrefutably contributed much to the methods and aims of foreign language education' (Wilkinson, 2012, pp. 304-305), a question might still arise problematising the ability FL learners have when looking at culture through a reflective critical lens.

Unfortunately, empirical studies investigating the effects of such critical (inter)cultural measures on FL students are very sparse. In fact, till now very few studies have been conducted about the effects of the presentation of intercultural content and on FL learner criticality. Similarly, studies investigating the ability of children and adolescents to perceive culture through a critical lens are also very uncommon. Actually, a one-off study investigating the topic indicates that when a group of eleven-year-old young learners were presented with intercultural content, they did not manage to sustain it alone over time (Zhu, Jiang \& Watson, 2011).

Notwithstanding these results, findings by Barrett (2005) do indicate that already from a very early age, six-year-old children can identify national stereotypes of other national groups. Reporting further on these findings Zhu, Jiang and Watson (2011) elaborate that an early study by Lambert and Klineberg (1967, cited in Barrett, 2005, p. 265) found age differences in the primary sources: while 6-year-olds reportedly rely primarily on their parents, direct contact with foreigners, television and movies, 10 and 14 year olds resort to input from television, movies, books, school, course work, textbooks and magazines (ibid., p. 145).

Maijala (2008), who has researched extensively German as a Foreign Language [GFL] textbooks, identifies trends similar to those observed in the case of textbooks designed to teach other Foreign Languages'1. In one study the author highlights that the cultural representation of Germany is very often reduced to punctuality, feasts, drunk Bavarians and strict environmental awareness (Maijala, 2006). A later study 
which analysed books used to teach GFL in Finland and Sweden, shows that whereas topics like globalisation and migration are increasingly appearing in the newly published series, Multiculturalism features very rarely in the same series (Maijala, 2008). In this same study the author highlights that these homogeneous stereotypes usually grow deeper through sections or chapters aiming for political correctness and which usually end up comparing the target culture and the native culture of students.

Furthermore, in a study conducted earlier, in which the same author analyses thirty-eight textbooks used to teach GFL in various countries, including the UK, Estonia, Finland, France and Norway, Maijala points out that the history of the country where the textbook is being used, is very influential on the way the cultural representation are perceived (Maijala, 2004). One other study (Maijala, 2009) refers to gender-oriented stereotypes. The author points out that the texts frequently present males in Germany as people occupying leading roles and working with prominent companies. Females in Germany, on the other hand, are still often subtly presented as followers or inferior to the masculine gender.

Other studies also indicate that these stereotypes may be reinforced not only through sections specifically oriented at presenting/discussing culture but also through other sections of the FL textbook which at first glance appear not to be culture related. These include grammatical exercises content. Stereotyped sentences like "'Mary likes cooking'; 'John likes football', 'The French like...', 'Germans are ...', 'Older people...' used to teach a particular grammar point are commonly found in $\mathrm{FL}$ textbooks and may also serve as channels through which ideology may be inculcated" (Byram, Gribkova \& Starkey, 2002, p. 21).

\section{Methodology: how data was collected}

Aware of the situation where similar studies are sparse, with the intention of contributing to knowledge in the field, as a teacher of GFL I embarked on a research venture focusing on two particular research questions:

1. Which cultural representations of Germany are held by first year secondary students in the Maltese German as a Foreign Language (GFL) learning context? 
2. Which characteristics (i.e. their nature and qualities) do these representations of Germany tend to manifest?

The design I have opted for applies the mixed-methods approach defined in John Creswell's Convergent Parallel Mixed Methods, where the researcher collects both quantitative and qualitative data, analyzes them separately and then compares the results to see if the findings confirm or disconfirm each other. The key assumption of this approach is that both qualitative and quantitative data provide different types of information - often detailed views of participants qualitatively and scores on instruments quantitatively - and together they yield results that should be the same (Creswell, 2013, p. 261).

At the beginning and end of scholastic year 2012-2013, I collected student questionnaires that offered a snapshot of Maltese first-year state school GFL student representations of Germany. A sample of 160 students (from 14 GFL classes) selected from a population of 196 possible participants completed both parts of the questionnaire. Assuming a $95 \%$ confidence level, this has guaranteed a maximum margin of error of $3.33 \%$.

From the same GFL classes, in both phases, I also collected student drawings, which helped me further understand (because they gave me more details) the nature of the cultural representations of Germany presented in the student questionnaires. I also adopted convenience sampling techniques and chose one of the fourteen classes that filled out the student questionnaires. I interviewed each student in this particular class at the beginning and at the end of the first GFL learning experience. Through the interviews and through the thematic analysis of their outcomes, I intended to glean deeper understandings of the data collected through the student questionnaires.

\section{How things stand: A brief results outline}

After a long data-analysis exercise, from the two sets of cultural representations collected from the first year Maltese GFL learning context I could identify: 
Table 1: An overview of my interpretation of the results obtained from the Maltese GFL learning context (A detailed article about this can be found in Cremona, 2016).

\begin{tabular}{l|l} 
Perspectives & $\begin{array}{l}\text { Within the Maltese first year GFL learning context essentialist } \\
\text { perspectives adopted were frequently limited. Students only } \\
\text { edopted } \\
\text { essentialised about Germany (i.e. the nation) and its people } \\
\text { (the individuals living in Germany). Although the perspectives } \\
\text { referred to in the textbook used were somewhat more } \\
\text { inclusive, they still tended to lack the wider (i.e. the global) } \\
\text { perspectives and details about the included perspectives; }\end{array}$ \\
$\begin{array}{l}\text { Attitudes } \\
\text { and their nature }\end{array}$ & $\begin{array}{l}\text { Within the Maltese first year GFL learning context attitudes } \\
\text { were frequently judgmental. Very often attitudes towards } \\
\text { Germany are (very) positive while attitudes toward the people } \\
\text { living in the country are generally somewhat less positive; }\end{array}$ \\
\hline observed with time & $\begin{array}{l}\text { Within the Maltese first year GFL learning context changes } \\
\text { in representations from the beginning to the end of the year } \\
\text { were very limited and rather shallow; }\end{array}$ \\
\hline $\begin{array}{l}\text { Cultural knowledge } \\
\text { and its nature }\end{array}$ & $\begin{array}{l}\text { Within the Maltese first year GFL learning context the } \\
\text { cultural knowledge was based on limited reduced essentialist } \\
\text { information. The predominant essentialist representations } \\
\text { which one can observe in the Maltese GFL learning context } \\
\text { usually only referred to non-contextualised and traditional } \\
\text { dominant discourses. }\end{array}$
\end{tabular}

An evaluation of these four recurring elements in the light of intercultural and global competence frameworks based on Saniei (2012), Guilherme (2002) and Maijala (2006) indicated that the Maltese GFL learning context could (and needs to) adopt curriculum measures through which a broader, diverse and more Critical Cultural Awareness of the German target language context might be developed.

My definition of critical (inter)culturally aware FL student is in synchrony with Maiala's (2006) views suggesting that while critical culturally aware students naturally still essentialise about the foreign culture, rather than just absorbing the first (few) essentialist representations, i.e. those based on limited one sided essentialist dominant discourses presented to them, they keep looking for situations through which they can multiply their essentialist cultural representations and critically question them and think about them. In this way, gradually, the reduced one-sided essentialist ideology-laden representations of culture stop being nuisances and instead start 
serving as sources of reflection, hopefully leading to more balanced and informed representations of the foreign culture. Seen in this light, therefore my position in this chapter deliberately refrains from rejecting 'essentialism' and instead argues for the need for a wider range of 'essentialist representations' in GFL teaching in order to make students more aware and thereby critical of essentialism.

As a reaction to all this, I felt I had to start thinking of ways through which I could myself contribute to start bringing about this change. I tried to think of ways how the Maltese curriculum could change and I planned to come up with a set of suggestions through which hopefully those learning within the Maltese GFL learning context could start: questioning dominant cultural patterns and seeking the reasons which lead to these patterns being blindly accepted and unquestioned (Guilherme, 2002, p. 19).

Once I started working on the task, I felt that what would help is a checklist based on the outcomes of the study (Cremona, 2015 i.e. a summary presented in Tables 1 above) which could serve as an emergent and critical conceptual tool through which the Maltese GFL learning context, particularly GFL students and their teachers can unpack, examine, contest and transform taken-for-granted assumptions that are ingrained in language programme direction, curricular and teaching practices (Levine \& Phipps, 2012).

\section{Proposing the PACK checklist: a tool for curricular change}

Based on my interpretation of the data sets collected from the Maltese first year GFL learning context (see Table 1) as well as on the interviewed GFL teacher views and voices (see Cremona, 2015, Chapter 6), I felt I could finalise a list of suggestions aimed to lead to curricular change within the Maltese learning context. Keeping this unpacking idea in mind, I took the initial letters of the four most recurring points (i.e. Perspectives, Attitudes, Changes, Knowledge) and formed the acronym PACK. What follows in Table 2 below is a presentation of the PACK checklist aimed as a tool through which curricular change may be effected and/or facilitated within the Maltese GFL learning context. 
Table 1: The PACK Checklist - Suggestions through which cultural knowledge and (critical) cultural awareness may be facilitated within the Maltese GFL learning context

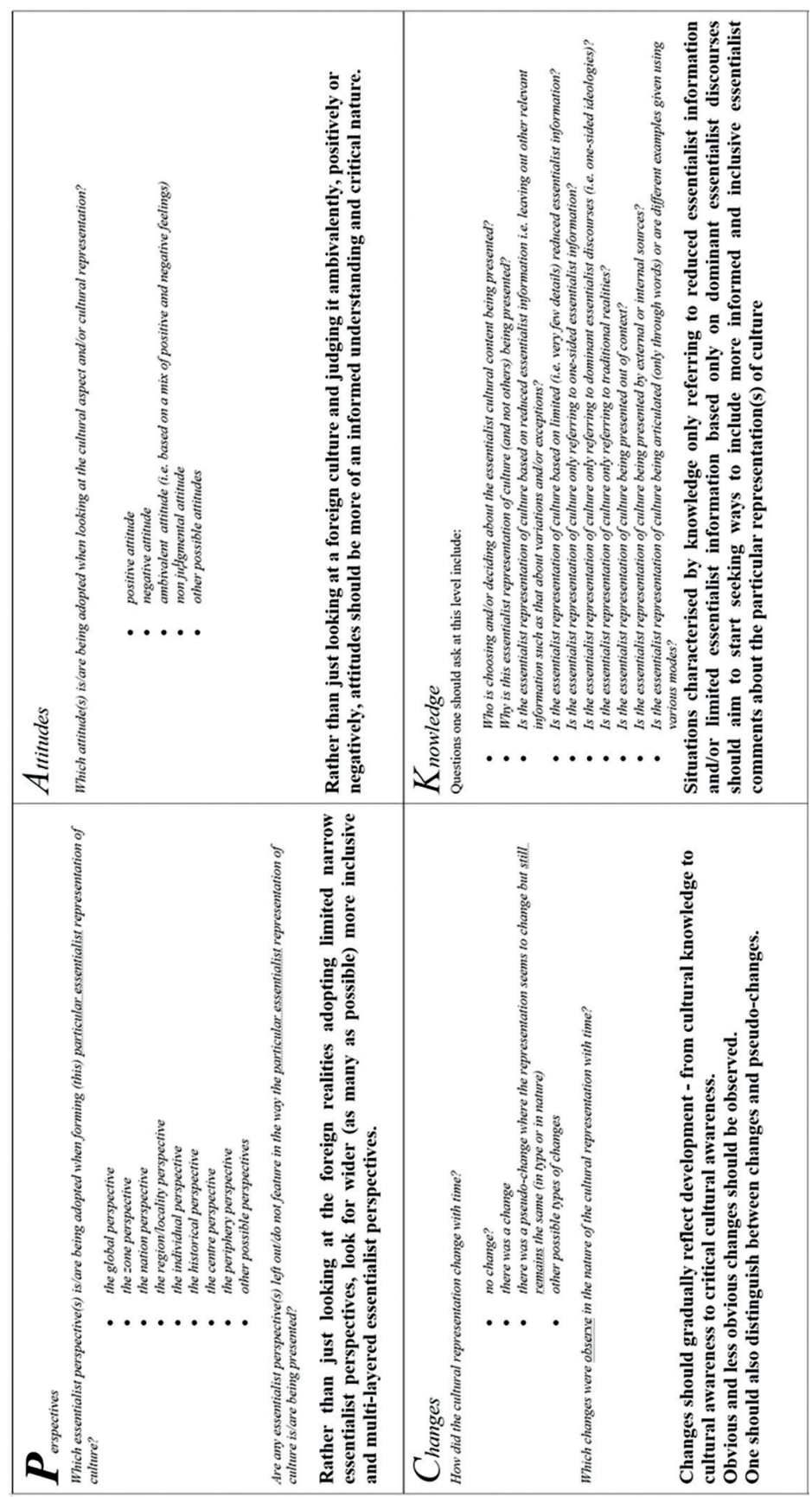




\section{Practical initiatives based on the PACK checklist: initial recommendations}

Curricular change might need some time to start and/or to be effected within the Maltese GFL learning context. Aware of this, with the intention to hopefully increase (even further) my contribution to the field, I went on thinking of further possible ways and measures through which I could facilitate the process towards curricular change based on the PACK checklist.

I now move on to focus on four levels, namely the classroom level, the school (wide) level, the policymaking level and the teacher education level in Malta. I present a set of practical initiatives and examples of curricular change which might result as an effect of the use of the PACK checklist and the questions it includes.

From the beginning, I would like to clearly point out that while these initiatives and examples (as are the suggestions included in the PACK checklist) in themselves are a contribution to the field, I constantly offer and present this material (i.e. the PACK checklist and practical curricular change it might lead to) as points to be discussed further with the different stakeholders involved in the teaching and learning of GFL in Malta (and elsewhere). I intentionally refrain from offering my views and suggestions as rules or top-down laws based on the outcomes of this study.

Instead, I present and share these with others through continuous activities which include school lessons, projects with GFL teachers, workshops, and seminars. Through these activities my aim is to give the major stakeholders including students, teachers, school administrators, prospective teachers, parents and policymakers in Malta, the opportunity to share their views, challenge my suggestions (and therefore the PACK checklist) and give feedback about these and other related suggestions/ questions/initiatives they can think of. Only through such continuous discussions could we all get the opportunity to start heading towards curricular change, moving from our limited cultural knowledge towards cultural awareness and (hopefully) later to situations based on Critical Cultural Awareness. 


\section{Possible curricular change through measures at classroom level}

To start with, the PACK checklist might serve to initiate curricular change through a number of initiatives at classroom level i.e. at the roots where things actually happen on a daily basis. Among others, at this level the questions included in the checklist should/could help teachers and students:

1. when looking for GFL resources and when using these GFL resources. The questions set in the checklist and the suggestions should help those in class realise that any resource they have at hand should be viewed as a tool presenting just one/a limited number of many possible essentialist realities (Jorgensen \& Philipps, 2002) from (within) Germany and/or the people living in Germany. Furthermore, when defining the term 'texts', teachers and students should realise that textbooks are just one of the many resources through which they can obtain essentialist representations of Germany and its people. The definition of 'text' should be extended to include other types of resources (Walker, Bean \& Dillard, 2010) among others the Internet, media sources and other authentic materials from Germany;

2. when designing self-made resources. Teachers should also think about ways how to help students think themselves about the content of the PACK checklist. This gradually could start leading to situations where students themselves develop a number of resources to be used in class (Cummins et al., 2005);

3. when discussing/reacting critically about essentialist representations presented during the GFL lesson and/or about other essentialist representations they encounter in other contexts outside the GFL learning context (e.g. at home, on the media).

\section{Possible curricular change through measures at school level}

Stopping at initiatives only addressing the GFL classes could imply that the latter do not operate within a wider educational context i.e. the school context. Instead, the questions and suggestions of the PACK checklist could also lead to curricular change addressing the wider school learning context where the GFL classrooms are located. 
For example, when setting physical spaces such as the German room i.e. a special class where all those learning GFL meet for the lesson, one should consider keeping in mind the points raised by the PACK checklist. The charts, authentic materials and other resources which the GFL teacher exhibits inside and outside (e.g. on the door or on notice boards hanging outside) the special German classroom, all directly and indirectly present a number of cultural representations (Kilickaya, 2004) to those learning German as well as to other students who do not learn German but who frequent the same school. Among these there might also be students who opt to study German at a later stage. Therefore, critically following the elements of the PACK checklist could help in the choice of these resources related to Germany.

On a similar note, the way school administrators, guidance teachers and teachers talk about GFL should - as much as possible - consider points raised by the PACK checklist and among others avoid comparisons between GFL and other subjects. Very often these comparisons happen before students choose to study the subject (Dörnyei \& Uschioda, 2001).

Frequently those helping students to make subject choices (i.e. guidance teachers) describe GFL either as the toughest among the foreign languages or as a harsh language linked to negative historic connotations. Instead of these judgmental prejudices (Arnold, 1999; Richards and Lockhart, 1994), the criteria highlighted by the PACK checklist could help in the school-wide presentation of GFL. This would lead to a presentation which is as non-judgmental as possible. GFL should be presented as a foreign language offering benefits and challenges as all the other FLs which students can choose from.

Another school-based event where the PACK checklist and questions might help is the language awareness day organised annually by most Maltese state schools. These days aim to offer all the students attending the particular school the opportunity to experience various elements from within the different countries speaking the different FLs offered in the particular school (Hawkins, 1984). As the teacher and student interviews indicate, very frequently on these language awareness days GFL teachers in Malta encourage their students to prepare charts and hang them in the main hall of the school for all to see. Seen in the light of the suggestions included in the PACK checklist, the student charts and exhibits - as seen in the example below presented in 
Figure 3 - frequently only include a number of very reduced essentialist representations (Soons, 2008) presenting very limited tiny segments of what is presented as 'the German reality'. Students (even non-GFL learners) are invited to try the German sausages and 'Lebkuchen' (i.e. a traditional German baked cookie, somewhat resembling gingerbread). These two food items are presented as 'the food people living in Germany eat'.

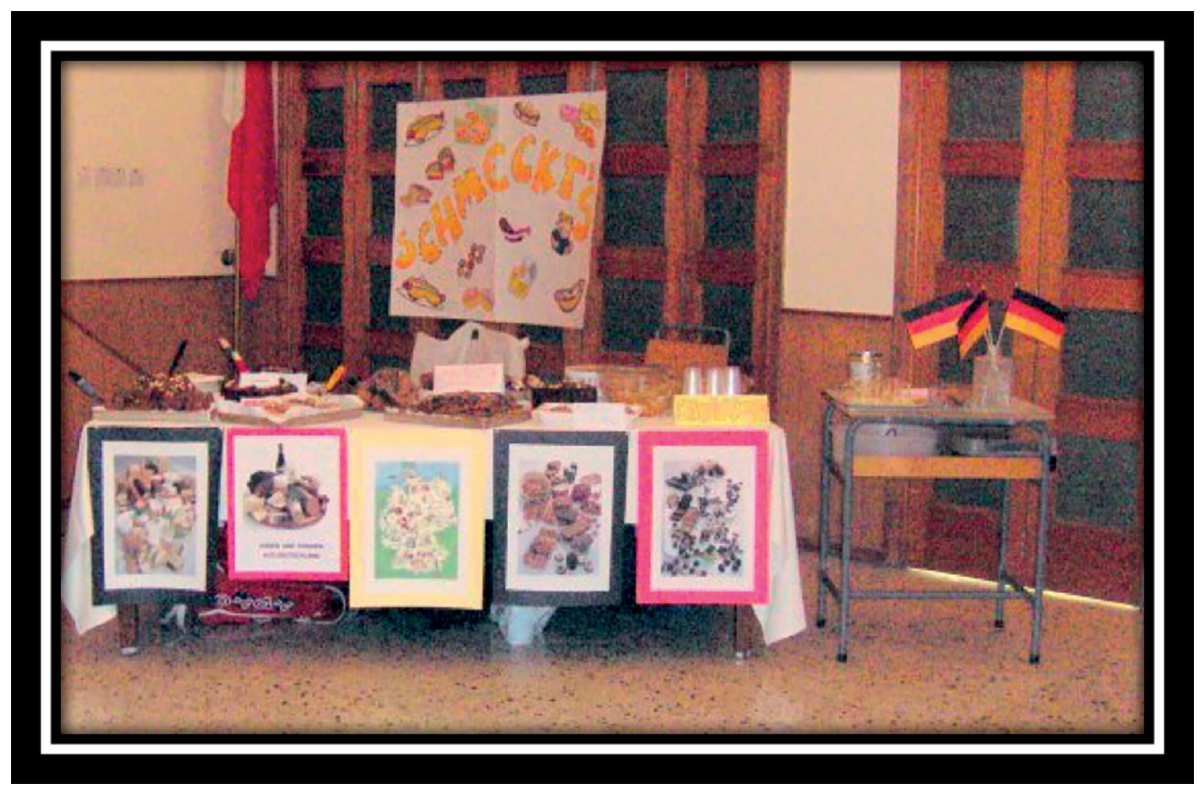

Figure 3: The 'German corner' set up in the main hall of a Maltese state school on one of the language awareness days.

The charts prepared by students and teachers include very reduced and limited essentialist representations of Germany. On the smaller table with the three flags, one can also see cooked sausages being presented as delicious German delicacies. Students visiting the stand could pre-order and buy this 'typical German food'.

For example, the Maltese girls' state school in which I took the photo (above), selects two GFL students yearly and asks them to wear the traditional Bavarian 'Dirndl' (female) and 'Lederhosen' (i.e. a female student wears the costume usually worn by males in Germany). An annual competition is organised. The GFL students attending the 
school are very willing to be among the winners selected to wear what is presented as the 'clothes people living in Germany wear'. Similarly, in December GFL teachers in Maltese states schools organise German Christmas markets. These events, once again, frequently present very limited sets of essentialist representations of Germany and its people only referring to reduced essentialist dominant discourses. Among others, on such occasions German weather is presented as very cold with snow. In these Christmas Markets sausages and pastry (presented as the food one eats in Germany) are also sold. Therefore, on similar occasions the PACK checklist could serve as a guidance to GFL teachers and their students helping them to choose, present and integrate more inclusive and informed essentialist representations of Germany and its people during these school-based activities.

The same applies for GFL teachers and other non-GFL teachers who organise school exchanges and educational trips to Germany. Since GFL and non-GFL students are frequently allowed to participate in these trips, I feel this point affects the whole school cohort i.e. not just the GFL students. Very frequently when drafting the trip programme, these teachers end up focusing only on very limited essentialist representations (Kirkebæk, Du \& Jensen, 2013) of Germany and its people. Instead the PACK checklist and the questions it includes could help these teachers to organise and to plan these school exchange programmes differently. Rather than just offering their students the opportunity to experience the main tourist attractions, teachers keeping the PACK suggestions in mind when drafting the programme would also include other less touristic elements. This would give students (and the teachers themselves) the opportunity to encounter more authentic realities which different people living in Germany experience daily.

\section{Possible curricular change through measures at the Maltese policymaking level}

I feel that, most of the above-mentioned initiatives - proposed for the classroom and the school level - can be actually effective (and effected to the full) only if the policymakers, administrators and education directors in Malta think about them critically and evaluate their relevance (Honig, 2006). If those drafting policies and making decisions do reach this stage where they critically evaluate the proposed suggestions and questions included in the PACK checklist, it gets easier 
for those working in schools and within classrooms to start reflecting about and hopefully benefiting from the PACK suggestions and the recommendations included in the checklist.

These discussions with policymakers need to point out and encourage the idea that any curricular change(s) we aim to do/reach following or based on the PACK checklist should avoid monologues among policymakers and instead involve the GFL teachers (and to a certain extent their students) from the very initial stages (Griffin, 1995). Avoidance of such top-down implementations would make it easier for those at the grassroots to accept more readily the policies which they should implement. Once teachers feel involved from the very initial stages i.e. not simply at the policy implementation stage, they would have a greater sense of ownership over the policies since they would have had the opportunity to comment and share their views about what is being proposed before its actual implementation (Kolderie, 2003). This approach very frequently also serves to bring policymakers closer to the grassroots since those writing policies in Malta (with the exception of heads of departments) very frequently are those with administrative roles and frequently have limited direct contact with the classroom level and what happens within it (Coburn \& Stein, 2006). Therefore, having teachers involved from the very initial stages of policy drafting, facilitates policy implementation success.

I feel taking this stance would be very appropriate in a context seemingly characterised by a tradition of top-down measures imposed on Maltese GFL teachers and learners. A number of interviewed GFL teachers taking part in the discussion (see Cremona, 2015) indicated that one of the most recent top-down policy implementations which the teachers recently had to adapt to was the newly-drafted jam-packed syllabus, which in the view of the interviewed teachers constrains their daily conduct in class. The interviewed GFL teachers tended to feel that this top-down approach only led to a situation where they must rush against time in order to ensure that they cover as many syllabus topics as possible. All the interviewed GFL teachers tended to suggest that policymakers need to re-evaluate the methods of assessments (i.e. very summative exam-oriented assessments) that are currently used within the GFL learning context. Furthermore, they also indicated that in their view policymakers assumed that the way they had designed the new syllabus - i.e. setting the syllabus topics but 
leaving it up to the teacher which culture-related material to include gave GFL teachers autonomy while implementing the syllabus. However, the five GFL teachers indicated that this freedom is frequently leading to a situation where they end up feeling lost about which culturerelated topics they should talk about and others they should leave out. Probably such a situation could have been tackled or addressed better earlier if only the policymakers had involved teachers and students more while originally designing and drafting the new syllabus (Wang \& Cheng, 2005).

All this indicates that any curricular change we aim for should be based on hand-in-hand collaboration between policymakers and the GFL teachers. The former should help the latter through guidance rather than acting as top-down overseers over teachers (Schleicher, 2011). In this way the role of policymakers would eventually make it easier for teachers to feel more secure in their daily conduct since what they do in class has been discussed with those involved in policy drafting (Ledesma, 2011).

Instead of top-down measures, the two stakeholders (i.e. teachers and policymakers) could reflect about the questions set in the PACK checklist and constantly discuss challenges the teachers encounter in class. One of these discussions could be about the pros and cons of leaving value-related topics aside. Seen in the light of the PACK checklist, leaving these value-related topics aside would mean giving GFL students only reduced one-sided essentialist versions (i.e. perspective, attitudes and knowledge) of Germany and of the people living in Germany. Furthermore, through these initiatives based on collaboration, GFL teachers and policymakers could discuss and reevaluate the view shared by most of the interviewed GFL teachers that one should avoid these topics because first year students are still very young. The PACK checklist should help the two sides reflect about the possibility that this avoidance of certain topics too could lead to a situation where students start forming reduced essentialist representations of Germany and its people which later lead to confused misunderstandings. Seen in the light of the PACK checklist, leaving these representations for later stages would mean that students start forming reduced and limited essentialist representations of the country and its people which they have to change later, once (if ever) these value-related topics are presented in class. Therefore, in these continuous collaborations between policymakers and GFL teachers, 
the PACK checklist could help both sides discuss about the effects and risks brought about by the inclusion of these topics from the earliest stages of the GFL experience. Through these critical reflections based on the content of the PACK checklist, teachers and policymakers could possibly help their students form a more consistent essentialist representation of Germany and its people throughout the course.

Furthermore, the PACK checklist could also help policymakers and GFL teachers:

1. consider (and think about) the importance of presenting as many perspectives and situations as possible. These should also include sensitive value-related topics which are still frequently considered as taboos (Arabski \& Wojtaszek, 2011) within the GFL learning context;

2. think about ways through which they can present the cultural topics in a way which appeals to the younger target audience (Beebe \& Beebe, 2011). Therefore it is not only the choice of topic which matters, but the way in which the topic is presented to the particular target audience;

3. stop fearing that discussions referring to more inclusive essentialist representations of Germany would just increase prejudices and/or intolerance and see these more inclusive essentialist representations as a way through which students may become more critical. This would help students (and teachers themselves) avoid adopting positive or negative attitudes and instead try to look at things (with the help of their teachers) adopting more informed non-judgmental attitudes (Maijala, 2008).

This curricular change should be given time and these initiatives at policy level should be seen as a gradual (possibly lifelong) process. Additionally, the process should start from the very first day of the GFL learning experience, therefore as early as the first primary school sessions (i.e. the Foreign Language Awareness Programme: a set of 10 lessons offered to primary school students in Malta through which students get their first taste of the various Foreign Languages they can choose from once they start their secondary school experience). This should go on throughout (i.e. every single lesson of) the secondary GFL school learning experience and be extended to the post-secondary and tertiary levels, even reaching those interested to further their GFL studies. 


\section{Possible curricular change through measures at teacher training level}

As subject coordinator for German at the University of Malta one of the many responsibilities I have is drafting and implementing teachertraining programmes for future Maltese GFL teachers. The questions set in the PACK checklist continuously give me further insight(s) about the way I should/could draft and re-draft the university courses offered by my faculty (i.e. the Faculty of Education).

Eventually, this could also have an impact on a national level since in (the near or further) future when these GFL university students start teaching:

1. they would feel more prepared and hopefully constantly reevaluate and think critically about the representations of Germany they present in class;

2. they may one day be policymakers and in this way the ideas discussed during lectures might be contributing to facilitate further the development of cultural knowledge and Critical Cultural Awareness within the Maltese GFL learning context.

Furthermore, bearing in mind the above-mentioned top-down situations which seemingly lead to little success, when I lecture I feel I should not present the PACK suggestions as fixed rules. Instead, university students and my other colleagues should constantly be given the opportunity to discuss and share their views about the checklist. Through this, as a team, we can constantly re-evaluate cultural representations of Germany included in materials presented during lectures. This should also help me to re-evaluate continuously the contents of the PACK checklist (i.e. therefore my current position) and adapt it accordingly.

In addition, my role at the Faculty of Education at the University of Malta gives me the possibility to develop workshops and professional development training seminars offered to experienced and lessexperienced Maltese GFL teachers as well as to policymakers. Through these too, I feel that the PACK checklist can help me initiate discussions about measures which could facilitate (and lead to) nation-wide curricular change. I constantly remind myself that the approach these sessions should adopt, should avoid lengthy sermon-like one way explanations. Instead, policymakers and teachers should get the opportunity to: 
1. familiarise themselves with and react to the results collected from the first year GFL learning context;

2. get to know/listen to what the PACK checklist suggests;

3. discuss and share their views about the PACK checklist while even offering further suggestions/alternatives based on their own experience(s);

4. link other theoretical ideas through which Cultural Knowledge and (Critical) Cultural Awareness may be developed in practice;

5. acknowledge that this development entails a gradual (possibly lifelong) process.

The offer of such training courses is also open to other GFL teachers elsewhere (i.e. not only in Malta). Similarly, the suggestions raised might also serve as helpful tips for other FL teachers who do not teach GFL. From all these suggestions, the latter could find valuable suggestions through which they could develop their own checklist (similar to the PACK checklist) and apply it critically in their daily conduct.

\section{Conclusion: slowly but hopefully steadily}

It should be clear - through the main points raised by the discussion in this chapter - that curricular change is needed within the Maltese first year GFL learning context. Student representations of Germany could start moving towards more cultural knowledge and then gradually move towards (critical) cultural awareness through the set of ideas and practical sample initiatives which I have included in this chapter.

Based on the outcomes of the study (i.e. the situation summarised in Table 1), the chapter presented the original PACK checklist as a tool through which the major stakeholders working, learning and teaching within the Maltese GFL learning context could start moving towards curricular change. However, I also feel that this conclusion, rather than just highlighting the need of curricular change should re-emphasise the idea that everything should happen constantly, gradually and at its own pace. This rate towards curricular change could be slowed even further (i.e. at all levels including the classroom level, the wider school level, the policymaking level and the teacher education level) by my suggestion to avoid top-down measures towards curricular change. Moreover, moving slowly means proceeding steadily, hopefully being more successful and effective in reaping the desired fruit proposed throughout this chapter. 


\section{References}

$\rightarrow$ Arabski, J. \& Wojtaszek, A. (2001). Aspects of culture in second language acquisition and foreign language learning. Berlin: Springer, 2011.

$\rightarrow$ Arnold, J. (1999). Affect in language learning. Cambridge, U.K.: Cambridge University Press.

$\rightarrow$ Barrett, M. D. \& Buchanan-Barrow, E. (2005). Children's understanding of society. Hove: Psychology Press.

$\rightarrow$ Beebe, S. A., Beebe, S. J. \& Steven A. Beebe, S.A. (2005). The public speaking handbook. Boston: Allyn and Bacon.

$\rightarrow$ Byram, M., Gribkova, B. \& Starkey, H. (2002). Developing the intercultural dimension in language teaching: A practical introduction for teachers. Strasbourg: Council of Europe.

$\rightarrow$ Caruana, S., George, C. Vella, A. (2013). Language use, perception and attitudes amongst Maltese primary school children. In S. Caruana, L. Coposescu \& S. Scaglione (Eds.), Migration, multilingualism and schooling in southern Europe (pp. 304-343). Newcastle upon Tyne: Cambridge Scholars.

$\rightarrow$ Coburn, C. \& Stein, M. K. (Eds) (2006). Communities of practice: Theory and the role of teacher professional community in policy implementation. Albany: SUNY Press.

$\rightarrow$ Cremona, G. (2015). Cultural representation of Germany in the Maltese German as a Foreign Language (GFL) Learning Context: A critical interpretation. Unpublished PhD thesis. UCL Institute of Education.

$\rightarrow$ Cremona, G. (2016). Predominant ideologies in the cultural representation of Germany collected from the Maltese first year German as a Foreign Language (GFL) learning context. In R. Heimrath \& A. Kremer (Eds.), Insularity. Small worlds in linguistic and cultural perspectives (pp. 185-205). Königshausen and Neumann: Würzburg.

$\rightarrow$ Creswell, J. (2013). Qualitative inquiry \& research design: Choosing among five approaches. Los Angeles: SAGE Publications. 
$\rightarrow$ Cummins, J., Bismilla, V., Chow, P., Cohen, S., Giampapa, F., Leoni, L., Sandhu, P. \& Sastri, P. (2005). Affirming identity in multilingual classrooms. Educational Leadership, 63 (1), 38-43.

$\rightarrow$ Dörnyei, Z. \& Uschioda, E. (2001). Teaching and researching motivation. Harlow, England: Longman,.

$\rightarrow$ Griffin, G. A. (1995). Influences of shared decision making on school and classroomactivity: Conversation with five teachers. The Elementary School Journal, 96 (1), Special Issue: Teacher Leadership, 29-45.

$\rightarrow$ Guilherme, M. (2002). Critical citizens for an intercultural world: Foreign language education as cultural politics. Clevedon: Multilingual Matters.

$\rightarrow$ Hawkins, E. W. (1984). Awareness of language: An introduction. Cambridge: Cambridge University Press.

$\rightarrow$ Honig, M. I. (2006). New directions in education policy implementation: Confronting complexity. Albany: State University of New York Press.

$\rightarrow$ Jones, S.. M., Bouffard, S. M. \& Lesaux, N. (2012). Social and emotional learning in schools: From programs to strategies. Sharing Child and Youth Development Knowledge, 26 (4), 1-2.

$\rightarrow$ Jørgensen, M. \& Phillips, L. (2002). Discourse analysis as theory and method. London: Sage Publications.

$\rightarrow$ Kilickaya, F. (2014). Authentic materials and cultural content in EFL classrooms. The Internet TESL Journal, 10 (7). Accessed 28th January 2012. Available online: http://iteslj.org/Techniques/Kilickaya-AutenticMaterial.html.

$\rightarrow$ Kirkebæk, M. J., Du, X.-Y. \& Jensen, A. A. (2013). Teaching and learning culture: Negotiating the context. Rotterdam: Sense Publishers.

$\rightarrow$ Kolderie, T. (2003). Teacher-ownership as entrepreneurship in public education. Dublin: Senate Hall Academic Publishing.

$\rightarrow$ Ledesma, P. (2011). Moving towards productive dialogue between teachers and policy makers. Accessed 28th January 2012. Available at: http://blogs. edweek.org/teachers/leading_from_the_classroom/2011/09/moving_towards_ productive_dialogue_between_teachers_and_policy_makers.html

$\rightarrow$ Levine, G. \& Phipps, A. (2012). Critical and intercultural theory and language pedagogy. Boston, MA.: Heinle, Cengage Learning.

$\rightarrow$ Maijala, M. (2004). Deutschland von Außen Gesehen. Geschichtliche Inhalte in Deutschlehrbüchern Ausgewählter Europäischer Länder. Frankfurt a. M.: Lang.

$\rightarrow$ Maijala, M. (2006). Klischees im Spiegel landeskundlicher Inhalte von Sprachlehrwerken. Über stereotype Darstellungen fremder Kultur(en). Jahrbuch Deutsch als Fremdsprache, 32 (6), 126-139. 
$\rightarrow$ Maijala, M. (2008). Zwischen den Welten - Reflexionen zu interkulturellen Aspekten im DaF-Unterricht und in DaF-Lehrwerken. Zeitschrift für Interkulturellen Fremdsprachenunterricht, 13 (1), 1-18.

$\rightarrow$ Maijala, M. (2009). Typisch Frau... Typisch Mann... Zur Gender-Problematik in Lehrwerken für Deutsch als Fremdsprache. Zielsprache Deutsch, 36 (1), 33-60.

$\rightarrow$ Richards, J.C. \& Lockhart, Ch. (1994). Reflective teaching in Second Language Classrooms. Cambridge: Cambridge University Press.

$\rightarrow$ Saniei, A. (2012). Developing cultural awareness in language instructional materials. IPEDR 33, 10-15.

$\rightarrow$ Schleicher, A. (2011). Building a high-quality teaching profession: Lessons from around the world. Paris: OECD Publishing.

$\rightarrow$ Soons, M. P. (2008). The importance of language awareness: Ambiguities in the understanding of language awareness and the practical implications. Malmö Högskola: Lärarutbildningen Kultur-Språk-Medier.

$\rightarrow$ Walker, N. T., Bean, T. W. \& Dillard, B. (2010). When textbooks fall short: New ways, new texts, new sources of information in the content areas. Portsmouth, $\mathrm{NH}$ : Heinemann.

$\rightarrow$ Wang, H. \& Cheng, L. (2005). The impact of curriculum innovation on the cultures of teaching. Asian EFL Journal, 7 (4), 7-32.

$\rightarrow$ Wilkinson, J. (2012). The intercultural speaker and the acquisition of intercultural/ global competence. In J. Jackson (Ed.). The Routledge handbook of language and intercultural communication (pp. 296-309). Milton Park, Abingdon, Oxon: Routledge.

$\rightarrow$ Zhu, H., Jiang, Y. \& Watson, J. (2011). Children's perceptions of the impact of participation in an intercultural educational programme. Language and Intercultural Communication, 11 (2), 142 - 160. 


\section{Biographical note:}

Dr. George Cremona coordinates German programmes offered by the Faculty of Education at the University of Malta. He lectures in German language teaching methodology and gives lectures about Multimodality. Currently (since January 2012) he is also working on a research project series called 'Multimodality in Practice'. This project aims to implement Multimodal concepts and theories in practice particularly in local and foreign schools and through the media (i.e. radio programmes, tv programmes and the internet). For this, in 2017 he was awarded the prestigious IGM national award. In 2009 he scripted and published a 13-week German for beginners course - for TV and also available online - which later was nationally recognized as the best educational TV series of the year. 

The Teacher Education Policy in Europe (TEPE) Scientific Network is an academic network that builds on the work and community from the previous European collaborative projects in the field of teacher education policy including TNTEE and EUDORA.

TEPE Network central goals relate to: advancing research in and on Teacher Education, increasing mobility and extending the European Dimension in Teacher Education, enhancing quality through the renewal of evaluation cultures in Teacher Education.

The motivation for the theme of this book Teacher Education Policy and Practice International Perspectives and Inspirations has been to create a platform for contributing to international debate on policy, innovative thinking, practice and research in teacher education across contexts. Our position as editors of this book is that teachers' learning in a professional context requires a broad and robust research base in order to clearly understand what they go through in the various phases of their learning journey. We hope that this book contributes to other valid research in the area.

Michelle Attard Tonna and Joanna Madalińska-Michalak

Foundation for the Development of the Education System (FRSE) operates as the Polish National Agency of the Erasmus+ Programme implemented in the years 2014-2020. FRSE is also responsible for other European educational and information initiatives in Poland: eTwinning, Eurodesk, Eurydice, Europass, ECVET and EPALE. The Foundation also supports cooperation with countries in the East via the Polish-Lithuanian Youth Exchange Fund, the Polish Ukrainian Council of Youth Exchange and SALTO-EECA Eastern Europe and Caucasus Resource Centre. Since 2014, FRSE has been involved in the implementation of the Operational Programme Knowledge Education Development.

The Foundation organizes many educational events including competitions promoting projects' results. It coordinates the European Youth Week and co-organizes events in the framework of European Day of Languages. It also conducts research and has a publishing house which issues, among others, such quarterly magazines as Języki Obce w Szkole (Foreign Languages at School) and Europa dla Aktywnych (Europe for the Active). 